AuRENICE dA CRUZ FIgUeIRA

MANOBRA DE ULTRAPASSAGEM EM PISTA SIMPLES BIDIRECIONAL COM SIMULADOR DE DIREÇÃO

SÃo CARLOS

2019 

AURENICE DA CRUZ FIGUEIRA

\title{
MANOBRA DE ULTRAPASSAGEM EM PISTA SIMPLES BIDIRECIONAL COM SIMULADOR DE DIREÇÃO
}

\author{
Tese apresentada à Escola de Engenharia de São Carlos da \\ Universidade de São Paulo (EESC/USP), para obtenção do \\ título de Doutora em Engenharia de Transportes. \\ Área de Concentração: Infraestrutura de Transporte. \\ Orientadora: Profa. Dra. Ana Paula Camargo Larocca
}

\section{SÃO CARLOS}

2019

EXEMPLAR DEFINITIVO (CORRIGIDO). EXEMPLAR ORIGINAL DISPONÍVEL NA CPG DA EESC-USP. 
AUTORIZO A REPRODUÇÃO TOTAL OU PARCIAL DESTE TRABALHO, POR QUALQUER MEIO CONVENCIONAL OU ELETRÔNICO, PARA FINS DE ESTUDO E PESQUISA, DESDE QUE CITADA A FONTE.

Ficha catalográfica elaborada pela Biblioteca Prof. Dr. Sérgio Rodrigues Fontes da EESC/USP com os dados inseridos pelo(a) autor(a).

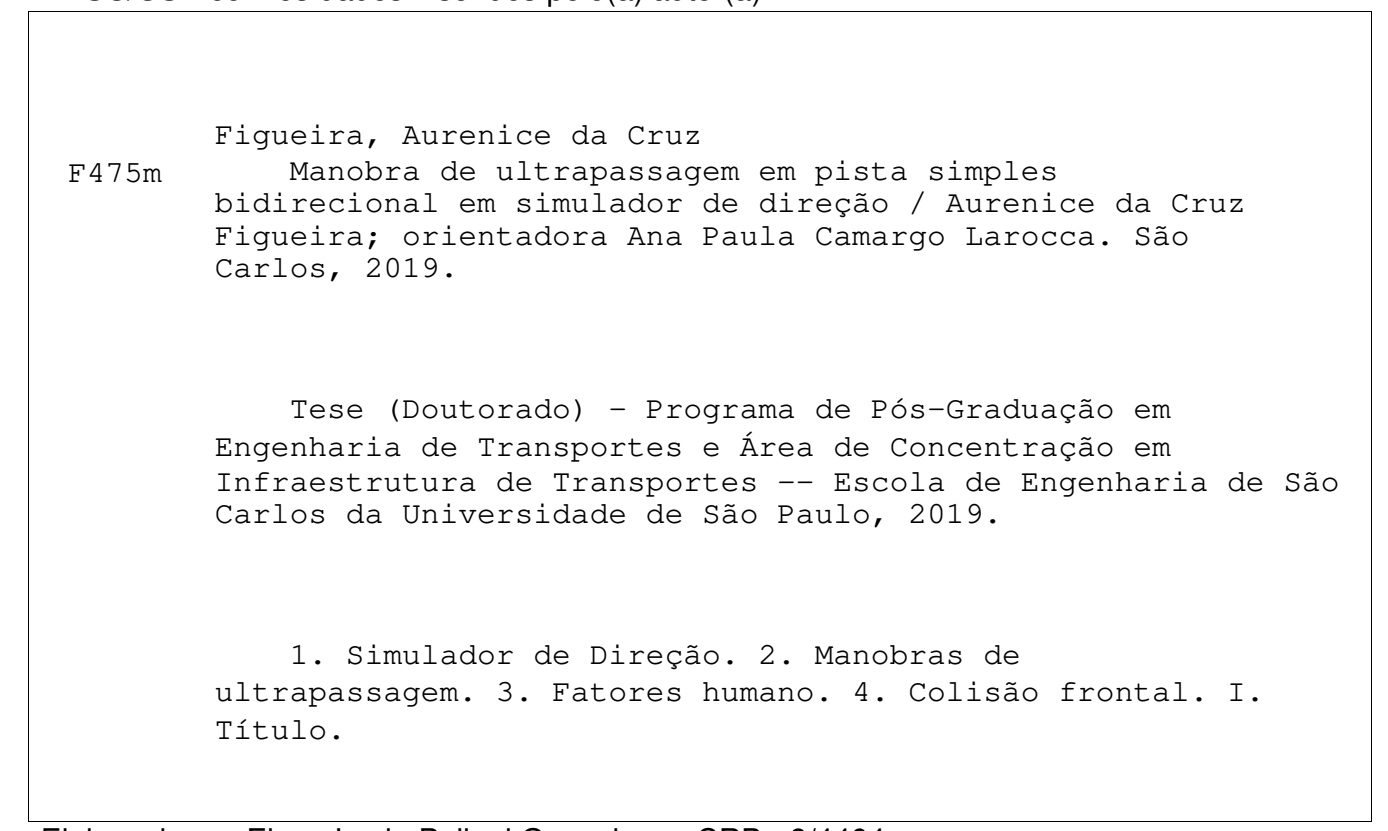

Elaborado por Elena Luzia Palloni Gonçalves - CRB - 8/4464 


\section{FOLHA DE JULGAMENTO}

Candidata: Tecnóloga AURENICE DA CRUZ FIGUEIRA.

Título da tese: "Manobra de ultrapassagem em pista simples bidirecional com simulador de direção".

Data da defesa: 07/08/2019.

\section{Comissão Julgadora:}

Profa. Associada Ana Paula Camargo Larocca (Orientadora)

(Escola de Engenharia de São Carlos/EESC)

Prof. Dr. Fernando Santos Osório

(Instituto de Ciências Matemáticas e de Computação/ICMC-USP)

Prof. Associado Felipe Issa Kabbach Junior

(Escola Politécnica/EP-USP)

Prof. Dr. Daniel Sergio Presta Garcia

(Universidade Federal do Rio Grande do SUI/UFRGS)

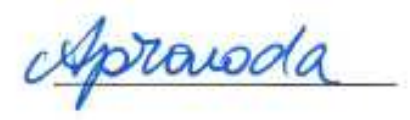

Profa. Dra. Anabela dos Santos Aleixo Simões

(Universidade Lusófona de Humanidades e Tecnologia/ULHT)

Coordenadora do Programa de Pós-Graduação em Engenharia de Transportes:

Profa. Associada Ana Paula Camargo Larocca

Presidente da Comissão de Pós-Graduação:

Prof. Titular Murilo Araujo Romero
Resultado:

opruovoda 

DEDICATÓRIA

A uma Maria chamada Aurora

(in memoriam) 

A Deus pela força imensurável que recebi no último ano do doutorado, quando perdi um "pedaço de mim" e à Nossa Senhora pela proteção constante. À minha família, pais, irmãos, sobrinhos, cunhadas (o) pelo entendimento da ausência para dedicação intensa ao sonho desta cabocla paraense.

Minha eterna gratidão à minha orientadora Ana Paula Camargo Larocca pelos anos de amizade, apoio incondicional e auxílio total na busca da almejada carreira acadêmica.

À profa. Anabela Simões e ao prof. José Carvalhais pelo apoio e contribuições durante o período de estágio em Portugal.

À profa. Linda Lee Ho pelos direcionamentos no delineamento do experimento e ao professor Felipe Kabbach Jr. pela disponibilidade para as reuniões e esclarecimentos que embasaram tecnicamente esta pesquisa.

A todos os professores do Departamento de Engenharia de Transportes (STT/EESC) pelo conhecimento transmitido que proporcionaram meu crescimento acadêmico. Ao corpo técnico e administrativo pelo suporte e colaboração durante todos esses anos. Aos colegas do departamento por ouvirem até cansar sobre esta pesquisa, me auxiliando a desenvolver e fundamentar as ideias e pelos momentos de descontração durante o reabastecimento da cafeína.

Minha gratidão aos colegas da equipe de pesquisa com simulador de direção - Fábio Vieira, Felipe Calsavara, Gustavo Santos, Maria Izabel Santos, Miguel Castillo e Paulo Tadeu. Em especial ao amigo Tiago Torquato pela solidariedade e partilha de conhecimento durante todo - período da pesquisa e também ao "pupilo" Luiz Gustavo Buzon pela parceria e disponibilidade em todas as fases.

Aos colegas de orientação - José Venâncio e Renaude Carneiro - meu agradecimento por tornar esse período mais agradável e divertido.

Às amigas Cintia Campos, Diana Meneses, Elaine Ribeiro, Natália Panice e Sandra Bertollo pelo apoio nesse período distante da família, minha gratidão por serem a família adotiva que precisei em tantos momentos. 
À minha amiga Grace Oliveira (in memoriam), uma incentivadora constante e que foi tirada do meu convívio por um condutor irresponsável. Saiba que esteve em meus pensamentos em cada passo dessa jornada.

Meu sincero agradecimento ao amigo Francisco Roza ("Chico") por estar sempre à disposição, sendo como piloto de testes, auxiliando nas dúvidas da elaboração do algoritmo para extração dos dados e nas fotos ilustrativas do simulador.

Aos oitenta e dois voluntários que doaram seu tempo e participaram com comprometimento nos testes do simulador de direção. Sem vocês seria impossível a realização desta pesquisa. A ciência agradece.

Ao Conselho Nacional de Pesquisa Científica (CNPq) pela bolsa de fomento e à Fundação de Amparo à Pesquisa de São Paulo (FAPESP) e Agência Nacional de Transportes Terrestres (ANTT) pela colaboração no financiamento do simulador de direção. 
“Um trabalho te dá um propósito e um significado. A vida é vazia sem ambos."

Stephen Hawking 

FIGUEIRA, A. C. Manobra de ultrapassagem em pista simples bidirecional em simulador de direção. 2019. 216 p. Tese (Doutorado) - Escola de Engenharia de São Carlos, Universidade de São Paulo, São Paulo, 2019.

No Brasil, entre 2008 e 2018, foram registrados 1,5 milhão de acidentes em rodovias federais. Acidentes do tipo colisão frontal representaram 3,2\% do total de acidentes e em relação às mortes registradas, a colisão frontal foi responsável por 31\% das mortes: 25 mil mortes, 17 mil feridos graves e 25 mil feridos leves. Estes dados mostram que a ultrapassagem em rodovias de pista simples é uma das manobras mais complexas e arriscadas das rodovias brasileiras. Devido a estes valores, as atividades de pesquisa e análise de dados da acidentalidade rodoviária, juntamente com a influência de diversos fatores - infraestrutura rodoviária, componente veicular e comportamento do condutor - constituem uma parte essencial do projeto geométrico da rodovia e da segurança viária. O processo de ultrapassagem envolve manobras de mudança de faixa, aceleração, desaceleração, ações e estimativa da velocidade relativa dos veículos ultrapassados e o comportamento do condutor. O principal objetivo desta tese foi analisar as manobras de ultrapassagem em rodovias de pesquisa simples bidirecional. Para isso, foram formuladas três hipóteses e um método para confrontar os parâmetros que compõem o modelo de distância de visibilidade de ultrapassagem (AASHTO e DNIT), através de um experimento fatorial de medidas repetidas que contou com oitenta voluntários, que dirigiram num trecho virtual de rodovia no simulador de direção. $O$ experimento possibilitou investigar as fases da manobra de ultrapassagem; caracterizar o perfil do condutor a partir do nível de risco mensurado nas ultrapassagens realizadas; o grau de confiança - realismo - do simulador de direção de base fixa para as pesquisas sobre fatores humanos em manobra de ultrapassagem e mensurar as distâncias e tempos das fases da manobra de ultrapassagem em ambiente simulado e compará-las ao modelo de distância de visibilidade normatizado.

Palavras-chave: Simulador de direção. Manobras de ultrapassagem. Fatores humanos. Colisão frontal. 

FIGUEIRA, A. C. Maneuver of overtaking on two-lane highways in driving simulator. 2019. 216p. Tese (Doutorado) - Escola de Engenharia de São Carlos, Universidade de São Paulo, São Paulo, 2019.

In Brazil, between 2008 and 2018, 1.5 million accidents were recorded on federal highways. The frontal collision represented $3.2 \%$ of all accidents and, in relation to recorded deaths, the frontal collision was responsible for $31 \%$ of deaths $-25,000$ deaths, 17,000 serious injuries, and 25,000 minor injuries. These data show that overtaking on two-lane highways is one of the most complex and riskiest maneuvers on Brazilian highways. Because of these values, research and analysis of road accident data, coupled with the influence of various factors road infrastructure and driver behavior - are an essential of road geometric design and road safety. The overtaking process involves maneuvers of the lane change, acceleration, deceleration, actions, and estimation of the relative speed of outdated vehicles and driver behavior. The main objective of this thesis was to analyze the maneuvers of overtaking on twolane highways. Three hypotheses and one method were used to compare the parameters that compose the passing sight distance model (AASHTO and DNIT), through a factorial experiment of repeated measures that counted with eighty volunteers. The participants drove on a virtual highway in the driving simulator. The experiment allowed to investigate the phases of the overtaking maneuver; characterize the profile of the driver from the level of risk measured in the overtakes performed; the degree of confidence - realism - of the fixed base driving simulator for the research of human factors in the overtaking maneuver, and to measure the distances and times of the overtravel maneuver phases in a simulated environment and compare them with the standardized passing sight distance model.

Keywords: Driving simulator. Overtaking. Human factors. Frontal collision. 

Figura 1 - Tipo de acidente por mortos em rodovias federais - 2008 a 2018. 26

Figura 2 - Síntese do método. 31

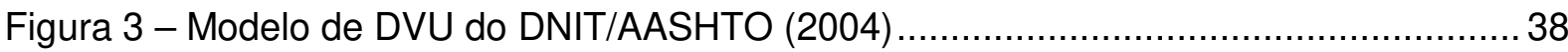

Figura 4 - Diagrama espaço-tempo do modelo de Glennon. .......................................... 42

Figura 5 - Diagrama espaço-tempo do modelo de Hassan et.al ..................................... 46

Figura 6 - Estágios da manobra de ultrapassagem do modelo de Wang e Cartmell ........... 49

Figura 7 - llustração da aproximação do S utilizado do modelo de Wang e Cartmell ...........50

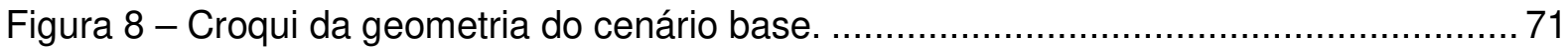

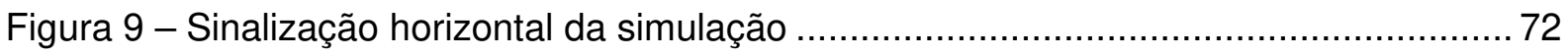

Figura 10 - Sinalização vertical utilizada no cenário da simulação ................................... 73

Figura 11 - Croqui de sinalização do cenário virtual entre o km 4,8 e km 5,4 ................... 74

Figura 12 - Ponto de vista do condutor no simulador com veículo lento - carro de passeio 76

Figura 13 - Ponto de vista do condutor no simulador com veículo lento - caminhão........... 77

Figura 14 - Processo de modelagem e simulação do cenário virtual .................................. 79

Figura 15 - Cockpit e disposição do sistema de processamento. ..................................... 79

Figura 16 - Sistema de rastreio do olhar ................................................................. 80

Figura 17 - Detalhe da câmera do SmartEye e disposição das câmeras no simulador. ....... 80

Figura 18 - Fluxograma das fases do experimento no simulador ................................... 85

Figura 19 - Sistema inercial de coordenadas do veículo ............................................... 91

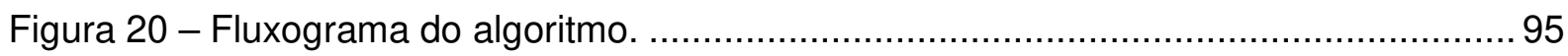

Figura 21 - Quilometragem mensal percorrida por faixa etária ...................................... 101

Figura 22 - Frequência de direção em rodovia de pista simples dos participantes. ........... 102

Figura 23 - Envolvimento dos participantes em acidentes............................................ 102

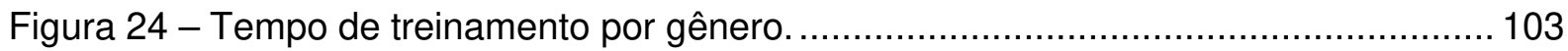

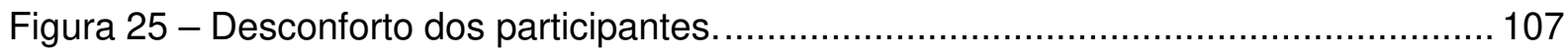

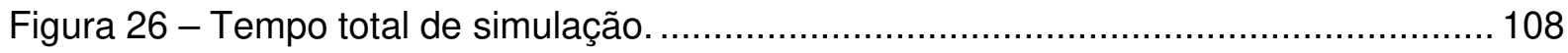

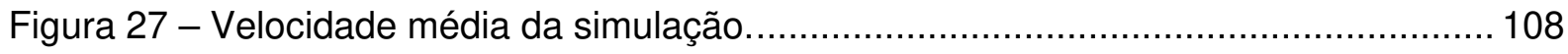

Figura 28 - Velocidade média por tratamento......................................................... 110

Figura 29 - Distância ao veículo lento por tratamento. …........................................... 111

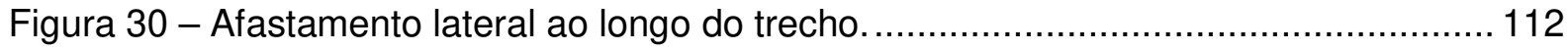

Figura 31 - Velocidade do condutor ao longo do trecho (Condutor \#16)...........................112

Figura 32 - Gráficos de dispersão, densidade e correlação de ultrapassagens U0 .......... 113

Figura 33 - Gráficos de dispersão, densidade e correlação de ultrapassagens U1.......... 114 
Figura 34 - Gráficos de dispersão, densidade e correlação de ultrapassagens U2. 115

Figura 35 - Afastamento lateral na ultrapassagem por tipo de veículo. 116

Figura 36 - Gráfico de interação com Log das médias entre VelVL e DistU. 119

Figura 37 - Gráfico de interação com médias originais entre VelVL e DistU. 119

Figura 38 - Árvore de decisão para classificação dos condutores. 130

Figura 39 - Condutores envolvidos em acidentes do tipo colisão frontal por gênero e faixa etária entre 2008 e 2018 (DATATRAN). 131

Figura 40 - Resultados do questionário de avaliação da simulação. 139

Figura 41 - Ordem de prioridades dos fatores que influenciam na ultrapassagem. 140

Figura 42 - Tipos de trajetórias dos veículos em curvas. 141

Figura 43 - Histograma do afastamento lateral médio nas curvas. 142

Figura 44 - Histograma o afastamento lateral médio das curvas a esquerda e a direita.... 142

Figura 45 - Afastamento lateral médio nas curvas. 143

Figura 46 - Regiões de interesse para verificação de fixações. 144

Figura 47 - Comportamento visual do condutor 20 entre o tempo 00:50 e 1:34. 145

Figura 48 - Total de fixações do condutor \#20 entre o tempo 00:50 e 1:34. 146

Figura 49 - Mapa de calor das fixações acumuladas no segmento 1 (Condutor \#20). 146

Figura 50 - Mapa de calor das fixações acumuladas no trecho simulado. 147 
Tabela 1 - Distância de visibilidade de ultrapassagem do Manual de Projeto Geométrico. . 40

Tabela 2 - Distância de visibilidade de ultrapassagem do Manual de Sinalização................ 40

Tabela 3 - Distância de visibilidade de ultrapassagem no MUTCD. ..................................... 41

Tabela 4 - Distância de visibilidade de ultrapassagem do modelo de Glennon. ……........... 45

Tabela 5 - Distância mínima de visibilidade a partir de Wang e Cartmell. ............................ 51

Tabela 6 - Equações de $\mathrm{S}$ e $\mathrm{X}$ dos estágios do modelo de Wang e Cartmell .........................52

Tabela 7 - Comparativo de valores de DVU entre as normas técnicas................................56

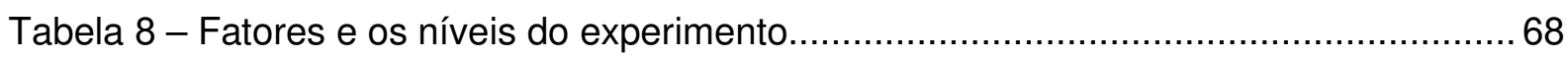

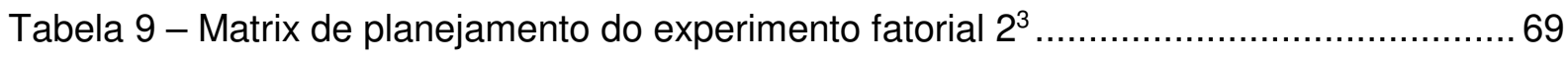

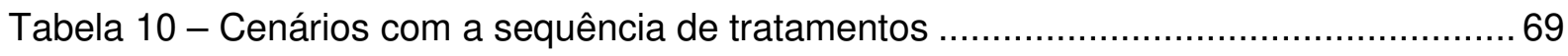

Tabela 11 - Cores dos veículos lentos e veículos opostos por tratamento ........................... 75

Tabela 12 - Variáveis do veículo rápido (veículo participante) utilizadas no algoritmo......... 91

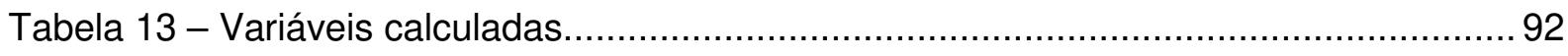

Tabela 14 - Resumo das análises estatísticas aplicadas na pesquisa ................................. 99

Tabela 15 - Faixa Etária por gênero e tempo de habilitação ............................................ 101

Tabela 16 - Matriz de componentes rotacionados obtida pela CATPCA. ……………..... 105

Tabela 17 - Frequência absoluta (frequência relativa) do questionário de desconforto. .... 106

Tabela 18 - Resposta total do desconforto dos participantes por nível.............................. 106

Tabela 19 - Frequência do tipo de ultrapassagem e tentativa. ......................................... 109

Tabela 20 - Frequência do tipo de ultrapassagem e tentativa por tratamento. ....................110

Tabela 21 - Teste de Komogorov-Smirnov com a variável dependente transformada....... 116

Tabela 22 - Tabela simplificada da ANOVA de efeitos dentre sujeitos........................... 117

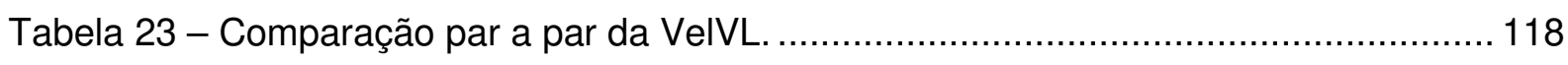

Tabela 24 - Comparação par a par da VelVL e DistU...................................................... 118

Tabela 25 - Comparação par a par da VelVL, TipoVL e DistU. ....................................... 120

Tabela 26 - Ajustes dos modelos e a contribuição dos preditores $(\mathrm{N}=640)$. ....................... 122

Tabela 27 - Parâmetros do modelo multinomial para tipo de ultrapassagem. .................... 124

Tabela 28 - Classificação do modelo logit multinomial ................................................ 125

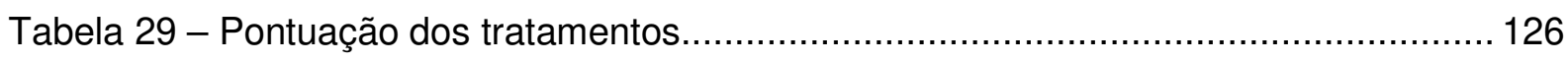

Tabela 30 - Descrição das variáveis do cadastro de participantes. ................................... 128

Tabela 31 - Importância das variáveis normalizadas..................................................... 128

Tabela 32 - Ultrapassagens completas por tratamento ……......................................... 132 

CPRv Comando de Policiamento Rodoviário de São Paulo

AASHTO American Association of State Highway and Transportation Officials

$A D$

Árvore de Decisão

ANOVA Análise de Variância

APA Internacional American Psychological Association

CART Classification and Regression Tree

CATPCA Componentes Principais Categóricos

CTB Código de Trânsito Brasileiro

CEP Conselho de Ética e Pesquisa

CONTRAN Conselho Nacional de Trânsito

DENATRAN Departamento Nacional de Trânsito

DNIT Departamento Nacional de Infraestrutura de Transportes

DVU Distância de Visibilidade de Ultrapassagem

FHWA Federal Highway Administration

MUTCD Manual on Uniform Traffic Control Devices for Streets and Highways

PRF Polícia Rodoviária Federal

PSD Passing Sight Distance

QP Questionário de Presença

RLM Regressão Logística Multinomial

ROI Regiões de Interesse

ROR Risk Odds Ratio 
SPSS

SSQ

TCLE

TTC

$\mathrm{VL}$

VO

VR

VTD
Statistical Package for Social Sciences

Simulator Sickness Questionnaire

Termo de Consentimento Livre e Esclarecido

Time to Collision

Veículo Lento

Veículo Oposto

Veículo Rápido

Virtual Test Drive 


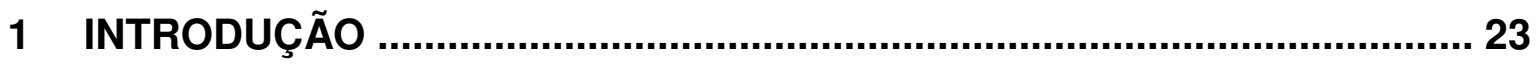

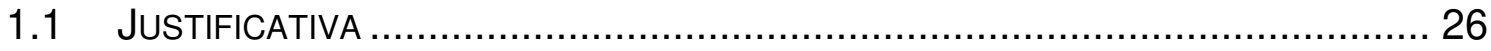

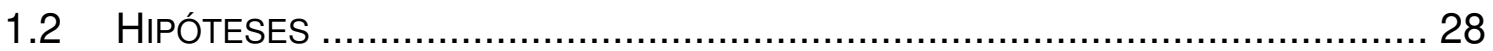

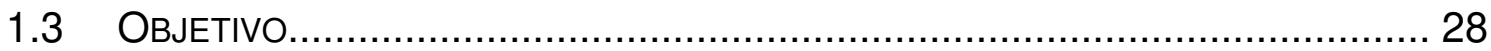

1.4 CONTRIBUIÇÃO DA PESQUISA PARA O ESTADO DA ARTE ............................ 29

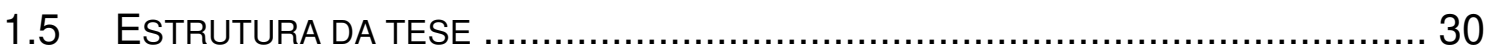

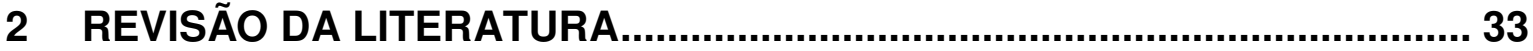

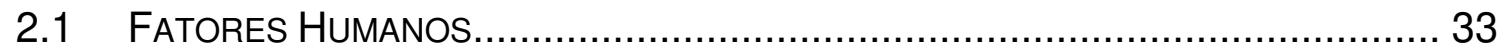

2.2 DISTÂNCIA DE VISIBILIDADE DE ULTRAPASSAGEM (DVU) ............................ 35

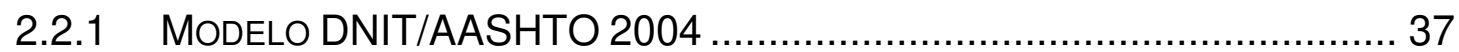

2.2.2 MODELO DE GLENNON............................................................. 41

2.2.3 MODELO DE HASSAN ET. AL ................................................... 45

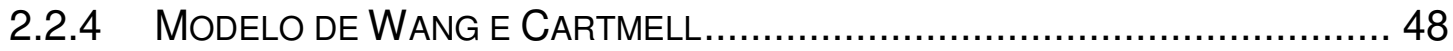

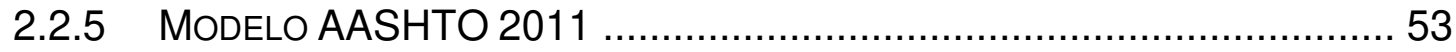

2.3 PESQUISAS COM ENFOQUE EM MANOBRAS DE ULTRAPASSAGEM ….............. 57

2.3.1 VEÍCULO INSTRUMENTADO ....................................................... 5

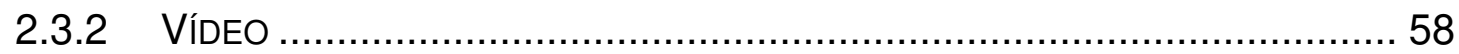

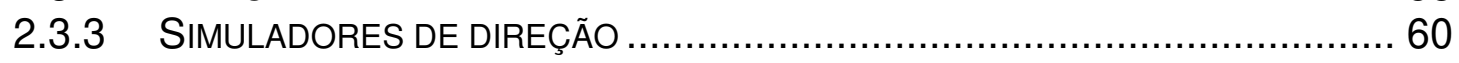

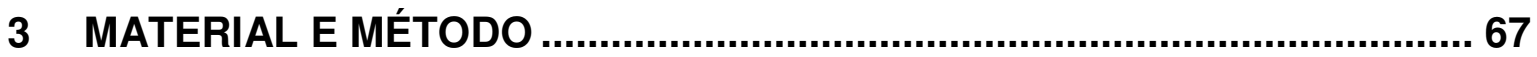

3.1 DELINEAMENTO DO EXPERIMENTO .............................................. 67

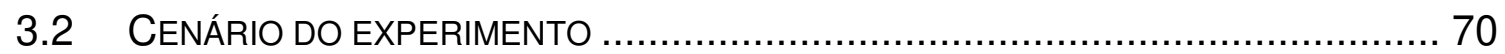

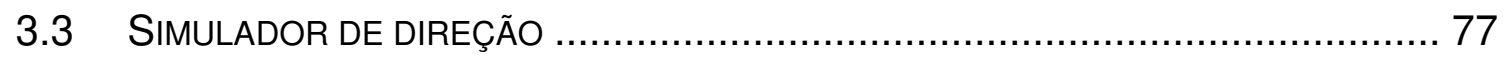

3.4 QUESTIONÁRIOS DE AVALIAÇÃO ........................................................ 81

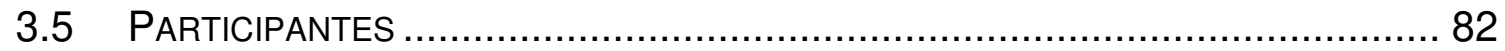

3.6 PROCEDIMENTO EXPERIMENTAL .................................................... 83

3.7 ALGORITMO PARA EXTRAÇÃO DOS DADOS ........................................... 86

3.7.1 FASES DA MANOBRA DE ULTRAPASSAGEM .................................... 86

3.7.2 CLASSIFICAÇÃO DAS ULTRAPASSAGENS ..................................... 89

3.7.3 CLASSIFICAÇÃO DAS TENTATIVAS DE ULTRAPASSAGEM ...................... 90

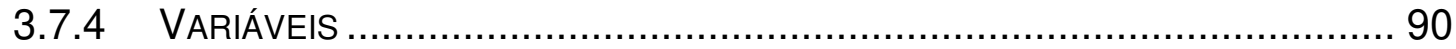

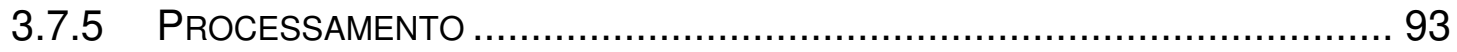

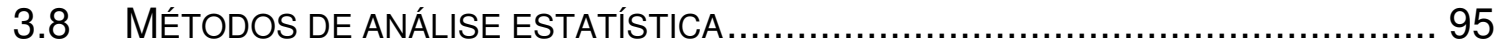

4 ANÁLISE E DISCUSSÃO DOS RESULTADOS .......................................... 101

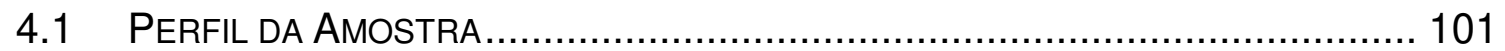

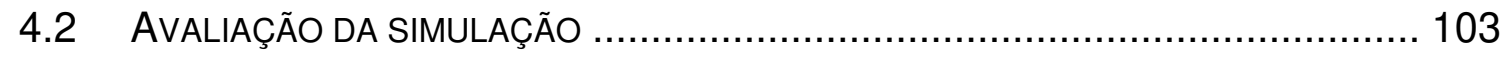

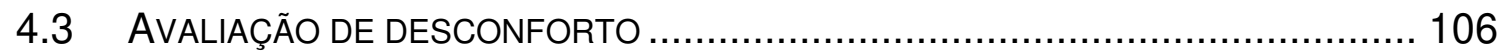

4.4 ANÁLISE EXPLORATÓRIA ............................................................. 107

4.5 A INFLUÊNCIA DOS FATORES SOBRE A DISTÂNCIA AO VEÍCULO LENTO............. 116

4.6 TIPOS DE ULTRAPASSAGEM......................................................... 121 


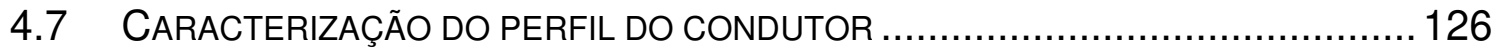

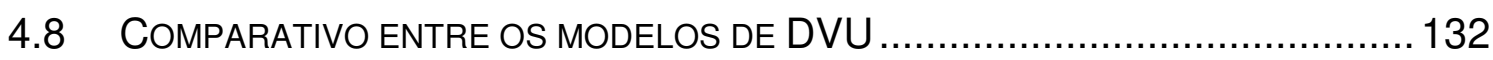

4.8.1 PARÂMETROS DAS ULTRAPASSAGENS - SIMULAÇÃO .............................132

4.8.2 DISTÂNCIA DE ULTRAPASSAGEM: SIMULADOR X MODELO DNIT ..............135

4.9 VALIDAÇÃO DO EXPERIMENTO EM SIMULADOR DE DIREÇÃO …......................137

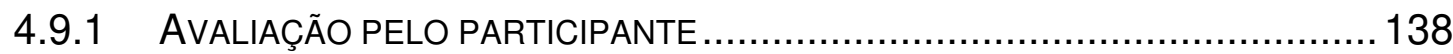

4.9.2 POSIÇÃO LATERAL NAS CURVAS …….......................................... 141

4.9.3 COMPORTAMENTO VISUAL NAS ULTRAPASSAGENS .............................144

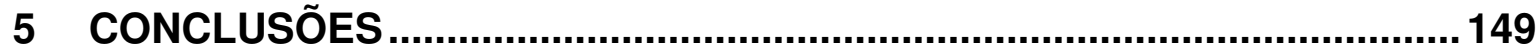

5.1 SUGESTÕES PARA TRABALHOS FUtUROS................................................. 153

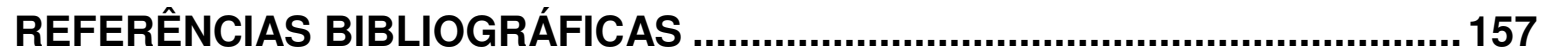

APÊNDICE A - Gráficos de afastamento lateral dos condutores................. 165

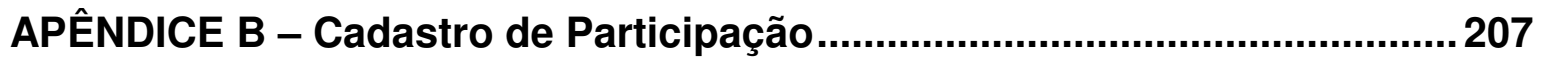

APÊNDICE C - Termo de Consentimento Livre e Esclarecido (TCLE) ........ 209

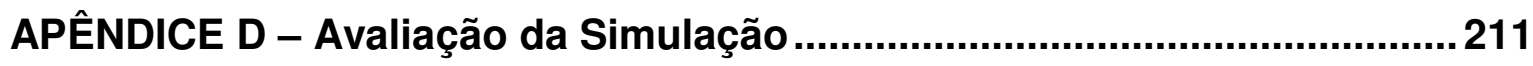

APÊNDICE E - Avaliação de Sintomas de Desconforto...................................213

ANEXO A - Parecer do Conselho de Ética e Pesquisa (CEP)........................215 


\section{INTRODUÇÃO}

Segundo as estatísticas, no Brasil, $50 \%$ dos acidentes ocorrem em rodovias rurais. A análise dos acidentes nestas rodovias mostra que 50 a $60 \%$ desses acidentes acontecem em rodovias de pista simples bidirecional, que constituem cerca de $88 \%$ de todas as rodovias do país (CNT/SEST SENAT, 2018). Apesar de uma redução em relação aos anos anteriores, em 2018 foram registradas mais de 4,5 mil mortes e 49 mil ferimentos, entre leves a graves, segundo registros da Polícia Rodoviária Federal (PRF).

O sistema rodoviário possui três componentes principais: a via, o veículo e os usuários condutores e vulneráveis. Para que o sistema rodoviário funcione de forma eficiente e segura, cada um desses componentes deve trabalhar em conjunto como uma unidade combinada. Essa tarefa não é fácil, em grande parte devido à grande variedade dos ambientes rodoviários, veículos e comportamento dos usuários (CAMPBELL et al., 2012). Dessa forma, pode-se dizer que os acidente rodoviários são o resultado de um problema na interação entre esses fatores.

Nas rodovias de pista simples bidirecionais, por exemplo, os veículos que viajam em velocidades mais baixas causam atrasos em veículos mais rápidos. As manobras de ultrapassagem permitem que os motoristas mais rápidos viajem nas velocidades desejadas e minimizem tais atrasos. No entanto, é necessário ocupar a faixa oposta para ultrapassar um veículo mais lento. Como resultado, a interação com o tráfego oposto tem implicações operacionais e de segurança. Os motoristas tomam decisões passageiras com base em seu próprio comportamento, experiência e veículo, bem como nas condições de trânsito e do entorno.

Se essas manobras ocorrerem em zonas proibidas ou resultarem em falha na ultrapassagem, elas podem levar a acidentes graves, com aumento do grau de severidade (sequelas, amputações e etc) ou mesmo resultar em óbito dos envolvidos (COUFAL; SEMELA, 2016). Portanto, a manobra de ultrapassagem é uma das mais perigosas em rodovias e a gravidade do acidente é significativamente maior do que a de outros tipos de acidentes (BAR-GERA; SHINAR, 2005; ZEFREH; TÖRÖK, 2016).

Dessa forma, o projeto geométrico e de sinalização do trecho para o motorista realizar as manobras de ultrapassagem, que inclui o modelo analítico para cálculo da distância de visibilidade de ultrapassagem (DVU) é um fator importante nas rodovias de pistas simples. Este tópico tem sido tratado extensivamente por pesquisadores de todo o mundo (JENKINS; 
RILETT, 2004; FARAH; TOLEDO, 2010; MOHAMMED, 2013; VLAHOGIANNI, 2013; MILETICS, 2016; RICHTER et al., 2016; FARAH; AZEVEDO, 2017).

Devido às estatísticas e às particularidades sobre os acidentes resultantes de manobras de ultrapassagem e seus fatores de influência (desejo de ultrapassar, decisão de aprovação, aceitação de intervalo de aprovação e desempenho de aprovação) são uma parte essencial no projeto geométrico de rodovias. O avanço subsequente de avalição das diretrizes para projeto geométrico e operação de rodovias rurais é uma contribuição significativa para melhorar a segurança na via. Entretanto, o tempo que pode levar às agências, concessionárias e governos decidirem pela duplicação de uma rodovia de simples ou mesmo implantar faixas adicionais de tráfego em trechos críticos, em geral trecho em rampa, pode levar anos nessa decisão e custar muitas vidas.

Adicionalmente, em geral, os motoristas se comportam de maneira complexa e intuitiva, e não considera-se que este comportamento pode impactar os números de acidentes do tipo colisão frontal (LEE et al., 2011). A compreensão dos fatores humanos - características, habilidades, atuação e limitações dos motoristas, ciclistas e pedestres - é essencial para um bom projeto de rodovia, para a operação do tráfego e para a segurança (DEPARTAMENTO NACIONAL DE INFRAESTRUTURA DE TRANSPORTES - DNIT, 2010). A questão crucial é como a ocorrência de erros no tráfego pode ser reduzida, em rodovias já implantadas e em operação?

A análise do comportamento dos motoristas em manobras de ultrapassagem pode ser realizada por meio de coleta de dados no instante real da ultrapassagem, incluindo as medidas das trajetórias dos veículos que ultrapassam, dos que são ultrapassados e os que estão na pista oposta. Entretanto, as coletas de dados em campo são uma tarefa difícil, complexa e dispendiosas. Além disso, seria necessário um período muito longo para capturar observações suficientes para uma análise robusta para a estatística. O uso de simuladores de direção tem sido proposto como alternativa para obtenção de dados que cruzam as informações do projeto geométrico da via, da sinalização, do veículo, do tráfego e do condutor. Existem diversas vantagens em usar simuladores de direção nas pesquisas comportamentais, principalmente porque não traz risco à vida e permite controlar todos os fatores (variáveis) que podem interferir nos experimentos e nos resultados.

Os simuladores de direção permitem a investigação de efeitos de elementos rodoviários (infraestrutura, variações de pavimentos e etc) em situações de risco e os condutores podem ser repetidamente confrontados com eventos que raramente ocorrem na realidade. No contexto do estudo do comportamento do motorista, os dados coletados com simuladores de direção têm sido utilizados por vários autores. Por exemplo, Jenkins e Rilett (2005) usaram 
dados de simulador de direção para desenvolver uma classificação de manobras de passagem; Bar-Gera e Shinar (2005) avaliaram o impacto da diferença de velocidade entre o veículo do condutor que deseja ultrapassar e veículo a ser ultrapassado; Farah et al. desenvolveram um modelo que considera o intervalo da ultrapassagem e o impacto da geometria da via, as condições de tráfego e as características dos condutores; Bella e D’Agostini (2010) utilizaram um simulador de direção de base fixa para analisar a extremidade traseira do veículo a ser ultrapassado e o risco de colisão em várias condições geométricas da via; e, Vlahogianni e Golias (2012) estudaram o comportamento de motoristas jovens em manobras de ultrapassagem em rodovia de pista simples bidirecional e os fatores que os influenciam.

Outros estudos, por exemplo, analisaram o impacto da idade, sexo e atraso na aprovação de decisões e manobras (JENKINS; RILETT, 2004; FARAH; TOLEDO, 2010) e o efeito das condições de tráfego (BELLA, 2011). Os simuladores de direção, de qualquer forma, são validados não somente para outros temas abordados pela segurança viária (ESKANDARIAN et al., 2008; LLORCA; FARAH, 2016) e desenvolvimento de projeto geométrico de rodovias (TÖRNROS, 1998; MOLINO; KATZ; HERMOSILLO, 2010), mas, também para temas similares ao desenvolvido neste trabalho (UNDERWOOD; CRUNDALL; CHAPMAN, 2011; FARAH, 2013).

Diante do exposto, esta pesquisa, a partir de três hipóteses formuladas, analisou as manobras de ultrapassagem em rodovias de pistas simples bidirecionais em simulador de direção. Para isso, foi elaborado um experimento fatorial de medidas repetidas com três fatores e dois níveis, que contou com uma amostra de 80 (oitenta) participantes, que dirigiram num trecho virtual de rodovia construído de acordo com o padrão das rodovias de pista simples brasileiras. O experimento foi validado no simulador, com o uso do equipamento de rastreio do olhar (eye tracking system) através da abordagem conhecida como validação ecológica (MULLEN et al., 2011). Parte dos resultados que corroboraram as hipóteses testadas, encontrou que dentre os fatores avaliados no experimento, a velocidade do veículo lento teve efeito significativo sobre a variável resposta (distância entre o veículo lento e o veículo do participante); os dados obtidos no simulador de direção foram compatíveis com os parâmetros do modelo normatizado do DNIT; e, o simulador de direção de base fixa é um equipamento viável para estudos que abordem fatores humanos em manobras de ultrapassagem. 


\subsection{JUSTIFICATIVA}

Considerando a mortalidade por tipo de acidente em 10 anos, os acidentes do tipo colisão frontal ( $4 \%$ do total dos acidentes) foram responsáveis por $31 \%$ das mortes ( 25 mil pessoas). Aproximadamente $56 \%$ dos acidentes com vítimas fatais ocorreram em zonas rurais e $20 \%$ das mortes foram causadas por excesso de velocidade ou ultrapassagem indevida. Esses tipos de acidente foram os mais letais (Figura 1) (POLÍCIA RODOVIÁRIA FEDERAL - PRF, 2018).

Dentre as causas prováveis desse tipo de acidente foram registradas como mais frequentes e que resultaram em fatalidades, temos: a falta de atenção, velocidade incompatível com o trecho, ultrapassagem em trecho proibido e ingestão de álcool. Todas elas sinalizam a ocorrência do erro humano, sendo este, consequentemente, como a causa principal desse tipo de acidente.

Figura 1 - Tipo de acidente por mortos em rodovias federais - 2008 a 2018.

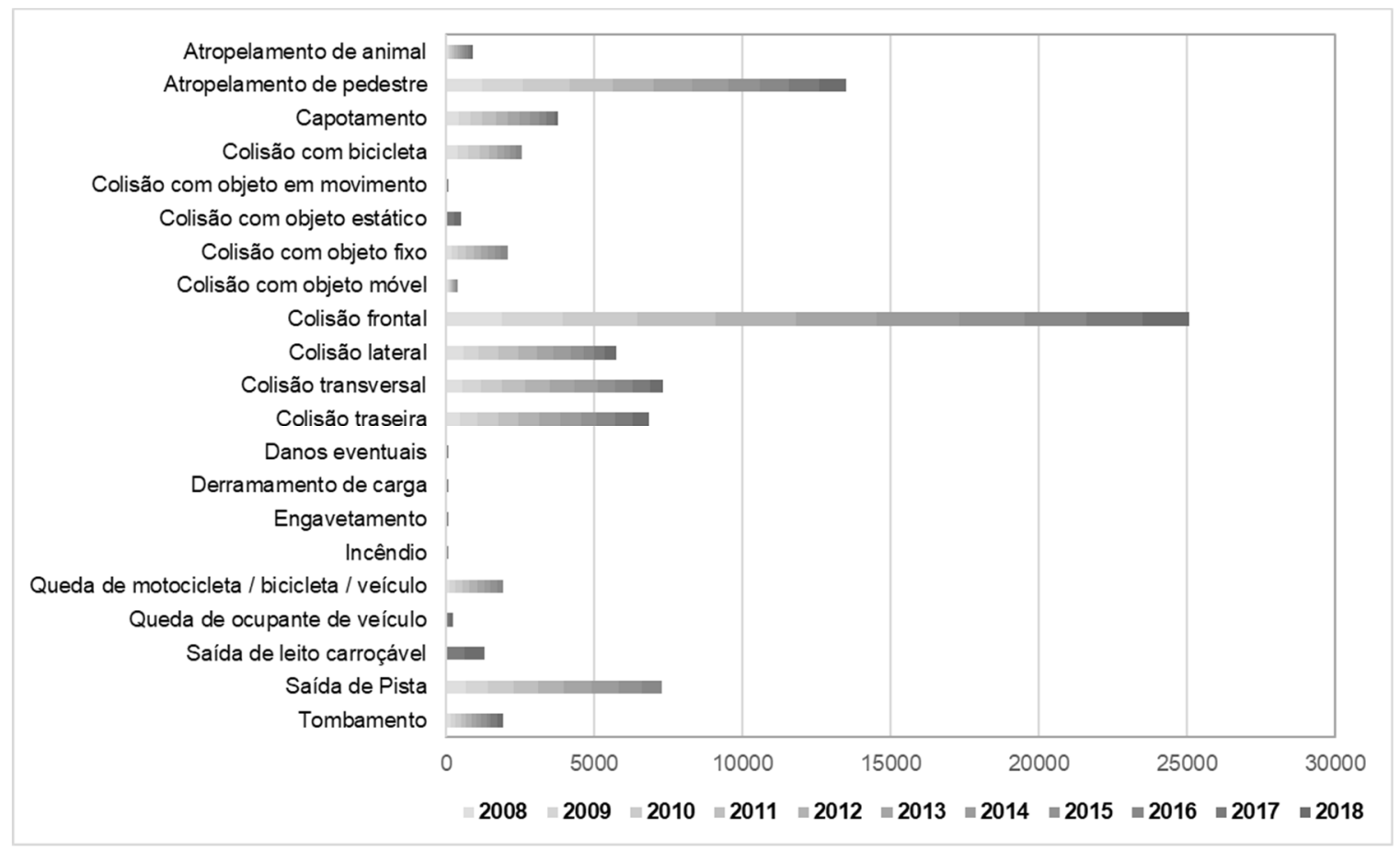

Fonte: PRF (2018)

A tendência se mantém quando se observa o panorama das rodovias estaduais do estado de São Paulo. De acordo com os registros de acidentes do Comando de Policiamento Rodoviário de São Paulo (CPRv), no período de 2012 a 2014, o acidente tipo colisão frontal correspondeu a $2 \%$ dos acidentes ocorridos.

Ao analisar os registros de vítimas fatais, os acidentes do tipo colisão frontal representam $23 \%$ das mortes. Apesar dos dados da CPRv não informar a causa provável do acidente, percebe- 
se uma similaridade entre os dados das rodovias federais e estaduais, com alto percentual de vítimas fatais decorrente do tipo de acidente colisão frontal. Dessa forma, pode-se inferir que as causas prováveis também estejam relacionadas à ultrapassagem indevida.

De forma geral, as estatísticas desse tipo de acidente refletem a necessidade de imprimir esforços substanciais nas pesquisas para investigar e compreender os fatores causais significativos. Particularmente, no caso de manobras de ultrapassagem em rodovias de pista simples bidirecional, estão envolvidos diversos fatores que dependem exclusivamente dos condutores envolvidos, como: o julgamento e tomada de decisão de ultrapassagem do motorista, os riscos que o condutor está disposto a assumir, as ações do motorista que está sendo ultrapassado e as ações dos outros motoristas nas proximidades, além da velocidade e tamanho dos veículos envolvidos. Por outro lado, deve-se considerar os comportamentos inapropriados, como: falta de atenção dos motoristas, inabilidades de observação do entorno, excesso de velocidade, não obediência às regras de trânsito, fadiga e sonolência (HASSAN et al., 2014).

Para colaborar com essa necessidade de pesquisas prementes, os simuladores de direção tornam-se cada vez mais importantes para viabilizar a investigação em ambiente controlado, com diferentes cenários e possibilidade de expor o condutor às diversas situações sem risco à vida. Dessa forma, vários aspectos do comportamento humano podem ser investigados em eventos controlados, de forma eficaz, revelando as reações dos usuários para uma dada situação (CHARISSIS et al., 2008).

Adicionalmente, diversas pesquisas relacionadas a este tema e relatadas na literatura (JENKINS; RILETT, 2004; HARWOOD et al., 2008; FARAH; BEKHOR; POLUS, 2009; VASSILIS et al., 2015; KASHANI; AYAZI; RAVASANI, 2016; MWESIGE et al., 2016) foram realizadas em outros países e, muito embora, não refletem as condições de infraestrutura das rodovias brasileiras, bem como, as características e perfil do comportamento do condutor brasileiro. Ainda assim, os resultados obtidos por esses pesquisadores e demais agências estrangeiras (AMERICAN ASSOCIATION OF STATE HIGHWAY AND TRANSPORTATION OFFICIALS - AASHTO, 2004) norteiam há anos, as tomadas de decisões em políticas públicas para adaptações em normativas sobre segurança viária, projeto geométrico de rodovias, pela falta de capacidade financeira do Brasil, para realizar experimentos similares.

Desta forma, particularmente no Brasil, por conta das estatísticas da acidentalidade rodoviária, é incontornável e de extrema importância a necessidade de desenvolver investigações em campo ou em ambiente simulado de direção, que considerem a infraestrutura rodoviária brasileira, o perfil do condutor brasileiro e as suas especificidades, 
bem como as avaliações de nível de serviços e a fidelidade de modelos de simulação de tráfego.

\subsection{HIPÓTESES}

Nesta pesquisa apresentam-se três hipóteses principais sobre manobras de ultrapassagens analisadas a partir de dados obtidos em simulador de direção, que seguem:

(A) Os fatores: tipo de veículo a ser ultrapassado, a velocidade do veículo a ser ultrapassado e a distância disponível para a manobra de ultrapassagem influenciam na manobra de ultrapassagem.

(B) Os dados obtidos em simulador de direção são compatíveis com os parâmetros do modelo atual utilizado para definir as distâncias de visibilidade de ultrapassagem normatizados.

(C) O simulador de direção de base fixa é uma ferramenta viável para estudos de fatores humanos em manobras de ultrapassagem.

\subsection{Objetivo}

O presente trabalho propõe como objetivo principal analisar manobras de ultrapassagem obtidas em simulador de direção de base fixa, realizadas em pista simples bidirecional. $O$ experimento foi validado através da abordagem conhecida por validação ecológica.

A partir do objetivo geral do trabalho foram estabelecidos os seguintes objetivos específicos:

- Investigar a influência da velocidade do veículo ao ultrapassar, do tipo de veículo a ultrapassar e a distância de visibilidade de ultrapassagem disponível;

- Caracterizar o perfil do condutor a partir do nível de risco mensurado a partir das ultrapassagens realizadas;

- Verificar o grau de confiança - realismo do simulador de direção de base fixa para pesquisas sobre fatores humanos em manobra de ultrapassagem;

- Mensurar as distâncias e tempos das fases do processo de ultrapassagem em ambiente simulado e compará-las ao modelo de ultrapassagem normatizado. 


\subsection{CONTRIBUIÇÃo dA PESQUISA PARA O ESTADO DA ARTE}

As estatísticas das publicações relacionadas ao tema de manobras de ultrapassagem tanto em ambiente simulador de direção, ou por outros meios, ao longo dos últimos 10 anos, ilustram a relação crítica entre os acidentes do tipo colisão frontal e o número de mortes registradas em rodovias.

A contribuição desta pesquisa para o estado da arte das publicações encontradas na literatura internacional se apoia primeiramente, de forma pioneira, na elaboração do método que utiliza a validação de experimento em simulador de direção com o cruzamento de dados extraídos do equipamento de rastreio do olhar e - não somente das informações extraídas do simulador - velocidade do veículo, trajetória, entre outros. O tamanho da amostra (oitenta condutores) utilizada, o que é muito superior às amostras utilizadas nos experimentos relatados na literatura internacional, possibilitou aplicar diversas técnicas estatísticas, desde as paramétricas como as não paramétricas e, consequentemente, obter resultados significativos que contribuem para o estado da arte do tema em tela.

Para o Brasil, um dos pontos que destaca a contribuição desta pesquisa, diz respeito à confrontação dos modelos (AASHTO e DNIT) de orientações que embasam os valores de parâmetros que compõem as recomendações das distâncias de visibilidade de ultrapassagem para projetos geométricos rodoviários. Os valores recomendados pelo DNIT advêm de pesquisas e resultados obtidos de normas norte americanas desatualizadas, como por exemplo o Green Book de 1994, uma vez que estas foram e são periodicamente atualizadas, ao passo que o manual geométrico do DNIT, não. O modelo de distância de visibilidade de ultrapassagem da AASHTO foi reformulada em 2010, a partir de estudos observacionais de campo para se adequar às evoluções da dinâmica veicular e do comportamento do condutor ao longo dos anos. No Brasil, contraponto, não houve qualquer atualização até a presente data.

Diante disso, no Brasil, é incontornável a necessidade de estudos sobre o comportamento dos condutores torna-se prementemente necessários para que as recomendações dos manuais possam ser atualizadas com parâmetros que contemplem as particularidades dos condutores brasileiros, em conjunto com as particularidades da infraestrutura rodoviária brasileira. Desta forma, esta pesquisa contribui também para o avanço da literatura nacional, na qual se registra a ausência de estudos sobre esse tema, com a apresentação de um estudo sobre manobras de ultrapassagem com enfoque no comportamento humano - do condutor. Complementarmente, com os dados obtidos nos experimentos, apresenta-se uma análise comparativa com as distâncias de visibilidade de ultrapassagens obtidas em ambiente 
simulado e a distância de visibilidade de ultrapassagem calculadas através do modelo recomendado.

\subsection{ESTRUTURA DA TESE}

A tese está estruturada em cinco capítulos. O capítulo 1 é um introdutório com apresentação da proposta e objetivo da pesquisa.

O capítulo 2 engloba a revisão da literatura e apresenta um embasamento teórico com os principais modelos de distância de visibilidade de ultrapassagem (DVU). Dentre estes, o modelo aplicado atualmente em projetos geométricos no Brasil disponível no manual do DNIT e os modelos de Glennon e Hassan que foram utilizados para revisão do modelo da AASHTO (2011). Adicionalmente, também é descrito o modelo de Wang e Cartmell que se destaca por incorporar parâmetros veiculares na elaboração do modelo. Em seguida são apresentadas pesquisas com enfoque em manobras de ultrapassagem e fator humano com métodos utilizados em diversos países.

O capítulo 3 apresenta os materiais e métodos para extração das manobras de ultrapassagem com o detalhamento do delineamento do experimento, o cenário elaborado para 0 experimento e treinamento, a estrutura do simulador de direção de base fixa, os questionários de avaliação da simulação e desconforto, o procedimento experimental adotado, o algoritmo de extração dos dados, o procedimento de recrutamento dos participantes e os métodos de análise estatística utilizados para análise dos resultados. A Figura 2 exibe um esquema sintético do método adotado nesta pesquisa com os respectivos tempos para elaboração das etapas.

No capítulo 4 são relatadas as análises estatísticas dos dados obtidos no experimento e a discussão dos resultados.

Por fim, o capítulo 5 traz as conclusões desta pesquisa com as respostas para as três hipóteses testadas, os objetivos estabelecidos e sugestões para trabalhos futuros. Adicionalmente, foram incorporados os produtos resultantes desta pesquisa em cinco apêndices. O Apêndice A apresenta os gráficos de afastamento lateral de todos os participantes, ao longo do trecho simulado. Os apêndices seguintes exibem os formulários e questionários utilizados, quais sejam: Apêndice B - Cadastro de participação; Apêndice C Termo de consentimento livre e esclarecido; Apêndice D - Questionário da avaliação da simulação; Apêndice E - Questionário de avaliação de sintomas de desconforto. E por último o Anexo A com o parecer de autorização do Conselho de Ética e Pesquisa (CEP). 
Figura 2 - Síntese do método.

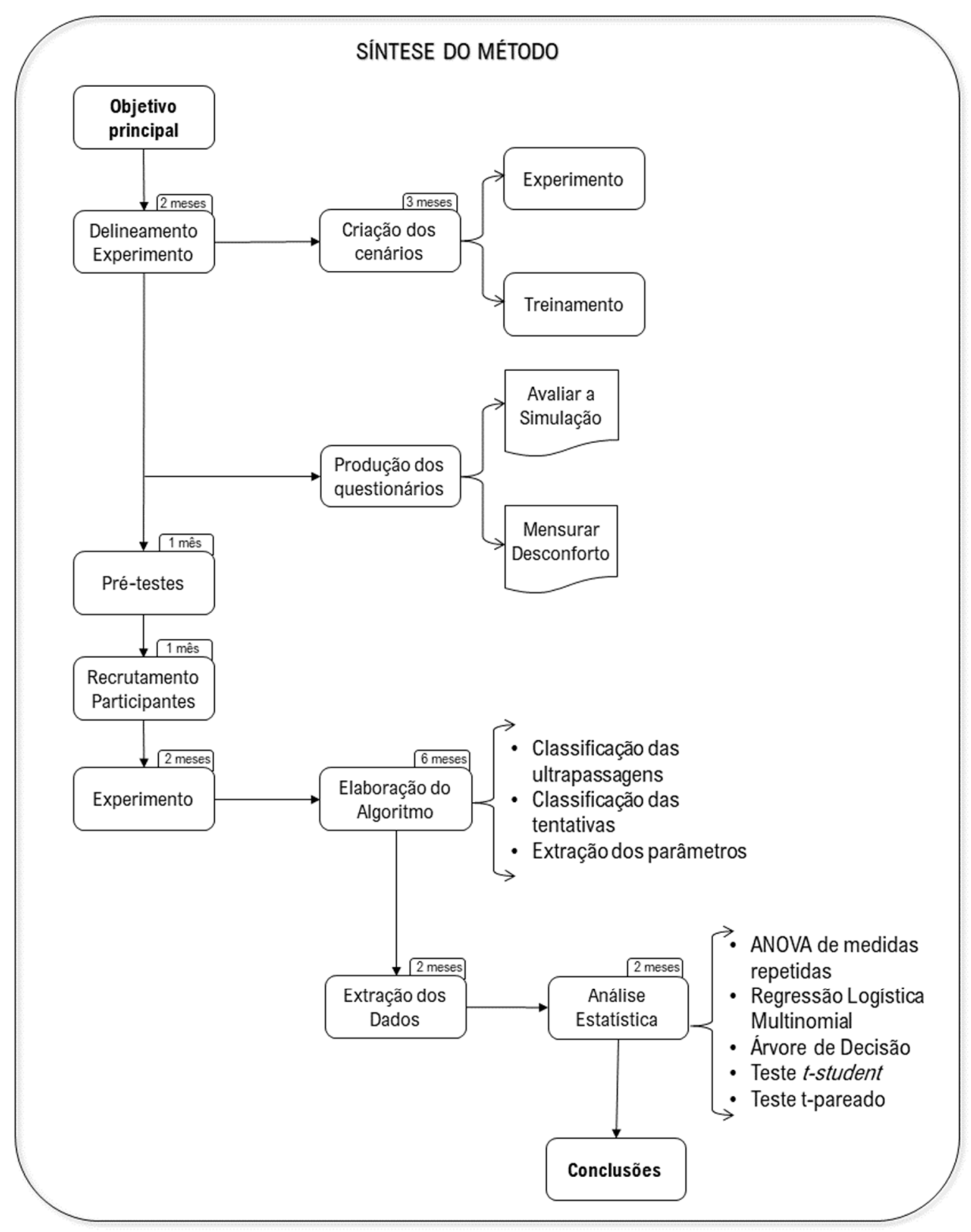

Fonte: a autora 



\section{REVISÃO DA LITERATURA}

O primeiro item abordado diz respeito aos fatores humanos e comportamento do condutor que tem vital influência sobre a probabilidade de ocorrência do acidente. Em seguida é apresentado o conceito de distância de visibilidade de ultrapassagem (DVU), acompanhado dos modelos de determinação deste parâmetro de projeto. Destaca-se o modelo do DNIT (1999) utilizado atualmente em projetos geométricos brasileiros, os modelos de Hassan et al. (1996), que foram utilizados para remodelagem das normas da AASHTO (2011) e o modelo de Wang e Cartmell (1998) sendo um dos mais representativos do sistema dinâmico veicular.

$\mathrm{Na}$ sequência, são apresentados o estado da arte em pesquisas com enfoque em estudos sobre fatores humanos e manobras de ultrapassagem com aplicação de tecnologias de coleta de dados com veículo instrumentado, através de vídeo e com o uso de simuladores de direção - equipamento adotado nesta pesquisa - acrescentando o sistema de rastreio do olhar.

\subsection{Fatores Humanos}

O sistema de tráfego é composto por três elementos principais: a via, o veículo e o usuário. Sendo atribuído como falha do elemento humano a 90\% dos acidentes registrados (NODARI; BOTTESINI, 2011; CAMPBELL et al., 2012)

Na segurança rodoviária, frequentemente é dado como certo que "fatores humanos", "erros humanos" e/ou "comportamento humano" é a principal causa de acidentes. No entanto é necessário esclarecer a diferença entre esses conceitos, especificamente o caso dos chamados "fatores humanos" e "erros humanos".

O termo "fatores humanos" geralmente representa todos os aspectos humanos envolvidos em qualquer atividade, sejam estes positivos ou negativos. Sendo um termo genérico que abrange a ciência da compreensão da capacidade humana. Acidentes são explicados por múltiplos fatores causais que caracterizam um defeito em seus componentes e nas suas interações. Assim, os fatores humanos de acidentes referem-se às variáveis que caracterizam o componente humano (o nível de experiência, de fadiga, de atenção, etc.), e que combinados com a inadequação das variáveis que caracterizam os outros componentes (geometria da estrada, veículo, meio ambiente, tráfego) produzem "erros humanos" (VAN ELSLANDE; NAING; ENGEL, 2008)

Os pesquisadores (VAN ELSLANDE; NAING; ENGEL, 2008) ressaltam que normalmente o "erro" é confundido e tomado como sinônimo de "falha". O problema em confundir os erros 
humanos e fatores humanos de acidente faz com se perca qualquer potencialidade da solução, além do fatalismo e punição. A análise científica de acidentes precisa de uma caracterização dos "erros humanos", que podem ser humanos, ambientais, veicular, etc. Esta diferenciação poderá apresentar soluções mais eficientes para a prevenção dos erros humanos, agindo sobre suas causas bem identificadas e uma melhor ergonomia do sistema de condução de acordo com as capacidades e fraquezas humanas.

Cabe ainda destacar a diferença entre comportamento e desempenho do motorista. Desempenho do condutor refere-se às habilidades do motorista, ou o que este pode fazer, enquanto que comportamento do condutor se refere ao que o motorista faz, de fato, durante a condução do veículo.

Dessa forma, o comportamento do motorista assume papel decisivo na segurança viária, uma vez que, mesmo ele sendo capaz de reconhecer um sinal de proibição de ultrapassagem (desempenho do motorista), ele pode optar por ultrapassar em local proibido (comportamento do motorista) (NODARI; BOTTESINI, 2011). Os projetistas de rodovias e engenheiros de tráfego devem estar cientes dessas características do fator humano e usá-las de maneira a melhorar ou otimizar a segurança do sistema rodoviário que estão projetando e controlando (CAMPBELL et al., 2012).

É importante que as estradas sejam auto-explicativas para induzir o comportamento do usuário com base no projeto e não em "agentes externos", como placas e sinais de trânsito (THEEUWES; GODTHELP, 1995). Uma rodovia autoexplicativa depende de um projetado centrado no ser humano. A rotatória é um bom exemplo. Em vez de esperar o condutor parar em um cruzamento sinalizado, a rotatória minimiza a necessidade de parar. As pessoas inevitavelmente cometem erros. Um bom projeto antecipa estes erros e minimiza as suas consequências (KEITH et al., 2005)

Um paradigma que vem ganhando espaço e tem despertado grande interesse e apoio em muitas partes do mundo pois contempla a abordagem do ponto de vista do condutor é o "Visão Zero". O "Visão Zero" surgiu na Suécia e consiste em uma estratégia para a concepção de um sistema de transporte rodoviário seguro, em que as estradas e veículos devam adaptarse a capacidade do condutor, sendo inaceitável a perda de vidas humanas no trânsito. Para isto é necessário conhecimento sobre como as pessoas se comportam e realizam tarefas em ambientes complexos e dinâmicos (VAN DER HORST; HOGEMA, 2011).

Contudo a grande variedade de características culturais, físicas e psicológicas das pessoas dificulta o controle sobre o fator humano (DEWAR; OLSON, 2002). Assim, são necessárias pesquisas para compreensão do comportamento dos condutores no sistema de trânsito e 
suas particularidades, principalmente em situações de risco com maior probabilidade de acidentes fatais, a exemplo das manobras de ultrapassagem.

\subsection{DistânCIA DE VISIBILIDADE DE ULTRAPASSAGEM (DVU)}

Ultrapassagem, segundo o artigo 199 do Código de Trânsito Brasileiro (CTB), é o movimento de passar à frente de outro veículo que se desloca no mesmo sentido, em menor velocidade e na mesma faixa de tráfego, necessitando sair e retornar à faixa de origem.

As ultrapassagens são classificadas em função da forma que iniciam ou concluem a manobra. Geralmente são denominadas como ultrapassagem rápida (flying) e ultrapassagem com retardamento (accelerative). A ultrapassagem rápida ocorre quando um veículo mais rápido se aproxima de um veículo lento em um fluxo livre e o veículo rápido muda de faixa a uma distância maior do veículo lento sem nenhuma desaceleração. A ultrapassagem com retardamento ocorre quando o veículo rápido se aproxima de um veículo lento, desacelera e segue o veículo lento durante algum tempo, dependendo do espaço disponível na faixa oposta. Uma vez que o veículo rápido tenha espaço suficiente na faixa oposta, ele começa a mudar de faixa e acelera e conclui a manobra de ultrapassagem (POLUS; LIVNEH; FRISCHER, 2000; ASAITHAMBI; SHRAVANI, 2017; KABBACH JR, 2017)

A distância de visibilidade de ultrapassagem (DVU) ou Passing Sight Distance (PSD) é definida como o comprimento de via necessário para que um veículo possa ultrapassar outro, pela faixa de tráfego oposta, com segurança (DNIT, 1999; AASHTO, 2004; PIMENTA et al., 2017). O estudo para melhoramento da determinação de DVU tem aplicado novos recursos como Sistema de Informação Geográfica (SIG) e modelagem digital (CASTRO; GARCIAESPONA; IGLESIAS, 2015). Outras pesquisas tem buscado a análise e verificação dos parâmetros recomendados na presença de veículos de grande porte (GARCíA et al., 2014, 2016).

A DVU é um dos parâmetros geométricos que compõe o conjunto de elementos que garantem a segurança viária. Quanto maior a DVU, maior a segurança da rodovia. Assim, o projetista deve sempre procurar soluções eficientes que permitam que o condutor tenha condições de efetuar a ultrapassagem de veículos lentos. Porém, estabelecer um critério adequado para o cálculo de distância de visibilidade de ultrapassagem (DVU) é uma tarefa difícil, pois os motoristas reagem de forma diferente quando decidem ultrapassar.

Projetistas e engenheiros de tráfego da estrada, muitas vezes usam a distância de velocidade (ou seja, a distância de frenagem, distância de visibilidade de ultrapassagem) como critérios para especificar os elementos de projeto da rodovia e colocação de dispositivos de controle 
de tráfego, mas os critérios de distância são sempre baseados no tempo e como os condutores os utilizam (CAMPBELL et al., 2012).

A manobra de ultrapassagem é uma das mais arriscadas em uma estrada, porque a ação a ser executada depende de uma quantidade substancial de fatores, tais como: estado atual do veículo, posição e velocidade dos veículos do entorno, além do desempenho do condutor. No caso de pista simples bidirecional é necessário que existam trechos com visibilidade suficiente para que os veículos mais rápidos possam ultrapassar os mais lentos.

Nesse tipo de manobra, o motorista deve estimar simultaneamente o tempo de colisão (TTC - Time to Collision) com um veículo que se aproxima na faixa oposta, monitorar o TTC com o veículo a ultrapassar para evitar uma colisão traseira e estimar o tempo necessário para completar a ultrapassagem com base na velocidade atual, condições e conhecimento das capacidades do seu próprio veículo.

Além disso, os motoristas tendem a se comportar de forma diferente no mesmo cenário de ultrapassagens. Por exemplo, headways ${ }^{1}$ e afastamento lateral diferentes são preferidos por condutores diferentes, em grande parte dependente de seu estilo de condução (ZHANG et al., 2015).

A eficiência operacional de muitas rodovias de pista simples depende da oportunidade de que motoristas mais rápidos ultrapassem motoristas mais lentos. Quando os condutores mais rápidos encontram um veículo mais lento e não conseguem ultrapassar, os pelotões se formam e o nível de serviço da rodovia é afetado. A distância de visibilidade de ultrapassagem é fornecida no projeto de rodovias de pista simples a fim de garantir oportunidades para que condutores mais rápidos ultrapassem onde as lacunas no tráfego oposto permitam.

Diversos modelos foram desenvolvidos para determinar a distância mínima de visibilidade necessária para uma operação segura e eficiente em rodovias de pista simples bidirecional. Alguns destes modelos, serão apresentados em mais detalhes a seguir.

\footnotetext{
${ }^{1}$ Termo que referencia uma medida de distância ou tempo entre veículos em um sistema de trânsito.
} 


\subsubsection{Modelo DNIT/AASHTO 2004}

No Brasil, o critério para a distância de visibilidade de ultrapassagem (DVU) mínima recomendada é apresentado no Manual de Projeto Geométrico de Rodovias Rurais (1999) do Departamento Nacional de Infraestrutura de Transportes (DNIT) e se baseia na edição de 1994 da norma americana "A Policy on Geometric Design of Highways and Streets" (Green Book), da American Association of State Highway and Transportation Officials (AASHTO) que permaneceu inalterado até a versão do Green Book de 2004.

O manual de projeto geométrico orienta que a distância de visibilidade de ultrapassagem a ser empregada para fins de projeto deve ser calculada com base na distância necessária para completar com segurança as manobras normais de ultrapassagem. E que, por motivos práticos, considera-se apenas o caso mais simples em que um único veículo ultrapassa outro (DNIT, 1999; AASHTO, 2004).

Para o cálculo das distâncias mínimas de ultrapassagem admitem-se a seguintes condições razoáveis para um elevado percentual de motoristas:

- O veículo mais lento (VL) a ser ultrapassado viaja com velocidade uniforme.

- O veículo mais rápido (VR), que ultrapassará, está logo atrás do veículo VL e com mesma velocidade quando atinge o ponto inicial (PI) do intervalo de ultrapassagem.

- Após atingir o ponto inicial o motorista de VR precisa de um certo período de tempo para perceber a possibilidade de ultrapassar e iniciar a manobra: tempo de percepção e reação.

- O veículo VR acelera durante a manobra e sua velocidade média durante o período em que está na faixa esquerda é $15 \mathrm{~km} / \mathrm{h}$ (DNIT, 1999; AASHTO, 2004), maior que a do veículo VL.

- Quando VR volta para a faixa direita há uma distância razoável do veículo que vem em sentido contrário.

A distância de visibilidade mínima de ultrapassagem é determinada pelo somatório de quatro distâncias. A Figura 3 ilustra o esquema da manobra de ultrapassagem e apresenta os elementos que compõem a distância total de visibilidade de ultrapassagem, onde: 
$\mathrm{d}_{1} \quad$ :distância percorrida durante o tempo de percepção e reação e durante a aceleração inicial para o ponto de invasão da faixa esquerda;

$\mathrm{d}_{2}$ :distância percorrida enquanto o veículo rápido (VR) ocupa a faixa da esquerda;

$d_{3}$ :distância entre o veículo rápido (VR) e o veículo em sentido oposto (VO) ao final da manobra.

$\mathrm{d}_{4}$ :distância percorrida pelo veículo em sentido oposto (VO), que equivale a 2/3 da distância de $\mathrm{d}_{2}$.

Figura 3 - Modelo de DVU do DNIT/AASHTO (2004)

$1^{\mathrm{a}}$ FASE

A

B

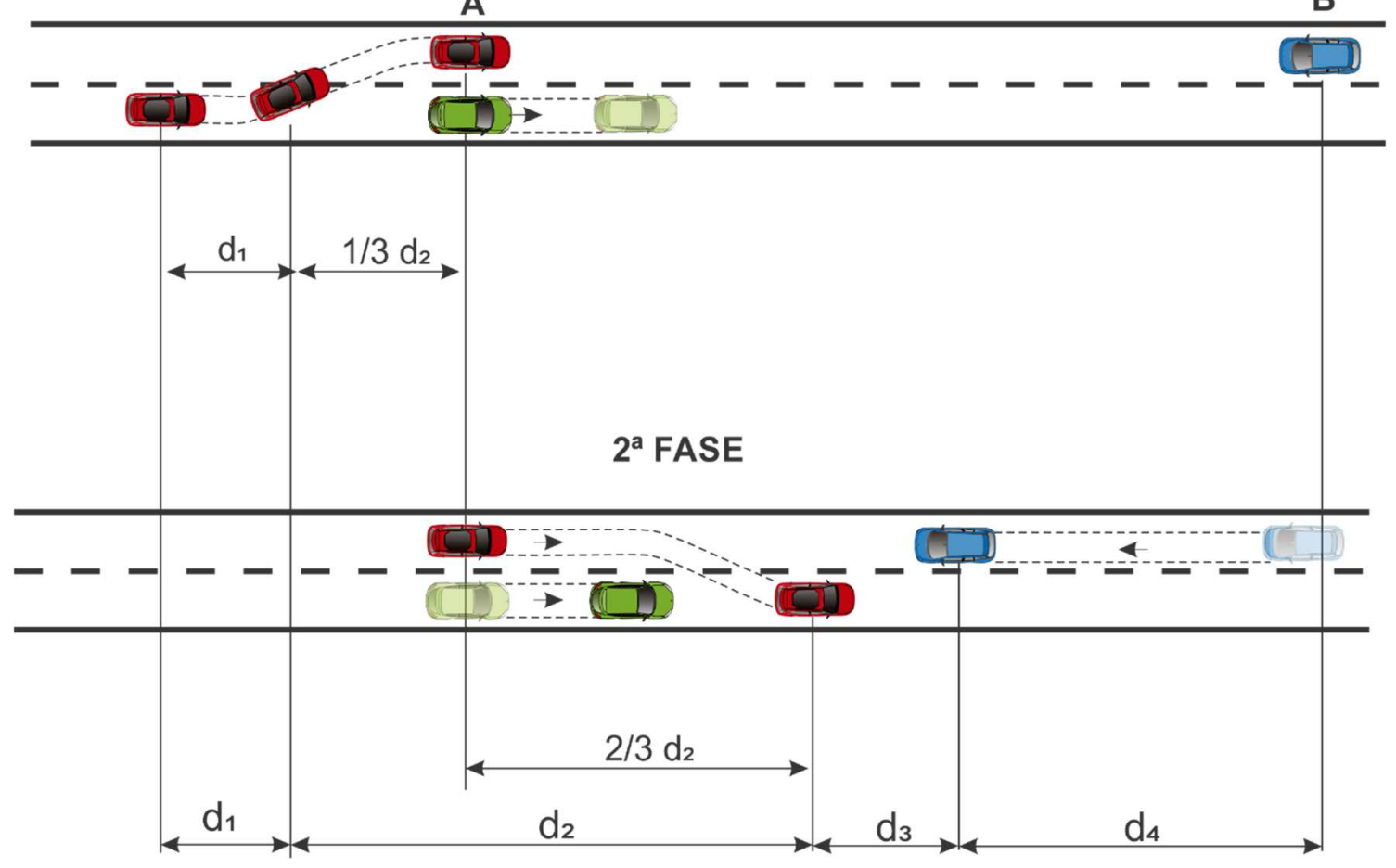

Fonte: Adaptado de DNIT (1999).

A distância de manobra inicial $\left(d_{1}\right)$ é dividida em duas partes, um tempo de percepção e reação e o intervalo em que o veículo rápido se direciona até o ponto de invasão da faixa esquerda. Em grandes extensões esses dois tempos se sobrepõem. Estudos mostram que a média de aceleração neste início é menor do que o potencial máximo, indicando que essa manobra inicial contém um elemento do tempo de reação e percepção. Contudo, alguns condutores podem permanecer na mesma posição enquanto decidem ultrapassar. A posição exata do veículo rápido durante a manobra inicial não é considerada importante, nesta versão, porque as diferenças são insignificantes na distância de ultrapassagem resultante. 
A distância $d_{2}$ é medida a partir do ponto em que o pneu dianteiro esquerdo cruzou a linha central do eixo da via até ao ponto em que o mesmo pneu dianteiro do veículo em questão cruzou a linha central retornando à faixa da direita (CAMPBELL et al., 2012).

A AASHTO (2004) apresenta ainda valores de tempo de ultrapassagem obtidos em estudos para a distância em que o veículo rápido ocupa a faixa da esquerda $\left(d_{2}\right)$, entre 9,3 e 10,4 segundos. E para a distância de folga $\left(\mathrm{d}_{3}\right)$ entre o veículo rápido e o veículo oposto, após a conclusão da ultrapassagem, que varia de 30 a 75 metros, dependente da velocidade média do veículo rápido.

A distância percorrida pelo veículo oposto durante a manobra de ultrapassagem $\left(\mathrm{d}_{4}\right)$ é acrescida à distância total de ultrapassagem para minimizar a chance de o veículo rápido encontrar o veículo oposto enquanto percorre a faixa da esquerda. Durante a primeira fase da manobra de ultrapassagem o veículo rápido ainda não se aproximou do veículo lento e mesmo que o veículo rápido ocupe a faixa da esquerda, o condutor pode retornar à faixa da direita se um veículo oposto for avistado. Esse tempo não é incluído na distância total percorrida pelo veículo oposto e corresponde a 1/3 de tempo que o veículo rápido ocupa a faixa da esquerda. Sendo assim, a distância $d_{4}$ corresponde a $2 / 3$ da distância percorrida pelo veículo rápido na faixa da esquerda $\left(d_{2}\right)$. A velocidade do veículo oposto é considerada a mesma velocidade percorrida pelo veículo rápido. As equações para computar as distâncias são apresentadas a seguir.

$$
\begin{aligned}
& d_{1}=0,278 t_{1}\left(v-m+\frac{a t_{1}}{2}\right) \\
& d_{2}=0,278 v t_{2} \\
& d_{3}=30 \text { a } 75 \text { metros } \\
& d_{4}=\frac{2}{3} d_{2}
\end{aligned}
$$

Onde:

$\begin{array}{lll}\mathrm{t}_{1} & (\mathrm{~s}) & \text { tempo da manobra inicial } \\ \mathrm{a} & (\mathrm{km} / \mathrm{h} / \mathrm{s}) & \text { aceleração média } \\ \mathrm{v} & (\mathrm{km} / \mathrm{h}) & \text { velocidade média do veículo rápido } \\ \mathrm{m} & (\mathrm{km} / \mathrm{h}) & \text { diferença de velocidade entre o veículo rápido e o veículo lento } \\ \mathrm{t}_{2} & (\mathrm{~km} / \mathrm{h}) & \text { tempo em que o veículo rápido ocupa a faixa da esquerda } \\ \mathrm{d}_{2} & (\mathrm{~m}) & \text { distância percorrida ocupando a faixa da esquerda }\end{array}$


Com base nessas equações são apresentadas na Tabela 1 as distâncias de visibilidade de ultrapassagem para as velocidades de $30 \mathrm{~km} / \mathrm{h}$ a $120 \mathrm{~km} / \mathrm{h}$ que constam no Manual de Projeto Geométrico do DNIT (1999).

Tabela 1 - Distância de visibilidade de ultrapassagem do Manual de Projeto Geométrico.

\begin{tabular}{c|c|c|c|c|c|c|c|c|c|c}
\hline $\begin{array}{c}\text { Velocidade } \\
\text { regulamentada } \\
(\mathbf{k m} / \mathbf{h})\end{array}$ & 30 & $\mathbf{4 0}$ & $\mathbf{5 0}$ & $\mathbf{6 0}$ & $\mathbf{7 0}$ & $\mathbf{8 0}$ & $\mathbf{9 0}$ & $\mathbf{1 0 0}$ & $\mathbf{1 1 0}$ & $\mathbf{1 2 0}$ \\
\hline $\begin{array}{c}\text { Distância de } \\
\text { visibilidade de } \\
\text { ultrapassagem }(\mathrm{m})\end{array}$ & 180 & 270 & 350 & 420 & 490 & 560 & 620 & 680 & 730 & 800 \\
\hline Fonte: DNIT (1999)
\end{tabular}

Os projetos de sinalização para demarcação das linhas de proibição de ultrapassagem seguem os critérios com distância mínima de visibilidade apresentados na Tabela 2 que constam no Manual de Sinalização Rodoviária (DNIT, 2010) e no Manual Brasileiro de Sinalização de Trânsito - Volume IV (CONSELHO NACIONAL DE TRÂNSITO - CONTRAN, 2007a).

Tabela 2 - Distância de visibilidade de ultrapassagem do Manual de Sinalização.

\begin{tabular}{|c|c|c|c|c|c|c|c|c|}
\hline $\begin{array}{c}\text { Velocidade } \\
\text { regulamentada } \\
(\mathrm{km} / \mathrm{h})\end{array}$ & 40 & 50 & 60 & 70 & 80 & 90 & 100 & 110 \\
\hline $\begin{array}{c}\text { Distância de } \\
\text { visibilidade de } \\
\text { ultrapassagem }(\mathrm{m})\end{array}$ & 140 & 160 & 180 & 210 & 245 & 280 & 320 & 355 \\
\hline
\end{tabular}

Apesar de estar ciente de que o motorista médio brasileiro tem características próprias, ainda não se dispõe de estudos conclusivos sobre o assunto. O critério proposto pela AASHTO e adotado pelo DNIT vem sendo aplicado a novos projetos e tem apresentado bons resultados (PIMENTA et al., 2017).

A adoção de outros critérios, como os utilizados para definir trechos com proibição de ultrapassagem nos projetos de sinalização, podem redundar em valores diferentes no que tange às distâncias de visibilidades necessárias.

O Manual on Uniform Traffic Control Devices (MUTCD), que define as normas americanas para implantação dos dispositivos de sinalização vertical e horizontal, apresenta distâncias mínimas de visibilidade de ultrapassagem para marcações em zonas de ultrapassagem proibida, menores que os apresentados na AASHTO (2004). 
Tabela 3 - Distância de visibilidade de ultrapassagem no MUTCD.

\begin{tabular}{c|c|c|c|c|c|c|c|c|c|c}
\hline $\begin{array}{c}\text { Velocidade } \\
\text { regulamentada } \\
(\mathbf{k m} / \mathbf{h})\end{array}$ & $\mathbf{4 0}$ & $\mathbf{5 0}$ & $\mathbf{5 5}$ & $\mathbf{6 5}$ & $\mathbf{7 0}$ & $\mathbf{8 0}$ & $\mathbf{9 0}$ & $\mathbf{9 5}$ & $\mathbf{1 0 5}$ & $\mathbf{1 1 0}$ \\
\hline $\begin{array}{c}\text { Distância de } \\
\text { visibilidade de } \\
\text { ultrapassagem (m) }\end{array}$ & 137 & 152 & 167 & 183 & 213 & 244 & 274 & 305 & 335 & 366 \\
\hline Fonte: FHWA (2012)
\end{tabular}

O modelo da AASHTO (2004) para a distância de visibilidade de ultrapassagem ignora a possibilidade de uma manobra abortada e, portanto, determina distâncias excessivamente longas. Além disso, os critérios mais longos de DVU, apresentados no Green Book AASHTO (2004), podem proporcionar maior eficiência operacional ao tráfego, mas muitas vezes são considerados tão longos que são impraticáveis na execução do projeto.

\subsubsection{Modelo de Glennon}

Em 1971, os pesquisadores Weaver, Glennon, Van Valkenberg e Michael (GLENNON, 1988) apresentaram críticas sobre o modelo da AASHTO de 1954 para distância de visibilidade de ultrapassagem. Nesses estudos, os pesquisadores deduziram que a execução de uma manobra de ultrapassagem segura não requer quantidades variáveis de DVU e que existe uma posição relativa entre o veículo rápido e o veículo lento, onde a distância para completar a ultrapassagem é igual à distância para abortar a ultrapassagem. Weaver e Glennon nomeiam essa distância como "posição crítica" (critical position) e Van Valkenberg e Michael como "ponto de não-retorno".

A posição crítica pode ser definida como o ponto onde a distância de visibilidade de ultrapassagem necessária para completar a ultrapassagem é igual a distância de visibilidade de ultrapassagem necessária para a abortar.

O modelo de Glennon (1988) difere do modelo da AASHTO por considerar as ultrapassagens abortadas e completas. Glennon se baseia na hipótese de que no início da ultrapassagem, a distância de visibilidade necessária para abortar a ultrapassagem é menor que a distância necessária para completar, ao contrário do que ao final da ultrapassagem a distância para completar a manobra é menor que a distância necessária para abortar a ultrapassagem.

A Figura 4 apresenta os diagramas espaço-tempo para a manobra de ultrapassagem completa (A) e a manobra de passagem abortada (B) da posição crítica, onde a DVU necessária para uma conclusão segura, é igual à DVU necessária para a abortagem segura. Se um veículo oposto surge antes do veículo rápido atingir a posição crítica, a DVU necessária para abortar a ultrapassagem é menor do que a DVU necessária na posição crítica. Da mesma 
forma, se um veículo oposto surge depois que o veículo rápido atinge a posição crítica, a DVU necessária para completar a ultrapassagem é menor do que a DVU necessária na posição crítica. Portanto, a DVU máxima ou crítica é aquela necessária na posição crítica.

O modelo proposto assume que o veículo oposto trafega na velocidade de projeto e que o veículo rápido acelera até a velocidade de projeto na posição crítica, ou antes dela, e continua nessa velocidade a menos que a ultrapassagem seja abortada, e o veículo lento trafega a uma velocidade constante com um incremento menor que a velocidade de projeto. A parte inicial da ultrapassagem não tem relevância na determinação da distância de visibilidade crítica (Sc), a Figura 4 inicia com o veículo rápido na posição crítica e equaciona as duas manobras possíveis no tempo e no espaço. O submodelo para a ultrapassagem completa assume que cada veículo mantém uma velocidade constante e que ao final da ultrapassagem há uma folga aceitável entre os veículos rápido e oposto $(C)$ e uma distância aceitável entre os veículos rápido e lento (G). Para a ultrapassagem abortada, os veículos lentos e opostos mantêm suas velocidades constantes, mas o veículo rápido após um tempo de percepção e reação de 1 (um) segundo desacelera com velocidade d, até atingir uma espaço aceitável $\mathbf{G}$, atrás do veículo lento (GLENNON, 1988).

Figura 4 - Diagrama espaço-tempo do modelo de Glennon.

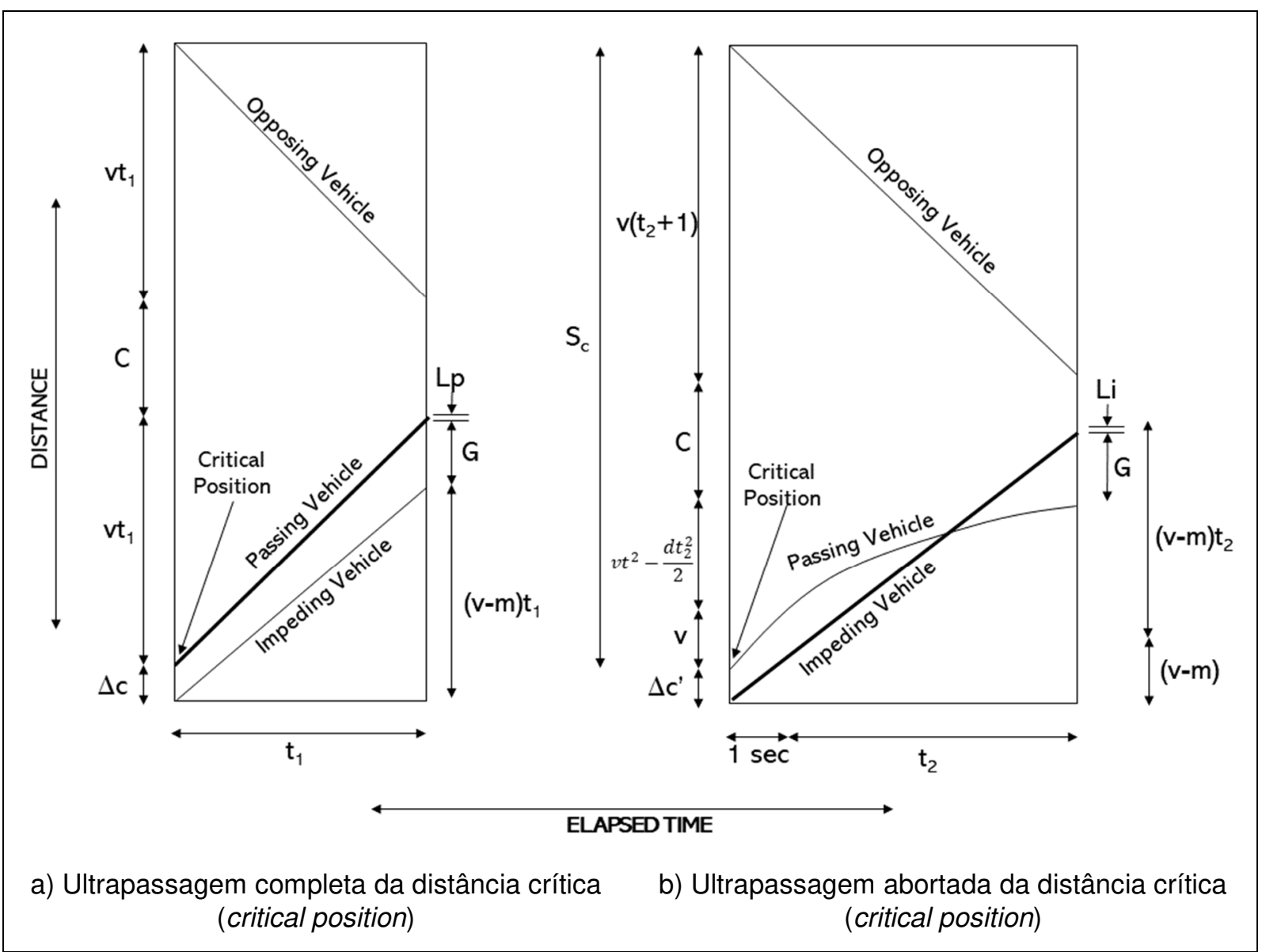

Fonte: Glennon (1988). 
Onde:

\begin{tabular}{|c|c|c|}
\hline Sc & $(\mathrm{m})$ & distância de visibilidade crítica \\
\hline$\Delta c=\Delta c^{\prime}$ & $(\mathrm{m})$ & $\begin{array}{l}\text { distância crítica entre o veículo rápido (passing vehicle) e o veículo lento } \\
\text { (impeding vehicle) }\end{array}$ \\
\hline $\mathrm{C}$ & (m) & $\begin{array}{l}\text { distância de folga entre o veículo rápido e o veículo oposto ao final da } \\
\text { ultrapassagem }\end{array}$ \\
\hline G & (m) & $\begin{array}{l}\text { distância de folga entre o veículo rápido e o veículo lento ao final da } \\
\text { ultrapassagem }\end{array}$ \\
\hline Lp & (m) & comprimento do veículo rápido \\
\hline $\mathrm{Li}$ & (m) & comprimento do veículo lento \\
\hline $\mathrm{v}$ & $(\mathrm{km} / \mathrm{h})$ & velocidade de projeto, do veículo rápido e do veículo oposto \\
\hline $\mathrm{m}$ & $(\mathrm{km} / \mathrm{h})$ & diferença entre a velocidade do veículo rápido e o veículo lento \\
\hline$d$ & $\left(\mathrm{~m} / \mathrm{s}^{2}\right)$ & taxa de desaceleração do veículo rápido ao abortar a ultrapassagem \\
\hline$t_{1}$ & (s) & tempo desde a posição crítica ao fim da ultrapassagem completa \\
\hline$t_{2}$ & (s) & $\begin{array}{l}\text { tempo desde a posição crítica ao fim da ultrapassagem abortada, menos } \\
1 \text { segundo para percepção e reação }\end{array}$ \\
\hline
\end{tabular}

O desenvolvimento em detalhes do modelo é apresentado no estudo de Glennon (1988), com as soluções simultâneas de equações para as ultrapassagens concluída e abortada, sabendo por definição que suas posições críticas e distâncias de visibilidade críticas são iguais.

Em resumo, a seguir são apresentadas as equações da distância crítica $(\Delta c)$ calculada entre a frente do para-choque do veículo rápido e o para-choque traseiro do veículo lento, e da distância de visibilidade crítica (Sc) que assume um headway mínimo aceitável de 1-s. As equações originais foram adaptadas segundo o sistema internacional de unidades (SI).

$$
\begin{gathered}
\Delta c=L p+\frac{m}{3,6}\left[\frac{\frac{m}{3,6}+L i+L p}{\frac{(2 v-m)}{3,6}}-\sqrt{\left.\frac{4 \frac{v}{3,6}\left(\frac{m}{3,6}+L i+L p\right)}{d \frac{(2 v-m)}{3,6}}\right]}\right. \\
S c=2 \frac{v}{3,6}\left[2+\frac{L p-\Delta c}{\frac{m}{3,6}}\right]
\end{gathered}
$$


Para desenvolvimento do modelo são adotadas as seguintes recomendações:

1. O comprimento do carro de passeio médio (Lp) é de 4,87 metros.

2. Uma taxa de desaceleração (d) razoavelmente segura na manobra de abortagem é de $2,4 \mathrm{~m} / \mathrm{s}^{2}$.

3. A diferença de velocidade entre o veículo rápido e veículo lento $(\mathrm{m})$ varia de 13 a 19 $\mathrm{km} / \mathrm{h}$, em função da velocidade de projeto, com baixas diferença de velocidade para altas velocidade de projeto.

4. As velocidades do veículo rápido e do veículo oposto são iguais e correspondem à velocidade de projeto da rodovia.

5. O veículo que passa possui capacidade de aceleração suficiente para atingir a diferença de velocidade especificada em relação ao veículo ultrapassado no momento em que alcança a posição crítica.

6. O tempo de reação e percepção do motorista antes de começar uma ultrapassagem é de 1 (um) segundo.

7. Para uma ultrapassagem completa, o headway entre os veículos rápido e lento, no final da manobra, é de 1 (um) segundo.

8. Para uma abortagem cancelada, o headway entre os veículos rápido e lento, ao final da manobra, é de 1 (um) segundo.

9. A folga mínima entre os veículos rápido e o veículo oposto, no ponto em que o veículo rápido retorna à sua própria pista é de 1 (um) segundo.

Os valores obtidos da distância de visibilidade de ultrapassagem com este modelo são consideravelmente menores que os requisitos da AASHTO, mas são próximos dos apresentados no MUTCD (Tabela 4). Além disso, constata-se que a distância de visibilidade de ultrapassagem resultante é sensível à variação do comprimento do veículo, ou seja, aumenta em função do comprimento do veículo, mas não tão drasticamente como previamente apresentado na literatura. 
Tabela 4 - Distância de visibilidade de ultrapassagem do modelo de Glennon.

\begin{tabular}{c|c|c|c|c}
\hline $\begin{array}{c}\text { Velocidade } \\
\text { Diretriz } \\
(\mathbf{k m} / \mathbf{h})\end{array}$ & $\begin{array}{c}\text { Distância } \\
\text { Crítica } \\
\mathbf{( m )}\end{array}$ & $\begin{array}{c}\text { Máxima Posição } \\
\text { de Abortagem } \\
(\mathbf{m})\end{array}$ & $\begin{array}{c}\text { Comprimento } \\
\text { Mínimo de } \\
\text { Distância de } \\
\text { Ultrapassagem }\end{array}$ & DVU \\
\hline 64 & -13 & $-3,0$ & 183 & 204 \\
80 & -12 & $-3,0$ & 274 & 253 \\
96 & -10 & $-2,5$ & 366 & 302 \\
113 & -8 & $-1,5$ & 457 & 347 \\
\hline
\end{tabular}

Fonte: Glennon (1988)

O autor sugere que o modelo derivado pode ser usado para revisar as normas da AASHTO e MUTCD, de modo que uma base consistente seja usada tanto para o projeto quanto para a marcação das zonas de ultrapassagem.

O modelo de Glennon (1988) foi um dos mais representativos de uma manobra de ultrapassagem e serviu como base para modelos modificados subsequentes, a exemplo do modelo de Hassan et al. (1996).

\subsubsection{Modelo de Hassan et. al}

Hassan, Easa e Abd El Halim (1996) buscaram melhoramento dos modelos para incorporar as relações cinemáticas entre os veículos que fazem parte do processo da manobra de ultrapassagem.

Os autores buscaram um equilíbrio entre os princípios de aprovação comprovados e os comportamentos dos condutores conhecidos, localizando com precisão a posição crítica da manobra de ultrapassagem. Em última análise, os autores decidiram que os modelos de Glennon (1998) e Rillet et al. (1990) eram necessários para estimar as PSDs apropriados com base na localização do para-choque dianteiro do veículo rápido em relação ao para-choque dianteiro do veículo lento (posição crítica).

O modelo revisado de Hassan et al. (1996) tem em conta algumas considerações do mecanismo da manobra de ultrapassagem. Durante a manobra de ultrapassagem, as velocidades do veículo lento $(V-m)$ e o veículo oposto $(V)$, trafegam à velocidade constante. No início da ultrapassagem o veículo rápido está posicionado atrás do veículo lento, trafegando na velocidade $V$ - $m$. Então, o veículo rápido acelera a uma taxa constante (a) até atingir a velocidade de ultrapassagem $(V)$, enquanto se desloca para a faixa da esquerda. $A$ distância de visibilidade requerida nesse estágio é mínima e corresponde à mesma distância para abortar a ultrapassagem com segurança. À medida que avança, a distância de visibilidade necessária para o veículo rápido abortar a ultrapassagem aumenta e a necessária para completar a ultrapassagem diminui. 
Caso, em algum momento, o condutor do veículo rápido decida abortar a ultrapassagem, deve ser mantido um headway mínimo $\left(h_{1}\right)$ entre para-choque frontal do veículo rápido e parachoque traseiro do veículo lento. Assim também, um headway mínimo $\left(h_{0}\right)$ entre para-choque frontal do veículo rápido e para-choque frontal do veículo oposto. Em uma ultrapassagem abortada, o condutor do veículo rápido demanda um tempo de percepção e reação $(P)$, antes de acionar os freios. Durante o tempo de percepção e reação $(P)$, o perfil de velocidade do veículo rápido não é influenciado pela necessidade de abortar a ultrapassagem. Então, o veículo rápido desacelera a uma taxa constante $(d)$, até retornar para a faixa da direita.

Em relação à posição crítica $(\Delta \mathrm{c})$, a distância de visibilidade necessária para abortar a ultrapassagem é igual à distância necessária para completá-la. Nesse ponto, o veículo já atingiu a velocidade de projeto ( $v$ ) e pode completar a manobra em segurança. No final da manobra de ultrapassagem o headway mínimo $\left(h_{0}\right.$ e $\left.h_{1}\right)$ deve ser mantido entre o veículo oposto e o veículo lento, respectivamente.

O diagrama espaço/tempo do modelo para manobra de ultrapassagem completa e manobra de ultrapassagem abortada é apresentado na Figura 5.

Figura 5 - Diagrama espaço-tempo do modelo de Hassan et.al

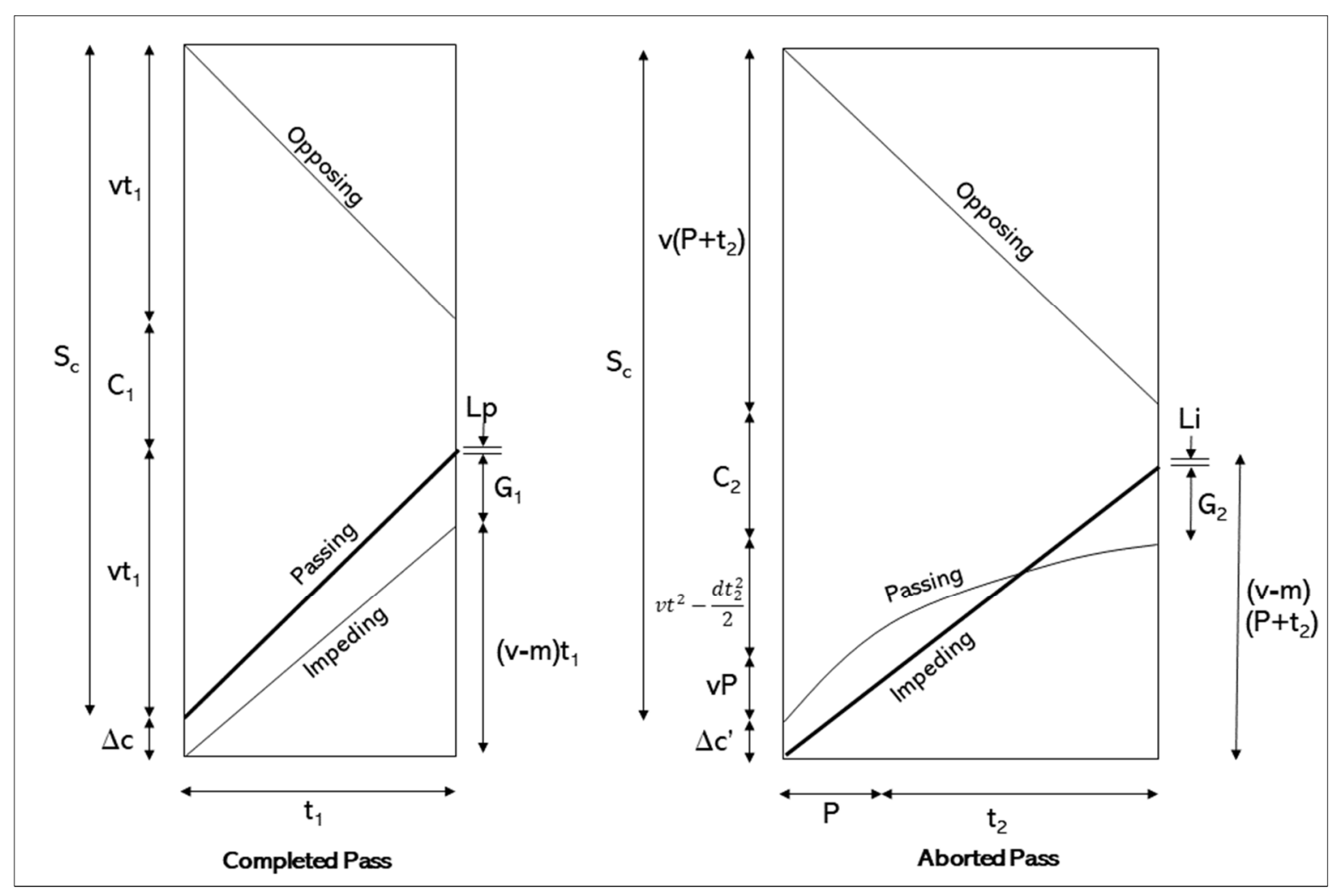

Fonte: Hassan et al. (1996). 
Hassan et al. (1996) desenvolveu um modelo para localização da posição crítica $(\Delta c)$, similar ao conceito apresentado por Glennon, onde $\Delta c$ é a distância entre os para-choques frontais do veículo rápido e o veículo lento na posição crítica. Quando $\Delta c<0$, significa que o veículo rápido está atrás do veículo lento e quando $\Delta c>0$ indica que o veículo rápido está posicionado à frente do veículo lento.

$$
\Delta c=L_{p}+\frac{(V-m)}{3,6} h-\frac{m}{3,6} t_{1}
$$

Devido a variação do $\Delta c$ os autores concluíram que seria improvável que um condutor que realiza a manobra de ultrapassagem decida abortar quando posicionado à frente do parachoque do veículo ultrapassado, mesmo que abortar a manobra exija menos distância de visibilidade do que completá-la. Portanto, propuseram uma distância de visibilidade adicional de modo que qualquer manobra de ultrapassagem possa ser concluída a partir da posição em que os para-choques dianteiros dos veículos rápido e lento estão lado a lado.

As equações para o cálculo da distância de visibilidade crítica (Sc) do modelo de Hassan et al. quando $h_{0}=h_{1}=h$, são apresentadas a seguir.

$$
\begin{aligned}
& S_{C}=2 \frac{V_{d}}{3,6}\left(t_{1}+h\right) \\
& t_{1}=P+t_{2}-\frac{d t_{2}}{4 \frac{V_{d}}{3,6}}\left(t_{2}+2 h\right) \quad \Delta c \leq 0 \\
& t_{1}=\frac{\frac{\left(V_{d}-m\right)}{3,6} h+L_{p}}{m / 3,6} \quad \Delta c>0 \\
& t_{2}=-h+\sqrt{h^{2}+\frac{4 \frac{V_{d}}{3,6}\left[L_{p}+L_{i}+h \frac{\left(2 V_{d}-m\right)}{3,6}\right]}{d_{a} \frac{\left(2 V_{d}-m\right)}{3,6}}}
\end{aligned}
$$


Onde:

t1 (s) tempo necessário para o veículo rápido retornar para sua própria faixa a partir da posição crítica até a completar a manobra de ultrapassagem

t2 (s) tempo necessário para abortar a manobra de ultrapassagem a partir da posição crítica (após o tempo de percepção e reação).

h (s) headway mínimo entre o veículo rápido e o veículo lento no fim da manobra completa ou da manobra abortada e o headway mínimo entre o veículo rápido e o veículo oposto no fim da manobra completa ou da manobra abortada

P (s) tempo de percepção e reação necessária para o condutor do veículo rápido decida abortar a manobra de ultrapassagem

da $(\mathrm{m} / \mathrm{s} 2)$ taxa de desaceleração usada pelo veículo rápido na abortagem da manobra de ultrapassagem

Lp (m) comprimento do veículo rápido

$\mathrm{Li} \quad(\mathrm{m}) \quad$ comprimento do veículo lento

$\operatorname{Vd}(\mathrm{km} / \mathrm{h}) \quad$ velocidade de projeto

$\mathrm{m}(\mathrm{km} / \mathrm{h})$ diferença de velocidade entre o veículo rápido e o veículo a lento

O modelo de Hassan et. al fornece uma margem de segurança para as manobras de ultrapassagem que aumentam em função da velocidade de projeto e, portanto, superaria qualquer desvio para qualquer um dos parâmetros do projeto. As suposições utilizadas no modelo foram testadas para garantir a simplicidade do modelo sem comprometer sua precisão. Os resultados do modelo revisados sugerem que são necessárias grandes revisões dos padrões de marcação do MUTCD. Essas revisões podem ser estabelecidas usando o modelo revisado com base nas características de tráfego predominantes e no desempenho do veículo em cada rodovia (HARWOOD et al., 2008).

\subsubsection{Modelo de Wang e Cartmell}

Dentre os modelos alternativos propostos, o modelo de Wang e Cartmell (1998) é um dos mais complexos, pois incorpora a trajetória do veículo rápido durante a ultrapassagem.

A distância de visibilidade de ultrapassagem segura (DVU) decorrente do modelo de Wang e Cartmell (1998) passa por três estágios e tem muita similaridade com o modelo da AASHTO (2004).

O estágio 1 inicia com a saída do veículo rápido de trás do veículo lento e termina quando o para-choque do veículo rápido está alinhado ao para-choque traseiro do veículo lento. $\mathrm{O}$ estágio 2 começa no final do primeiro estágio e abrange o período durante o qual o veículo 
rápido ocupa a faixa da esquerda e avança. O estágio 3 consiste num procedimento de mudança e começa a partir do final do segundo estágio e termina quando a ultrapassagem é concluída. A Figura 6 ilustra os estágios que compõem o modelo de Wang e Cartmell.

Figura 6 - Estágios da manobra de ultrapassagem do modelo de Wang e Cartmell

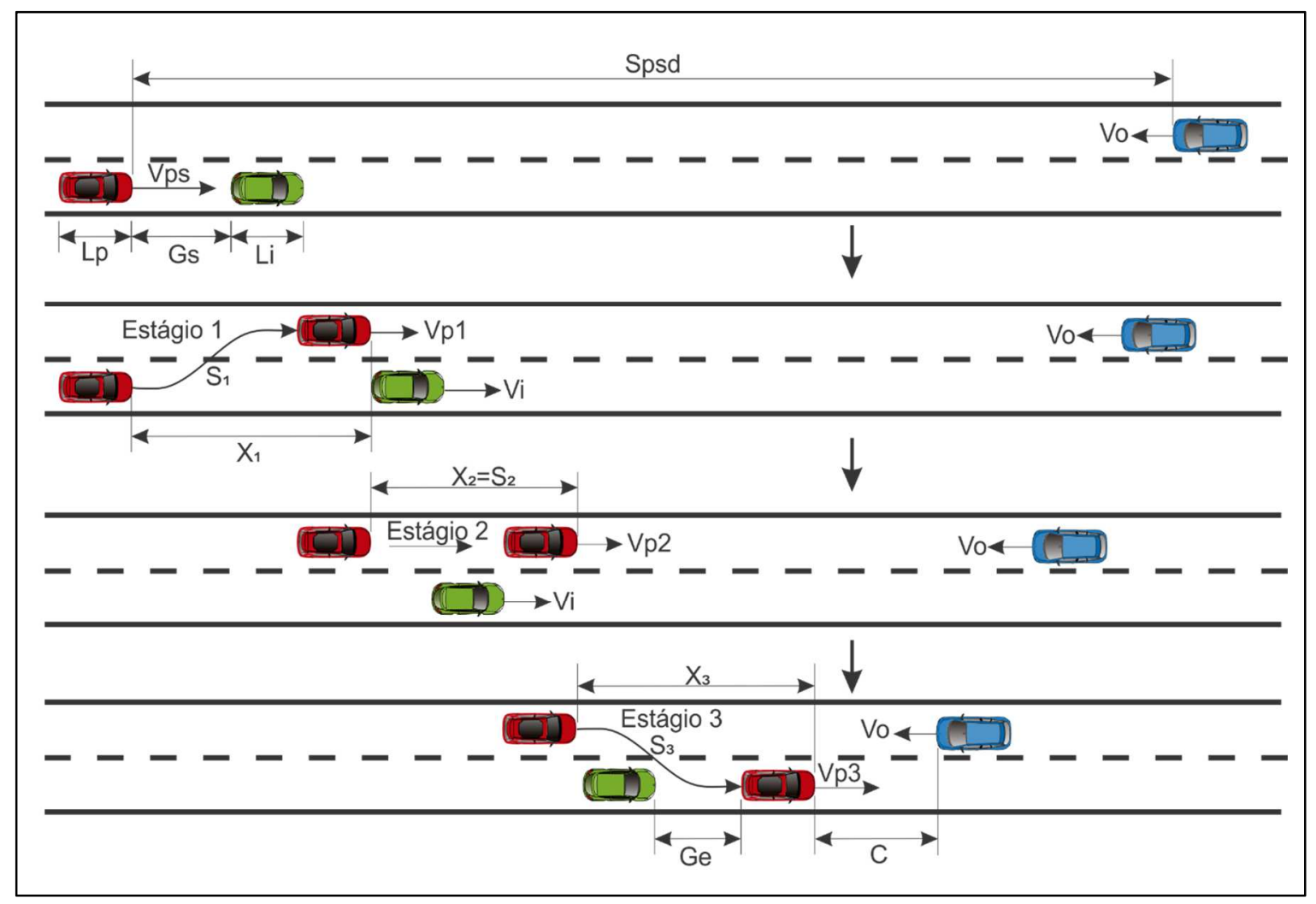

Fonte: Adaptado de Wang e Cartmell (1998)

Onde:

\begin{tabular}{|c|c|c|}
\hline$S_{1}, S_{2}, S_{3}$ & (m) & $\begin{array}{l}\text { distância percorrida pelo veículo rápido nos estágios } 1,2 \text { e 3, } \\
\text { respectivamente. }\end{array}$ \\
\hline$X_{1}, X_{2}, X_{3}$ & $(\mathrm{~m})$ & $\begin{array}{l}\text { distância percorrida pelo veículo rápido nos estágios } 1,2 \text { e } 3 \text {, } \\
\text { respectivamente, na direção horizontal do eixo x. }\end{array}$ \\
\hline $\mathrm{T}_{1}, \mathrm{~T}_{2}, \mathrm{~T}_{3}$ & $(\mathrm{~s})$ & tempo decorrido durante as distâncias $S_{1}, S_{2}, S_{3}$ \\
\hline C & (m) & $\begin{array}{l}\text { distância de folga entre o a frente do veículo rápido e o veículo } \\
\text { oposto ao final da manobra de ultrapassagem. }\end{array}$ \\
\hline Vo & $(\mathrm{km} / \mathrm{h})$ & velocidade constante do veículo oposto durante a manobra \\
\hline $\mathrm{Vi}$ & $(\mathrm{km} / \mathrm{h})$ & velocidade do veículo lento. \\
\hline $\mathrm{Vps}_{1}, \mathrm{Vps}_{2}, \mathrm{Vps}_{3}$ & $(\mathrm{~km} / \mathrm{h})$ & $\begin{array}{l}\text { velocidade do veículo rápido os estágios } 1,2 \text { e } 3 \text {, } \\
\text { respectivamente. }\end{array}$ \\
\hline Gs & (m) & $\begin{array}{l}\text { distância entre a frente do veículo rápido e a traseira do veículo } \\
\text { lento no início da manobra de ultrapassagem. }\end{array}$ \\
\hline $\mathrm{Ge}$ & (m) & $\begin{array}{l}\text { distância entre a traseira do veículo rápido e a frente do veículo } \\
\text { lento ao final da manobra de ultrapassagem. }\end{array}$ \\
\hline Lp & $(\mathrm{m})$ & primento do veículo rápido. \\
\hline $\mathrm{Li}$ & (m) & orimento do veículo lento. \\
\hline
\end{tabular}


Sendo assim a distância de visibilidade de ultrapassagem ( $\left.\mathrm{S}_{\mathrm{psd}}\right)$ corresponde à equação (11) que considera a velocidade constante do veículo oposto $\left(\mathrm{V}_{\mathrm{o}}\right)$, mas não inclui o tempo de percepção e reação do condutor antes do início da manobra de ultrapassagem. Caso opte-se pela inclusão desta distância de percepção e reação, então a distância de visibilidade de ultrapassagem segura (Spr) é calculada pela equação (12), onde $V_{p s}$ é a velocidade do veículo rápido no início da ultrapassagem, considerada constante durante o tempo de reação e

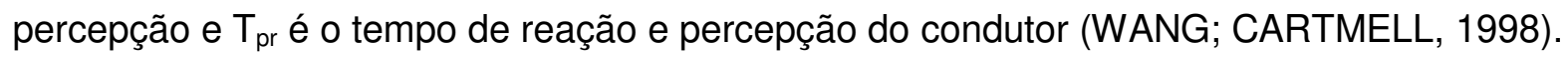

$$
\begin{gathered}
\text { Spsd }=X_{1}+X_{2}+X_{3}+C+V_{o}\left(T_{1}+T_{2}+T_{3}\right) \\
S p r=\left(V_{p s}+V_{o}\right) T_{p r}
\end{gathered}
$$

O cálculo da distância de visibilidade de ultrapassagem $\left(S_{p s d}\right)$ não considera o tempo de percepção e reação, pois utiliza o parâmetro Gs que representa a distância de folga entre a frente do veículo rápido e a traseira do veículo lento no início da ultrapassagem e é utilizada para compensar o tempo de reação e percepção.

A trajetória do veículo que realiza a manobra de ultrapassagem pode ser representada por curvas geométricas e linhas retas, cujos os detalhes das formulações resultantes são apresentados em Wang e Cartmell (1998). De forma resumida, os três estágios que compõem o modelo podem ser descritos, respectivamente, por um polinômio de quinto grau, uma linha reta e outro polinômio do quinto grau, ilustrado na Figura 7, onde X é o comprimento na direção do eixo $x$ horizontal e $Y$ é a largura na direção do eixo y vertical, que de forma conservadora obteve-se a equação (13) para determinação da distância de visibilidade de ultrapassagem (S) segura.

Figura 7 - Ilustração da aproximação do S utilizado do modelo de Wang e Cartmell

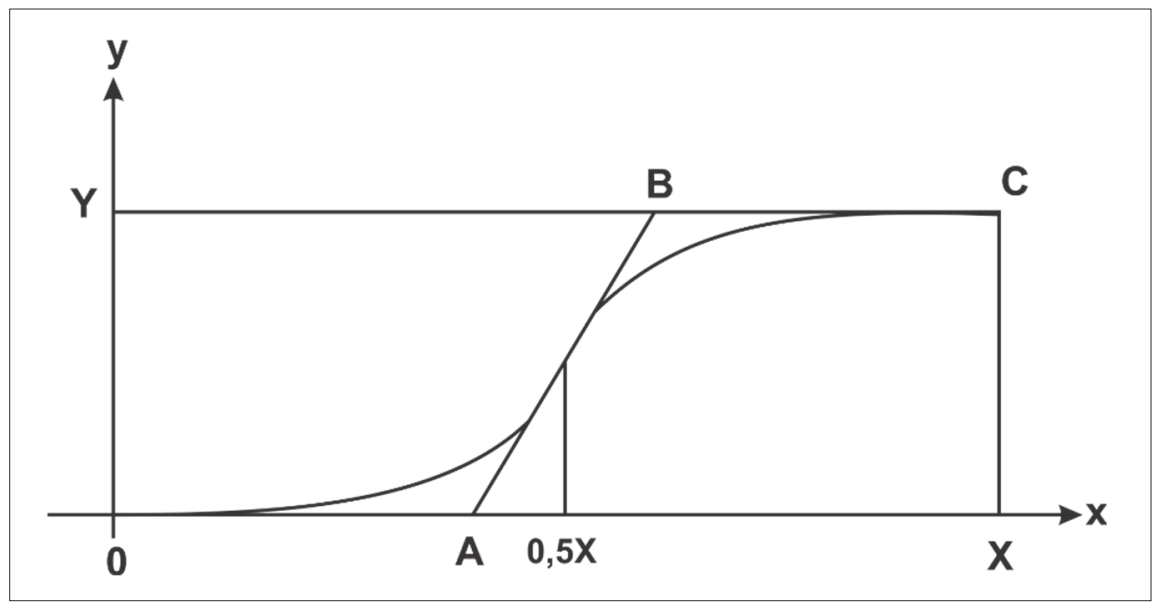

Fonte: Wang e Cartmell (1998) 


$$
S=7 X / 15+\left[(8 X / 15)^{2}+Y^{2}\right]^{1 / 2}
$$

A relação espaço-tempo entre o veículo rápido e o veículo lento durante a manobra de ultrapassagem é dado pela distância percorrida pelo veículo rápido (14), que inicia a manobra no ponto de velocidade máxima $\left(\mathrm{V}_{\mathrm{pmax}}\right)$ é alcançada e o tempo máximo (15) corresponde ao tempo máximo utilizado, e $A_{p m a x}$ corresponde à aceleração do veículo rápido.

$$
\begin{gathered}
S_{p \max }=\left[V_{p \max }^{2}-V_{p s}{ }^{2}\right] / 2 * A_{p \max } \\
T_{p \max }=\left[V_{p \max }-V_{p s}\right] / A_{p \max }
\end{gathered}
$$

Sendo assim, as distâncias $S$ e $X$ em cada estágio podem ser calculadas em função de parâmetros iniciais $\left(L_{p}, L_{s}, V_{p s}, V_{i}, V_{p \max }, A_{p m a x}, G_{e}, G_{s}, Y\right)$, onde a velocidade máxima $\left(V_{p m a x}\right)$ pode ser alcançada no estágio 1, 2 ou 3 ou não ser alcançada ao final do estágio 3 . Cada caso é apresentado na Tabela 6.

Para testar a validade do modelo desenvolvido foram utilizados os parâmetros da AASHTO (1994), onde $V_{p m a x}=V_{p s}+20 \mathrm{~km} / \mathrm{h}$ e $V_{i}=V_{o}=V_{p s}$. Como a velocidade de projeto aumenta, 0 $\mathrm{G}_{\mathrm{s}}$ é escolhido e varia de 8 a 10,4 $\mathrm{m}$ e $\circ \mathrm{G}_{\mathrm{e}}$ de 3,5 a $5,9 \mathrm{~m}$. O valor $C$ varia de 30 a $75 \mathrm{~m}$ conforme sugerido pela AASHTO. Para $L_{i}=25 \mathrm{~m}, L_{p}=4,5 \mathrm{~m}$ e $Y=3,5 \mathrm{~m}$. Os resultados resumidos são apresentados na Tabela 5 completo são apresentados em Wang e Cartmell (1998).

Tabela 5 - Distância mínima de visibilidade a partir de Wang e Cartmell.

\begin{tabular}{c|c|c|c|c|c|c|c}
\hline $\begin{array}{l}\text { Velocidade } \\
\text { de Projeto }\end{array}$ & $\mathbf{V}_{\mathbf{p s}}$ & $\mathbf{V}_{\mathbf{p m a x}}$ & $\mathbf{V}_{\mathbf{i}}$ & $\mathbf{V}_{\mathbf{o}}$ & \multicolumn{3}{|c}{$\begin{array}{c}\text { Distância mínima de } \\
\text { visibilidade de } \\
\text { ultrapassagem }\end{array}$} \\
\hline 30 & & & & & $\mathrm{a}$ & $\mathrm{b}$ & $\mathrm{c}$ \\
\cline { 4 - 7 } & 29 & 49 & 29 & 29 & 265 & 205 & 217 \\
50 & 36 & 56 & 36 & 36 & 318 & 244 & 285 \\
60 & 44 & 64 & 44 & 44 & 378 & 289 & 345 \\
70 & 51 & 71 & 51 & 51 & 432 & 330 & 407 \\
80 & 59 & 79 & 59 & 59 & 493 & 375 & 482 \\
90 & 65 & 85 & 65 & 65 & 538 & 412 & 541 \\
100 & 73 & 93 & 73 & 73 & 601 & 462 & 605 \\
110 & 79 & 99 & 79 & 79 & 653 & 503 & 670 \\
120 & 85 & 105 & 85 & 85 & 707 & 547 & 728 \\
\hline
\end{tabular}

a. Resultados do modelo com $A_{\text {pmax }}=2,25-2,30 \mathrm{~km} / \mathrm{h} / \mathrm{s}$

b. Resultados do modelo com $A_{\text {pmax }}=9,97-14,47 \mathrm{~km} / \mathrm{h} / \mathrm{s}$

c. Resultados do modelo da AASHTO 1994

Fonte: Wang e Cartmell (1998) 
Tabela 6 - Equações de S e X dos estágios do modelo de Wang e Cartmell

\begin{tabular}{|c|c|c|c|}
\hline \multirow{4}{*}{$\begin{array}{l}\text { Caso 1: } \\
\text { Velocidade } \\
\text { máxima } \\
\text { alcançada no } \\
\text { Estágio } 1\end{array}$} & Estágio 1 & $\begin{array}{c}S_{1}=S_{p \max }+V_{p \max }\left(T_{1}-T_{p \max }\right) \\
X_{1}=V_{1} T_{1}+G_{s}\end{array}$ & $\begin{array}{l}(16) \\
(17)\end{array}$ \\
\hline & Estágio 2 & $\begin{array}{c}S_{2}=V_{p \max } T_{2} \\
X_{2}=V_{1} T_{2}+L_{p}+L_{i}\end{array}$ & $\begin{array}{l}(18) \\
(19)\end{array}$ \\
\hline & Estágio 3 & $S_{3}=V_{p \max } T_{3}$ & (20) \\
\hline & & $X_{3}=V_{1} T_{3}+G_{e}$ & (21) \\
\hline \multirow{4}{*}{$\begin{array}{l}\text { Caso 2: } \\
\text { Velocidade } \\
\text { máxima } \\
\text { alcançada no } \\
\text { Estágio } 2\end{array}$} & Estágio 1 & $\begin{array}{c}S_{1}=V_{p s} T_{1}+0,5 A_{p \max }\left(T_{1}\right)^{2} \\
X_{1}=V_{1} T_{1}+G_{s}\end{array}$ & $\begin{array}{l}\text { (22) } \\
\text { (23) }\end{array}$ \\
\hline & Estágio 2 & $\begin{array}{c}S_{1}+S_{2}=S_{p \max }+V_{p \max }\left(T_{1}+T_{2}-T_{p \max }\right) \\
X_{2}=V_{1} T_{2}+L_{p}+L_{i}\end{array}$ & $\begin{array}{l}(24) \\
(25)\end{array}$ \\
\hline & Estágio 3 & & \\
\hline & & $X_{3}=V_{1} T_{3}+G_{e}$ & (27) \\
\hline \multirow{3}{*}{$\begin{array}{l}\text { Caso 3: } \\
\text { Velocidade } \\
\text { máxima } \\
\text { alcançada no } \\
\text { Estágio } 3\end{array}$} & Estágio 1 & $\begin{array}{c}S_{1}=V_{p s} T_{1}+0,5 A_{p \max }\left(T_{1}\right)^{2} \\
X_{1}=V_{1} T_{1}+G_{s}\end{array}$ & $\begin{array}{l}\text { (28) } \\
\text { (29) }\end{array}$ \\
\hline & Estágio 2 & $\begin{array}{c}S_{1}+S_{2}=V_{p s}\left(T_{1}+T_{2}\right)+0,5 A_{\text {pmax }}\left(T_{1}+T_{2}\right)^{2} \\
X_{2}=V_{1} T_{2}+L_{p}+L_{i}\end{array}$ & $\begin{array}{l}\text { (30) } \\
\text { (31) }\end{array}$ \\
\hline & Estágio 3 & $\begin{array}{c}S_{1}+S_{2}+S_{3}=S_{p \max }+V_{p \max }\left(T_{1}+T_{2}+T_{3}-T_{p \max }\right) \\
X_{3}=V_{1} T_{3}+G_{e}\end{array}$ & $\begin{array}{l}\text { (32) } \\
\text { (33) }\end{array}$ \\
\hline \multirow{3}{*}{$\begin{array}{l}\text { Caso 4: } \\
\text { Velocidade } \\
\text { máxima não } \\
\text { seja } \\
\text { alcançada } \\
\text { no Estágio } 3\end{array}$} & Estágio 1 & $\begin{array}{c}S_{1}=V_{p s} T_{1}+0,5 A_{p \max }\left(T_{1}\right)^{2} \\
X_{1}=V_{1} T_{1}+G_{s}\end{array}$ & $\begin{array}{l}\text { (34) } \\
\text { (35) }\end{array}$ \\
\hline & Estágio 2 & $\begin{array}{c}S_{1}+S_{2}=V_{p s}\left(T_{1}+T_{2}\right)+0,5 A_{p \max }\left(T_{1}+T_{2}\right)^{2} \\
X_{2}=V_{1} T_{2}+L_{p}+L_{i}\end{array}$ & $\begin{array}{l}\text { (36) } \\
\text { (37) }\end{array}$ \\
\hline & Estágio 3 & $\begin{array}{c}S_{1}+S_{2}+S_{3}=V_{p s}\left(T_{1}+T_{2}+T_{3}\right)+0,5 A_{p \max }\left(T_{1}+T_{2}+T_{3}\right)^{2} \\
X_{3}=V_{1} T_{3}+G_{e}\end{array}$ & $\begin{array}{l}\text { (38) } \\
\text { (39) }\end{array}$ \\
\hline
\end{tabular}

Fonte: Wang e Cartmell (1998) 
Dentre as características do modelo de Wang e Cartmell a distância e o tempo total calculados representam a trajetória percorrida pelo veículo rápido durante a manobra. Além disso, foram avaliados os efeitos de todos os parâmetros que influenciam na determinação da distância de visibilidade de ultrapassagem (DVU) segura e dentre estes, apenas Y e C não influenciaram os resultados.

O estudo de Wang e Cartmell (1998) também indicou que o aumento do comprimento do veículo tem um impacto importante na distância de visibilidade de ultrapassagem (DVU) permitida, ou seja, a DVU é consideravelmente maior ao ultrapassar um caminhão longo do que ultrapassar um carro de passeio comum. Os pesquisadores complementam ainda que, o modelo da AASHTO (2004) é conservador para os veículos modernos e que a distância percorrida durante o tempo de reação e percepção varia com a velocidade do veículo oposto e a velocidade do veículo rápido no início da posição de ultrapassagem, bem como as características individuais dos condutores.

\subsubsection{Modelo AASHTO 2011}

Os procedimentos usados para determinar a distância de visibilidade de ultrapassagem (DVU) na American Association of State Highway and Transportation Officials (AASHTO) de 2001, publicados no "A Policy on Geometric Design of Highways and Streets" (o "Green Book"), foram calculados com base no comportamento de motoristas e permaneceram praticamente inalterados desde que foram incorporados à edição de 1954. O modelo de 1954 foi determinado a partir de um procedimento baseado em um relatório resumido de observações de campo de manobras realizadas entre 1938 a 1941 por Prisk, publicado no Proceedings HRB, Volume 21, e validados em 1958 (HARWOOD et al., 2008).

Pesquisas conduzidas entre 1971 e 1978 detectaram que os valores da AASHTO para DVU eram conservadores, exceto em ultrapassagem com velocidades dos veículos acima de 105 $\mathrm{km} / \mathrm{h}$, mas esses valores continuaram a ser usados nas edições do Green Book de 1984, 1990, 1994 e 2001. Outros trabalhos foram desenvolvidos e apresentados nos anos seguintes, mas os procedimentos permaneceram inalterados.

Nos últimos 50 anos, a frota de veículos, as condições de operação e as características do motorista mudaram consideravelmente, mas os procedimentos da DVU não consideraram essas variáveis em consideração. Além disso, o Manual on Uniform Traffic Control Devices for Streets and Highways (MUTCD), da Federal Highway Administration (FHWA) e o Green Book 2004 exibem diferentes valores de DVU para condições semelhantes. 
Uma pesquisa (HARWOOD et al., 2008) financiada pela AASHTO e FHWA avaliou os métodos atuais para determinar os requisitos mínimos de distância de ultrapassagem. $O$ projeto incluiu uma análise extensiva de vários modelos alternativos de DVU e testes de campo subsequentes. Os estudos de campo serviram para caracterizar o comportamento do motorista, quantificar as medidas de desempenho do tráfego para manobras de ultrapassagem e a possível influência de caminhões mais longos e de motoristas idosos.

Com base nos resultados obtidos, os pesquisadores avaliaram as orientações sobre DVU fornecidas no Green Book da AASHTO e no MUTCD. O relatório final intitulado NCHRP 605 - Passing Sight Distante Criteria (HARWOOD et al., 2008) apresenta recomendações para trazer consistência entre os padrões de projeto de DVU e as marcações de sinalização vertical do pavimento do MUTCD.

Dentre os modelos alternativos avaliados os que representaram mais adequadamente as necessidades da distância de visibilidade de ultrapassagem dos condutores foram os desenvolvidos por Glennon (1988) e Hassan et al. (1996). Ambos os modelos reconhecem que, nos estágios iniciais de uma manobra de ultrapassagem, o motorista que ultrapassa pode abortar com facilidade e segurança a manobra.

No entanto, Glennon modelou a posição crítica como a posição em que as distâncias de visibilidade necessárias para completar ou abortar a passagem com segurança são iguais. Hassan et al. notou que a posição crítica de Glennon frequentemente ocorre quando o veículo rápido está posicionado à frente do veículo lento e propôs que a posição crítica deveria ser a posição onde os para-choques dianteiros dos dois veículos estão lado a lado ou a posição onde as distâncias de visibilidade para completar ou abortar a ultrapassagem são iguais, o que for atingido primeiro pelo veículo que ultrapassa (HARWOOD et al., 2008).

O modelo de Glennon produziu valores de DVU iguais ou ligeiramente inferiores aos valores de DVU do MUTCD. Os mesmos dados aplicados ao modelo de Hassan et al. produziu valores de DVU inferiores aos valores do MUTCD a velocidades de $72 \mathrm{~km} / \mathrm{h}$ ou menos e superiores aos valores MUTCD por apenas 6 a $40 \mathrm{~m}$ a velocidades de $80 \mathrm{~km} / \mathrm{h}$ ou mais. Essas pequenas diferenças na DVU, juntamente com o bom registro de segurança para manobras de passagem em rodovias de duas faixas existentes, não indicam qualquer necessidade de modificar os critérios atuais da DVU da MUTCD (CAMPBELL et al., 2012).

Em manobras de ultrapassagem, pesquisas sugerem que os motoristas fazem estimativas razoáveis da distância de um carro que se aproxima no fluxo oposto, mas não de sua velocidade. Esta incapacidade de estimar razoavelmente a velocidade pode ser um problema mais aparente nos condutores idosos. 
As estimativas imprecisas dos motoristas não podem ser compensadas aumentando a distância de visibilidade, porque o problema está relacionado ao mal julgamento de tempo que os motoristas têm para ultrapassar quando do surgimento do veículo oposto e este problema permanece o mesmo, independentemente de quão longe os condutores conseguem ver. Em vez disso, esses tipos de falhas devem ser resolvidos por meio de medidas de controle de velocidade ou fatores do local que melhorem os julgamentos de velocidade (CAMPBELL et al., 2012).

Com isso, os valores de distância de visibilidade de ultrapassagem (DVU) recomendada foram atualizados e incorporados no Green Book 2011 (AASHTO, 2011). E para se adequar a esses modelos, alguns parâmetros foram alterados ou inclusos, como:

- A diferença de velocidade entre o veículo rápido $(\mathrm{VR})$ e o veículo lento $(\mathrm{VL})$ foi alterada para $19 \mathrm{~km} / \mathrm{h}$.

- O VR possui capacidade de aceleração suficiente para atingir a diferença de velocidade especificada em relação ao veículo ultrapassado quando alcança a posição crítica, o que geralmente ocorre em cerca de $40 \%$ da manobra de ultrapassagem.

- O comprimento do VR e VL é de 5,8 metros.

- O tempo de percepção e reação é de 1s, que corresponde ao mesmo valor admitido para abortar a ultrapassagem.

- Caso a manobra de ultrapassagem seja abortada, a taxa de desaceleração do VR é de $3,4 \mathrm{~m} / \mathrm{s}^{2}$.

- Para uma ultrapassagem completa ou ultrapassagem abortada, o headway entre o VR e o VL é de 1 segundo.

- A distância mínima entre o veículo rápido (VR) e o veículo oposto (VO) na conclusão da ultrapassagem em que o VR retorna à faixa da direita é de 1 segundo.

As distâncias de visibilidade de ultrapassagem (DVU) resultantes são apresentadas na Tabela 7, comparativamente aos valores de DVU das normas abordadas anteriormente. 
Tabela 7 - Comparativo de valores de DVU entre as normas técnicas.

\begin{tabular}{|c|c|c|c|c|c|c|c|c|}
\hline \multirow{3}{*}{$\begin{array}{l}\text { Velocidade } \\
\text { de Projeto } \\
(\mathrm{km} / \mathrm{h})\end{array}$} & \multirow{3}{*}{$\begin{array}{c}\begin{array}{c}\text { DNIT } \\
(1999)\end{array} \\
\text { DVU } \\
(\mathrm{m})\end{array}$} & \multirow{3}{*}{$\begin{array}{c}\begin{array}{c}\text { MUTCD } \\
(2009)\end{array} \\
\begin{array}{c}\text { DVU } \\
(\mathrm{m})\end{array}\end{array}$} & \multicolumn{3}{|c|}{ AASHTO (2004) } & \multicolumn{3}{|c|}{$\begin{array}{c}\text { CONTRAN }(2007) \\
\text { DNIT }(2010) \\
\text { AASHTO }(2011)\end{array}$} \\
\hline & & & \multicolumn{2}{|c|}{ Velocidade $(\mathrm{km} / \mathrm{h})$} & \multirow{2}{*}{$\begin{array}{l}\text { DVU } \\
(\mathrm{m})\end{array}$} & \multicolumn{2}{|c|}{ Velocidade $(\mathrm{km} / \mathrm{h})$} & \multirow{2}{*}{$\begin{array}{r}\text { DVL } \\
(\mathrm{m})\end{array}$} \\
\hline & & & $\begin{array}{l}\text { Veículo } \\
\text { Lento }\end{array}$ & $\begin{array}{l}\text { Veículo } \\
\text { Rápido }\end{array}$ & & $\begin{array}{l}\text { Veículo } \\
\text { Lento }\end{array}$ & $\begin{array}{l}\text { Veículo } \\
\text { Rápido }\end{array}$ & \\
\hline 30 & 180 & & 29 & 44 & 200 & 11 & 30 & 120 \\
\hline 40 & 270 & 137 & 36 & 51 & 270 & 21 & 40 & 140 \\
\hline 50 & 350 & 152 & 44 & 59 & 345 & 31 & 50 & 160 \\
\hline 60 & 420 & 183 & 51 & 66 & 410 & 41 & 60 & 180 \\
\hline 70 & 490 & 213 & 59 & 74 & 485 & 51 & 70 & 210 \\
\hline 80 & 560 & 244 & 65 & 80 & 540 & 61 & 80 & 245 \\
\hline 90 & 620 & 274 & 73 & 88 & 615 & 71 & 90 & 280 \\
\hline 100 & 680 & 305 & 79 & 94 & 670 & 81 & 100 & 320 \\
\hline 110 & 730 & 335 & 85 & 100 & 730 & 91 & 110 & 355 \\
\hline 120 & 800 & 365 & 90 & 105 & 775 & 101 & 120 & 395 \\
\hline
\end{tabular}

Fonte: A autora

Pesquisas verificaram que os valores de distância de visibilidade de ultrapassagem apresentada pela AASHTO (Tabela 7) são consistentes com manobras de ultrapassagem observadas em campo (AASHTO, 2011). Contudo, alguns valores devem ser adotados com parcimônia, por exemplo, optar o comprimento do veículo lento (VL) de 5,8 m para a situação brasileira com alto percentual de veículos de carga é uma condição temerária.

Muitos estudos demonstraram que os erros e violações humanas têm uma influência considerável nos acidentes rodoviários. As violações podem ser conectadas a fatores sociais e motivacionais, enquanto que erros estão ligados ao processamento de informações do indivíduo.

Durante o treinamento para a habilitação de direção os condutores têm pouca oportunidade de aprender e praticar essa manobra, esse alto grau de erro em julgar quando é seguro iniciar uma ultrapassagem não é surpreendente. A fim de reduzir o número de acidentes de ultrapassagem, é crucial identificar as fontes desses erros (GRAY; REGAN, 2005).

Para extração dos dados da simulação utilizou-se o modelo de distância de visibilidade de ultrapassagem definido no Manual Geométrico de Rodovias Rurais (DNIT, 1999) que tem como base o modelo da AASHTO (1994). Esse modelo embasa os parâmetros de projetos rodoviários aplicados no Brasil. 


\subsection{Pesquisas Com enfoque em manobras de Ultrapassagem}

O sistema viário é composto por três elementos principais: a via, o veículo e o usuário. Sendo atribuído como falha do elemento humano a $90 \%$ dos acidentes registrados (NODARI; BOTTESINI, 2011; CAMPBELL et al., 2012).

Dessa forma, o comportamento do motorista assume papel decisivo na segurança viária, uma vez que, mesmo ele sendo capaz de reconhecer um sinal de proibição de ultrapassagem (desempenho do motorista), ele pode optar por ultrapassar em local proibido (comportamento do motorista) (NODARI; BOTTESINI, 2011). Os projetistas de rodovias e engenheiros de tráfego devem estar cientes dessas características do fator humano e usá-las de maneira a melhorar ou otimizar a segurança do sistema rodoviário que estão projetando e controlando (CAMPBELL et al., 2012).

Contudo, a grande variedade de características culturais, físicas e psicológicas das pessoas dificulta o controle sobre o fator humano (DEWAR; OLSON, 2002). Assim, são necessárias pesquisas para compreender o comportamento dos condutores no sistema de trânsito e suas particularidades, principalmente em situações de risco com maior probabilidade de acidentes fatais, a exemplo das manobras de ultrapassagem.

Pesquisas sobre fatores humanos oferecem vários métodos que variam desde modelos matemáticos, experimentos de laboratório, observações em situações reais, como a análise de acidentes, as observações de vídeo, pesquisas com veículos instrumentados, testes operacionais de campo, entre outros.

A coleta de dados detalhados de manobras de ultrapassagem na vida real, incluindo as trajetórias de ultrapassagem e os veículos no sentido oposto, é uma tarefa difícil e complexa. A escolha do método a ser utilizado divide-se em similaridade ao mundo real e a flexibilidade e interpretação do experimento.

\subsubsection{Veículo Instrumentado}

A realização de estudos naturalísticos torna a observação mais próxima do mundo real, contudo limita o controle da situação no momento da manobra de ultrapassagem, pois ocorrem em situações diferentes entre si (VASSILIS et al., 2015).

Hegeman, Hoogendoorn e Brookhuis (2005) utilizaram um veículo instrumentado para coleta de dados em campo na Holanda e apresentaram uma análise das observações das ultrapassagens em estradas rurais de pista simples para compreender o comportamento do motorista antes, durante e depois de uma manobra de ultrapassagem. As diferenças na 
duração das manobras de ultrapassagem entre diferentes estratégias de ultrapassagem e diferentes velocidades dos veículos foram observadas. Os resultados indicam a viabilidade de desenvolvimento de um assistente de ultrapassagem, atendendo a todas as estratégias de ultrapassagem e uma ampla faixa de velocidade impulsionada pelo veículo ultrapassado.

Mocsári (2009) analisou o comportamento de ultrapassagem de veículos em estradas rurais de pista simples na Hungria usando os dados coletados por um veículo instrumentado. Das 230 ultrapassagens, 55\% foram ultrapassagens aceleradas, 20\% foram ultrapassagens contínuas e as restantes foram ultrapassagens de múltiplos veículos. No caso de ultrapassagens contínuas, houve uma diferença maior na velocidade média dos veículos em comparação com as ultrapassagens aceleradas. No entanto, o tempo de ultrapassagem não diferiu significativamente porque a distância de ultrapassagem foi mais longa para ultrapassagens contínuas. O tempo médio de ultrapassagem para ultrapassagens aceleradas foi de 8,5 segundos e para ultrapassagens contínuas foi de 7,9 segundos. Em ultrapassagens aceleradas, a distância entre os veículos que ultrapassam e o veículo ultrapassado não depende da velocidade e do tipo de veículo a ser ultrapassado.

Neste tipo de metodologia, os motoristas envolvidos na manobra de ultrapassagem estão expostos aos perigos do tráfego em movimento. Portanto, outro método é necessário para capturar dados abrangentes de comportamento de ultrapassagem de maneira segura. Por isso, algumas pesquisas incluem o uso de filmagens para a observação das ultrapassagens.

\subsubsection{Vídeo}

Pellegrini (2006) realizou uma análise crítica dos parâmetros a partir de filmagens em campo e elaborou modelos alternativos simplificados para fixação de distância de visibilidade de ultrapassagem mínimas para demarcação da sinalização e critério geométrico aplicando a velocidade de projeto da via.

Polus, Livneh e Frischer (2000) desenvolveram modelos para quantificar os principais componentes do processo de aprovação e compararam os resultados com os modelos existentes de projeto de rodovias. Os componentes da manobra de ultrapassagem foram avaliados com base em tempos reais de ultrapassagem e distâncias para as quais os dados foram coletados para cerca de 1.500 ultrapassagens em estradas rurais de duas pistas, registradas através de gravação em vídeo a partir de pontos fixos de observação ou de um helicóptero sobrevoando a rodovia. Os resultados mostraram uma relação entre a velocidade do veículo lento e a distância de ultrapassagem e autores sugerem que o modelo de ultrapassagem da AASHTO seja ajustado para considerar as ultrapassagens de caminhões. 
Llorca e García (2011) propuseram uma metodologia para observar manobras de ultrapassagem em rodovias existentes com a ajuda de câmeras de vídeo instaladas em um ponto fixo próximo a zonas de ultrapassagem em Valença, na Espanha. A metodologia aplicada registrou 234 manobras em quatro zonas de ultrapassagem. A diferença de velocidade média observada entre veículos que ultrapassam e os veículos ultrapassados foi significativamente maior ( $23 \mathrm{~km} / \mathrm{h}$ ), quando comparada aos valores dos modelos de DVU (16 $\mathrm{km} / \mathrm{h}$ ). As variáveis com maior influência no tempo e na distância percorrida na faixa oposta foram o tipo e a velocidade do veículo ultrapassado e o comprimento da zona de ultrapassagem.

Estudos de campo coletaram dados de manobras de ultrapassagem em rodovias de pista simples através de classificadores de tráfego e vídeo, nos estados do Missouri, Pensilvânia e Texas. Os estudos de campo consideraram a observação de 462 ultrapassagens em zonas de ultrapassagem longas (300 a $1650 \mathrm{~m}$ ) e curtas (120 a $240 \mathrm{~m}$ ). Os dados de vídeo foram utilizados para determinar a velocidade e as distâncias dos veículos envolvidos nas ultrapassagens observadas. Os resultados foram utilizados no desenvolvimento de um modelo modificado de distância de visibilidade de ultrapassagem (DVU) que foi incorporado ao Green Book da AASHTO 2011 (HARWOOD et al., 2008).

Hassan et al. (2014) exploraram os fatores que afetam a velocidade de um veículo de ultrapassagem em seção de rodovia na Malásia. Os dados para este estudo foram coletados em uma extensão de $280 \mathrm{~m}$ de rodovia, utilizando um o levantamento por vídeo durante $6 \mathrm{~h}$, cobrindo as horas de pico e fora de pico. A análise estatística encontrou cinco parâmetros que tiveram uma correlação com a velocidade de ultrapassagem do veículo, que incluiu a velocidade do veículo ultrapassado, os tempos de decisão do motorista, o tempo de ultrapassagem, a aceleração do veículo de ultrapassagem e a margem de segurança.

Os dados através de vídeo são difíceis de coletar devido a extensão dos locais onde essas manobras podem ser efetuadas (FARAH; TOLEDO, 2010), sendo necessário monitoramento contínuo para coleta do maior número de observações. Além disso, a análise do comportamento do condutor em manobras ultrapassagens através de gravações em vídeo torna-se difícil, pois permite somente a observação do ponto de vista externo do veículo (LLORCA; GARCÍA, 2011).

Como um método de coleta de dados alternativo, o uso de um ambiente simulado remove o observador e os condutores da exposição ao tráfego e os coloca em um ambiente seguro e controlado, permitindo ainda a aquisição de grande quantidade de dados com precisão. Estas são vantagens definitivas sobre as metodologias tradicionais de estudo de campo. Além disso, 
o estudo de direção em ambiente simulado fornece contato direto com o condutor, permitindo coletar informações como tempo de habilitação, idade e gênero, que poderão ser cruzadas com os dados de condução.

\subsubsection{Simuladores de direção}

Simuladores de direção foram inicialmente desenvolvidos para avaliar as habilidades e competências dos operadores de transporte público no início da década de 1910. Nas décadas seguintes, foram utilizados equipamentos com dispositivos para testar a resposta dos motoristas a vários estímulos. No entanto, a partir da década de 60 , as fábricas automobilísticas, companhias de seguro, agências militares, universidade e empresas aeroespaciais utilizaram simuladores para pesquisas envolvendo uma variedade de equipamentos visuais (STRAUS, 2005).

Em pesquisas acadêmicas, os simuladores de direção foram introduzidos na década de 70, nas mais diversas áreas e aplicações. Kronfol e Grimm (1990) elencaram o uso de simuladores em várias pesquisas, entre o ano de 1966 a 1990, com temas ligados à álcool/drogas, projetos de engenharia, treinamento do condutor, condutores com deficiência, desempenho do condutor, stress/fadiga, tomada de risco, sinalização e visão.

O progresso do uso de simuladores em pesquisas é percebido quando se verifica o crescimento de publicações em journals. Uma busca na base de dados ScienceDirect incluindo como palavra-chave "driving simulator" no título, resumo ou palavra-chave foram encontrados 88 artigos, publicados entre 1968 e 1999. Entre os anos de 2000 a 2009, foram publicados 194 artigos. A partir de 2010 e contabilizando até 2018, as publicações somam 853 artigos. Simuladores de direção tornaram-se uma ferramenta amplamente utilizada para investigar o impacto das diferenças individuais dos motoristas, tecnologia dos veículos, sistema de apoio ao condutor, projetos de estradas e a eficácia das intervenções em segurança viária.

Os benefícios do uso de simuladores de direção em pesquisas de segurança viária têm sido documentados através de pesquisas que objetivam reduzir a velocidade do condutor, alternativas para evitar a fadiga durante a condução (MERAT; JAMSON, 2013), simular seções de estrada do mundo real onde novas geometrias e contramedidas de segurança baseadas em infraestrutura propostas possam ser avaliadas (KELLY; LASSACHER; SHIPSTEAD, 2007)

A principal vantagem dos simuladores de direção é prover um ambiente artificial de pesquisa seguro, que pode ser fácil e economicamente configurando para investigar uma variedade de 
problemas de pesquisas com fatores humanos ao avaliar situações perigosas (KAPTEIN; THEEUWES; VAN DER HORST, 1996; SHECHTMAN et al., 2009; WINTER et al., 2012; KLÜVER et al., 2016), sendo possível controlar as condições do experimento e testar variáveis que possam ser modificadas de uma condição para outra.

O Federal Highway Administration (FHWA), através do Centro de Pesquisa Turner-Fairbank Highway Research Center (TFHRC), dispõe de um Human Factors Laboratory. O laboratório investiga questões de desempenho do motorista relacionadas à rodovia e engenharia de tráfego. Sua missão é melhorar os elementos e operações de projeto de rodovias, obtendo informações sobre o desempenho do motorista e aplicar essas informações à engenharia de tráfego e à concepção de sistemas de informação embarcados em veículos (WOCHINGER; EMERY; ALICANDRI, 1999).

O Human Factors Laboratory possui o simulador de direção Highway Driving Simulator (HDS) utilizado para uma variedade de estudos comportamentais e projetos de visualização. Estudos recentes realizados no simulador examinaram a eficácia de várias marcações de estrada para auxiliar motoristas na navegação em estradas rurais montanhosas no período noturno, sinalização em rotatórias, compreensão do condutor em novos projetos de interseção e a variabilidade nas respostas dos condutores para alteração de placas de sinalização.

O Instituto de Pesquisas de Transporte da Universidade de Michigan (UMTRI) atua em diferentes áreas do transporte através de projetos multidisciplinares, dentre estes, pesquisas em fatores humanos e comportamento do condutor. $O$ instituto possui um simulador de direção com pesquisas voltadas à avaliação de desempenho dos condutores jovens, uso de dispositivos com acesso à internet e envio de mensagens durante a condução e avaliação de fatores de risco advindo da interação entre motoristas e ciclistas (PRADHAN, 2016).

O Departamento de Engenharia de Transportes da EESC/USP dispõe de um simulador de direção de base fixa e atua em pesquisas relacionadas à avaliação da percepção do condutor em relação à sinalização da rodovia (CASTILLO, 2015), avaliação do comportamento do condutor sobre distração mental (VIEIRA, 2016) e análise de consistência de traçado geométrico da via (TORQUATO, 2019). Assim, esta pesquisa agrega ao grupo de estudo como uma das primeiras abordagens com ênfase em análise de manobra de ultrapassagem.

A credibilidade de pesquisas com o uso de simuladores está altamente dependente do realismo que o simulador é capaz de reproduzir. Contudo, não há comprovação científica da exigência de simuladores de alto nível para pesquisas que analisam o comportamento do condutor em situações de ultrapassagem, onde a trajetória parece ser mais dependente das 
variações individuais dos condutores do que a presença de interação aerodinâmica entre o veículo ultrapassado e veículo que ultrapassa (BRUZELIUS; KARLSSON; AUGUSTO, 2013).

Os acidentes decorrentes de uma manobra de ultrapassagem geralmente são acidentes muito sérios nas rodovias rurais. Eles ocorrem principalmente em seções onde é permitida a ultrapassagem. As análises revelaram que uma grande proporção de acidentes de ultrapassagem ocorre em áreas com distância de visibilidade de ultrapassagem insuficientes e onde nenhuma regulação de trânsito foi tomada para contrariar manobras de ultrapassagem (RICHTER et al., 2016) .

São inúmeras as maneiras pelas quais uma manobra de ultrapassagem pode levar a erros e acidentes. As medidas estruturais e operacionais na estrada rural podem melhorar a percepção de dificuldades situacionais e chamar a atenção do motorista para as áreas problemáticas. As medidas de infraestrutura contra o ultrapassagem podem ser diferenciadas em atuação positiva (pistas de ultrapassagem adicionais) e medidas de ação negativa (restrições sobre ultrapassagem e limitações de velocidade).

Mas, também ocorrem situações em que os condutores que estão na rodovia e querem passar um veículo mais lento percebem uma zona de ultrapassagem próxima muito antes do início desta zona. Assim, o motorista decidirá passar antes de chegar à zona de passagem (FORBES, 1990), ou seja, fora da zona permitida para ultrapassagem.

Além de ser um processo de condução muito complexo a ultrapassagem é influeciada por uma variedade de fatores. E o motorista, freqüentemente, é fisicamente e mentalmente incapaz de capturar racionalmente todos os fatores de influência que se sobrepõem, desfavorecendo a tomada de decisão com base em uma ponderação clara.

Dentre os fatores que afetam a distância de ultrapassagem em uma estrada plana, podemos considerar: velocidade do veículo que ultrapassa, a velocidade do veículo a ser ultrapassado e do veículo que trafega no fluxo contrário, o tamanho dos veículos envolvidos, o tempo de reação do motorista e a taxa de aceleração da ultrapassagem (CAPALDO; RISOLI, 2012). Campbell et al. (2012) elenca ainda algumas condições que também podem influenciar no aumento do tempo necessário para executar uma manobra de ultrapassagem como (1) um veículo de passeio ultrapassando vários veículos, (2) um veículo de passeio ultrapassando um caminhão, (3) um caminhão ultrapassando outro veículo e (4) a ultrapassagem ocorrendo em um greide íngreme. 
Pesquisas sobre as ultrapassagens são menos frequentes em comparação às pesquisas sobre outros comportamentos de direção, apesar dos acidentes nessa situação possam ser bastante comuns em algumas áreas e, muitas vezes, fatais (GRAY; REGAN, 2005).

Dentre as pesquisas relacionadas às manobras de ultrapassagem várias abordagens e objetivos, como: identificar índices de risco para comprimentos de DVU (distância de visibilidade de ultrapassagem) com simulação microscópica (KHOURY; HOBEIKA, 2007); analisar o impacto de soluções sensoriais relacionados à posição lateral em curvas verticais convexas (AUBERLET et al., 2012); modelar a duração e distância da manobra de ultrapassagem em função das condições de tráfego e características do motorista (FARAH, 2013); avaliar a decisão de ultrapassagem influenciada pelo tamanho do veículo presente no fluxo oposto (LEVULIS; DELUCIA; JUPE, 2015); determinar as variáveis de infraestrutura e trânsito que influenciam a ocorrência e consequências dos acidentes de ultrapassagem, bem como o comportamento de ultrapassagem dos condutores (RICHTER et al., 2016); identificar fatores significativos em ultrapassagem com análise de dados de entrevistas dos condutores coletados em campo (KASHANI; AYAZI; RAVASANI, 2016).

Alguns estudos também discutiram a distância de visibilidade necessária (BROWN; HUMMER, 2000; POLUS; LIVNEH; FRISCHER, 2000), a diferença de velocidade entre o veículo ultrapassado e o veículo que ultrapassa na quantidade de manobras de ultrapassagem (BAR-GERA; SHINAR, 2005), a classificação das manobras de ultrapassagem (JENKINS; RILETT, 2004) e frequências de ultrapassagem (HEGEMAN; HOOGENDOORN; BROOKHUIS, 2005).

Gray e Regan (2005) investigaram as estratégias de controle visual e tomada de decisão em manobras de ultrapassagem com simulador de direção. Os pesquisadores verificaram que, em vários casos, os motoristas iniciaram uma manobra de ultrapassagem quando a distância do veículo na faixa oposta estava acima de um valor crítico, embora não houvesse tempo suficiente para completar uma manobra segura. A adaptação à velocidade de conclusão da manobra também teve efeitos significativos no comportamento de ultrapassagem.

Jenkins e Rilett (2004) investigaram o impacto da velocidade e do comprimento do veículo a ser ultrapassado na distância e tempo de ultrapassagem integrando dados obtidos em microsimulação para geração de volumes específicos. O aumento na velocidade e tamanho do veículo ultrapassado influenciaram no tempo e distância de ultrapassagem. Os resultados obtidos foram maiores quando comparados com observações de campo, que pode ter relação com a propensão dos motoristas subestimarem as distâncias percebidas em ambientes simulados. 
Vlahogianni (2013) propôs a modelagem da manobra de ultrapassagem em rodovias de pista simples utilizando princípios de análise de sobrevivência em dados obtidos em simulador de direção. Diferentes modelos foram desenvolvidos para descrever a duração total de ultrapassagem, bem como a duração das fases de aceleração e retorno para faixa do fluxo. Os resultados mostraram que a duração de cada uma das fases de ultrapassagem consideradas, assim como a duração total de ultrapassagem, pode ser melhor descrita por uma distribuição log-logística. Dentre os fatores que influenciam a ultrapassagem identificou-se o efeito do gênero, da diferença de velocidade e da velocidade do tráfego oposto, bem como se o motorista efetuou múltiplas ultrapassagens.

Farah em parceria com outros pesquisadores estruturou um experimento usando simulador de direção para coletar dados do comportamento do condutor em manobras de ultrapassagem. $O$ experimento produziu 16 cenários diferentes para captar o impacto de fatores relacionados com os vários veículos envolvidos, a geometria da estrada e as características de motorista com uma amostra de 100 voluntários. Com os dados obtidos foi possível produzir diversos modelos e análises sob diferentes perspectivas, como modelos que predizem o risco associado ao comportamento de ultrapassagem, utilizando variáveis que capturam o impacto da geometria da estrada, condições de tráfego e integram as características dos condutores (FARAH; BEKHOR; POLUS, 2009).

Farah e Toledo (2010) desenvolveram um modelo que tentou capturar o desejo do motorista ultrapassar e suas decisões de aceitação de lacunas para completar uma ultrapassagem estimado a partir de dados coletados em simulador de direção. Os resultados identificaram que o desejo de ultrapassar é influenciado pela diferença de velocidade do veículo a ultrapassar e o veículo que ultrapassa e a distância entre eles. A característica do motorista que foi considerada significativa é a idade do motorista. Além disso, um termo de erro latente de característica que foi usado no modelo revelou heterogeneidade significativa no comportamento de ultrapassagem da amostra.

Em 2013, Farah modelou o tempo e a distância percorrida da ultrapassagem em função das características de motorista, geométrica e de tráfego. Os resultados dos modelos estimados mostraram que, além das variáveis relacionadas ao tráfego, as características dos motoristas, principalmente a idade dos motoristas, têm um impacto significativo no tempo total e na distância de ultrapassagem. Ou seja, motoristas mais idosos necessitam de mais tempo para realizar a manobra do que condutores jovens.

Llorca e Farah (2016) realizaram um estudo comparativo entre manobras de ultrapassagem obtidas, via gravação em vídeo, por câmeras posicionadas ao longo da rodovia e dados 
coletados em simulador de direção. Os resultados mostraram semelhanças entre o tempo de passagem e a distância de manobras completadas (durante a ocupação da pista oposta). No entanto, os motoristas passaram mais rápido no simulador de direção, mantendo folgas maiores. As decisões de aceitação da lacuna também foram encontradas como similares, já que as distribuições das lacunas aceitas e rejeitadas foram semelhantes, embora as lacunas críticas tenham sido menores no simulador de direção.

Yang et al. (2018) examinaram o efeito do nível de serviço sobre as mudanças de faixas e manobras de ultrapassagem em ambiente simulado em rodovia com múltiplas faixas. Os resultados indicaram que à medida que a densidade de tráfego aumenta, a intenção dos condutores em mudar de faixa e ultrapassar aumenta. Além disso, verificou-se que os condutores não têm preferência de direção nas manobras de mudança de faixa ou de ultrapassagem. No entanto, as ultrapassagens pelo lado direito envolvem mais riscos do que ultrapassagens pelo lado esquerdo com menor tempo e distância / menor headway antes da ultrapassagem, maior aceleração instantânea e campo de visão mais restrito. Estas conclusões contribuem para uma melhor compreensão das manobras de mudança de faixa e ultrapassagem sob diferentes densidades de tráfego e revelam o risco potencial da ultrapassagem pelo lado direito.

As vantagens do uso de simuladores para análise de manobras de ultrapassagem são inegáveis. No entanto, a investigação empírica, em condução no mundo real continua a ser necessária para a validação, calibração e verificação de resultados de pesquisas com simuladores de direção (VAN DER HORST; HOGEMA, 2011). 



\section{MATERIAL E MÉTODO}

De forma, para testar as três hipóteses formuladas e cumprir o objetivo de analisar as manobras de ultrapassagem em rodovias de pista simples utilizou-se de pesquisa experimental, que seguiu um planejamento rigoroso. As etapas incluíram desde o detalhamento do delineamento experimental, criação dos cenários, produção dos questionários, os pré-testes, testes no simulador de direção, a elaboração do algoritmo para extrair os dados de interesse e, por fim, os métodos estatísticos aplicados para análise dos dados resultantes.

\subsection{Delineamento do experimento}

O delineamento adotado nesta pesquisa foi um experimento fatorial com medidas repetidas, que é utilizado para estudar o efeito de um ou mais fatores, caracterizando-se pela aplicação de todos os níveis dos fatores aos mesmos sujeitos.

Dentre as vantagens, um delineamento de medidas repetidas requer menos participantes que um delineamento completamente aleatorizado e permite eliminar a variação residual devido as diferenças entre os sujeitos, aumentando a precisão obtida, pois utiliza cada sujeito como seu próprio controle.

Em contrapartida, é necessário atentar alguns efeitos decorrentes da utilização dos mesmos sujeitos, como o efeito de prática (sensibilização), que é quando os participantes desempenham melhor a tarefa em função da repetição dos testes, ou seja, estarão familiarizadas com a tarefa e como consequência o tratamento administrado por último parece mais efetivo que o tratamento apresentado em primeiro; e o efeito de fadiga (tédio), quando o desempenho dos participantes é prejudicado pela fadiga devido a longa exposição ao experimento (VERCRUYSSEN; HENDRICK, 1981; FIELD, 2009).

A análise da manobra ultrapassagem foi realizada através de um experimento fatorial de medidas repetidas composto por três fatores fixos com dois níveis $\left(2^{3}\right)$, sendo os fatores: tipo do veículo lento, velocidade do veículo lento e a distância de ultrapassagem permitida. Os fatores e seus níveis são apresentados na Tabela 8.

O tipo de veículo adotado no modelo de ultrapassagem do DNIT/AASHTO é um veículo de passeio. Contudo, nas rodovias brasileiras é elevada a taxa de veículos de carga (caminhões). 
Este tipo de veículo tende a restringir a visão durante a manobra devido à altura e à largura na via. Além do percentual elevado de veículos de carga nas rodovias brasileiras, a baixa potência e o excesso de peso destes tendem a reduzir a velocidade operacional, propiciando o aumento da ocorrência de ultrapassagens. Esta situação particular conduz à necessidade de uma investigação do comportamento do condutor brasileiro na ultrapassagem. Baseado nisso, para o fator tipo de veículo a ultrapassar foram escolhidos: carro de passeio (CP) e veículo de carga - caminhão (CA).

Outro fator diz respeito à velocidade do veículo a ultrapassar. O critério para a escolha das velocidades do veículo lento partiu da diferença de velocidade entre o veículo rápido e o veículo lento durante a manobra de ultrapassagem. A AASHTO (2011) apresenta um valor de $19 \mathrm{~km} / \mathrm{h}$, portanto, para uma velocidade regulamentada de $80 \mathrm{~km} / \mathrm{h}$ optou-se pelas velocidades de $60 \mathrm{~km} / \mathrm{h}$ e $40 \mathrm{~km} / \mathrm{h}$. Este último é duas vezes menor que a diferença da norma, ou, $50 \%$ da velocidade regulamentada.

Para a distância de ultrapassagem permitida que corresponde à marcação tracejada na zona de ultrapassagem permitida, foi utilizada a distância de $560 \mathrm{~m}$, que corresponde à distância recomendada pelo DNIT(1999) e de 446 m que é a distância mínima recomendada pela AASHTO (2011) para volumes de tráfego baixo (PIMENTA et al., 2017).

Tabela 8 - Fatores e os níveis do experimento

\begin{tabular}{l|c|c}
\hline \multirow{2}{*}{ Fatores } & \multicolumn{2}{c}{ Nível } \\
\cline { 2 - 3 } & Baixo & Alto \\
\hline Tipo de veículo lento (Tipo_VL) & Carro Passeio & Caminhão \\
Velocidade do veículo lento (Vel_VL) & $40 \mathrm{Km} / \mathrm{h}$ & $60 \mathrm{~km} / \mathrm{h}$ \\
Distância de ultrapassagem (DistUltra) & $446 \mathrm{~m}$ & $560 \mathrm{~m}$ \\
\hline
\end{tabular}

Fonte: a autora

As combinações dos níveis dos fatores resultam em oito tratamentos (Tabela 9) e para controlar os efeitos de prática e sensibilização decorrentes da ordem de apresentação dos tratamentos aos participantes, seriam necessários 40.320 cenários com a ordem dos tratamentos aleatorizados, o que inviabilizaria a execução do experimento. Para mitigar os efeitos da ordem dos tratamentos apresentados aos voluntários foi aplicado um contrabalanceamento.

O contrabalanceamento é usado em conjunto com o experimento de medidas repetidas para assegurar que quaisquer efeitos de transição e ordem (por exemplo, efeitos de prática ou fadiga), sejam distribuídos igualmente em todas as condições, eliminando assim a confusão entre o tratamento e a posição (FIELD, 2009). Os princípios gerais do contrabalanceamento são (1) cada tratamento é apresentado para cada participante em igual número de vezes, (2) 
cada tratamento dever ocorrer o mesmo número de vezes em cada sessão e, (3) cada tratamento deve preceder e seguir todos os tratamentos em igual número de vezes (VERCRUYSSEN; HENDRICK, 1981). Antes de realizar o contrabalanceamento, os tratamentos foram aleatorizados e o resultado é apresentado na coluna "ordem do teste" na Tabela 9, que foi utilizado para definir a ordem do tratamento em cada cenário.

Tabela 9 - Matrix de planejamento do experimento fatorial $2^{3}$

\begin{tabular}{|c|c|c|c|c|c|}
\hline \multirow{2}{*}{$\mathrm{Nr}$} & \multicolumn{3}{|c|}{ Fatores de controle } & \multirow{2}{*}{ Tratamento } & \multirow{2}{*}{$\begin{array}{c}\text { Ordem } \\
\text { do Teste }\end{array}$} \\
\hline & Vel_VL & Tipo_VL & DistUltra & & \\
\hline 1 & $40 \mathrm{~km} / \mathrm{h}$ & Carro Passeio & 446 & 40CP446 & 4 \\
\hline 5 & $40 \mathrm{~km} / \mathrm{h}$ & Carro Passeio & 560 & $40 \mathrm{CP} 560$ & 1 \\
\hline 3 & $40 \mathrm{~km} / \mathrm{h}$ & Caminhão & 446 & 40CA446 & 8 \\
\hline 7 & $40 \mathrm{~km} / \mathrm{h}$ & Caminhão & 560 & 40CA560 & 2 \\
\hline 2 & $60 \mathrm{~km} / \mathrm{h}$ & Carro Passeio & 446 & $60 \mathrm{CP} 446$ & 3 \\
\hline 6 & $60 \mathrm{~km} / \mathrm{h}$ & Carro Passeio & 560 & $60 \mathrm{CP} 560$ & 6 \\
\hline 4 & $60 \mathrm{~km} / \mathrm{h}$ & Caminhão & 446 & 60CA446 & 5 \\
\hline 8 & $60 \mathrm{~km} / \mathrm{h}$ & Caminhão & 560 & 60CA560 & 7 \\
\hline
\end{tabular}

Fonte: a autora

Nesta pesquisa adotou-se o contrabalanceamento denominado quadrado latino simples (VERCRUYSSEN; HENDRICK, 1981), que contempla o primeiro e segundo princípio do contrabalanceamento. Nos cenários ( $\mathrm{C} 1$ a $\mathrm{C} 8$ ), cada tratamento (1 a 8) ocorre igualmente em cada cenário. Ou seja, quando um tratamento é precedido ou seguido por outro tratamento, o mesmo tratamento sempre precede ou o segue (Tabela 10). Dessa forma todos os participantes passam por todos os tratamentos. Além disso, esta disposição garante que o primeiro tratamento não sofra influência dos tratamentos seguintes, mas também garanta a verificação da possível influência de todos os tratamentos anteriores sobre o último tratamento de cada cenário.

Tabela 10 - Cenários com a sequência de tratamentos

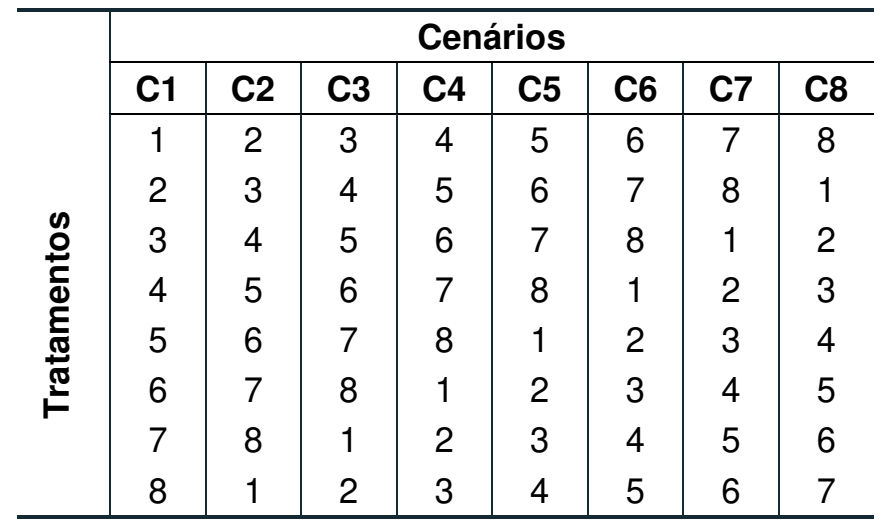

Fonte: a autora 


\subsection{Cenário do experimento}

O delineamento do experimento exigiu a criação de oito cenários virtuais (C1 a C8) para incorporar as sequências de tratamentos. Para isso definiu-se um traçado geométrico para a rodovia virtual a ser utilizado em todos os cenários. Na elaboração da geometria levou-se em consideração requisitos como o tempo de exposição no simulador, visto que quanto maior o tempo de simulação aumenta a possibilidade de eventual desconforto (motion sickness) e o realismo da simulação, buscando utilizar características similares às rodovias de pista simples brasileiras.

Partindo desses critérios, estabeleceu-se que o tempo do experimento seria em média de 10 minutos, sem contabilizar o tempo de treinamento para adaptação no simulador, ou seja, considerando a velocidade regulamentada da via de $80 \mathrm{~km} / \mathrm{h}$ definiu-se que a extensão adequada para o trecho seria de $13 \mathrm{~km}$.

$O$ traçado geométrico iniciou nas coordenadas $N=0,000$ e $E=0,000$ e foram definidas nove tangentes (T0 a T8), com extensão de 1500 metros cada com deflexão entre si de 45‥ As tangentes foram intercaladas com curvas circulares simples de raio $1000 \mathrm{~m}$, propiciando a harmonização do traçado. A disposição das curvas à direita (C-3, C-5, C-6, C-8) e curvas à esquerda (C-1, C-2, C-4, C-7) foi aleatorizada para isenção na escolha da composição do traçado do trecho. $\mathrm{O}$ croqui da geometria do cenário base é apresentado na Figura 8 com a tabela de curvas do alinhamento e quilometragens no eixo da via. 
Figura 8 - Croqui da geometria do cenário base.

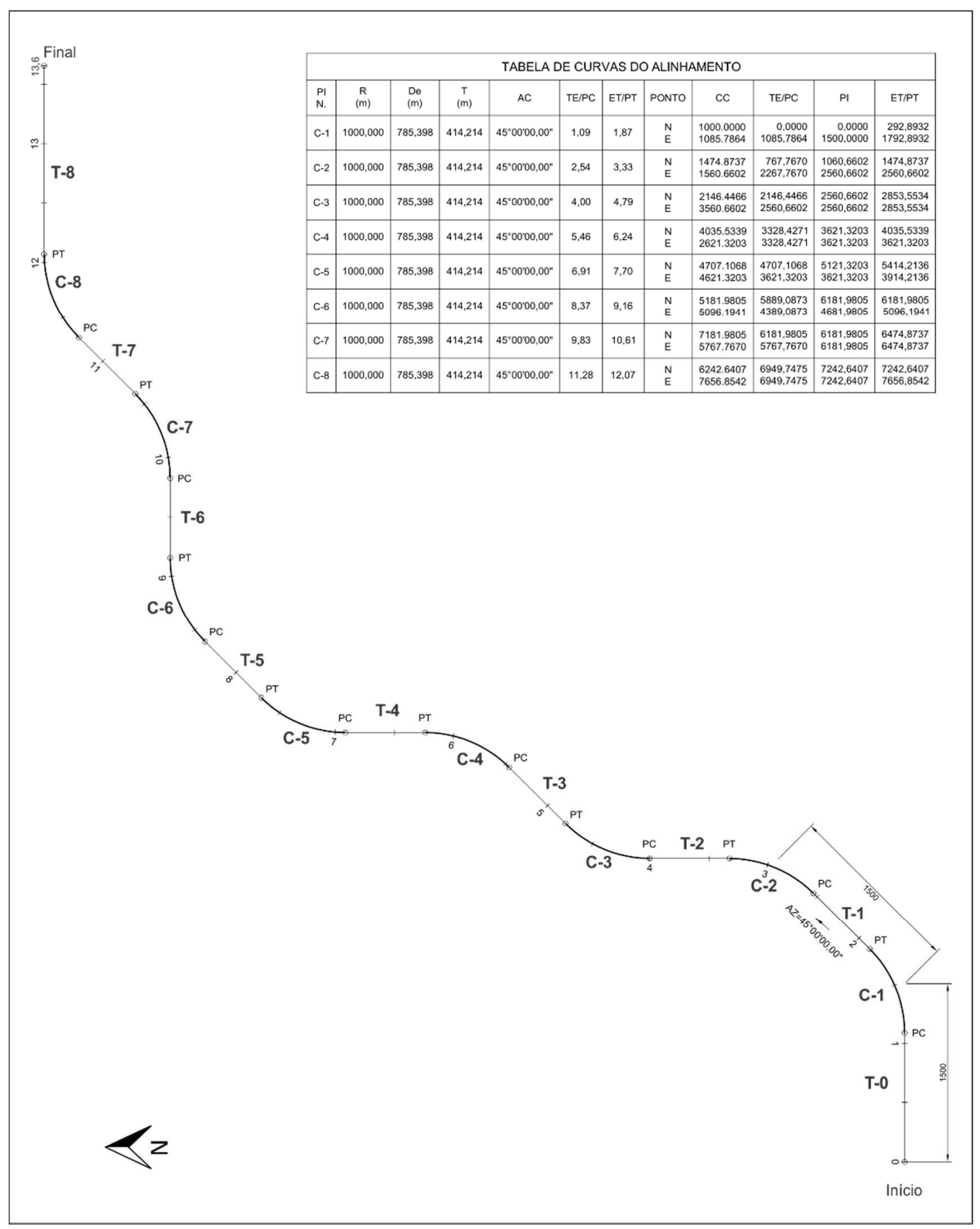

Fonte: a autora

Após a definição da geometria do cenário base foi utilizado o software ROD® da VI-Grade para renderização do cenário virtual. Esta etapa consiste na definição da plataforma da via, inserção da sinalização horizontal, vertical e dos elementos virtuais do entorno que irão compor a simulação.

A extensão total da rodovia de pista simples bidirecional foi de $13,6 \mathrm{~km}$. A plataforma de rolamento foi definida com largura de 7,20 metros (3,6 m cada faixa), sem acostamento, 
semelhante às características geométricas das rodovias federais brasileiras. O entorno da via abrange uma largura de 190 metros, considerando 95 metros para cada lado a partir do eixo da via. E tendo em conta a visibilidade do condutor e a movimentação dos veículos foram retirados arbustos e árvores de pequeno ou grande porte em uma distância de 8 metros, a contar do bordo da via. Nas curvas horizontais foi considerada uma superelevação de $8 \%$ por questões estéticas de visualização. Por se tratar de um simulador de base fixa não é possível transmitir ao participante a sensação da dinâmica veicular em resposta às superelevações da via, mas a perspectiva visual corresponde à uma situação real.

A sinalização horizontal e vertical inseridas no cenário da simulação seguem as normas do Conselho Nacional de Trânsito (CONTRAN). A sinalização horizontal dos trechos em que não é permitido ultrapassar apresentam linha dupla contínua amarela (LFO-3) que divide fluxos opostos de circulação, delimitando o espaço disponível para cada sentido e regulamentando os trechos em que a ultrapassagem e os deslocamentos laterais são proibidos para os dois sentidos (Figura 9). Os trechos em que é permitida a ultrapassagem apresentam linha simples seccionada (LFO-2) com largura (I) da linha definida em função da velocidade regulamentada na via, em que para velocidades maiores ou iguais a $80 \mathrm{~km} / \mathrm{h}$ deve ser de $0,15 \mathrm{~m}$ e cadência $(t: e)$ de $4 \mathrm{~m}: 12 \mathrm{~m}$.

Figura 9 - Sinalização horizontal da simulação

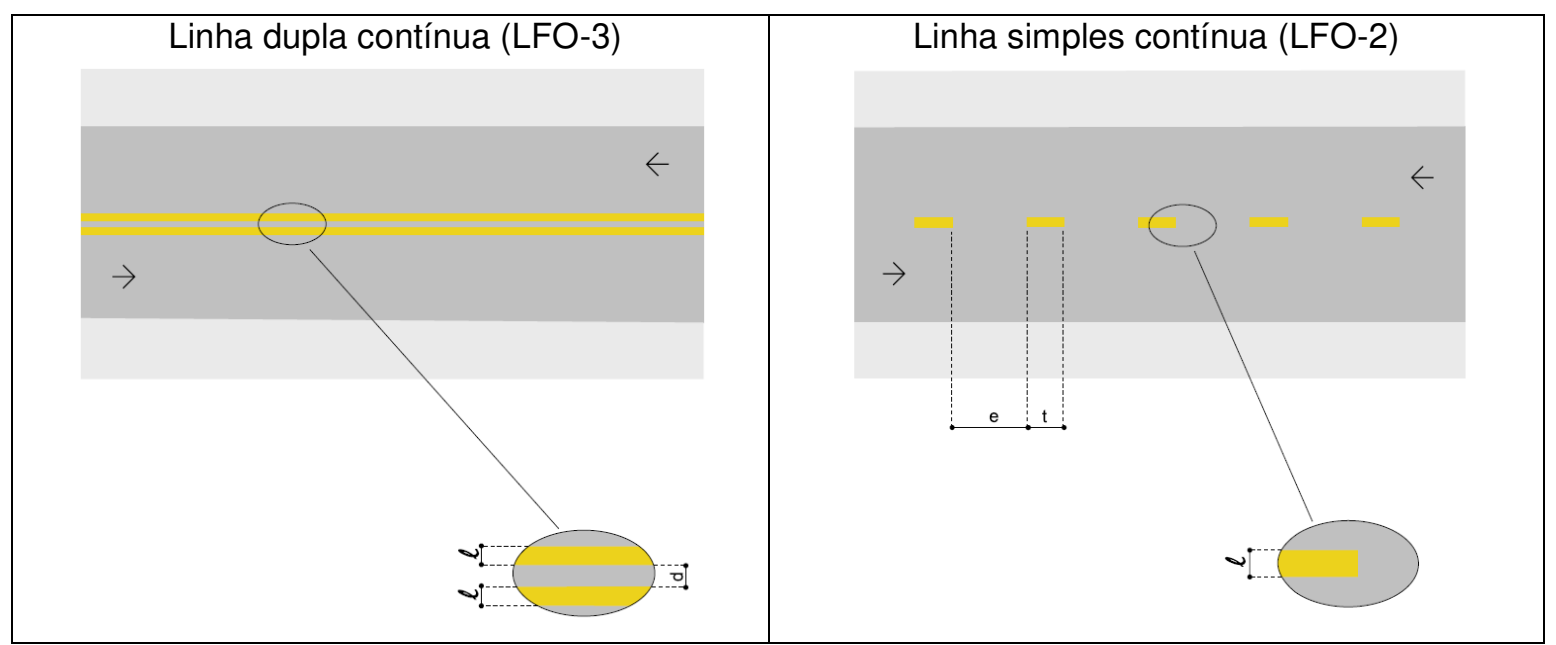

Fonte: CONTRAN (2007a)

As demarcações dos trechos de ultrapassagem permitida (LFO-2) foram inseridas nas tangentes de acordo com a sequência de tratamentos de cada cenário da Tabela 10. Para isso foram criados 8 cenários distintos que compartilham da mesma geometria do cenário base, e cuja as posições centrais (em metros) em relação ao eixo da via de cada tangente são: $\mathrm{T} 1=2207, \mathrm{~T} 2=3364, \mathrm{~T} 3=5121, \mathrm{~T} 4=6578, \mathrm{~T} 5=8035, \mathrm{~T} 6=9492, \mathrm{~T} 7=10949$, T8 $=$ 12613. A delimitação do início e fim da zona de ultrapassagem permitida em cada tangente 
se dá através da inserção do diâmetro correspondente à distância de ultrapassagem de cada tratamento no centro da tangente; por exemplo: o Cenário 1 (C1) com a sequência de tratamentos (1) 40CP560, (2) 40CA560, (3) 60CP446, (4) 40CA446, (5) 60CA446, (6) 60CP560, (7) 60CA560, (8) 40CA446), apresenta as seguintes distâncias de ultrapassagem permitidas: 560, 560, 446, 446, 446, 560, 560, 446 em metros. Sendo assim, na tangente T1 a posição inicial da zona de ultrapassagem permitida será 1927 (= 2207 - [560 / 2]) e a posição final será 2487 (= $2207+$ [560 / 2]), e assim, sucessivamente para o cálculo de todas as posições iniciais e finais de cada zona de ultrapassagem permitida ao longo de cada tratamento.

Em relação à sinalização vertical, esta pesquisa limitará ao uso das placas de "velocidade máxima permitida" (R-19) e "proibido ultrapassar" (R-7). O sinal de "velocidade máxima permitida" (R-7) regulamenta o limite máximo em que o veículo pode circular na pista ou faixa, válido a partir do ponto onde o sinal é colocado. As placas devem ser colocadas ao longo da via, de forma a manter o condutor permanentemente informado e deve ser colocada à direita da via/pista, perpendicular ao tráfego (CONSELHO NACIONAL DE TRÂNSITO (CONTRAN), 2007b). O CONTRAN sugere que a distância máxima entre as placas de regulamentação de velocidade ao longo da via seja de $10 \mathrm{~km}$, quando a velocidade é inferior ou igual a $80 \mathrm{~km} / \mathrm{h}$. Nesta pesquisa por se tratar de um trecho curto $(13 \mathrm{~km})$ as placas de velocidade máxima foram inseridas a cada 1500 metros, a contar da posição $500 \mathrm{~m}$ do trecho, com o intuito de alertar a velocidade regulamentada permitida visto que em simuladores de direção os participantes tendem a conduzir em velocidades maiores (TÖRNROS, 1998).

A placa de "Proibido Ultrapassar" (R-19) assinala ao condutor do veículo que é proibido realizar o movimento de ultrapassagem no trecho regulamentado, pela(s) faixa(s) destinada(s) ao sentido oposto de circulação (Figura 10). A placa R-19 foi colocada no início do trecho em que a proibição é válida, no lado direito da via/pista.

Figura 10 - Sinalização vertical utilizada no cenário da simulação

Sinal Proibido Ultrapassar (R-7)

Fonte: CONTRAN (2007b) 
A regra geral de posicionamento das placas de sinalização consiste em colocá-las no lado direito da via no sentido do fluxo de tráfego. As placas de sinalização foram implantadas com $1,2 \mathrm{~m}$ de altura, a contar da borda inferior da placa à superfície da pista de rolamento e com afastamento de 1,2 $\mathrm{m}$ do bordo externo da pista. Foram posicionadas em um ângulo de $93^{\circ} \mathrm{a}$ 95ํe em relação ao sentido do fluxo de tráfego, voltadas para o lado externo da via. Esta inclinação tem por objetivos assegurar boa visibilidade e leitura dos sinais, evitando o reflexo especular que pode ocorrer com a incidência de faróis de veículos ou de raios solares sobre a placa, adotou-se o mesmo critério para o cenário virtual.

Figura 11 - Croqui de sinalização do cenário virtual entre o km 4,8 e km 5,4.

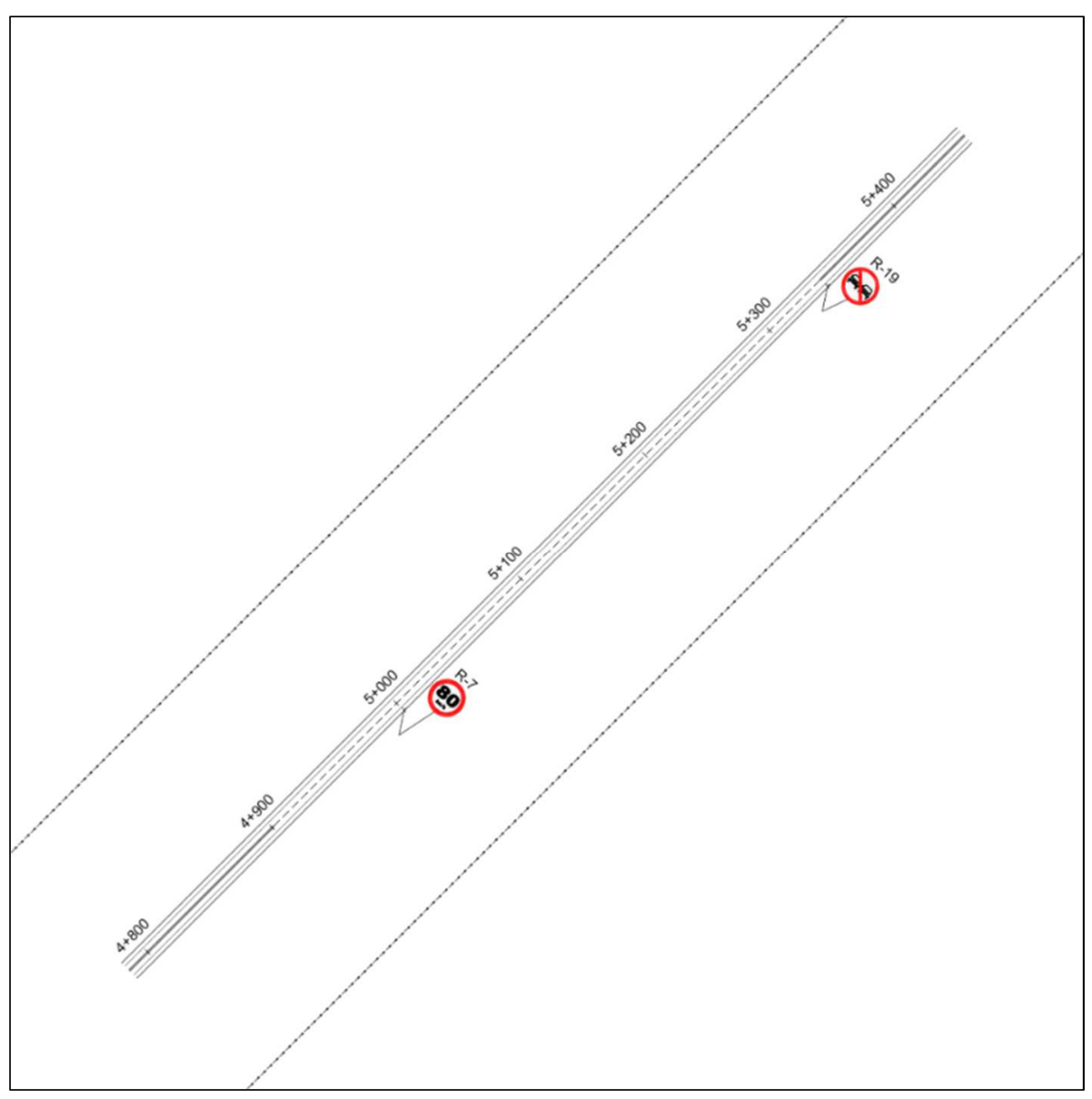

Fonte: a autora

A etapa seguinte consistiu na inserção dos veículos que compõem os tratamentos dos oito cenários renderizados. Cada cenário é composto por 8 tratamentos e cada tratamento possui 2 veículos envolvidos na manobra de ultrapassagem, totalizando 16 veículos em cada cenário, sendo 8 veículos lentos (VL) que, dependendo do tratamento, podem ser do tipo carro de passeio ou caminhão e 8 veículos opostos (VO) do tipo carro de passeio.

Para este procedimento foi utilizado o software Scenario Editor integrado ao software VTD® da VI-Grade, utilizado na simulação do ambiente virtual. Dentre as opções de modelos de 
veículos disponíveis no software foram escolhidos para o veículo do tipo carro de passeio o modelo Volkswagen Golf 2012 disponível nas cores preto, cinza, azul, branco ou vermelho. E para o veículo do tipo caminhão foi escolhido o modelo MB Actros 2007, disponível nas cores marrom, laranja, verde escuro ou branco. E para manter a premissa de incutir realismo ao cenário virtual, as cores dos veículos foram aleatorizadas e alocadas a cada tratamento, dispostas conforme a Tabela 11. Cabe ressaltar que o número do tratamento está associado ao conjunto de veículos (VL e VO) de mesmo número, independente da ordem no cenário.

Tabela 11 - Cores dos veículos lentos e veículos opostos por tratamento

\begin{tabular}{c|c|c|c|c|c}
\hline Tratamento & $\begin{array}{c}\text { Tipo de } \\
\text { VL }\end{array}$ & \multicolumn{2}{|c|}{ Veículo Lento (VL) } & \multicolumn{2}{c}{ Veículo Oposto (VO) } \\
\hline 1 & CP & VL1 & Preto & VO1 & Cinza \\
2 & CA & VL2 & Laranja & VO2 & Vermelho \\
3 & CP & VL3 & Branco & VO3 & Azul \\
4 & CP & VL4 & Vermelho & VO4 & Preto \\
5 & CA & VL5 & Verde Escuro & VO5 & Branco \\
6 & CP & VL6 & Cinza & VO6 & Cinza \\
7 & CA & VL7 & Marrom & VO7 & Vermelho \\
8 & CA & VL8 & Branco & VO8 & Azul \\
\hline
\end{tabular}

Fonte: a autora

Em seguida, foram definidas as posições dos veículos nos cenários virtuais. No que concerne a concepção de um experimento que avalia o processo de ultrapassagem, o principal desafio é criar oportunidades de ultrapassagem de uma forma razoavelmente natural e eficaz, considerando que participantes em simulador de direção estão cientes de que não estão expostos a nenhum perigo físico (MERAT; JAMSON, 2013). Este desafio é reforçado pelo fato que diferentes motoristas podem preferir diferentes velocidades de condução (BAR-GERA; SHINAR, 2005).

Para criar condições viáveis e realistas, o ideal é que os veículos (VL e VO) estejam posicionados no início e fim, respectivamente, da zona de ultrapassagem permitida, dando oportunidade de ultrapassagem caso o participante decida efetuar a manobra. Porém, devido à velocidade de condução variar de acordo com o perfil do condutor, foi necessário estabelecer um gatilho de controle. Assim, foram calculadas posições de ativação de movimento do veículo lento (VL) e veículo oposto (VO) em função da distância do veículo rápido (VR - veículo do participante), ou seja, o VL e VO iniciam a simulação parados e começam a se movimentar quando o veículo do participante se encontra a uma distância prédeterminada. Para os cálculos, admitiu-se que o veículo do participante estará trafegando na velocidade regulamentada da rodovia de $80 \mathrm{~km} / \mathrm{h}$. 
Em todos os tratamentos o veículo oposto (VO) trafega à velocidade de $80 \mathrm{~km} / \mathrm{h}$ e inicialmente encontra-se parado e posicionado $126 \mathrm{~m}$ à jusante da zona de ultrapassagem permitida, aguardando ativação. O veículo lento $(\mathrm{VL})$, dependo do tratamento, pode trafegar à velocidade de $40 \mathrm{~km} / \mathrm{h}$ ou $60 \mathrm{~km} / \mathrm{h}$. Quando no tratamento a velocidade do VL for de $40 \mathrm{~km} / \mathrm{h}$, este estará posicionado $68 \mathrm{~m}$ à montante da zona de ultrapassagem permitida e, quando no tratamento $\mathrm{a}$ velocidade do VL for de $60 \mathrm{~km} / \mathrm{h}$, este estará posicionado $89 \mathrm{~m}$ à montante da zona de ultrapassagem. A ativação dos veículos (VL e VO) em cada tratamento se dará quando o veículo do participante (VR) estiver a 200 m de distância do veículo lento (VL), independente da velocidade de condução do participante.

De acordo com esses parâmetros, quando o veículo lento (VL) estiver no início da zona de ultrapassagem permitida o veículo do participante estará a aproximadamente $50 \mathrm{~m}$ de distância do VL. E conforme recomendado pelo DENATRAN (2005), uma distância é considerada segura quando os veículos se encontram separados por um headway de dois segundos, que corresponde a aproximadamente 44 metros a uma velocidade de $80 \mathrm{~km} / \mathrm{h}$.

Em todos os cenários, as seções encontram-se em terreno nivelado e com condições diurnas e de bom tempo, que permite boa visibilidade. As figuras a seguir apresentam a visão do motorista no simulador quando na presença de um veículo lento (VL) carro de passeio (Figura 12) e um caminhão (Figura 13), em ambas as situações é possível perceber a presença do veículo oposto (VO). O link http://bit.ly/2ITkRCB dá acesso à um vídeo em formato AVI para visualização do cenário renderizado.

Figura 12 - Ponto de vista do condutor no simulador com veículo lento - carro de passeio

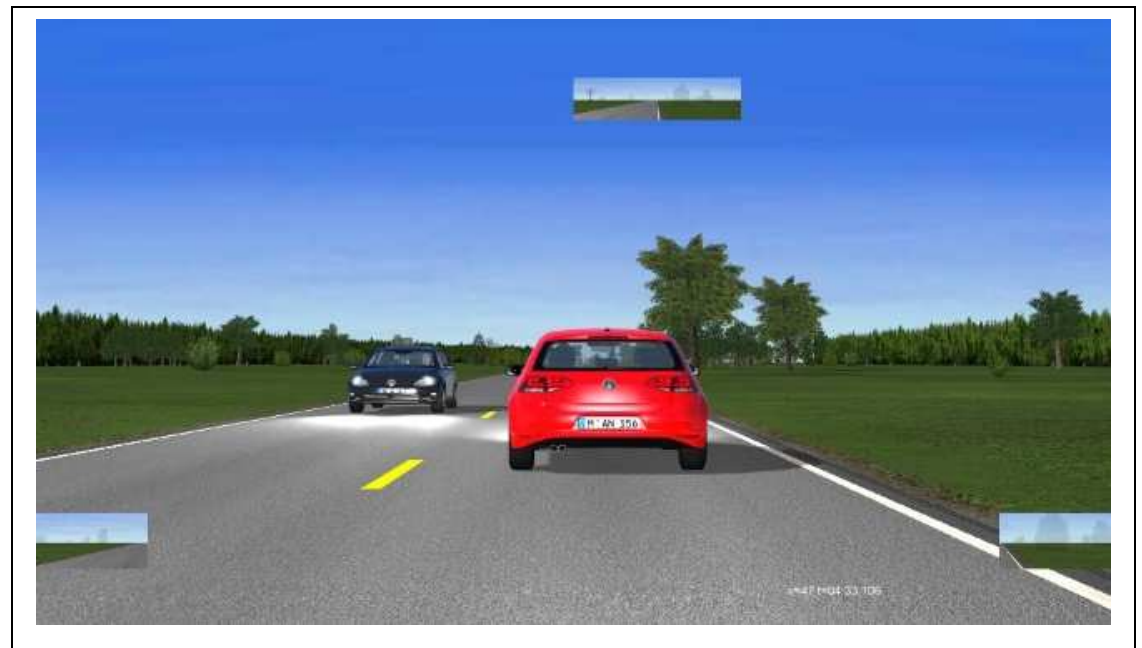

Fonte: a autora. 
Figura 13 - Ponto de vista do condutor no simulador com veículo lento - caminhão

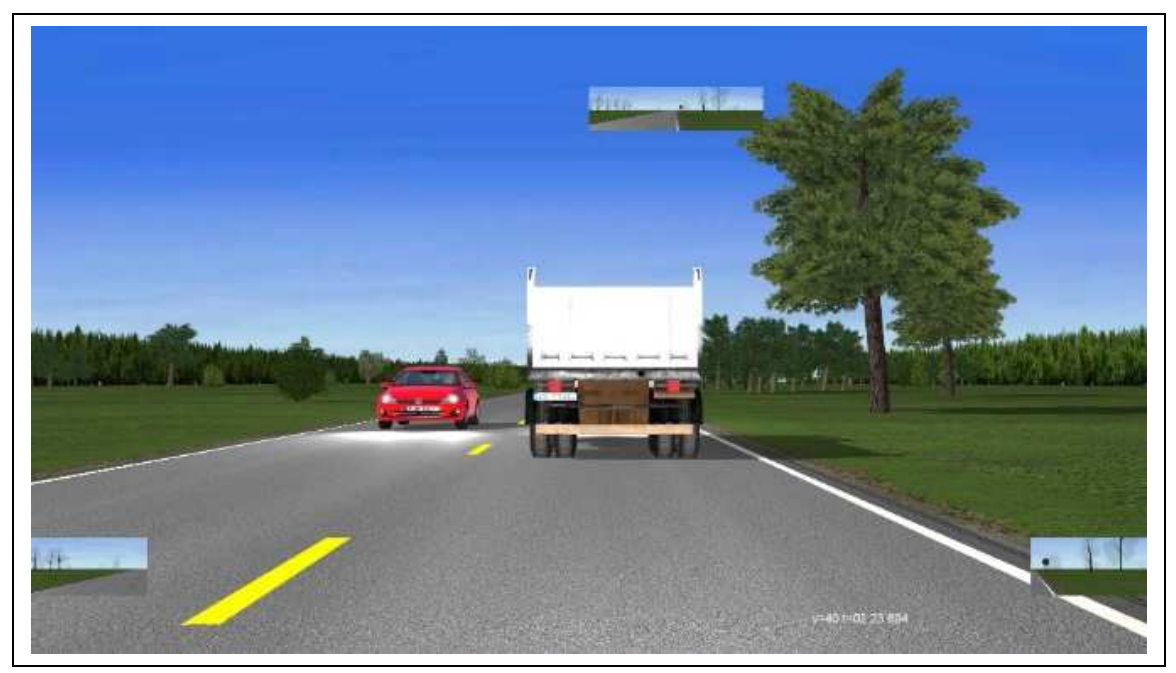

Fonte: a autora.

Para o caso em que o participante não efetue a ultrapassagem do veículo lento (VL) ao final da tangente de cada tratamento, o VL indicará com a seta de direção uma parada no acostamento e permanecerá estacionado na mesma posição até o final do experimento. Esta condição foi implementada para evitar a formação de um pelotão de veículos e para que o participante tenha acesso ao próximo tratamento sem a interferência do veículo retardatário.

Para avaliar possíveis alterações ou ajustes, os cenários do experimento foram avaliados previamente por alunos do Departamento de Engenharia de Transportes da EESC/USP. Os discentes foram escolhidos por possuir experiência com o simulador de direção devido participação em outras pesquisas, além de conhecimento técnico para identificar e sugerir aperfeiçoamentos. As colaborações e sugestões foram incorporadas ao cenário final.

\subsection{SIMULADOR DE DIREÇÃo}

O experimento foi conduzido em simulador de direção de base fixa instalado na Escola de Engenharia de Transportes (EESC/USP) e vinculado ao Departamento de Engenharia de Transportes (STT/EESC). A estrutura do simulador utilizado nesta pesquisa é apresentado em detalhes em Santos et al. (2017).

O simulador é constituído de componentes físicos e programas computacionais. Os componentes físicos se subdividem em sistema de controle do veículo, sistema de projeção e sistema de processamento.

O sistema de controle do veículo é composto por cockpit completo com banco, pedais de embreagem, freio e acelerador, alavanca de câmbio de 6 marchas e volante de direção 
Logitech G27, que proporciona torque no volante durante a condução. O sistema de projeção, por sua vez, é composto por projetor DepthQ, de resolução 1080p e taxa de projeção de $60 \mathrm{~Hz}$ e tela frontal de $1425 \times 800 \mathrm{~mm}$, onde projeta-se os espelhos retrovisor e traseiro na tela.

O sistema de processamento integra os componentes físicos e computacionais, composto por uma rede de três computadores de alto desempenho com configurações similares, incluindo processador Corel7, 8gb de RAM, placa de vídeo GeoForce com 1gb de RAM dedicada. Cada computador é responsável por um programa computacional, sendo estes: Virtual Test Drive®, VI-CarRealTime® e MAPPS®.

Os programas computacionais compreendem os sistemas virtuais responsáveis pela criação da geometria, renderização do cenário, inserção e controle de eventos, controle do veículo e armazenamento dos dados.

O Virtual Test Drive (VTD®) é uma ferramenta para aplicações em simuladores de direção. O VTD fornece o gerenciamento de dados para todos os componentes do "ambiente virtual". Inicia com o módulo de geração do cenário (ROD) para definição da rede viária e integra outros componentes VTD responsáveis pela simulação de tráfego, geração de imagem, simulação de som, dinâmica do veículo, processamento de dados etc.

O VI-CarRealTime fornece um ambiente de simulação em tempo real do veículo. O modelo veicular é responsável pela dinâmica do veículo em ambiente simulado. O modelo veicular utilizado no simulador é um carro de passeio similar ao modelo Peugeot Citröen C3, cedido pela empresa PSA Peugeot Citröen Brasil. O VI-CarRealTime interliga o modelo veicular ao simulador de direção, transmitindo as características do veículo ao sistema de controle, proporcionando sensação de realismo ao dirigir o veículo virtual em ambiente simulado.

Após a criação do cenário virtual do experimento, o programa Virtual Test Drive (VTD) modela o cenário em tempo real ao longo de cada simulação, que processa a uma taxa de 60 frames por segundo (isto é, uma imagem a cada 0,016 segundos) em simultâneo com a modelagem do veículo principal. O processo de criação do cenário e modelagem do cenário é apresentado no esquema da Figura 14. A Figura 15 apresenta a disposição do cockpit e a disposição do sistema de processamento. 
Figura 14 - Processo de modelagem e simulação do cenário virtual

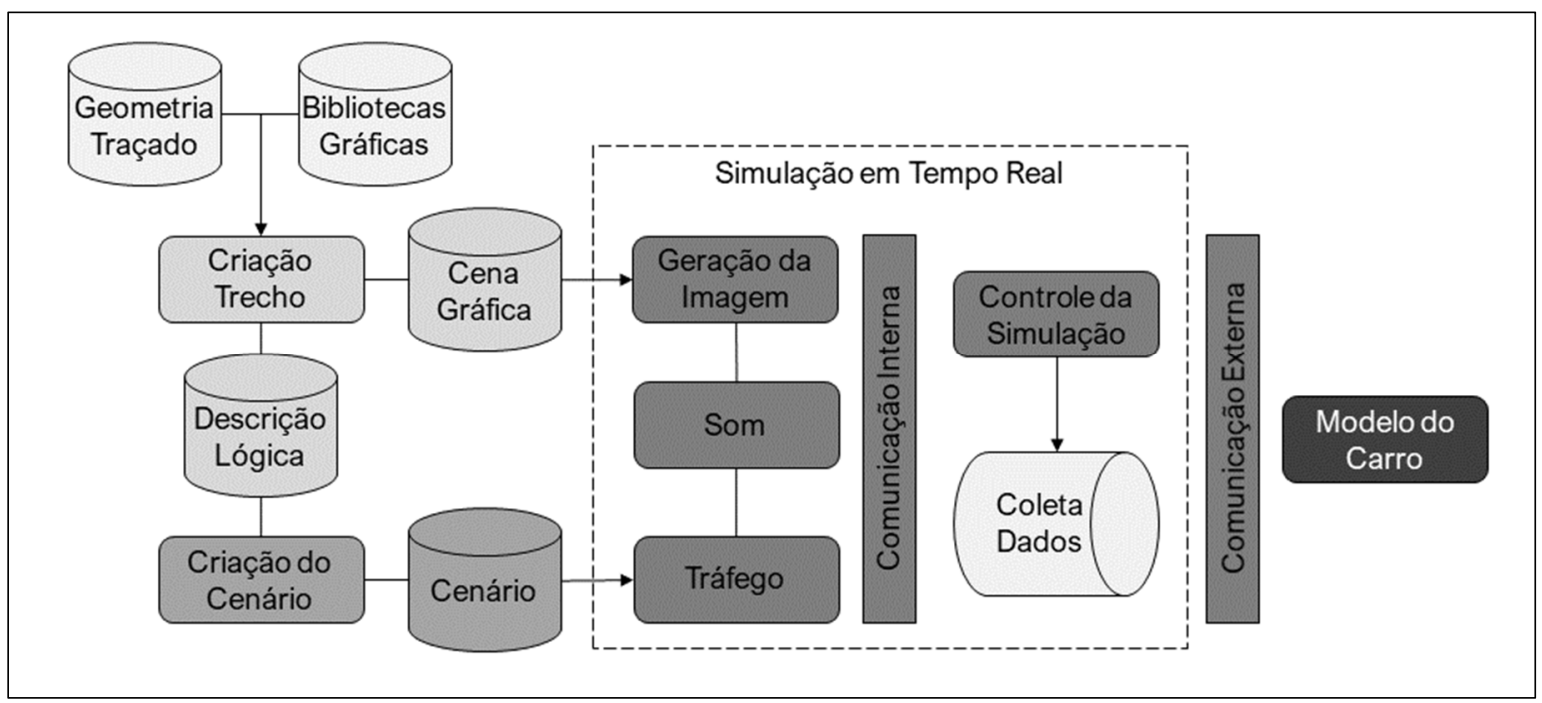

Fonte: Adaptado de Castillo (2015).

Figura 15 - Cockpit e disposição do sistema de processamento.

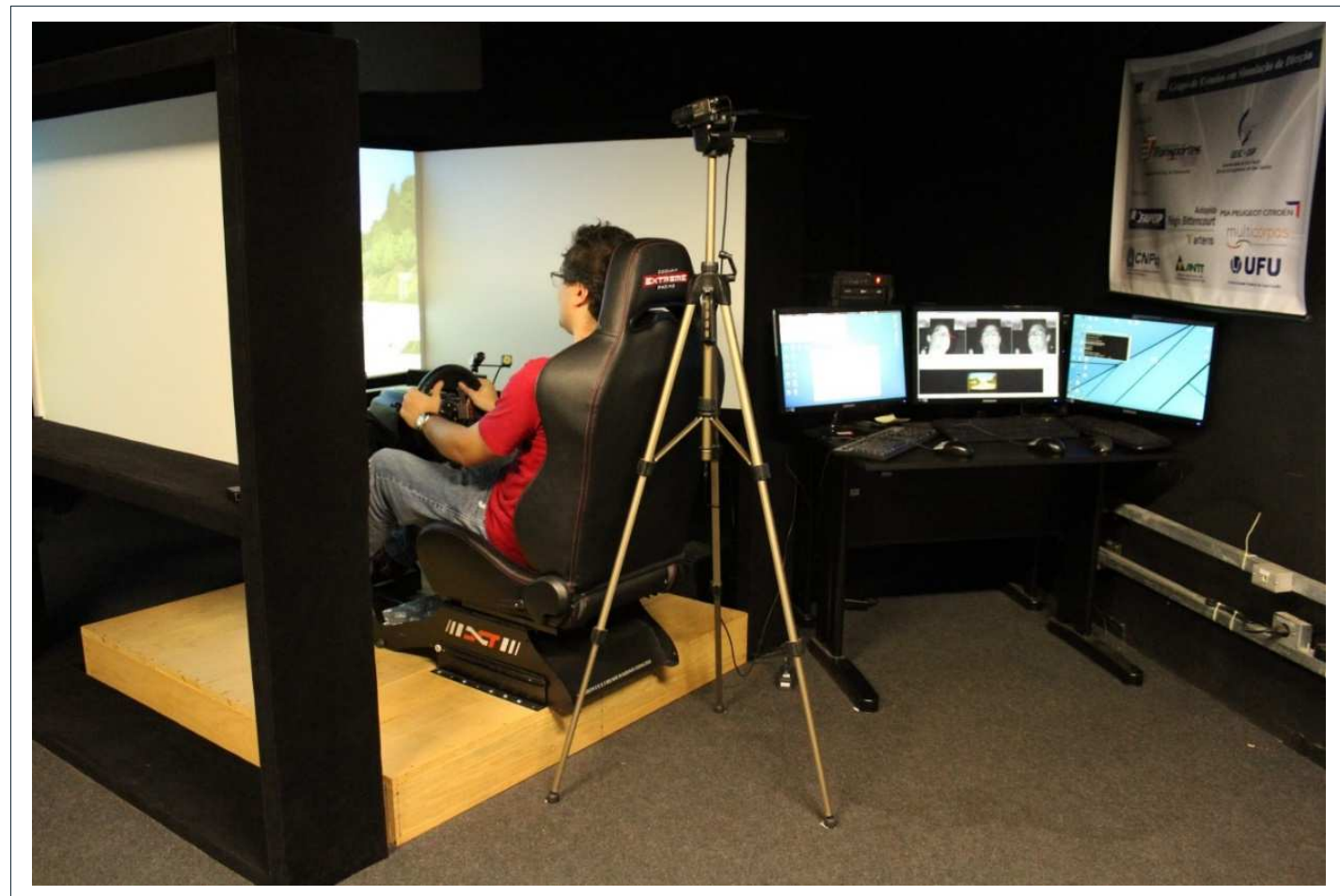

Fonte: a autora

Além dos sistemas descritos anteriormente, acoplado ao simulador de direção, encontra-se um sistema de rastreio do olhar. O SmartEye permite estimar a posição do olhar do condutor e mensurar o tempo alocado para cada posicionamento ocular em relação ao cenário, durante o experimento (Figura 16).

O sistema de rastreio do olhar é composto por 4 câmeras de vídeo sincronizadas por um sistema computacional. A distribuição das câmeras segue o esquema de 3 câmeras de vídeo 
(Figura 17) monocráticas (sendo 2 com sensor infravermelho) posicionadas na parte frontal, 15a abaixo dos olhos do condutor e separadas por $40 \mathrm{~cm}$, entre si. São responsáveis por gravar a face do condutor, por detectar a posição e orientação das pupilas, e registrar o posicionamento da cabeça do condutor. As informações são registradas à uma taxa de $60 \mathrm{~Hz}$.

A 4aㅡ câmera de vídeo é posicionada atrás do banco do condutor para gravação do cenário simulado a partir do campo de visão do participante. Durante o experimento capta imagens coloridas com uma resolução de 480p e taxa de aquisição de $25 \mathrm{~Hz}$.

Figura 16 - Sistema de rastreio do olhar

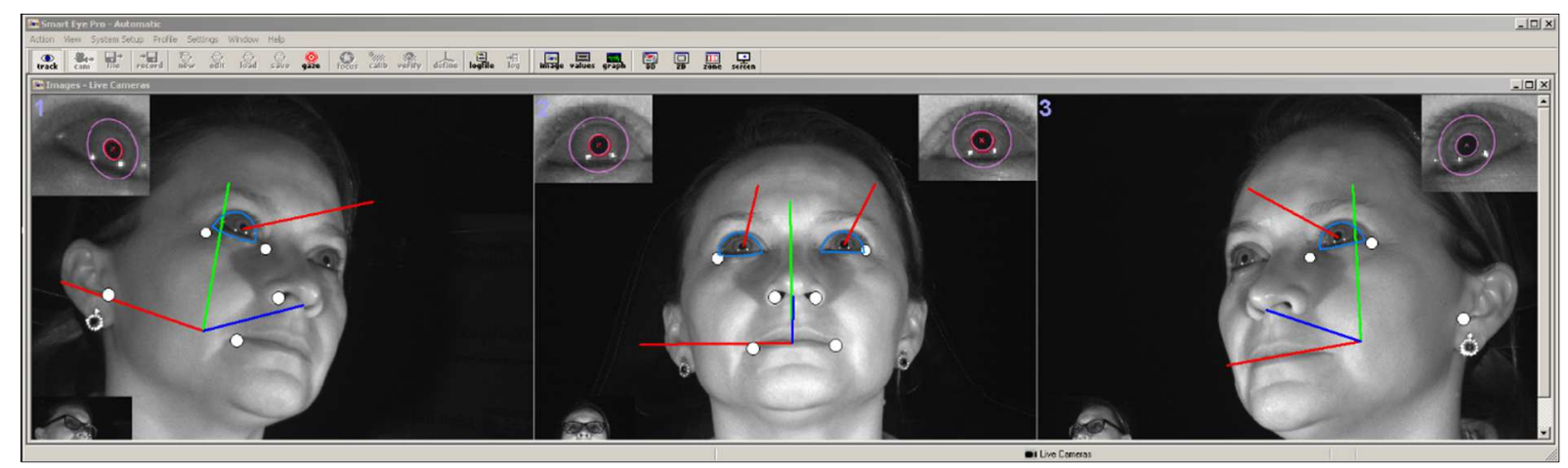

Fonte: a autora

Figura 17 - Detalhe da câmera do SmartEye e disposição das câmeras no simulador.

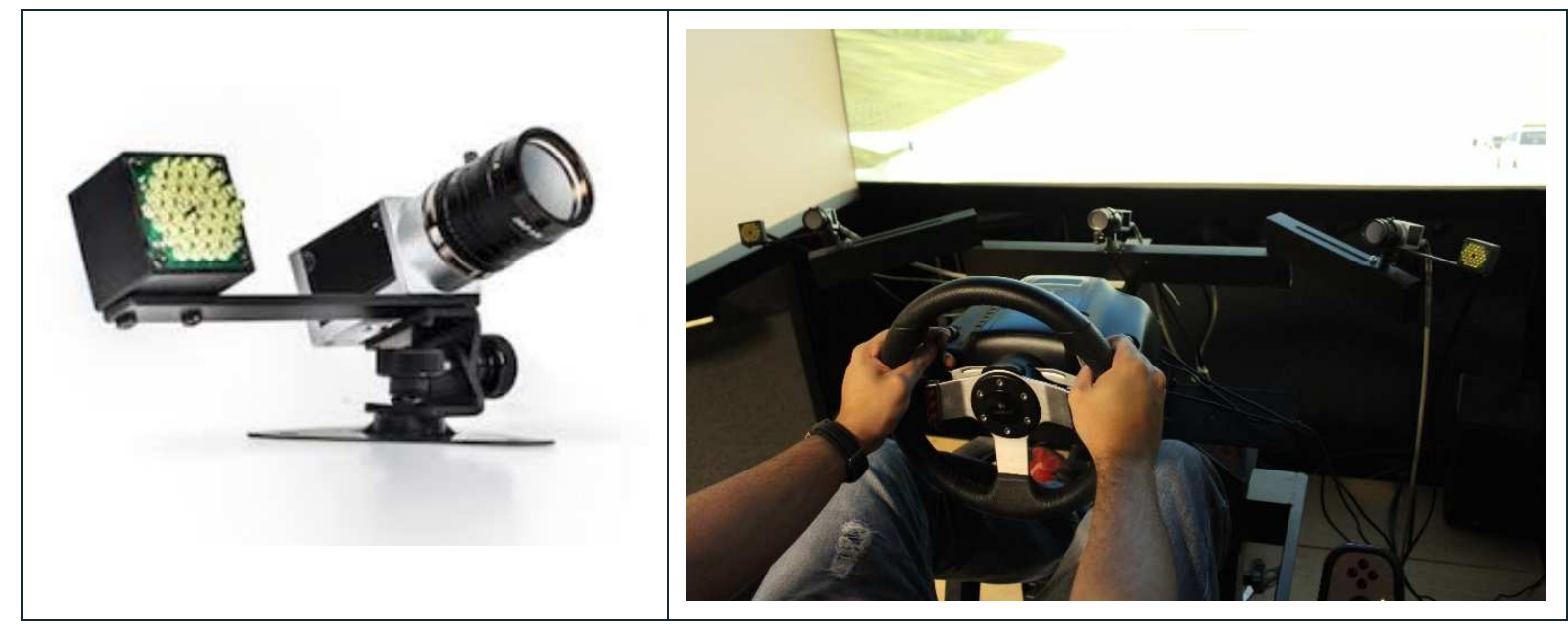

Fonte: a autora

Os dados obtidos com o SmartEye podem ser analisados com o programa MAPPS permitindo ao pesquisador definir regiões de interesse no cenário simulado e calcular o tempo de fixação nas regiões delimitadas. 


\subsection{QueStionáRIOS DE AVALIAÇão}

Nesta pesquisa foram utilizados dois questionários de avaliação pós-experimento no simulador. O primeiro propõe-se avaliar a simulação e o equipamento (Apêndice D) e o segundo pretende mensurar os possíveis sintomas de desconforto decorrentes do tempo de exposição na simulação (Apêndice E).

O realismo de um simulador normalmente é verificado através de questionários que são submetidos aos usuários para expressarem suas impressões e opiniões da condução no simulador. Os pesquisadores utilizam diferente tipos de questionários com diferentes escalas de medição (BLANA, 1996).

Witmer e Singer (1998) desenvolveram um Questionário de Presença (QP) objetivando mensurar o nível de presença em ambiente virtual. O senso de presença é definido como a experiência subjetiva de estar em um ambiente ou lugar mesmo estando em outro fisicamente. Para mensurar o sentimento subjetivo de presença são utilizadas escalas de auto relato através de questionários. Witmer e Singer (1998) elaboraram um questionário com 32 itens, com escala Likert de 7 pontos. A validação do questionário original baseou-se em experimentos em ambientes virtuais imersivos e realidade virtual.

No experimento conduzindo nesta pesquisa, o condutor interage com o simulador de direção de forma similar a uma situação de condução real, não havendo necessidade de respostas ao toque, como em realidade virtual. Sendo assim, o questionário de avaliação da simulação (Apêndice D) foi reestruturado com 21 (vinte e uma) questões do questionário original, de Witmer e Singer (1998), que foram adaptadas para uma interpretação relacionada ao simulador de direção e cenário virtual de rodovia. Além disso, o layout foi reformulado e a escalado tipo Likert adotada compreendeu 6 pontos, que variam numa escala de 0 a 5.

Ao questionário de avaliação da simulação foi incorporado a questão 22 , que solicita ao voluntário que "enumere os fatores, em ordem crescente de motivação (de 1 a 3) que o (a) influencia a realizar uma manobra de ultrapassagem: ( ) Velocidade do veículo lento à frente; ( ) Distância permitida de ultrapassagem; ( ) Tipo de veículo à frente (caminhão ou carro de passeio)". O objetivo foi verificar se os fatores auto relatados pelos voluntários condizem com os resultados obtidos no simulador de direção.

Para avaliação do desconforto foi utilizado o Simulator Sickness Questionnaire (SSQ) elaborado por Kennedy et al. (1993) que é amplamente utilizado em pesquisas para descrever e avaliar desconforto em simuladores (motion sickness). 
Na síndrome de motion sickness ou simulator sickness os usuários recebem sinais visuais que podem induzir a uma ilusão de movimento do corpo, enquanto seus corpos estão fisicamente parados. Isso provocaria desacordo entre os estímulos visuais, vestibulares e proprioceptivos, culminando nos sintomas (LO; SO, 2001). Esses desacordos podem ser consequência de uma gama de fatores como renderização distorcida e pobre, tremulação da imagem, campo de visão reduzido e quantidade de movimentos da cabeça.

O questionário SSQ solicita aos participantes que classifiquem 16 sintomas de desconforto em uma escala de intervalo de 1 a 4 (Apêndice D). Ao final o questionário fornece uma pontuação total de severidade, bem como pontuações de subescalas que medem náusea, desorientação e desconforto ocular.

\subsection{PARTICIPANTES}

A seleção dos participantes foi realizada por amostragem de conveniência da população acessível, dada as dificuldades de logísticas e custos. E para dar legitimidade e isenção na seleção da amostra, optou-se pelo recrutamento e cadastro dos participantes de forma voluntária, através de formulário on-line (Apêndice B). Além disso, a participação voluntária também garante um maior comprometimento do participante no experimento, visto que não houve um convite direto ao mesmo.

A divulgação se deu por meio de redes sociais e aplicativo de mensagens em grupos de acadêmicos de diversas áreas das universidades locais e comunidade em geral da cidade de São Carlos. A exigência para participação no experimento era ter mais de 20 anos e possuir carteira de habilitação.

No formulário de cadastro foram solicitadas informações pessoais (gênero, data de nascimento, profissão e escolaridade); dados relativos ao motorista (ano e categoria da carteira de habilitação, estimativa de quilometrada percorrida e a frequência de condução em vias urbanas, pista simples e pista dupla), e por fim, que informasse a disponibilidade de horário e dia da semana para participação de forma voluntária no experimento e email ou telefone para contato posterior.

Posteriormente, foi realizada uma agenda para marcação das participações dos testes no simulador de direção de acordo com dia e horário de disponibilidade dos voluntários. Para facilitar o acesso dos voluntários, solicitou-se à prefeitura do campus uma vaga temporária de estacionamento localizada às proximidades do local do teste. 
O presente estudo segue as normas da Resolução 466/96 do Conselho Nacional de Saúde (CNS) tendo sido aprovado no dia 31/05/2017, sob o CAAE n 65267917.7.0000.5504 e Parecer nำ 2.094.027 pelo Comitê de Ética em Pesquisa (CEP) da Universidade Federal de São Carlos-SP (Anexo A).

\subsection{Procedimento experimental}

Os testes pilotos com os discentes do Departamento de Engenharia de Transportes (STT/EESC-USP) permitiram estimar o tempo total de cada coleta em aproximadamente 30 minutos e definir as fases que comporiam a coleta de dados: preparação, experimento e avaliação.

A fase de preparação iniciou com a verificação e preparação do simulador de direção para evitar possíveis atrasos ou a necessidade de cancelamento da coleta devido a mau funcionamento. Sendo assim, todos os softwares e hardwares eram conectados e conferidos com antecedência.

$\mathrm{Na}$ chegada, o participante recebia o Termo de Consentimento Livre e Esclarecido (TCLE) (Apêndice B) para autorização dos dados na pesquisa. Em seguida, era questionado se fez a leitura do TCLE quando realizou o cadastro on-line e, caso negativo, poderia fazer a leitura e assiná-lo em seguida, antes da participação.

O próximo passo foi o ajuste do cockpit em relação às características do participante, regulando-se o banco e distância aos pedais, para que a condução no simulador se desse de forma confortável. Por se tratar de um simulador de carro automático, o participante era instruído a respeito do câmbio de marcha e pedais.

Em pesquisas com uso de simuladores de direção recomenda-se que os participantes passem por um período de reconhecimento e adaptação ao equipamento. A aprendizagem é um processo de tentativa e erro em que os motoristas testam suas estratégias e habilidades. Portanto, o cenário de treinamento deve oferecer oportunidades para testar as suas habilidades de condução (julgamento de distância, pedais e controle de direção). A condução em uma estrada em linha reta a uma velocidade constante, não irá fornecer oportunidade suficiente para os condutores conhecerem a resposta dos pedais e volante (SAHAMI; SAYED, 2013).

Dessa forma, elaborou-se um trecho de treinamento específico e independente do trecho do experimento, mas com características semelhantes e extensão em torno de $6 \mathrm{~km}$ de pista 
simples bidirecional, a sinalização vertical compôs-se de placas de "proibido ultrapassar" (R7) e "regulamentação de velocidade" (R-19), a sinalização horizontal com zonas de ultrapassagem permitida e não permitida, fluxo de tráfego nos dois sentidos e entorno idêntico ao cenário do experimento.

O tempo de percurso no trecho de treinamento foi de 5 minutos, em média. Esse tempo é suficiente para adaptação do participante ao equipamento, contudo, caso este informe que necessita de mais tempo de aprendizagem, o participante poderia refazer o trecho de treinamento, limitando-se a 3 rodadas, perfazendo um total máximo de 15 min. Durante o treinamento solicitou-se ao participante que utilizasse o acelerador e freio, sem restrição, para que pudesse se familiarizar com a sensibilidade do equipamento.

Ao concluir o treinamento, questionou o participante se o mesmo estava sentindo algum tipo de desconforto, como dor de cabeça ou náusea, devido ao uso do simulador de direção. Caso o participante se sentisse indisposto o experimento seria encerrado nesse momento e o participante acompanhado até sua residência, caso o participante informasse que estava em condições normais, encaminhava-se para a próxima etapa do experimento.

A fase do experimento iniciava com a regulagem do $S m a r t E y e \circledR$ que faz a captação do rastreio do olhar do participante durante a simulação. As câmeras frontais eram ajustadas para englobar o rosto do participante e feita a calibração da direção do olhar na tela de projeção, assim como o ajuste da câmera atrás do cockpit, responsável por captar as imagens exibidas durante o experimento. Posteriormente, eram repassadas ao participante as instruções do experimento, informando que "o trecho a ser conduzido seria similar ao trecho de treinamento, uma rodovia de pista simples, com velocidade regulamentada de $80 \mathrm{~km} / \mathrm{h}$ e extensão de aproximadamente $13 \mathrm{~km}$ com um tempo aproximado de 10 min de duração". Também foi informado que haveria fluxo de veículos nos dois sentidos da via e que o mesmo deveria conduzir normalmente, como o faria no mundo real, estando nas mesmas condições. Ainda foi solicitado ao participante que não interagisse com a pesquisadora durante o experimento para evitar qualquer tipo de distração e que qualquer dúvida poderia ser esclarecida ao final do experimento. Contudo, caso houvesse alguma perda de sinal do equipamento de rastreio do olhar, seria solicitado ao participante que movimentasse a cabeça para restabelecer o sinal.

$\mathrm{Na}$ etapa que se refere à condução no cenário virtual do experimento, o participante é informado pelo pesquisador que pode iniciar a condução. Durante a condução do participante na simulação, todos os softwares eram monitorados pela pesquisadora, inclusive o rastreio do olhar do participante. Quando da falha do rastreio devido a algum tipo de interferência como, tirou a mão do volante e cobriu os infravermelhos posicionados à frente, ou ainda, 
quando o desvio lateral da cabeça excedia o limite e ocorria a perda de sinal, a pesquisadora solicitava ao participante que movimentasse a cabeça para que o equipamento se readequasse. Todas as interferências ou perdas de sinal do SmartEye foram registradas em uma planilha de controle para o caso de consulta posterior. Ao final os dados do rastreio do olhar e da simulação eram armazenados em arquivos separados.

A fase de avaliação corresponde ao feedback por parte dos participantes em relação à simulação e desconforto. Com esse intuito, após a conclusão do experimento solicitou-se ao participante que preenchesse dois questionários: (1) um para avaliar o realismo do cenário e suas impressões sobre a condução no simulador (Apêndice D) e um (2) questionário sobre sintomas de desconforto (motion sickness) que o participante sentiu decorrentes do uso do simulador de direção (Apêndice E) após o experimento. Ao término de todas as etapas, alguns participantes esclareciam suas dúvidas sobre os objetivos da pesquisa.

A Figura 18 apresenta um fluxograma resumido das etapas do procedimento experimental. Vale ressaltar que o experimento poderia ser interrompido a qualquer momento, por solicitação do participante.

Figura 18 - Fluxograma das fases do experimento no simulador

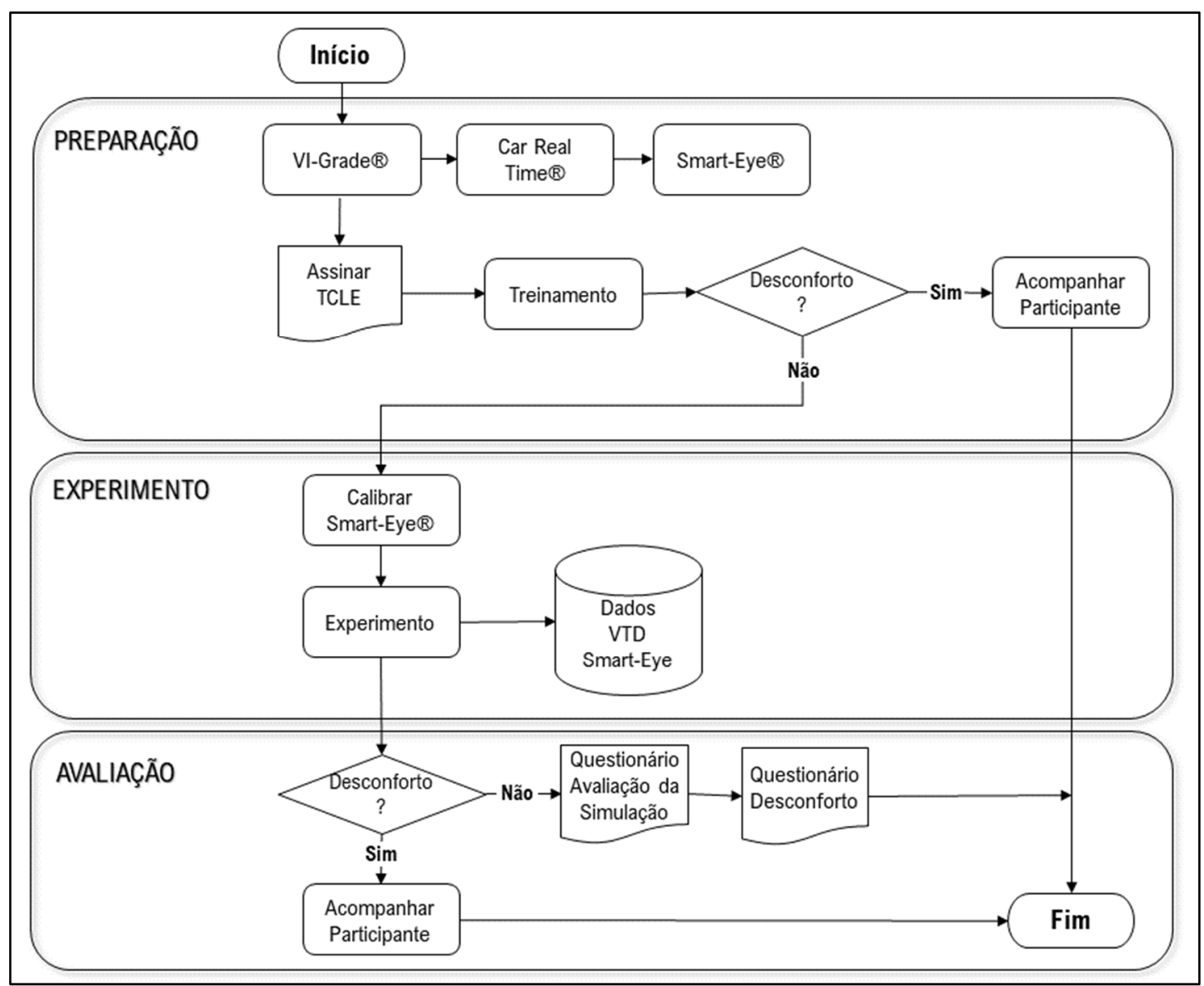

Fonte: a autora. 


\subsection{ALGORITMO PARA EXTRAÇÃO DOS DADOS}

Os dados coletados foram armazenados em arquivos individuais. As informações da condução no simulador em formato CSV e as informações do rastreio do olhar em um arquivo de vídeo no formato AVI e em formato TXT. A taxa de coleta das informações da simulação são de $60 \mathrm{~Hz}$, resultando em um arquivo de aproximadamente $400 \mathrm{Mb}$ para cada participante e com variáveis armazenados para cada veículo presente na simulação.

A demanda de processamento computacional para os cálculos em planilha eletrônica tornouse inviável devido ao tamanho do arquivo de cada participante. Portanto, a manipulação dos dados foi feita através do software $R$, que é uma linguagem e ambiente para computação estatística.

O R está disponível como Software Livre nos termos da Licença Pública Geral GNU da Free Software Foundation em código fonte, disponível em https://www.r-project.org/. E pode ser estendido através de pacotes (packages) que estão disponíveis por meio de sites da rede CRAN cobrindo uma ampla gama de estatísticas modernas (modelagem linear e não-linear, testes estatísticos clássicos, análise de séries temporais, classificação, agrupamento e etc.) e diversas ferramentas de auxílio.

Os modelos de distância de visibilidade mínima de ultrapassagem incorporam fases que abrangem desde a decisão de iniciar a ultrapassagem até a conclusão, quando o veículo retorna em segurança para a faixa de origem.

A seguir são apresentados os critérios utilizados nesta pesquisa para definir cada uma das fases, a classificação dos tipos de ultrapassagem, a classificação dos tipos de tentativas e as variáveis principais e secundárias que foram incluídas e obtidas no algoritmo.

\subsubsection{Fases da manobra de ultrapassagem}

A manobra de ultrapassagem pode ser dividida em quatro fases: (1) início da ultrapassagem; (2) ultrapassagem do veículo lento; (3) conclusão da ultrapassagem e (4) percurso do veículo oposto. Os detalhes de cada fase são descritos a seguir.

\section{- Fase 1 - Início da Ultrapassagem (percepção e reação)}

A determinação do ponto inicial da ultrapassagem é a que apresenta maior complexidade, pois depende do comportamento do condutor e engloba o tempo de percepção e reação. Esta fase abrange o momento em que o condutor toma a decisão de iniciar a ultrapassagem do 
veículo lento, percorrendo uma trajetória até que o pneu dianteiro esquerdo esteja posicionado sobre o eixo da via. Gray e Regan (2005) determinaram o ponto inicial de ultrapassagem quando a mudança da posição lateral em direção ao eixo da via fosse 3 vezes maior que o desvio padrão de $300 \mathrm{~m}$ em trecho reto ( $\left.\mathrm{pl}>\left[3^{*} \mathrm{Sd}_{300 \mathrm{~m}}\right]\right)$.

Nesta pesquisa, para determinação do ponto de tomada de decisão foi utilizado como parâmetro indicativo o afastamento lateral do veículo do participante em relação ao eixo da via (DistE), considerando que ao se aproximar do eixo da via o condutor indica o desejo de ultrapassar, quando na presença de um veículo lento que impeça o fluxo do tráfego.

Contudo, devido a pluralidade comportamental dos condutores deve se levar em consideração que a percepção e reação são características individuais relacionadas ao perfil do condutor e, portanto, é importante estabelecer algumas condutas que possam ser confundidas com um desejo de ultrapassar, mas trata-se de um comportamento usual ou decorrente de manobra anterior, como por exemplo:

a) Um condutor que dirige posicionando-se próximo ao eixo da rodovia. Nesse caso, o afastamento lateral (DistE) é pequeno e deve ser distinto de um início de ultrapassagem, portanto deve-se avaliar a moda do afastamento lateral no trecho que antecede a ultrapassagem.

b) Uma tentativa de ultrapassagem seguida de abortagem. Nesta situação o condutor após a abortagem se posiciona atrás do veículo lento e conduz próximo ao eixo via, com o intuito de melhorar a visibilidade e aguardar que o veículo oposto desocupe a faixa oposta.

c) Conclusão de ultrapassagem no final da tangente. Na urgência de concluir a ultrapassagem antes da curva seguinte, o condutor tende a girar o volante rapidamente para se posicionar na faixa a direita, este movimento gera ruído no afastamento lateral causado pela instabilidade do volante.

Sendo assim, partindo do pressuposto que o condutor cruzou o eixo da via para realizar a ultrapassagem (DistE tende a zero), identificou-se o ponto em que o veículo do participante está com o pneu dianteiro esquerdo posicionado sobre o eixo da via (indP). A partir deste ponto foram analisados 150 metros que antecedem (indl) o cruzamento do eixo até o indP. Para identificação do início da ultrapassagem foram utilizados dois métodos: (1) moda e desvio padrão e (2) pontos de inflexão (função INFLEXI). 
1) Para o cálculo da moda e desvio padrão:

a) Calculou-se a moda (m) e o desvio padrão (SD) da distância ao eixo (DistE) entre indl e indP para caracterizar o comportamento do condutor a variabilidade do condutor em relação ao seu posicionamento na faixa, indicando também o nível de controle do simulador.

b) O início de ultrapassagem é identificado quando satisfaz a condição em que a distância ao eixo (DistE) menos a moda é maior que o desvio padrão ([DistE $-\mathrm{m}]>\mathrm{SD}($ DistE)]). Esse ponto indica a posição em que o condutor modifica seu comportamento tendendo a reduzir a distância ao eixo, indicando o desejo de ultrapassar.

2) Para os pontos de inflexão (função INFLEXI):

a) A função INFLEXI (CHRISTOPOULOS, 2017) identifica os pontos de inflexão de um conjunto de dados discretos simples e com ruído através do processo de regressão de Taylor. Dentre os parâmetros para identificação dos pontos é necessário indicar o grau da função. Foram utilizados o grau 5 e o grau 6 para o polinômio de Taylor, retornando um ponto de inflexão entre o indl e IndP, para cada grau atribuído.

Assim, foram encontradas três posições com potencial associação ao ponto de início da ultrapassagem. Em seguida, calculou-se o tempo para cada uma das três posições até o ponto indP. E como critério de seleção foi escolhido o tempo mais próximo de 2 segundos, que corresponde ao tempo de reação e percepção utilizado em modelos de ultrapassagem e citado em literatura.

O final desta fase é estabelecido pela posição em que o veículo rápido está com o pneu dianteiro esquerdo posicionado sobre o eixo da via, para em seguida iniciar a invasão da faixa da esquerda.

\section{- Fase 2 - Ultrapassagem do veículo lento}

Nesta fase o veículo rápido inicia a invasão da faixa da esquerda para a ultrapassagem do veículo lento. Na fase 2 é determinada a posição em que os veículos estão emparelhados (lado a lado) e a partir desse ponto, são derivados os cálculos de outras posições em função dos tipos de veículo lento a ultrapassar. E outras condições necessárias para aplicação de outros modelos de ultrapassagem. 


\section{- Fase 3 - Conclusão da ultrapassagem}

Nesta fase o veículo rápido retorna à faixa da direita. A ultrapassagem foi considerada concluída quando o veículo rápido se encontra com a roda traseira esquerda sobre o eixo da via, ocupando a faixa da direita, ou seja, encontra-se em posição segura de não colisão quando na presença do veículo oposto. Contudo, na urgência de concluir a ultrapassagem, o participante tende a girar o volante e gerar instabilidade do controle do veículo e confundir os critérios determinados como conclusão. Essa situação deve ser levada em consideração.

\section{- Fase 4 - Percurso do veículo oposto}

Está fase corresponde ao percurso do veículo oposto durante a execução da manobra de ultrapassagem pelo veículo do participante. Os modelos citados diferem sobre o momento de início, por exemplo, o modelo da AASHTO começa a contabilizar a partir do momento em que veículo rápido e o veículo lento estão emparelhados, lado a lado. Enquanto que, o modelo de Wang e Cartmell contabiliza a distância desde o início da ultrapassagem quando o veículo rápido está posicionado atrás do veículo lento.

\subsubsection{Classificação das ultrapassagens}

Nesta pesquisa as manobras de ultrapassagem foram classificadas de acordo com a presença ou ausência do veículo oposto durante a execução da manobra ou quando não ocorre a ultrapassagem, resultando na seguinte classificação:

Não ultrapassagem (U0): o veículo do participante não ultrapassa o veículo lento no segmento e segue no trecho até o próximo segmento.

Ultrapassagem simples (U1): o veículo do participante segue o veículo lento até que o veículo oposto desocupe a faixa contrária e inicia a ultrapassagem do veículo lento.

Ultrapassagem completa (U2): o veículo do participante inicia a manobra de ultrapassagem do veículo lento, com a presença do veículo oposto no fluxo contrário. 


\subsubsection{Classificação das tentativas de ultrapassagem}

A tentativa de ultrapassagem consiste na ocupação da faixa da esquerda pelo veículo rápido, por um breve momento seguida de abortagem e retornou à posição atrás do veículo lento. Este movimento de ocupação da faixa esquerda não é considerado quando ocorreram nas curvas que antecedem a tangente. As manobras de ultrapassagens podem ou não ser precedidas por uma tentativa de ultrapassagem seguida de abortagem.

A classificação das tentativas foi feita em função da ocupação ou não da faixa da esquerda quando na presença do veículo oposto no fluxo contrário, que implicaria num risco de colisão. Assim, foram definidos três tipos de tentativas sendo:

Não houve Tentativa (A0): o veículo do participante não tentou ultrapassar o veículo lento no segmento.

Tentativa de Ultrapassagem sem Risco (A1): o veículo do participante se aproximou do eixo da via, posicionou a roda dianteira esquerda sobre a pintura central, em seguida reduziu a velocidade, acionando o freio ou retirando o pé do acelerador, e retornou à faixa da direita atrás do veículo lento.

Tentativa de Ultrapassagem com Risco (A2): o veículo do participante cruzou o eixo da via e ocupou a faixa da esquerda, acionou o freio ou retirou o pé do acelerador e retornou à faixa da direita posicionando-se atrás do veículo lento novamente.

\subsubsection{Variáveis}

Para elaboração do algoritmo foi necessário selecionar as variáveis a serem utilizadas nos cálculos e que possibilitassem as análises estatística da pesquisa. Por se tratar de um experimento com manobras de ultrapassagem, a posição do veículo do participante em relação aos veículos que compõem o tratamento e sua posição em relação ao trecho são essenciais para os cálculos das distâncias de ultrapassagem.

O terno de coordenadas que indica a posição do veículo no trecho durante a simulação é composto pelas variáveis inertial $X$, inertialY e inertialZ. A origem do sistema de coordenadas do veículo está posicionada no nível da via, no centro do eixo traseiro (Figura 19) tendo como referência o sistema de coordenadas do traçado. A variável inertialZ não foi necessária, pois o trecho da simulação não possui elevação. Dentre as variáveis da dinâmica veicular foram utilizadas a velocidade ( PPlayerX) e aceleração $($ aPlayerX) do veículo. A variável Time foi 
utilizada como identificador único para criar o vínculo entre as tabelas dos veículos do experimento.

Figura 19 - Sistema inercial de coordenadas do veículo

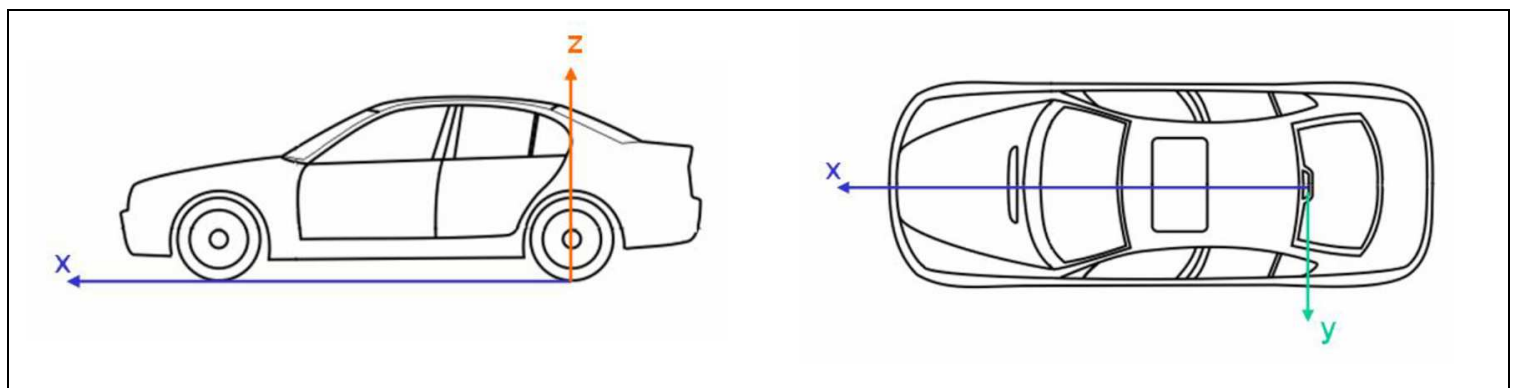

Fonte: Dupuis e Wunibald (2012)

Para os veículos (lento e oposto) presentes em cada tratamento foram utilizadas as variáveis: time, inertialX e inertialY. A Tabela 12 exibe as variáveis selecionadas para o veículo do participante e suas respectivas unidades de medida.

Tabela 12 - Variáveis do veículo rápido (veículo participante) utilizadas no algoritmo

\begin{tabular}{c|l|c|c}
\hline Item & \multicolumn{1}{|c|}{ Descrição } & Unidade & Nome Variável \\
\hline 1 & Tempo & $\mathrm{s}$ & time \\
2 & Posição em relação ao eixo X & $\mathrm{m}$ & inertialX \\
3 & Posição em relação ao eixo Y & $\mathrm{m}$ & inertialY \\
4 & Velocidade & $\mathrm{m} / \mathrm{s}$ & vPlayerX \\
5 & Aceleração & $\mathrm{m} / \mathrm{s}^{2}$ & aPlayerX \\
\hline
\end{tabular}

Fonte: a autora

Para auxiliar na determinação das distâncias das fases de ultrapassagem foram calculadas variáveis secundárias, onde:

S $(m)$ distância acumulada da trajetória do veículo rápido (VR) ao longo do trecho

DistE (m) afastamento lateral entre o veículo do rápido (VR) e o eixo da via

dVL $(m)$ distância entre o veículo rápido (VR) e o veículo lento $(V L)$ em cada segmento

dVO (m) distância entre o veículo rápido (VR) e o veículo oposto (VO) em cada segmento

As variáveis calculadas durante a manobra de ultrapassagem e suas respectivas unidades são descritas a seguir na Tabela 13. 
Tabela 13 - Variáveis calculadas.

\begin{tabular}{|c|c|c|c|}
\hline Fase & Variável & Unidade & Descrição \\
\hline \multirow{11}{*}{ 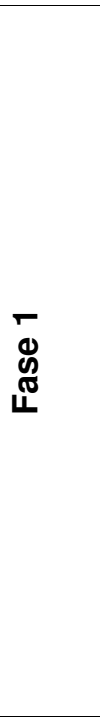 } & S1 & (m) & a posição do VR no início da percepção e reação \\
\hline & T1 & (seg) & o tempo referente a distância total percorrida \\
\hline & D1 & $(\mathrm{m})$ & a distância total entre o início da ultrapassagem e o final da fase 1 \\
\hline & Vin & $(\mathrm{km} / \mathrm{h})$ & a velocidade instantânea na posição S1 \\
\hline & VmdD1 & $(\mathrm{km} / \mathrm{h})$ & a velocidade média referente a distância total percorrida na fase 1 \\
\hline & VmaxD1 & $(\mathrm{km} / \mathrm{h})$ & a velocidade máxima referente a distância total percorrida na fase 1 \\
\hline & aCmdD1 & $(\mathrm{m} / \mathrm{s} 2)$ & a aceleração média referente a distância total percorrida na fase 1 \\
\hline & aCmaxD1 & $(\mathrm{m} / \mathrm{s} 2)$ & a aceleração máxima referente a distância total percorrida na fase 1 \\
\hline & dVL.D1 & (m) & a distância entre o VR e o VL na posição S1 \\
\hline & dVO.D1 & (m) & a distância entre o VR e o VO na posição S1 \\
\hline & Zul & & $\begin{array}{l}\text { Identifica se a ultrapassagem iniciou em uma zona de ultrapassagem } \\
\text { permitida (ZP) ou não (ZNP), ou ainda, caso não ocorra a } \\
\text { ultrapassagem (NU) }\end{array}$ \\
\hline \multirow{16}{*}{ 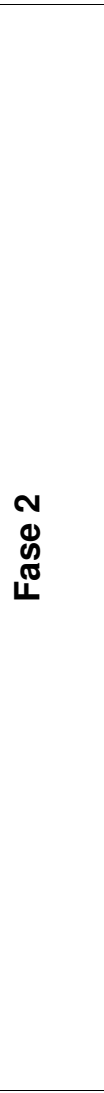 } & S2 & $(\mathrm{m})$ & a posição do VR no início da aproximação ao eixo da via \\
\hline & T2 & (seg) & o tempo total referente a distância total percorrida \\
\hline & D2 & (m) & a distância total entre o início da ultrapassagem e o final da fase 1 \\
\hline & VmdD2 & $(\mathrm{km} / \mathrm{h})$ & a velocidade média referente a distância total percorrida na fase 2 \\
\hline & VmaxD2 & $(\mathrm{km} / \mathrm{h})$ & a velocidade máxima na fase 2 \\
\hline & $\mathrm{aCmdD2}$ & $(\mathrm{m} / \mathrm{s} 2)$ & a aceleração média referente a distância total percorrida na fase 2 \\
\hline & aCmaxD2 & $(\mathrm{m} / \mathrm{s} 2)$ & a aceleração máxima referente a distância total percorrida na fase 2 \\
\hline & dVL.D2 & (m) & a distância entre o VR e o veículo lento na posição S \\
\hline & dVO.D2 & (m) & a distância entre o VR e o veículo oposto na posição $S$ \\
\hline & T2_1 & (seg) & o tempo referente a $1 / 3$ de $\mathrm{D} 2$ \\
\hline & D2_1 & $(\mathrm{m})$ & a distância referente a $1 / 3$ de D2 \\
\hline & VmaD2_1 & $(\mathrm{km} / \mathrm{h})$ & a velocidade média referente a $1 / 3$ de D2 \\
\hline & T2_2 & (seg) & o tempo referente a $2 / 3$ de $\mathrm{D} 2$ \\
\hline & D2_2 & (m) & a distância referente a 2/3 de D2 \\
\hline & VmdD2_2 & $(\mathrm{km} / \mathrm{h})$ & a velocidade média referente a 2/3 de D2 \\
\hline & $\begin{array}{c}\text { DistEVL } \\
\text { ZuF }\end{array}$ & $(\mathrm{m})$ & $\begin{array}{l}\text { afastamento lateral entre o VR e VL quando estão lado a lado na } \\
\text { ultrapassagem } \\
\text { Identifica se a ultrapassagem terminou em uma zona de } \\
\text { ultrapassagem permitida (ZP) ou não (ZNP), ou ainda, caso não } \\
\text { ocorra a ultrapassagem (NU) }\end{array}$ \\
\hline \multirow{2}{*}{ 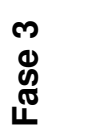 } & D3 & $(\mathrm{m})$ & a distância de folga entre o VR e VO ao final da ultrapassagem \\
\hline & T3 & $(\mathrm{seg})$ & o headway entre o VR e o VO ao final da ultrapassagem \\
\hline \multirow{2}{*}{ 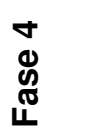 } & D4 & $(\mathrm{m})$ & a distância percorrida pelo VO durante a ultrapassagem \\
\hline & T4 & (seg) & o tempo utilizado pelo VO durante a ultrapassagem \\
\hline
\end{tabular}

Fonte: a autora 


\subsubsection{Processamento}

O algoritmo considerou duas possibilidades iniciais: (1) o participante ultrapassa no segmento ou (2) o participante não ultrapassa no segmento. A partir dessas condições o algoritmo foi sendo aperfeiçoado à medida que comportamentos particulares dos participantes eram identificados, que resultou nas classificações dos tipos de ultrapassagens e tipos de abortagens, citados anteriormente. Assim como, a identificação de padrões, como o posicionamento lateral na faixa durante a condução, que poderiam confundir-se com o desejo de ultrapassar.

Para auxiliar na verificação e análise do comportamento dos condutores foram utilizados os vídeos gravados pela câmera posicionada atrás do participante, sendo possível o esclarecimento de dúvidas nos resultados durante a elaboração do algoritmo. Outra forma de verificação utilizada foi a validação dos resultados através da exportação das coordenadas dos pontos coletados na simulação para ambiente CAD sobre o traçado da via, onde foi possível a confirmação das distâncias resultantes do algoritmo. A validação foi realizada com os dados de alguns participantes.

O algoritmo deve estar apto a extrair as informações de todos os arquivos dos participantes em lote, gerando uma saída em arquivo TXT para análise dos resultados. O fluxo de análise simplificado é descrito a seguir:

1) A trajetória do veículo do participante (inertialX/inertialY) foi sobreposta ao alinhamento do eixo do trecho para identificação dos pontos de cruzamento do eixo, ou seja, o ponto em que o veículo do participante cruzou o eixo da via e ocupou a faixa da esquerda e o ponto em que o participante cruzou o eixo da via e retornou à faixa da direita. Os cruzamentos resultantes foram classificados em abortagem ou ultrapassagem;

2) Caso o participante não faça uma tentativa de ultrapassagem do veículo lento no segmento, esta é classificada como uma não-tentativa (A0) e, por conseguinte uma não ultrapassagem (U0);

3) Caso o participante se aproxime do eixo, indicando o desejo de ultrapassar o veículo lento, é iniciada a Fase 1. Se o participante continua a manobra de ultrapassagem do veículo lento e segue para as Fases 2 e 3, esta é classificada como ultrapassagem completa (U2) e as distâncias da manobra de ultrapassagem são computadas. Também é calculada a Fase 4, que corresponde a distância percorrida pelo veículo oposto durante a ultrapassagem; 
4) Se o participante abortou a ultrapassagem após a Fase 1, esta tentativa pode ser classificada como:

a) Uma tentativa de ultrapassagem sem risco (A1), pois o veículo do participante não ocupou a faixa da esquerda

b) Uma tentativa de ultrapassagem com risco (A2), em que o veículo do participante ocupou a faixa da esquerda por um breve momento.

5) Após a abortagem anterior existe a possibilidade de o participante realizar uma nova tentativa de ultrapassagem. Caso o participante decida não ultrapassar o veículo lento, está é classificada como não ultrapassagem (U0) e, por conseguinte, precedida por uma não-tentativa $(\mathrm{A} 0)$;

6) Se o participante optou por iniciar a ultrapassagem do veículo lento dá-se início novamente à Fase1. Para chegar nesta etapa o participante realizou pelo menos uma tentativa que foi abortada, sendo assim, deduz-se que o participante percorreu grande parte do segmento e, portanto, o veículo oposto o ultrapassou na faixa contrária. Caso não seja realizada outra abortagem, o participante concluirá a ultrapassagem do veículo lento completando as Fase 2 e 3, e a ultrapassagem é classificada com ultrapassagem simples (U1);

7) No caso de uma segunda abortagem, a tentativa será classificada novamente em função de ocupação ou não da faixa da esquerda, como tentativa sem risco (A1) ou tentativa com risco (A2);

8) E por último, após a segunda abortagem do participante, devido à proximidade do fim do segmento, provavelmente, o participante não terá espaço suficiente para realizar uma nova tentativa de ultrapassagem e, portanto, a ultrapassagem será classificada como não ultrapassagem (U0). Ainda assim o algoritmo comporta uma nova tentativa de ultrapassagem.

O fluxograma da Figura 20 ilustra as etapas do algoritmo e classificação do tipo de ultrapassagem e abortagem para cada tratamento em cada segmento da simulação. 
Figura 20 - Fluxograma do algoritmo.

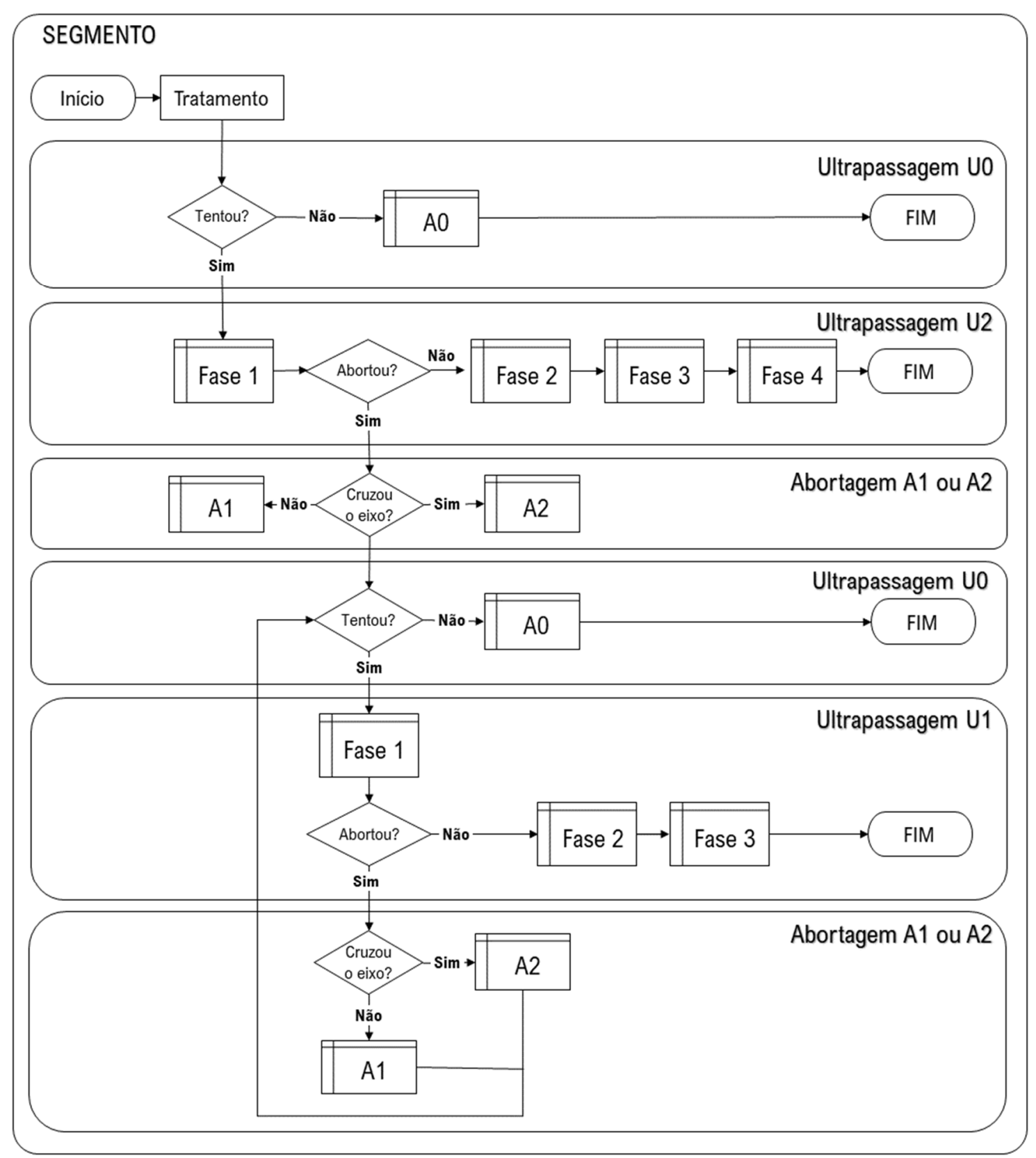

Fonte: a autora.

\subsection{MÉtodos de ANÁLISE ESTATística}

Os métodos estatísticos aplicados nesta pesquisa foram empregados de acordo com a variável resposta a ser analisada. Sendo assim, inicialmente procedeu-se uma análise exploratória dos dados coletados para entendimento e avaliação dos pressupostos exigidos para cada técnica, para em seguida determinar e proceder os testes estatísticos adequados. 
Por se tratar de um delineamento experimental com medidas repetidas, não existe variação entre grupos devido a diferenças individuas, pois, cada participante em cada grupo é o mesmo. Esta condição torna o delineamento mais poderoso do que o experimento entre participantes, pois cada participante serve como seu próprio controle.

A análise de variância (ANOVA) é o método recomendado para comparar as médias de três ou mais grupos, comparando a variância sistemática dos dados com a variância nãosistemática e testa a significância de diferença entre as médias amostrais. Esta análise permite investigar os efeitos de duas ou mais variáveis independentes (VI) ou da interação entre elas sobre uma variável dependente (VD), ou seja, analisar todas as possíveis fontes de variação no estudo.

A ANOVA de medidas repetidas foi realizada com os três fatores do delineamento experimental como variáveis independentes: a velocidade do veículo lento (VelVL), tipo de veículo lento (TipoVL) e a distância de ultrapassagem permitida (DistU). A variável dependente utilizada foi a distância entre o veículo do participante e o veículo lento (dVL) no início da manobra de ultrapassagem. E quando não ocorre uma ultrapassagem a distância entre os veículos foi registrada no momento em que o veículo do participante estava posicionado no início da zona de ultrapassagem permitida.

A ANOVA é um modelo paramétrico e, portanto, deve-se verificar se os dados atendem alguns pressupostos. A variável dependente deve possuir normalidade (dados devem apresentar distribuição normal) e homocedasticidade (homogeneidade na variância) e para a ANOVA de medidas repetidas existe uma restrição adicional - a da esfericidade. A esfericidade é avaliada pelo teste de Mauchly e consiste em verificar se uma população normal multivariada apresenta variâncias iguais e correlações nulas. O teste de esfericidade de Mauchly é aplicado quando existem três condições experimentais para o fator. Como neste caso, cada fator apresenta apenas dois níveis, dotou-se os valores corrigidos de Greenhouse-Geisser, que também são utilizados quando a esfericidade é violada.

A classificação de ultrapassagem obtidas no experimento permitiram analisar a razão de chance de um tipo de ultrapassagem ocorrer em função dos tratamentos, controlados no experimento através de regressão logística multinomial.

A regressão logística multinomial $(R L M)$ é um modelo de regressão logística que permite que a variável reposta assuma mais de duas categorias do tipo nominal. Nesta técnica estatística, uma das categorias da variável resposta deve ser adotada como referência, para que seja comparada com as demais e as variáveis independentes podem assumir valores métricos 
(covariáveis) e não métricos (categóricas). Assim é possível investigar o efeito das variáveis independentes sobre a variável resposta.

A estimação dos parâmetros da RLM baseia-se no método da máxima verossimilhança, que busca maximizar a probabilidade que um evento ocorra e a interpretação dos resultados por meio da razão de chance (risk odds ratio - ROR) de cada coeficiente.

$$
Z=\ln \left(\frac{p}{1-p}\right)=\alpha+\beta_{1} X_{1}+\beta_{2} X_{2}+\cdots+\beta_{k} X_{k}
$$

Em que $p$ indica a probabilidade de ocorrência de determinado evento de interesse, $X$ representa o vetor de variáveis explicativa e $\alpha$ e $\beta$ os parâmetros do modelo. $O$ termo $\ln (\mathrm{p} / 1$ p) é chamado de logit e o termo $(\mathrm{p} / 1-\mathrm{p})$ representa a chance (odds) de ocorrência de um evento de interesse.

O ROR é um indicador da mudança nas probabilidades resultantes da mudança de uma unidade no previsor. E quando o ROR é igual 1 indica que o evento tem igual chance de acontecer em ambos os grupos; se o ROR é maior que 1 indica que o evento tem maior chance de ocorrer no grupo de comparação do que no de referência; e se o ROR é menor 1 indica que o evento tem menor chance de ocorrer no grupo de comparação e mais chance de acontecer no grupo de referência.

Dentre os pressupostos para aplicação da regressão logística multinomial a variável dependente deve ser politômica e as variáveis independentes devem ser métricas ou dicotômicas. Como variável dependente foi escolhida o tipo de ultrapassagem (TipoU) com três respostas possíveis (U0, U1 e U2) e as variáveis independentes categóricas dicotômicas com dois níveis para cada fator do experimento (VelVL, TipoVL e DistU) e como co-variável a distância ao veículo lento na ultrapassagem (dVL).

O experimento conduzido em simulador de direção possibilita o acesso às informações individuais dos participantes mediante o cadastro preliminar ou após a participação no experimento, que não seria possível se fosse realizado através de observações de campo. Sendo assim, com as informações registradas no cadastro do participante e as ultrapassagens realizadas durante o experimento procedeu-se a caracterização do perfil do condutor utilizando a técnica de árvore de decisão.

As árvores de decisão $(A D)$ são ferramentas de mineração de dados não-lineares e nãoparamétricos para problemas de classificação e previsão supervisionadas. Uma árvore é um grafo orientado formado por um número finito de nós que partem do nó raiz. Em árvores binárias, cada nó pai está ligado a apenas dois nós filhos, ou seja, o nó esquerdo e o nó 
direito. Um ramo da árvore é uma sub-árvore obtida pela poda da árvore em um determinado nó interno. Por definição, os nós terminais apresentam um baixo grau de impureza em relação ao nó raiz. Na árvore crescente, preditores geram partições candidatos (ou divisões) em cada nó interno da árvore, de modo que um critério adequado precisa ser definido para escolher a melhor partição (ou melhor divisão) dos objetos. Na estrutura em árvore é possível ler as interações entre os preditores condicionais para explicar o comportamento da variável resposta (MONTELLA et al., 2012).

A variável dependente escolhida foi o comportamento do participante (CompCondt) durante o experimento. E para mensurar o comportamento do condutor atribuiu-se uma pontuação ao tratamento, um peso ao tipo de ultrapassagem e um peso ao tipo de abortagem realizadas no trecho de simulação, o somatório resultante foi utilizado para gerar a classificação do comportamento do participante em três níveis de risco: Baixo Risco, Médio Risco e Alto Risco. Os critérios adotados são descritos na análise e discussão dos resultados.

Para averiguar os valores de ultrapassagem obtidos na simulação em relação aos valores de referência normatizados de DVU, foi utilizado o teste $\mathrm{t}$ student para variável resposta que apresentaram normalidade e homocedasticidade. Caso esses pressupostos não possam ser atendidos, optou-se pelo teste não paramétrico de Wilcoxon. A análise será procedida para as variáveis por fase da manobra e tipo de ultrapassagem.

Para as análises dos dados utilizou-se o pacote estatístico IBM SPSS 22.0 (Statistical Package for Social Sciences) e pacotes gráficos do software R. Os resultados estatísticos foram reportados de acordo com o padrão internacional American Psychological Association (APA). Foram utilizadas as seguintes abreviações para os testes estatísticos: média $(M)$, mediana $(M d n)$, desvio padrão $(S D)$, erro padrão $(S E)$, graus de liberdade $(d f)$, análise de variância - ANOVA $(F)$, correlação de Spearman $\left(r_{s}\right)$, teste t de student $(t)$, teste de Wilcoxon $(Z)$, teste de Friedman $\left(X^{2}\right)$.

A Tabela 14 resume as análises estatísticas com os dados coletados em simulador de direção nesta pesquisa. 
Tabela 14 - Resumo das análises estatísticas aplicadas na pesquisa

\begin{tabular}{|c|c|c|c|}
\hline Teste estatístico & Variável dependente & $\begin{array}{c}\text { Variável } \\
\text { independente }\end{array}$ & Objetivo \\
\hline ANOVA & $\begin{array}{l}\text { - Distância entre o } \\
\text { veículo do } \\
\text { participante e o } \\
\text { veículo lento }\end{array}$ & $\begin{array}{l}\text { - Velocidade do } \\
\text { veículo lento } \\
\text { - Tipo de veículo } \\
\text { lento } \\
\text { - Distância de } \\
\text { visibilidade de } \\
\text { ultrapassagem }\end{array}$ & $\begin{array}{l}\text { Avaliar a influência } \\
\text { das variáveis } \\
\text { independentes } \\
\text { (fatores) sobre a } \\
\text { variável } \\
\text { dependente }\end{array}$ \\
\hline $\begin{array}{l}\text { Regressão Logística } \\
\text { Multinomial (RLM) }\end{array}$ & $\begin{array}{l}\text { - Tipos de } \\
\text { ultrapassagens }\end{array}$ & $\begin{array}{l}\text { - Velocidade do } \\
\text { veículo lento } \\
\text { - Tipo de veículo } \\
\text { lento } \\
\text { - Distância de } \\
\text { visibilidade de } \\
\text { ultrapassagem }\end{array}$ & $\begin{array}{l}\text { Avaliar a influência } \\
\text { das variáveis } \\
\text { independentes } \\
\text { (fatores) sobre o } \\
\text { tipo de } \\
\text { ultrapassagem } \\
\text { realizada }\end{array}$ \\
\hline $\begin{array}{l}\text { Árvore de Decisão } \\
\text { (AD) }\end{array}$ & - Nível de risco & $\begin{array}{l}\text { - Gênero } \\
\text { - Faixa etária } \\
\text { - Tempo de } \\
\text { habilitação } \\
\text { - Quilometragem } \\
\text { percorrida } \\
\text { - Frequência de } \\
\text { direção em pista } \\
\text { simples }\end{array}$ & $\begin{array}{l}\text { - Classificar o nível } \\
\text { de risco do } \\
\text { condutor }\end{array}$ \\
\hline Teste $t$-student & $\begin{array}{l}\text { Distância das } \\
\text { ultrapassagens } \\
\text { completas (U2) }\end{array}$ & $\begin{array}{l}\text { Distância de } \\
\text { visibilidade de } \\
\text { ultrapassagem }\end{array}$ & $\begin{array}{l}\text { - Significância entre } \\
\text { as médias das } \\
\text { distâncias }\end{array}$ \\
\hline Teste t-pareado & $\begin{array}{l}\text { Distância de } \\
\text { ultrapassagens } \\
\left(d_{1}+d_{2}+d_{3}+d_{4}\right)\end{array}$ & $\begin{array}{l}\text { Distâncias de } \\
\text { ultrapassagens } \\
\text { calculadas com o } \\
\text { modelo do DNIT }\end{array}$ & $\begin{array}{l}\text { - Significância entre } \\
\text { as médias das } \\
\text { distâncias obtidas } \\
\text { no simulador e } \\
\text { calculadas através } \\
\text { do modelo DNIT }\end{array}$ \\
\hline
\end{tabular}

Fonte: a autora 



\section{ANÁLISE E DISCUSSÃO DOS RESULTADOS}

\subsection{Perfil da Amostra}

Participaram da pesquisa 82 voluntários, em sua maioria acadêmicos de graduação e pósgraduação das universidades da cidade de São Carlos (SP). Da amostra total foram retirados 2 participantes por relatarem nível de desconforto elevado comparado aos demais, sem prejudicar a análise proposta. Os participantes foram alocados nos cenários (C1 a C8) totalizando 10 participantes em cada cenário, perfazendo um total de 80 participantes.

Assim, a amostra final desta pesquisa foi constituída por 55 (68,8\%) homens e 25 (31,3\%) mulheres, com idade entre 20 e 45 anos $(M=26,49$; $S D=5,37)$. O tempo de habilitação da amostra variou entre 1 e 23 anos $(M=6,53$; $S D=5,44)$ alocados por faixa etária e apresentados na Tabela 15.

Tabela 15 - Faixa Etária por gênero e tempo de habilitação

\begin{tabular}{c|c|c|c|c|c|c|c|c|c|c}
\hline \multicolumn{2}{c|}{} & \multicolumn{3}{c|}{ Gênero } & \multicolumn{5}{c|}{ Tempo Habilitação (anos) } & \multirow{2}{*}{ Total } \\
\cline { 3 - 10 } \multicolumn{2}{c}{} & Feminino & Masculino & $<5$ & 5 a 10 & 10 a 15 & 15 a 20 & $>20$ & \\
\hline \multirow{3}{*}{$\begin{array}{c}\text { Faixa } \\
\text { Etária }\end{array}$} & 20 a 25 & 11 & 31 & 36 & 6 & 0 & 0 & 0 & 42 \\
& 26 a 30 & 11 & 12 & 7 & 10 & 6 & 0 & 0 & 23 \\
& 31 a 35 & 1 & 8 & 1 & 2 & 4 & 2 & 0 & 9 \\
& 36 a 45 & 2 & 4 & 1 & 0 & 0 & 2 & 3 & 6 \\
\hline \multicolumn{2}{c}{ Total } & 25 & 55 & 45 & 18 & 10 & 4 & 3 & 80 \\
\hline
\end{tabular}

Os participantes relataram uma estimativa de quilometragem média percorrida por mês de 525,57 km apresentada por faixa etária na Figura 21.

Figura 21 - Quilometragem mensal percorrida por faixa etária

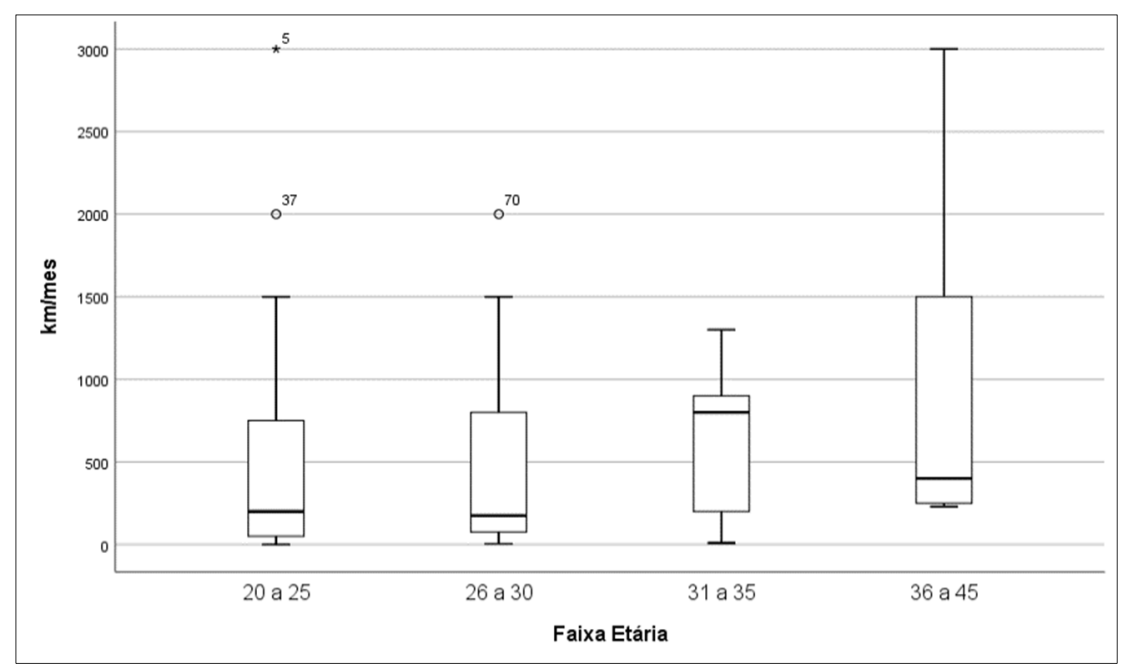


Ainda sobre os hábitos de direção, os participantes foram questionados sobre a frequência de direção em vias urbanas, em rodovias de pista dupla e em pista simples, as respostas foram reportadas em uma escala do tipo Likert de 1 a 5 níveis, sendo 1 = não dirijo até $5=$ dirijo todos os dias. Na Figura 22 é apresentada a frequência percentual da direção em rodovias de pista simples dos participantes, que foi avaliado por se tratar de um experimento que avalia as manobras de ultrapassagem nesse tipo de rodovia.

Figura 22 - Frequência de direção em rodovia de pista simples dos participantes.

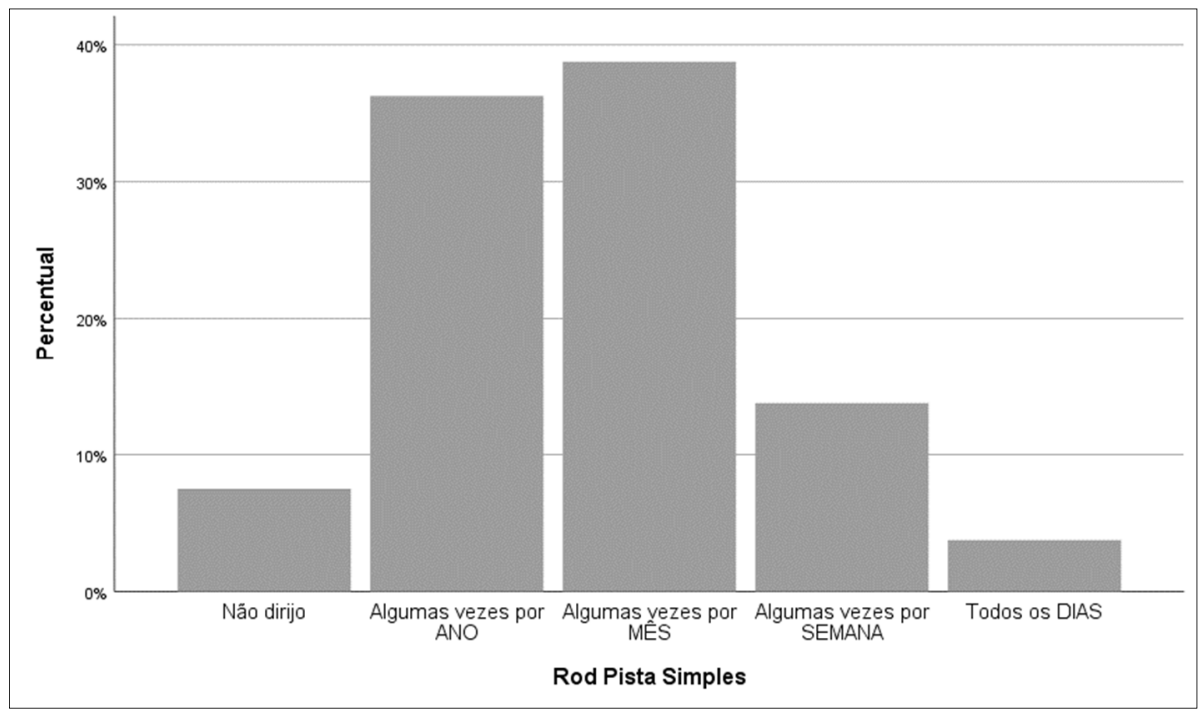

Os participantes informaram ainda o envolvimento em algum tipo de acidente, sendo que 54 $(67,5 \%)$ declararam nunca ter sofrido algum tipo acidente em ambiente viário e 15 (18,8\%) participantes informaram que já haviam se envolvido em acidentes como motoristas (Figura 23). Os demais se envolveram em acidentes como pedestre, ciclista ou como passageiro.

Figura 23 - Envolvimento dos participantes em acidentes.

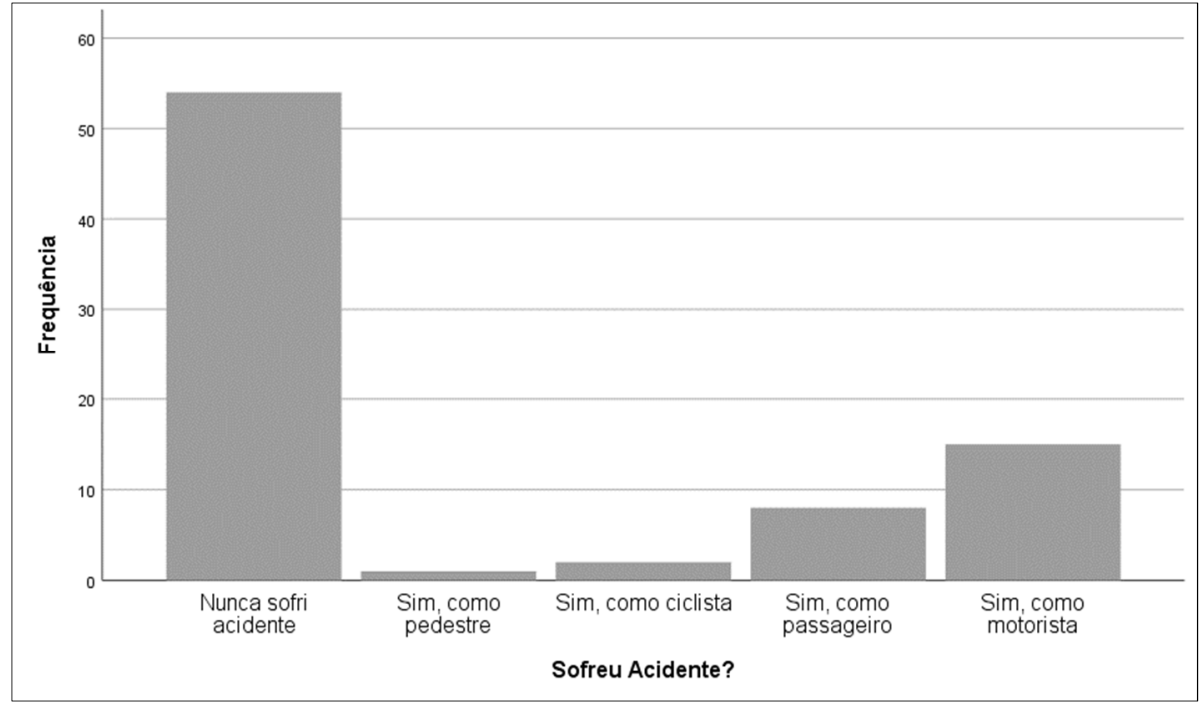


$\mathrm{Na}$ adaptação ao simulador o tempo de treinamento $76,4 \%$ dos homens praticaram por 5 min, que equivale a um ciclo no trecho de treinamento e $64,0 \%$ das mulheres fizeram o treinamento em dois ciclos, totalizando 10 min (Figura 24). Apenas dois voluntários solicitaram um terceiro ciclo de treinamento, totalizando 15 min de adaptação.

Figura 24 - Tempo de treinamento por gênero.

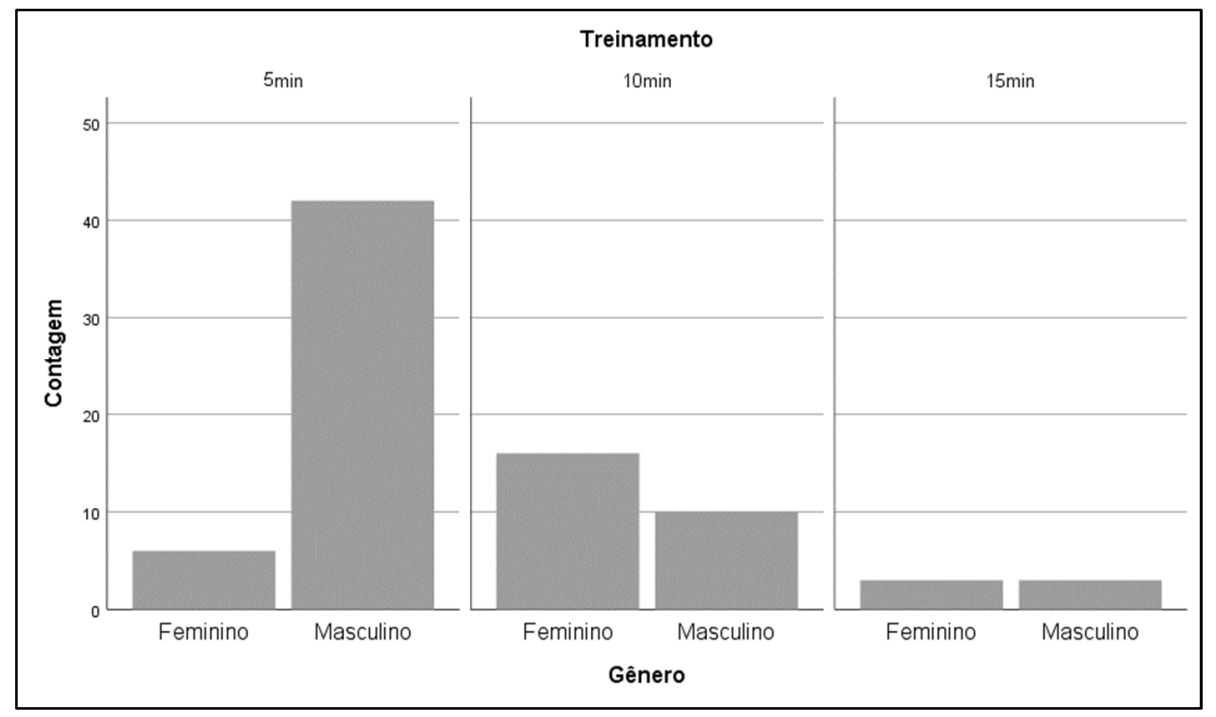

\subsection{AvaliaçÃo da SimulaÇÃo}

A avaliação da simulação tem por objetivo receber um feedback dos participantes sobre o simulador e cenário em relação à imersão, fidelidade e qualidade da interface.

A análise das respostas auto relatadas dos participantes resultou em um artigo com o título "Avaliação de simulador de direção a partir de questionário de presença" (FIGUEIRA; LAROCCA, 2018) publicado e apresentado no $32^{\circ}$ Congresso da Associação Nacional de Pesquisa e Ensino em Transportes (ANPET).

O questionário de avaliação da simulação (Apêndice D), utilizado nesta pesquisa, foi adaptado do questionário de presença (QP) de avaliação de ambientes imersivos elaborado por Witmer e Singer (1998). O questionário original destacou a presença de quatro fatores principais resultantes de uma análise de componentes principais: Envolvimento $(E V)$, com itens avaliando o estado de concentração, a atenção e a carga mental em estímulos, atividades coerentes ou significativamente relacionadas; Adaptação/Imersão (Al), no sentido de estar envolvido, imerso e interagindo com um fluxo contínuo de experiências e estímulos; Fidelidade Sensorial (FS), relacionada às percepções visuais, auditivas do cenário e equipamento virtual; e Qualidade da Interface (QI), avaliando a influência das 
interfaces visuais e de controle na experiência da simulação (WITMER; JEROME; SINGER, 2005).

Partindo do pressuposto dos quatro fatores principais identificados pelos autores, aplicou-se a análise de componentes principais categóricos (CATPCA) - um método não paramétrico que quantifica as variáveis categóricas por meio de um processo chamado de quantificação ideal, referido ainda como escalonamento ótimo ou pontuação ótima (MEULMAN; KOOIJ; HEISER, 2004).

A CATPCA foi realizada com as 21 questões do questionário de presença adaptado com rotação ortogonal (Varimax) e normalização Kaiser. A primeira maximiza a variação entre os pesos de cada componente principal, ou seja, simplifica as colunas do fator de carga matriz e a normalização de Kaiser recomenda a retenção de componentes com autovalores maiores que 1 , baseado na ideia de autovalores representar o montante de variação explicada por um fator e um autovalor de 1 representar um substancial montante de variação (FIELD, 2009).

Análises referentes à confiabilidade e consistência interna do questionário de presença (QP) adaptado foram realizadas pelo alfa de Cronbach, o qual verifica a fidedignidade dos dados em relação à adaptação realizada, ou seja, separa os dados em pares de todas as maneiras possíveis e calcula o coeficiente de correlação para cada dimensão, obtendo-se a média desses dados (FIELD, 2009).

O alfa de Cronbach total da escala, calculado com base nos autovalores, foi de 0,98 indicando forte consistência interna. E para cada um dos quatro fatores foi considerado bom: fator 1 ( $\alpha=$ $0,91)$, fator $2(\alpha=0,78)$, fator $3(\alpha=0,66)$ e fator $4(\alpha=0,62)$. O resultado das cargas fatoriais dos componentes rotacionados da CATPCA são apresentados na Tabela 16. Os itens apresentaram um carregamento acima de 0,3 e alguns apresentaram carga distribuída em mais de um fator. As questões do QP adaptado para o simulador de direção formaram fatores consistentes com o QP original, resultando em uma ferramenta viável para avaliação da simulação. 
Tabela 16 - Matriz de componentes rotacionados obtida pela CATPCA.

\begin{tabular}{|c|c|c|c|c|c|c|}
\hline \multirow{3}{*}{\multicolumn{2}{|c|}{$\begin{array}{c}\text { QP } \\
\text { Original }\end{array}$}} & \multirow{3}{*}{ QP adaptado } & \multicolumn{4}{|c|}{ Componentes } \\
\hline & & & \multirow{2}{*}{\begin{tabular}{c|}
1 \\
$E V$ \\
\end{tabular}} & \multirow{2}{*}{$\begin{array}{c}2 \\
\text { FS }\end{array}$} & \multirow{2}{*}{$\begin{array}{l}3 \\
\text { QI }\end{array}$} & \multirow{2}{*}{\begin{tabular}{|c|}
4 \\
Al
\end{tabular}} \\
\hline & & & & & & \\
\hline Q2 & EV & $\begin{array}{l}\text { Q2. Em função das respostas do simulador, qual o } \\
\text { nível de realidade sentida para suas ações? }\end{array}$ & & & & \\
\hline Q14 & EV & $\begin{array}{l}\text { Q12. Quão envolvido com o ambiente virtual você } \\
\text { esteve? }\end{array}$ & 0,985 & & & \\
\hline Q21 & $\mathrm{Al}$ & $\begin{array}{l}\text { Q15. No fim da simulação, como você classificaria } \\
\text { seu nível de aptidão para dirigir no simulador? }\end{array}$ & 0,985 & & & \\
\hline Q1 & EV & $\begin{array}{l}\text { Q1. Conseguiu controlar (volante, pedal, etc) o } \\
\text { veículo simulado? }\end{array}$ & 0,984 & & & \\
\hline Q19 & QI & $\begin{array}{l}\text { Q13. Como classifica o tempo entre uma ação } \\
\text { tomada e a resposta do simulador? }\end{array}$ & 0,982 & & & \\
\hline Q4 & EV & $\begin{array}{l}\text { Q4. Em que nível o aspecto visual do simulador } \\
\text { conseguiu te envolver no ambiente? }\end{array}$ & 0,756 & & & \\
\hline Q8 & EV & $\begin{array}{l}\text { Q7. Quão idêntico é o ambiente simulado } \\
\text { comparado com uma experiência de direção real? }\end{array}$ & 0,702 & & & \\
\hline Q18 & EV & Q14. O quanto se sentiu adaptado ao simulador? & 0,601 & & & \\
\hline Q23 & QI & $\begin{array}{l}\text { Q17. Os mecanismos de direção do cockpit } \\
\text { interferiram a realização de alguma tarefa? }\end{array}$ & 0,597 & & $0,416^{*}$ & \\
\hline Q11 & FS & $\begin{array}{l}\text { Q20. Quão bem você conseguiu identificar os } \\
\text { sons? }\end{array}$ & & 0,882 & & \\
\hline Q5 & FS & $\begin{array}{l}\text { Q19. Em que nível o aspecto auditivo conseguiu te } \\
\text { envolver no ambiente? }\end{array}$ & & 0,853 & & \\
\hline Q12 & FS & Q21. Conseguiu identificar as origens dos sons? & & 0,822 & & \\
\hline Q7 & EV & $\begin{array}{l}\text { Q6. Qual o nível de convicção que você daria para } \\
\text { os objetos presentes na simulação? }\end{array}$ & & 0,620 & & $0,383^{*}$ \\
\hline Q3 & EV & $\begin{array}{l}\text { Q3. Qual o nível de naturalidade com o qual você } \\
\text { interagiu com o simulador? }\end{array}$ & & 0,520 & & $0,377^{\star}$ \\
\hline Q24 & $\mathrm{Al}$ & $\begin{array}{l}\text { Q18. Quanto você conseguiu se concentrar } \\
\text { efetivamente na simulação, ao invés de desviar a } \\
\text { atenção para os mecanismos de direção? }\end{array}$ & & & 0,832 & \\
\hline Q6 & EV & $\begin{array}{l}\text { Q5. Como foi o seu controle dos mecanismos de } \\
\text { direção do simulador? }\end{array}$ & 0,551 & & $0,744^{\star}$ & \\
\hline Q22 & QI & $\begin{array}{l}\text { Q16. A qualidade do vídeo interferiu na realização } \\
\text { de alguma tarefa? }\end{array}$ & & & 0,588 & \\
\hline Q10 & EV & $\begin{array}{l}\text { Q9. Quanto você conseguiu explorar visualmente o } \\
\text { ambiente para tomar decisões baseadas no } \\
\text { entorno? }\end{array}$ & & 0,368 & $0,489^{*}$ & 0,401 \\
\hline Q16 & FS & $\begin{array}{l}\text { Q11. Considerando um mesmo objeto a diferentes } \\
\text { distâncias, você percebeu diferença no nível de } \\
\text { detalhamento? }\end{array}$ & & & & 0,777 \\
\hline Q9 & $\mathrm{Al}$ & $\begin{array}{l}\text { Q8. Você foi capaz de prever o que aconteceria na } \\
\text { simulação logo após executar alguma ação no } \\
\text { simulador (cockpit)? }\end{array}$ & & & & 0,678 \\
\hline Q15 & FS & $\begin{array}{l}\text { Q10. Quantos detalhes você foi capaz de identificar } \\
\text { nos objetos ao observá-los? }\end{array}$ & & $0,377^{\star}$ & & 0,466 \\
\hline
\end{tabular}

${ }^{\star}$ Foram os valores escolhidos após análise qualitativa 


\subsection{AvaliaçÃo de desconforto}

O questionário de avaliação de sintomas (Apêndice D) é um instrumento bastante utilizado nas investigações sobre motion sickness, que consiste no surgimento de sintomas desconfortáveis no participante em virtude do uso de ambientes virtuais. A ocorrência de motion sickness, causada pela simulação, pode enviesar as respostas dos participantes obtidas no experimento e devem ser retirados da amostra.

$\mathrm{Na}$ análise das respostas do questionário de avaliação de sintomas dos 80 participantes não foi relatado nenhum sintoma classificado como severo. O sintoma com maior destaque foi o esforço visual $(23,8 \%=$ Leve e $13,8 \%=$ Moderado) condizente com a exposição ao sistema de projeção. Os sintomas sem nenhum relato dos participantes foram: tontura com olhos fechados, dor de estômago ou gases/eructação (Tabela 17).

Tabela 17 - Frequência absoluta (frequência relativa) do questionário de desconforto.

\begin{tabular}{c|l|r|r|r|r}
\hline Item & \multicolumn{1}{|c|}{ Sintomas } & Não & \multicolumn{1}{c|}{ Leve } & \multicolumn{1}{c}{ Moderado } & \multicolumn{1}{c}{ Severo } \\
\hline 1 & Desconforto Geral & $61(76,3 \%)$ & $17(21,3 \%)$ & $2(2,5 \%)$ & $0(0,0 \%)$ \\
2 & Fadiga & $73(91,3 \%)$ & $7(8,8 \%)$ & $0(0,0 \%)$ & $0(0,0 \%)$ \\
3 & Dor de cabeça & $76(95,0 \%)$ & $4(5,0 \%)$ & $0(0,0 \%)$ & $0(0,0 \%)$ \\
4 & Esforço visual & $50(62,5 \%)$ & $19(23,8 \%)$ & $11(13,8 \%)$ & $0(0,0 \%)$ \\
5 & Dificuldade em focar & $70(87,5 \%)$ & $8(10,0 \%)$ & $2(2,5 \%)$ & $0(0,0 \%)$ \\
6 & Salivação excessiva & $78(97,5 \%)$ & $1(1,3 \%)$ & $1(1,3 \%)$ & $0(0,0 \%)$ \\
7 & Suor excessivo & $78(97,5 \%)$ & $1(1,3 \%)$ & $1(1,3 \%)$ & $0(0,0 \%)$ \\
8 & Náusea & $71(88,8 \%)$ & $9(11,3 \%)$ & $0(0,0 \%)$ & $0(0,0 \%)$ \\
9 & Dificuldade de concentração & $76(95,0 \%)$ & $4(5,0 \%)$ & $0(0,0 \%)$ & $0(0,0 \%)$ \\
10 & Cabeça pesada & $71(88,8 \%)$ & $8(10,0 \%)$ & $1(1,3 \%)$ & $0(0,0 \%)$ \\
11 & Visão turva & $75(93,8 \%)$ & $5(6,3 \%)$ & $0(0,0 \%)$ & $0(0,0 \%)$ \\
12 & Tontura com olhos abertos & $75(93,8 \%)$ & $5(6,3 \%)$ & $0(0,0 \%)$ & $0(0,0 \%)$ \\
13 & Tontura com olhos fechados & $80(100 \%)$ & $0(0,0 \%)$ & $0(0,0 \%)$ & $0(0,0 \%)$ \\
14 & Vertigem & $77(96,3 \%)$ & $3(3,8 \%)$ & $0(0,0 \%)$ & $0(0,0 \%)$ \\
15 & Dor de estômago & $80(100 \%)$ & $0(0,0 \%)$ & $0(0,0 \%)$ & $0(0,0 \%)$ \\
16 & Gases/Arrotos & $80(100 \%)$ & $0(0,0 \%)$ & $0(0,0 \%)$ & $0(0,0 \%)$ \\
\hline
\end{tabular}

As respostas contabilizadas por nível da escala (16 itens $\times 80$ participantes $=1280$ ) sem considerar o sintoma, obteve-se $91,5 \%$ das respostas como NÃO apresentando nenhum sintoma do questionário após a conclusão do experimento (Tabela 18).

Tabela 18 - Resposta total do desconforto dos participantes por nível.

\begin{tabular}{c|c|c}
\hline \multirow{2}{*}{ Desconforto } & \multicolumn{2}{|c}{ Respostas } \\
\cline { 2 - 3 } & $\mathbf{N}$ & $\%$ \\
\hline Não & 1171 & $91,5 \%$ \\
Leve & 91 & $7,1 \%$ \\
Moderado & 18 & $1,4 \%$ \\
Severo & 0 & $0 \%$ \\
\hline Total & 1280 & $100,0 \%$ \\
\hline
\end{tabular}


A Figura 25 condensa a análise da avaliação de desconforto e confirma a ausência de motion sickness para a amostra de participantes segundo as respostas auto relatadas no questionário $S S Q$, garantindo que as respostas obtidas não foram enviesadas por influência de desconforto durante a simulação.

Figura 25 - Desconforto dos participantes.

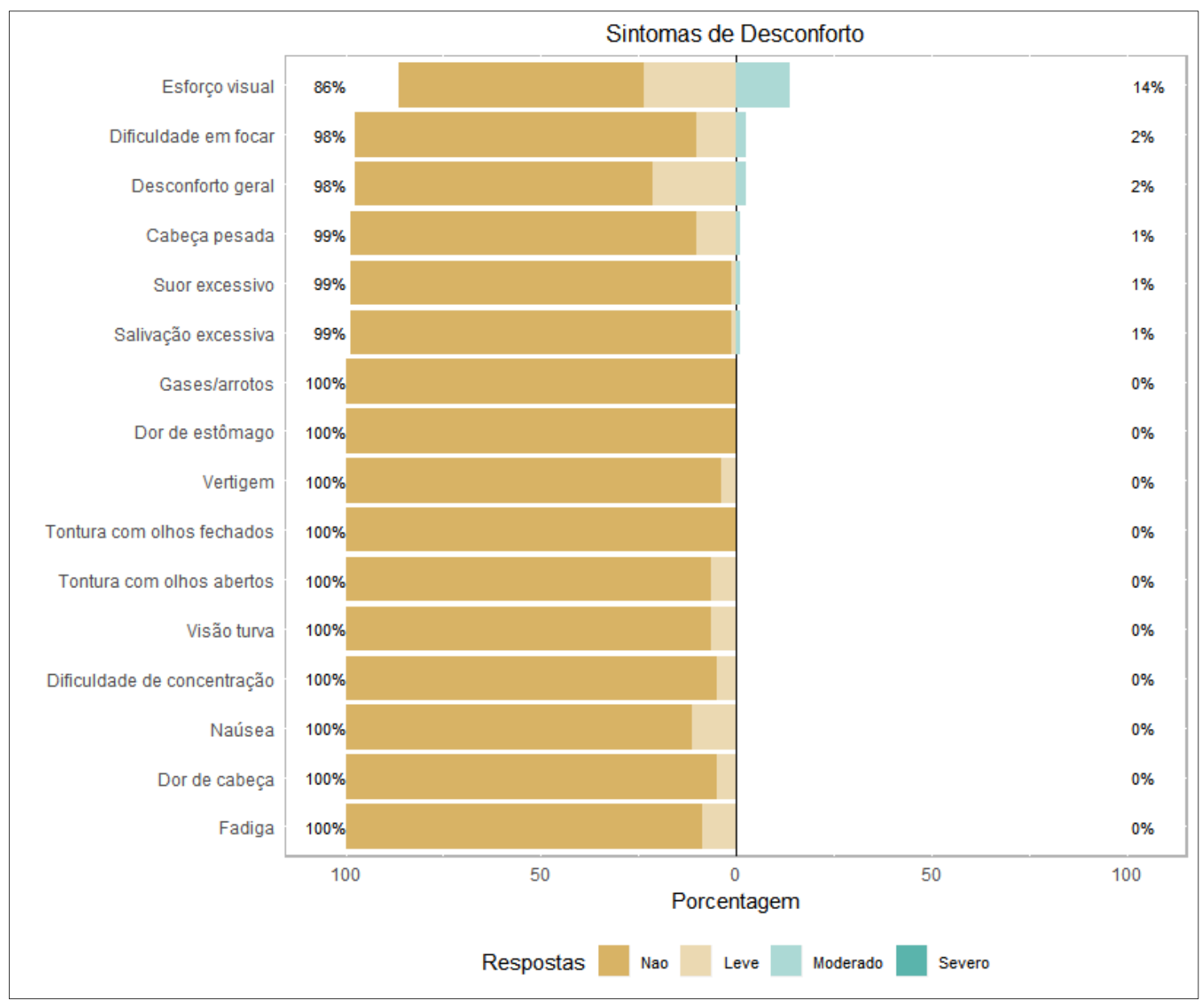

Fonte: a autora

\subsection{ANÁLISE EXPLORATÓRIA}

A análise exploratória dos dados obtidos da simulação foi realizada a fim de fornecer indícios que possam ou não embasar os métodos estatísticos realizados a posteriori.

O tempo médio de percurso na simulação foi de aproximadamente $10 \mathrm{~min}$, com o mínimo de $6,83 \mathrm{~min}$ e o máximo de 12,45 $\mathrm{min}$. A velocidade média de percurso foi de $77,72 \mathrm{~km} / \mathrm{h}$, abaixo da velocidade permitida da via, com velocidade média mínima de $61,62 \mathrm{~km} / \mathrm{h}$ e máxima de $112,40 \mathrm{~km} / \mathrm{h}$. 
Foram realizados os testes de normalidade de Kolmogorov-Smirnov para o tempo total $(D(80)$ $=0,13 ; p=0,002)$ e velocidade média dos condutores $(D(80)=0,17 ; p=0,001)$ e estes não apresentaram distribuição normal. A Figura 26 exibe o histograma do tempo total e a Figura 27 o histograma da velocidade média dos participantes na simulação.

Este resultado pode estar relacionado ao fato de os resultados advirem de experimento de ultrapassagem, onde o participante ao efetuar manobra tende a aumentar a velocidade na ultrapassagem do veículo havendo uma variabilidade na velocidade em função do tipo de ultrapassagem. Assim, se o condutor efetuou diferentes tipos de ultrapassagem ou até mesmo não realizou ultrapassagens, esse comportamento poderá afetar a velocidade média do percurso e, por conseguinte, o tempo total de percurso.

Figura 26 - Tempo total de simulação.

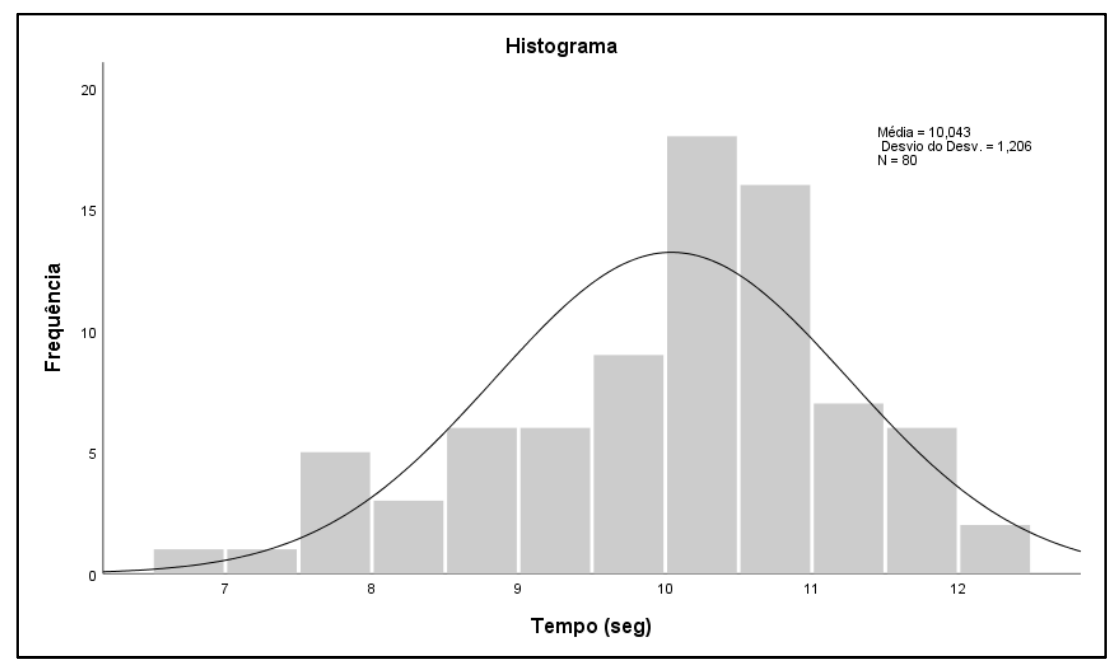

Figura 27 - Velocidade média da simulação.

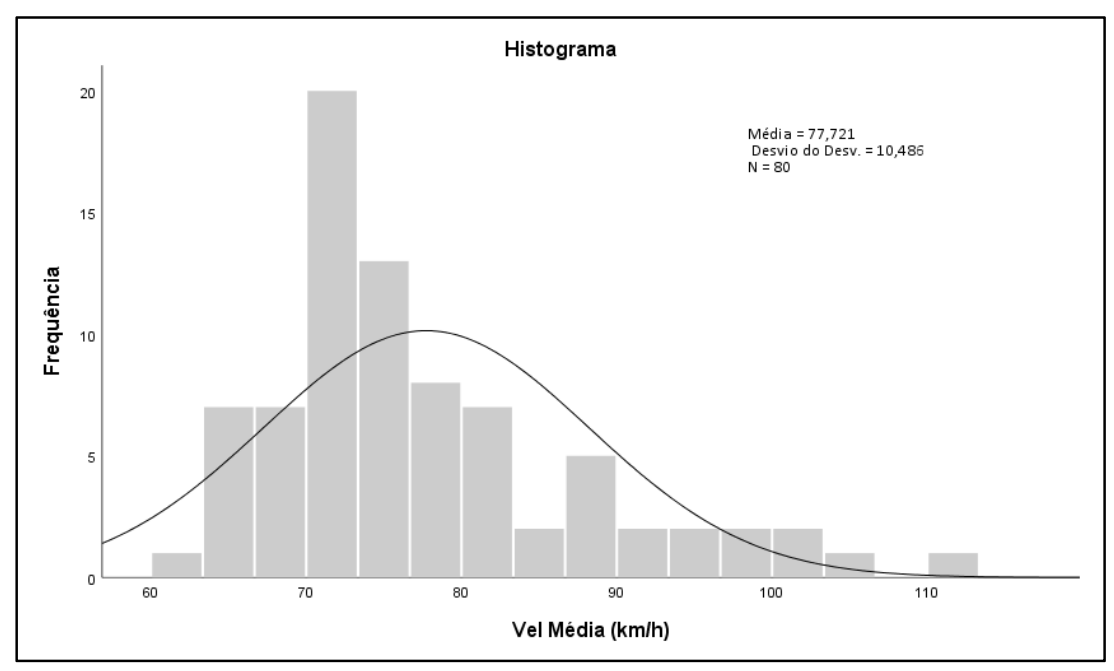


O delineamento do experimento possibilitou ao participante realizar até 8 ultrapassagens no trecho, totalizando 640 possibilidades de ultrapassagens (80 participantes $\times 8$ tratamentos). Como citado anteriormente, as ultrapassagens foram classificadas em U0 - não ultrapassagem, U1 - ultrapassagem simples e U2 - ultrapassagem completa e as tentativas de ultrapassagem como A0 - não tentativa, A1 - tentativa e abortagem sem risco e $\mathbf{A 2}$ tentativa e abortagem com risco.

A classificação dos tipos de ultrapassagens resultou em 134 não ultrapassagens (U0), 427 ultrapassagens simples (U1) e 79 ultrapassagens completas (U2). Dentre as tentativas, ocorreram 50 tentativas sem risco (A1) e 17 tentativas com risco (A2). A disposição da frequência do tipo de ultrapassagem por ocorrência de tentativa que resultou em abortagem são apresentadas na Tabela 19. A ultrapassagem completa (U2), como era esperado, não foi precedida por nenhum tipo de tentativa.

Tabela 19 - Frequência do tipo de ultrapassagem e tentativa.

\begin{tabular}{c|r|r|r|r}
\hline \multirow{2}{*}{ Ultrapassagens } & \multicolumn{3}{|c|}{ Tentativas } & \multirow{2}{*}{ Total } \\
\cline { 2 - 4 } & \multicolumn{1}{|c|}{ A0 } & \multicolumn{1}{|c|}{ A1 } & \multicolumn{1}{c|}{ A2 } & \multicolumn{1}{c}{ Tot } \\
\hline U0 & 112 & 19 & 3 & 134 \\
U1 & 382 & 31 & 14 & 427 \\
U2 & 79 & 0 & 0 & 79 \\
\hline Total & 573 & 50 & 17 & $\mathbf{6 4 0}$ \\
\hline
\end{tabular}

As ultrapassagens simples (U1) iniciaram a manobra na zona de ultrapassagem permitida, pois o condutor aguardou a liberação do fluxo na faixa oposta. Contudo, dependendo da posição do início da manobra a conclusão poderá ocorrer fora da zona de ultrapassagem permitida. No experimento esta condição ocorreu em 112 (26\%) das ultrapassagens simples.

Dentre as ultrapassagens completas (U2), 64 (81\%) iniciaram antes da zona de ultrapassagem permitida e devido a antecipação do início da manobra todas foram concluídas dentro da zona de ultrapassagem permitida. Esse comportamento já havia sido relatado por Forbes (1990).

Ao analisar os tipos de ultrapassagem por tratamento percebe-se que as não ultrapassagens (U0) ocorrem com mais frequência nos tratamentos cuja velocidade do VL é de $60 \mathrm{~km} / \mathrm{h}$. E as ultrapassagens do tipo U1 ocorreram com maior frequência em relação aos tratamentos 40CP560 (26 ocorrências) e 40CA560 (15 ocorrências). E a tentativa de ultrapassagem sem risco (A1) ocorreu com mais frequência nos tratamentos 60CA446 (10 ocorrências) e 60CA560 (9 ocorrências), ambos com o veículo lento do tipo caminhão trafegando a $60 \mathrm{~km} / \mathrm{h}$. 
Tabela 20 - Frequência do tipo de ultrapassagem e tentativa por tratamento.

\begin{tabular}{c|c|c|c|c|c|c}
\hline \multirow{2}{*}{ Tratamento } & \multicolumn{3}{|c|}{ Ultrapassagem } & \multicolumn{3}{c}{ Tentativas } \\
\cline { 2 - 7 } & U0 & U1 & U2 & A0 & A1 & A2 \\
\hline 40 CP446 & 4 & 69 & 7 & 75 & 3 & 2 \\
40 CP560 & 1 & 53 & 26 & 74 & 3 & 3 \\
40 CA446 & 4 & 69 & 7 & 71 & 7 & 2 \\
40CA560 & 3 & 62 & 15 & 71 & 7 & 2 \\
60CP446 & 39 & 37 & 4 & 72 & 7 & 1 \\
60CP560 & 26 & 45 & 9 & 73 & 4 & 3 \\
60CA446 & 35 & 42 & 3 & 66 & 10 & 4 \\
60CA560 & 22 & 50 & 8 & 71 & 9 & 0 \\
\hline Total & $\mathbf{1 3 4}$ & $\mathbf{4 2 7}$ & $\mathbf{7 9}$ & $\mathbf{5 7 3}$ & $\mathbf{5 0}$ & $\mathbf{1 7}$ \\
\hline
\end{tabular}

A Figura 28 apresenta o boxplot da velocidade média dos condutores do início das ultrapassagens U1 e U2 e a velocidade pontual no início da zona de ultrapassagem permitida para as não ultrapassagens (U0) por tratamento. As velocidades médias para os tratamentos, quando a velocidade do veículo lento (VelVL) era de $60 \mathrm{~km} / \mathrm{h}(\mathrm{M}=79,23)$, foram ligeiramente mais elevadas que as velocidades médias dos tratamentos quando a VelVL era de $40 \mathrm{~km} / \mathrm{h}$ $(M=62,37)$.

Figura 28 - Velocidade média por tratamento.

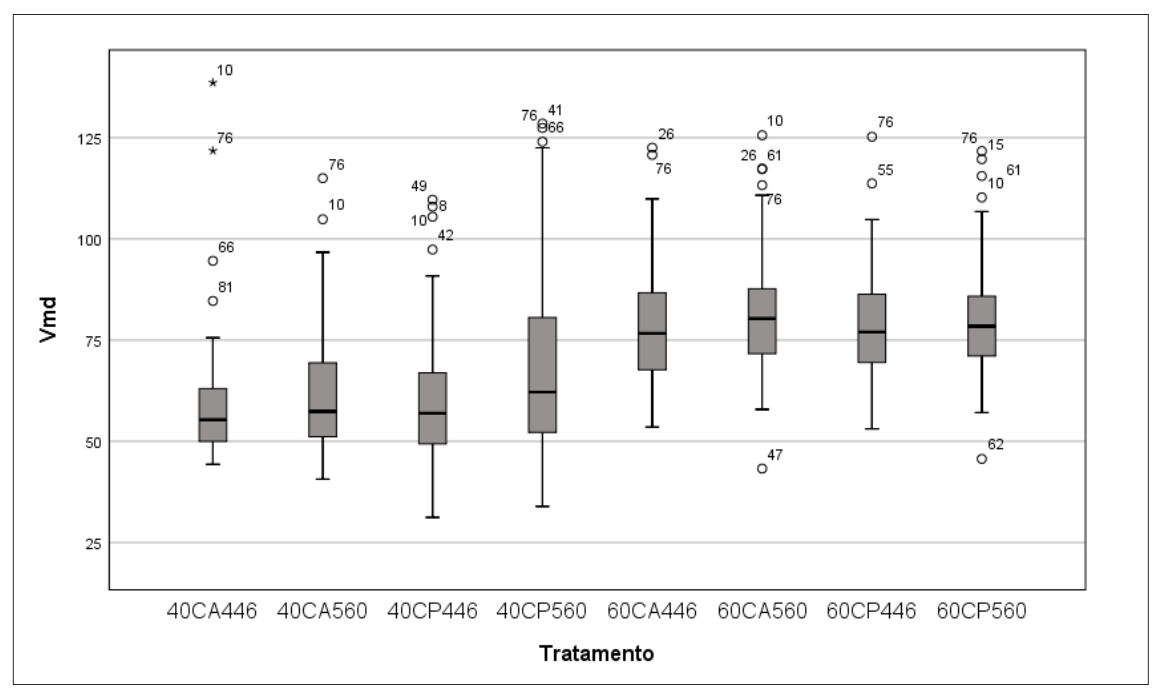

A distância ao veículo lento (dVL) no início ultrapassagem/não ultrapassagens será utilizada como a variável dependente para avaliar a influência dos fatores dos tratamentos. A Figura 29 apresenta o boxplot da distância ao veículo lento por tratamento, que apresentou valores médios mais amplos em relação à velocidade do veículo lento igual a $60 \mathrm{~km} / \mathrm{h}(\mathrm{M}=86,42)$ do que em relação a velocidade de $40 \mathrm{~km} / \mathrm{h}(\mathrm{M}=50,47)$. 
Figura 29 - Distância ao veículo lento por tratamento.

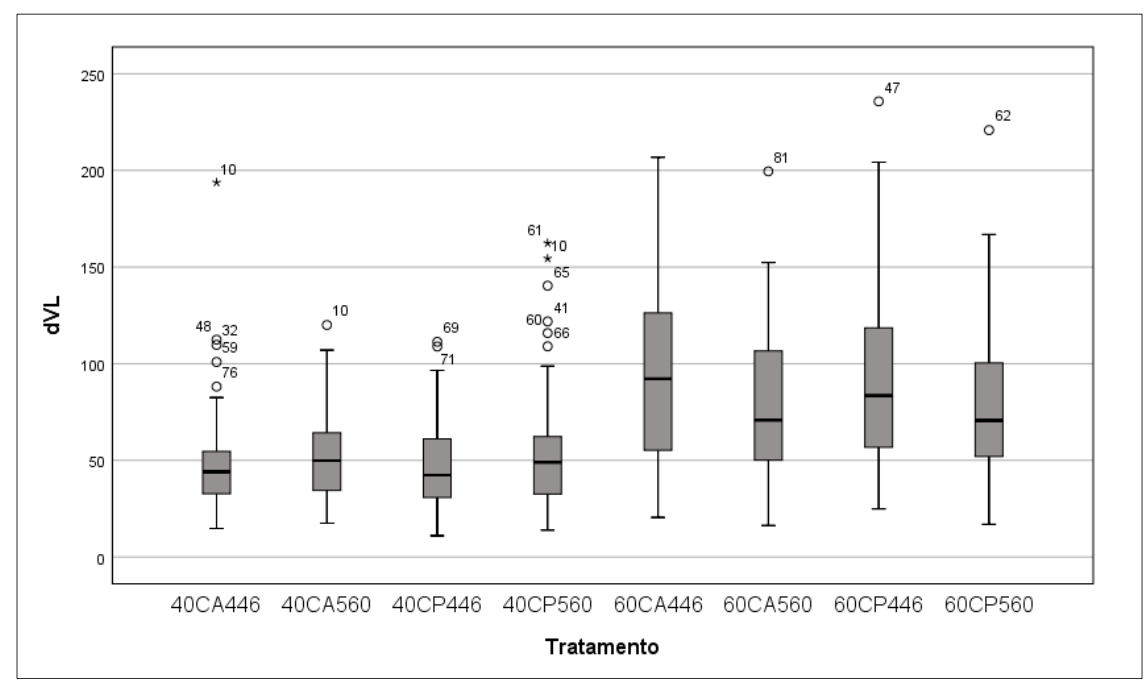

Para verificação e avaliação das ultrapassagens foram elaborados gráficos de cada condutor que permitiram analisar o afastamento lateral, a distância em relação ao veículo lento e veículo oposto e a velocidade ao longo do trecho simulado. Os comportamentos identificados possibilitaram o melhoramento do algoritmo para extração das distâncias de ultrapassagem.

O afastamento lateral (DistE) foi o parâmetro utilizado para identificar o início de ultrapassagem e corresponde a distância a partir do centro de gravidade do veículo ao eixo da via. A adoção desta métrica como indicativo de início de ultrapassagem teve que considerar comportamentos de condução particulares, como o caso do condutor \#16 apresentado na Figura 30.

O condutor \#16 dirigiu posicionando-se à esquerda na faixa de rolamento e, portanto, o afastamento lateral em relação ao eixo da via é menor que 1,8 metros medidos a partir do centro de gravidade do veículo. Esse tipo de condução induz a considerar como vários inícios de ultrapassagem ou tentativas de ultrapassagem, mas trata-se de comportamento normal do condutor.

Para complementar as informações foram incluídos no gráfico de afastamento lateral (Figura 30) os tipos de ultrapassagens efetuadas, o tratamento alocado em cada segmento, bem como a identificação das tangentes e curvas com sua respectivos sentidos à direita (D) ou esquerda (E). A ocupação da faixa oposta durante a ultrapassagem foi destacada em vermelho e corresponde ao afastamento lateral do condutor ao cruzar o eixo da via e retorno à faixa da direita. $O$ Apêndice $A$ apresenta os gráficos de afastamento lateral de todos os condutores voluntários do experimento. 
Figura 30 - Afastamento lateral ao longo do trecho.

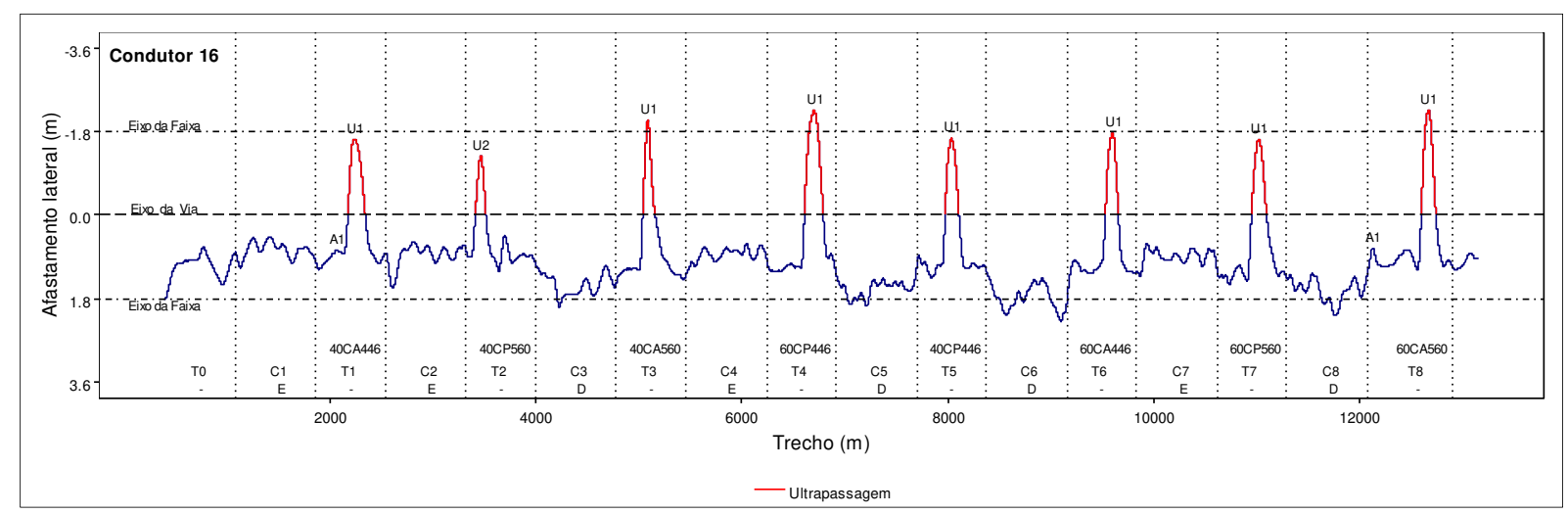

A Figura 31 apresenta a velocidade do condutor \#16 ao longo do trecho por segmento. Os trechos de ultrapassagens são indicados em vermelho onde pode se observar as velocidades desenvolvidas em relação à velocidade média de condução no trecho simulado. Por questão de economia de espaço, os gráficos de velocidade dos participantes não serão apresentados na pesquisa.

Figura 31 - Velocidade do condutor ao longo do trecho (Condutor \#16).

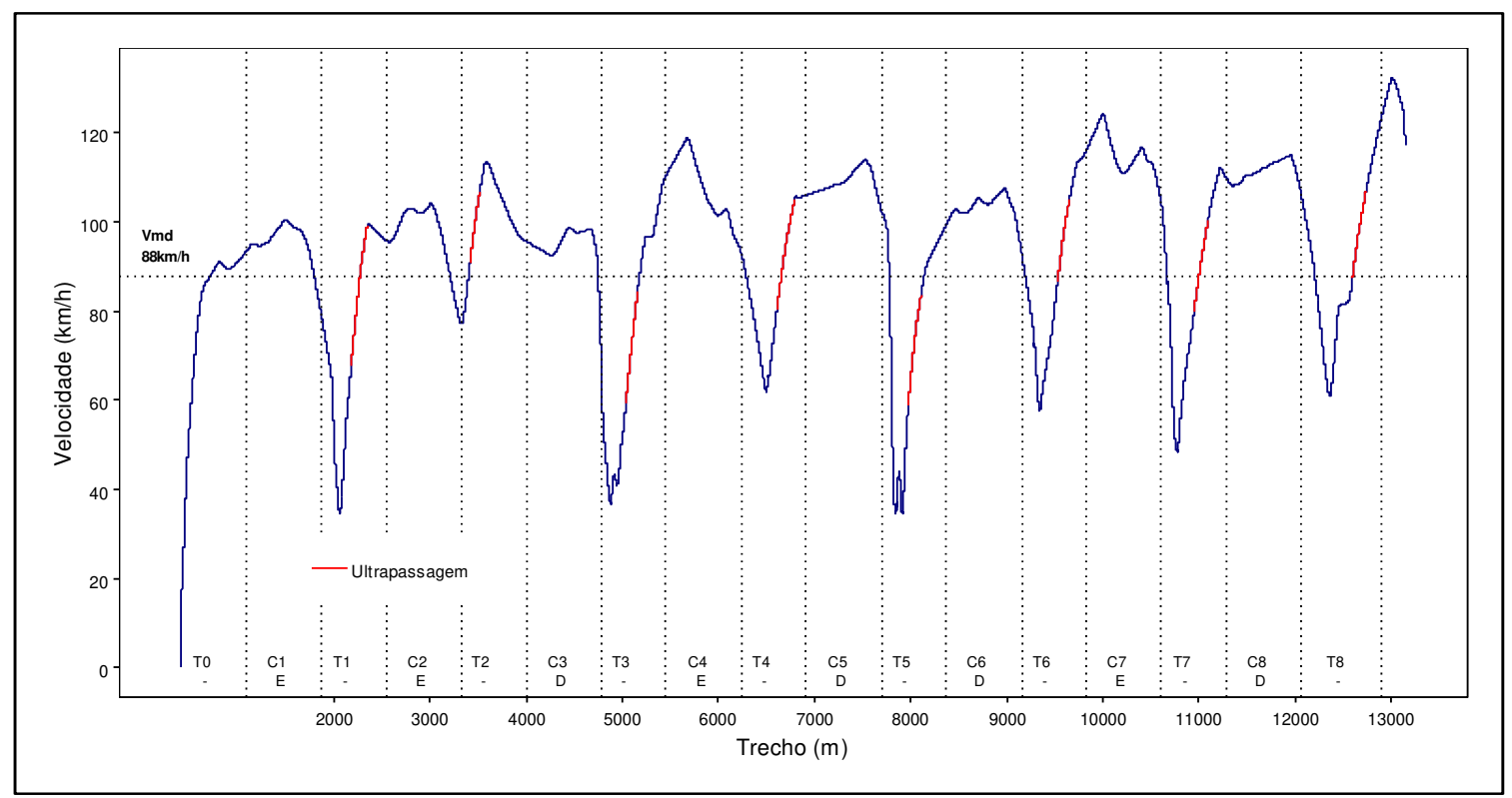

A análise descritiva dos tempos, velocidade média e distâncias das ultrapassagens foram feitas separadamente, agrupados por tipo de ultrapassagem através de correlação, gráficos de dispersão e densidade ilustrativos dos dados. 


\section{- Não Ultrapassagem (U0)}

As não ultrapassagens foram registradas em 134 tratamentos e foram analisadas as distâncias entre o veículo do participante ao veículo lento (dVL.U0) e ao veículo oposto (dVO.U0), a velocidade do participante (Vel.U0) e o afastamento lateral em relação ao eixo (DistE.U0) na posição de início da demarcação de ultrapassagem permitida.

O teste de Komogorov-Smirnov indicou que as variáveis Vel.U0 $(D(134)=0,92 ; p=0,008)$ e dVO.U0 $(D(134)=0,103 ; p=0,001)$ não seguem uma distribuição normal. Enquanto que as variáveis dVL.U0 $\left(D(134)=0,055 ; p=0,200^{*}\right)$ e DistE.U0 $\left(D(134)=0,052 ; p=0,200^{*}\right)$ apresentam distribuição normal ("limite inferior de significância verdadeira).

A Figura 32 apresenta os gráficos de dispersão: na diagonal os gráficos de densidade e os coeficientes das correlações de Spearman que não apresentaram correlações significativas, com exceção da correlação negativa entre a distância ao veículo lento e a distância ao veículo oposto $\left(r_{s}(134)=-0,561 ; p=0,001\right)$, ou seja, no início da zona de ultrapassagem permitida menores distância entre o veículo do participante e o veículo lento estão relacionadas a maiores distâncias entre o veículo do participante e o veículo oposto, e mesmo assim não houve ultrapassagem.

Figura 32 - Gráficos de dispersão, densidade e correlação de ultrapassagens U0.

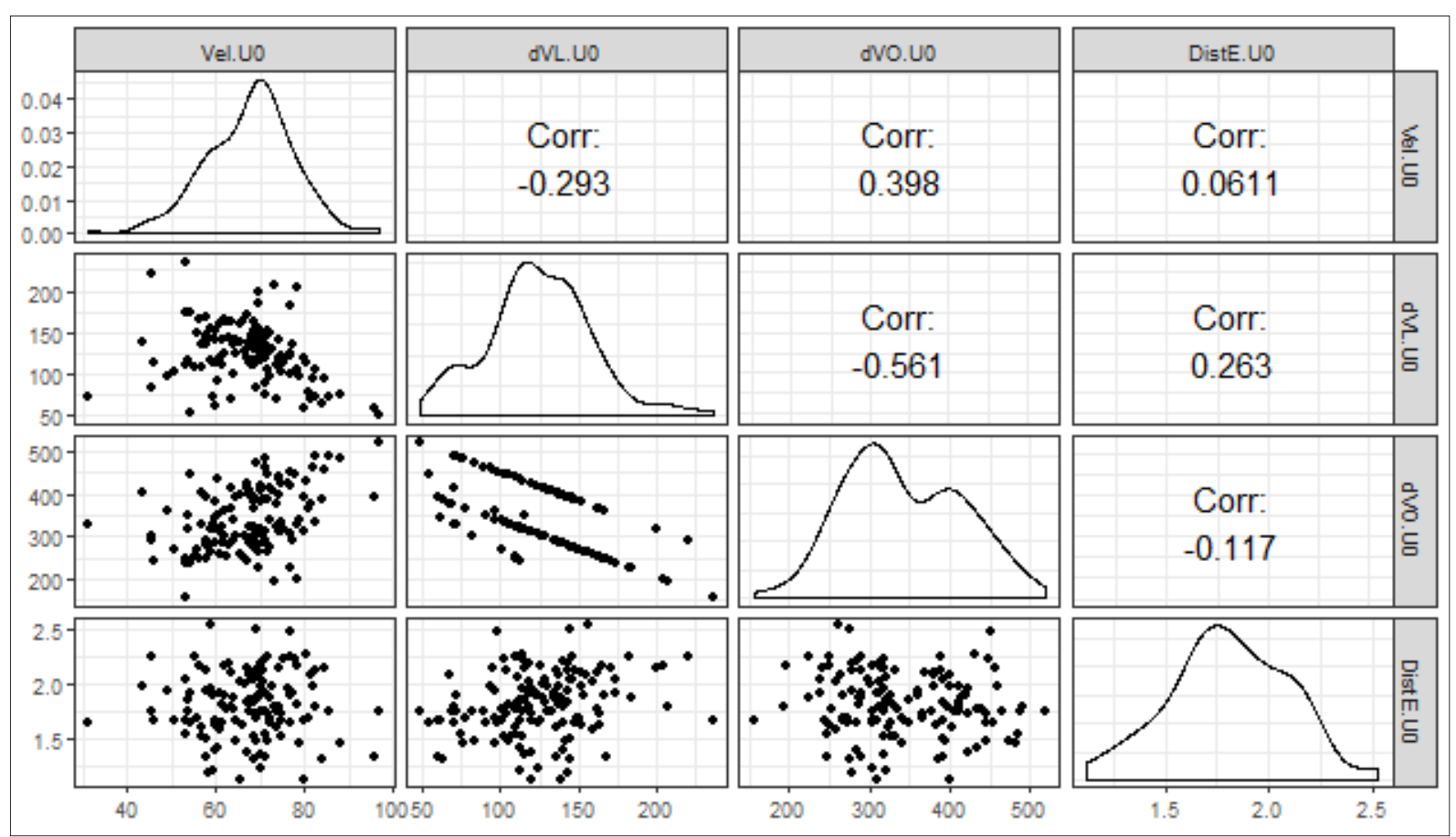




\section{- Ultrapassagem Simples (U1)}

As ultrapassagens simples (U1) foram registradas em 427 tratamentos, sendo o tipo de ultrapassagem mais frequente no experimento correspondendo à $84 \%$ das ultrapassagens concluídas. Nesse tipo de ultrapassagem o condutor aguarda a liberação da faixa oposta para efetuar a manobra e, portanto, não são contabilizadas as distâncias percorridas pelo veículo oposto. A Figura 33 apresenta os gráficos de dispersão, densidade e correlação entre as variáveis tempo total (TD1 e TD2), distância total (D1 e D2) e velocidade média do veículo (VmD1 e VmD2) para as fases de percepção e reação e ultrapassagem do veículo lento, e também a distância ao veículo lento (dVL.D1) no início da ultrapassagem.

As velocidades média na fase 1 (VmdD1) e as velocidades média na fase 2 (VmdD2) possuem correlação positiva forte $\left(r_{s}(427)=0,879 ; p<0,001\right)$, indicando que a velocidade média da fase 2 da ultrapassagem aumenta em relação velocidade média desenvolvida na fase inicial.

Figura 33 - Gráficos de dispersão, densidade e correlação de ultrapassagens U1.

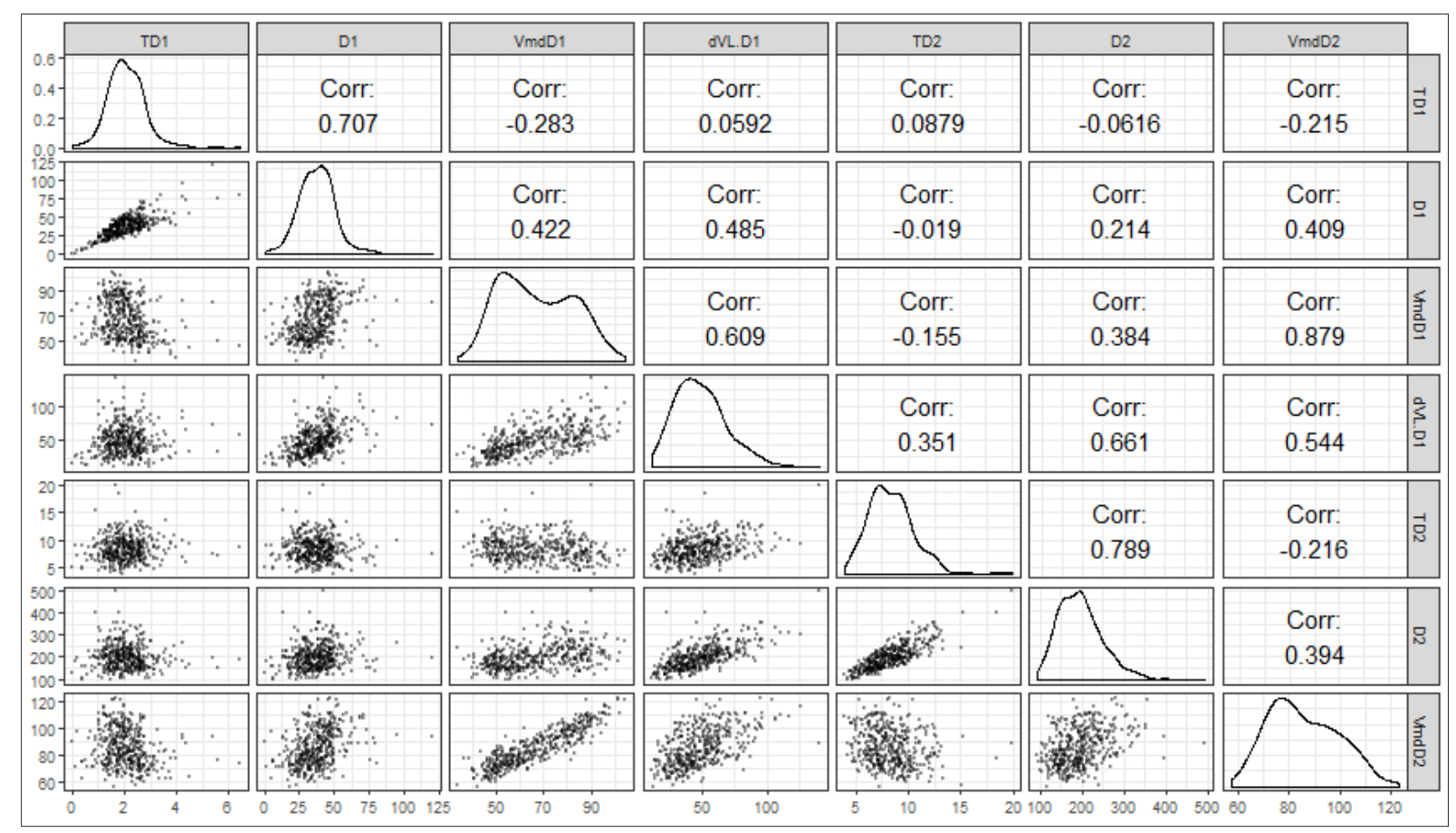

\section{- Ultrapassagem Completa (U2)}

As ultrapassagens completas foram identificadas em 79 tratamentos durante o experimento. Esse tipo de ultrapassagem contempla todas as fases da ultrapassagem e, portanto, além de serem contabilizadas as variáveis analisadas nas ultrapassagens simples, foram incluídas as varáveis computadas em função do veículo oposto, ou seja, a distância percorrida pelo veículo 
oposto durante a ultrapassagem $\left(\mathrm{d}_{4}\right)$ e a distância de folga entre o veículo do participante e o veículo oposto na conclusão da ultrapassagem $\left(\mathrm{d}_{3}\right)$. A Figura 34 apresenta os gráficos de dispersão, na diagonal os gráficos de densidade e os coeficientes das correlações de Spearman.

As velocidades média na fase 1 (VmdD1) e as velocidades média na fase 2 (VmdD2), similar ao ocorrido nas ultrapassagens simples, possuem correlação positiva forte $\left(r_{s}(79)=0,952 ; p\right.$ $<0,001$ ), indicando que a velocidade média da fase 2 da ultrapassagem aumenta em relação velocidade média desenvolvida na fase inicial.

Figura 34 - Gráficos de dispersão, densidade e correlação de ultrapassagens U2.

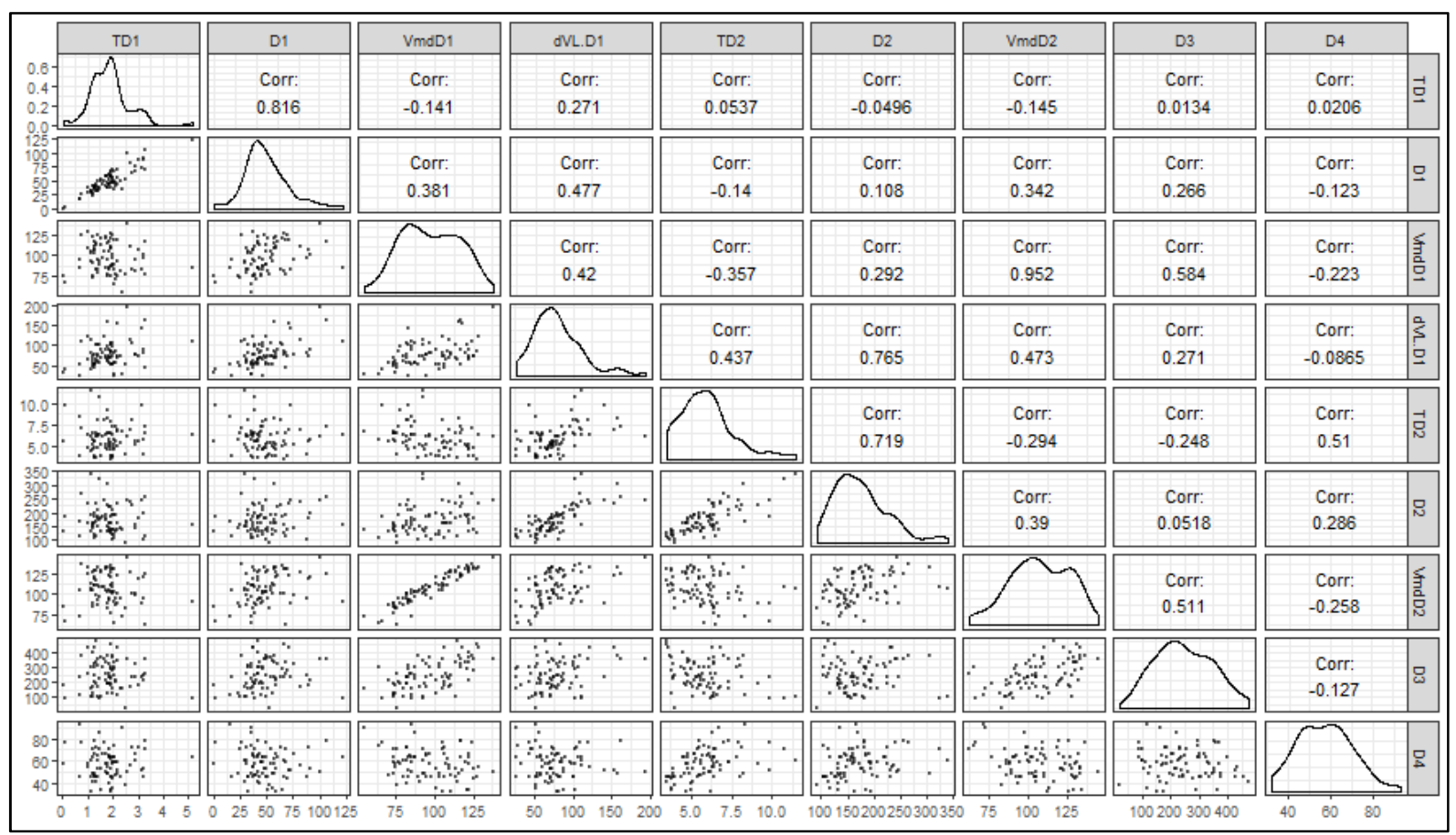

Para as ultrapassagens concluídas (simples e completa) verificou-se o afastamento lateral (afVL) entre os veículos na ultrapassagem, ou seja, a distância entre os eixos centrais dos veículos quando se encontram lado a lado na ultrapassagem por tipo de veículo ultrapassado. O afastamento lateral não diferiu ao ultrapassar um carro de passeio $(M=3,40 ; S D=0,44)$ ou um caminhão $(M=3,51 ; S D=0,44)$ como pode ser visto na Figura 35 . 
Figura 35 - Afastamento lateral na ultrapassagem por tipo de veículo.

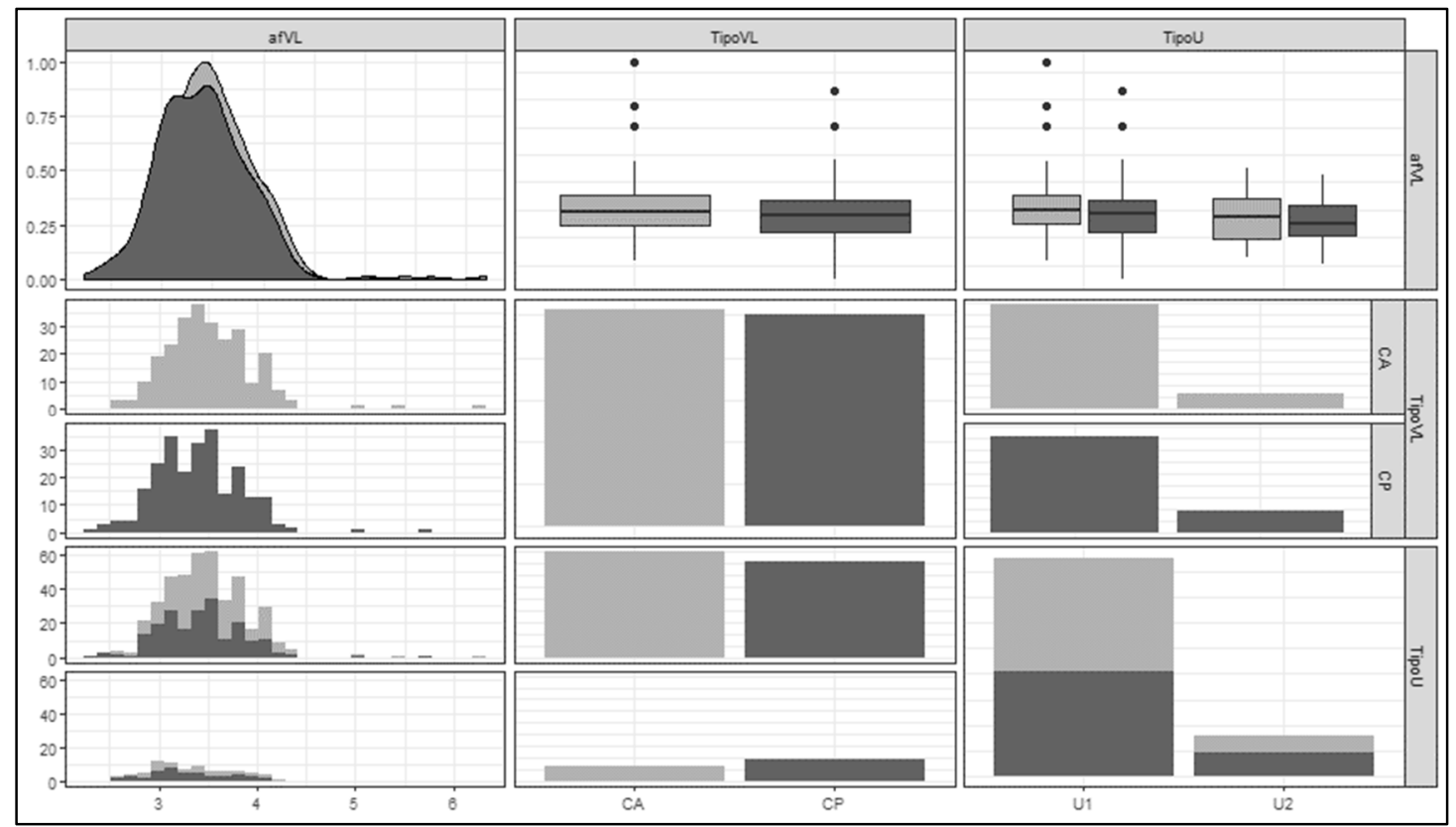

\subsection{A INFLUÊNCIA DOS FATORES SOBRE A DISTÂNCIA AO VEÍCULO LENTO}

A análise de variância (ANOVA) de medidas repetidas permite a identificação da influência de cada um dos fatores e a interação entre eles, ou seja, verifica se existe efeito da velocidade do veículo lento, do tipo de veículo lento, da distância de ultrapassagem ou da interação entre esses fatores sobre distância ao veículo lento durante a ultrapassagem (variável dependente).

Primeiramente, para atender ao teste de normalidade de Komogorov-Smirnov (Tabela 21) aplicou-se a transformação logarítmica da variável dependente ( $\mathrm{dVL}$ ) para cada tratamento. Após a transformação, dois tratamentos não apresentaram normalidade $(p<0,05)$, porém como a ANOVA é flexível frente a esta violação, pois mantém o erro tipo 1 ajustado, optou-se por continuar a análise.

Tabela 21 - Teste de Komogorov-Smirnov com a variável dependente transformada.

\begin{tabular}{c|c|c|c}
\hline $\begin{array}{c}\text { Variável } \\
\text { dependente }\end{array}$ & $\boldsymbol{D}$ & $\boldsymbol{g l}$ & $\boldsymbol{p}$ \\
\hline Log.dVL_40CP446 & 0,076 & 80 & $0,200^{*}$ \\
Log.dVL_40CP560 & 0,057 & 80 & $0,200^{*}$ \\
Log.dVL_40CA446 & 0,074 & 80 & $0,200^{*}$ \\
Log.dVL_40CA560 & 0,052 & 80 & $0,200^{*}$ \\
Log.dVL_60CP446 & 0,106 & 80 & $\mathbf{0 , 0 2 7}$ \\
Log.dVL_60CP560 & 0,059 & 80 & $0,200^{*}$ \\
Log.dVL_60CA446 & 0,132 & 80 & $\mathbf{0 , 0 0 1}$ \\
Log.dVL_60CA560 & 0,069 & 80 & $0,200^{*}$ \\
\hline
\end{tabular}

*. Este é um limite inferior da significância verdadeira.

a. Correlação de Significância de Lilliefors 
A ANOVA de medidas repetidas com a correção de Greenhouse-Geisser revelou que a velocidade do veículo lento (VelVL) teve efeito principal significativo $(F(1,79)=139,68 ; p<$ 0,$\left.001 ; \eta_{p}^{2}=0,64\right)$ sobre a distância entre o veículo do participante e o veículo lento (dVL), indicando que a velocidade do veículo lento tem $64 \%$ de influência na variância da distância entre o veículo do participante e o veículo lento. Os fatores tipo de veículo lento (TipoVL) e a distância de ultrapassagem permitida (DistU) não apresentaram efeitos significativos ( $p>$ $0,05)$. Para a interação dos fatores, houve interação significativa entre a VelVL - velocidade do veículo lento e a DistU - distância de ultrapassagem permitida $(F(1,79)=20,28 ; p<0,001$; $\eta_{p}{ }^{2}=20,4 \%$.) sobre a distância ao veículo lento ( $\left.d V L\right)$ com um $\eta^{2}$ de $20,4 \%$. Os resultados da ANOVA de todos os fatores e respectivas interações dentre os sujeitos são apresentados na Tabela 22.

Tabela 22 - Tabela simplificada da ANOVA de efeitos dentre sujeitos.

\begin{tabular}{|c|c|c|c|c|c|c|}
\hline $\begin{array}{c}\text { Componente da } \\
\text { Variância }\end{array}$ & SQ & df & QM & $\mathbf{F}$ & $\mathbf{p}$ & $\eta_{p}^{2}$ \\
\hline VelVL & 8,288 & 1 & 8,288 & 139,682 & 0,000 & 0,639 \\
\hline Erro(VelVL) & 4,687 & 79 & 0,059 & & & \\
\hline TipoVL & 0,018 & 1 & 0,018 & 0,647 & 0,424 & 0,008 \\
\hline Erro(TipoVL) & 2,169 & 79 & 0,027 & & & \\
\hline DistU & 0,007 & 1 & 0,007 & 0,200 & 0,656 & 0,003 \\
\hline Erro(DistU) & 2,717 & 79 & 0,034 & & & \\
\hline VelVL * TipoVL & 0,018 & 1 & 0,018 & 0,746 & 0,391 & 0,009 \\
\hline Erro(VelVL*TipoVL) & 1,901 & 79 & 0,024 & & & \\
\hline VelVL * DistU & 0,456 & 1 & 0,456 & 20,286 & 0,000 & 0,204 \\
\hline Erro(VelVL*DistU) & 1,774 & 79 & 0,022 & & & \\
\hline TipoVL * DistU & 0,004 & 1 & 0,004 & 0,117 & 0,733 & 0,001 \\
\hline Erro(TipoVL*DistU) & 2,808 & 79 & 0,036 & & & \\
\hline VelVL * TipoVL * DistU & 0,009 & 1 & 0,009 & 0,330 & 0,568 & 0,004 \\
\hline Erro(VeIVL*TipoVL*DistU) & 2,183 & 79 & 0,028 & & & \\
\hline
\end{tabular}

Nota: $\mathrm{SQ}$ = soma dos quadrados; $\mathrm{df}$ = graus de liberdade; $\mathrm{QM}$ = quadrado médio; $\mathrm{F}$ = estatística da ANOVA; $\mathrm{p}=$ nível de significância; $\eta \mathrm{p}^{2}=$ eta parcial quadrado.

A ANOVA analisa o efeito global, ou seja, informa se existem diferenças entre os grupos experimentais, porém não informa entre quais grupos existe diferença, sendo necessário aplicação post-hoc com correção de Bonferroni.

A análise par a par do fator VelVL (Tabela 23) evidencia que a distância do veículo do participante ao veículo lento em função da velocidade do veículo lento - $40 \mathrm{~km} / \mathrm{h}$ ou $60 \mathrm{~km} / \mathrm{h}$ - apresentou uma diferença média de 0,228 que equivale a aproximadamente 32 metros. 
Tabela 23 - Comparação par a par da VelVL.

\begin{tabular}{|c|c|c|c|c|c|c|}
\hline \multirow[b]{2}{*}{ (I) VelVL } & \multirow[b]{2}{*}{ (J) VelVL } & \multirow[b]{2}{*}{$\begin{array}{l}\text { Diferença } \\
\text { média (I-J) }\end{array}$} & \multirow[b]{2}{*}{ Erro } & \multirow[b]{2}{*}{$\mathbf{p}^{\mathbf{b}}$} & \multicolumn{2}{|c|}{ 95\% IC para Diferençab } \\
\hline & & & & & $\begin{array}{l}\text { Limite } \\
\text { inferior }\end{array}$ & $\begin{array}{l}\text { Limite } \\
\text { superior }\end{array}$ \\
\hline 40 & 60 & $-0,228^{*}$ & 0,19 & 0,000 & $-0,266$ & $-0,189$ \\
\hline 60 & 40 & $0,228^{*}$ & 0,19 & 0,000 & 0,189 & 0,266 \\
\hline
\end{tabular}

Baseado em médias marginais estimadas

*. A diferença média é significativa no nível 0,05.

b. Ajustamento para diversas comparações: Bonferroni.

Para a interação entre a velocidade do veículo e a distância de ultrapassagem permitida, o teste post hoc de Bonferroni (Tabela 24) com as comparações par a par foi possível observar que a DistU de $446 \mathrm{~m}$ e a DistU de $560 \mathrm{~m}$ apresentam diferenças significativas $(p<0,05)$ em relação a VelVL de $40 \mathrm{~km} / \mathrm{h}$ quanto em relação a VelVL de $60 \mathrm{~km} / \mathrm{h}$.

Tabela 24 - Comparação par a par da VelVL e DistU.

\begin{tabular}{|c|c|c|c|c|c|c|c|}
\hline \multirow{2}{*}{ VelVL } & \multirow{2}{*}{ (I) DistU } & \multirow{2}{*}{ (J) DistU } & \multirow{2}{*}{$\begin{array}{l}\text { Diferença } \\
\text { média (I-J) }\end{array}$} & \multirow{2}{*}{ Erro } & \multirow{2}{*}{$\mathbf{p}^{b}$} & \multicolumn{2}{|c|}{$\begin{array}{c}\text { 95\% IC para } \\
\text { Diferença }^{\mathrm{b}}\end{array}$} \\
\hline & & & & & & $\begin{array}{l}\text { Limite } \\
\text { inferior }\end{array}$ & $\begin{array}{l}\text { Limite } \\
\text { superior }\end{array}$ \\
\hline \multirow[t]{2}{*}{40} & 446 & 560 & $-0,047^{*}$ & 0,020 & 0,025 & $-0,087$ & $-0,006$ \\
\hline & 560 & 446 & $0,047^{\star}$ & 0,020 & 0,025 & 0,006 & 0,087 \\
\hline \multirow[t]{2}{*}{60} & 446 & 560 & $0,060^{*}$ & 0,017 & 0,001 & 0,026 & 0,094 \\
\hline & 560 & 446 & $-0,060^{*}$ & 0,017 & 0,001 & $-0,094$ & $-0,026$ \\
\hline
\end{tabular}

Baseado em médias marginais estimadas

*. A diferença média é significativa no nível $p=0,05$.

b. Ajustamento para diversas comparações: Bonferroni.

Para ilustrar da interação entre a VelVL e a DistU podemos avaliar gráfico de linhas para a média. A Figura 36 apresenta o gráfico com as distâncias transformadas em log e a

Figura 37 com as médias sem transformação. É possível visualizar que para a velocidade do veículo lento de $40 \mathrm{~km} / \mathrm{h}$ os condutores tendem a manter menores distâncias em relação ao veículo a ser ultrapassado, com pequena diferença média $(5,27 \mathrm{~m})$ em relação à distância de ultrapassagem permitida, sendo maior quando a distância de ultrapassagem é de $560 \mathrm{~m}$. $\mathrm{E}$ para a velocidade do veículo lento de $60 \mathrm{~km} / \mathrm{h}$ a diferença aumenta $(12,5 \mathrm{~m})$ e inverte em relação a situação anterior, sendo assim, para distâncias de ultrapassagem de $560 \mathrm{~m}$ a distância média ao veículo lento é menor que quando comparado à distância de ultrapassagem de $446 \mathrm{~m}$. 
Figura 36 - Gráfico de interação com Log das médias entre VelVL e DistU.

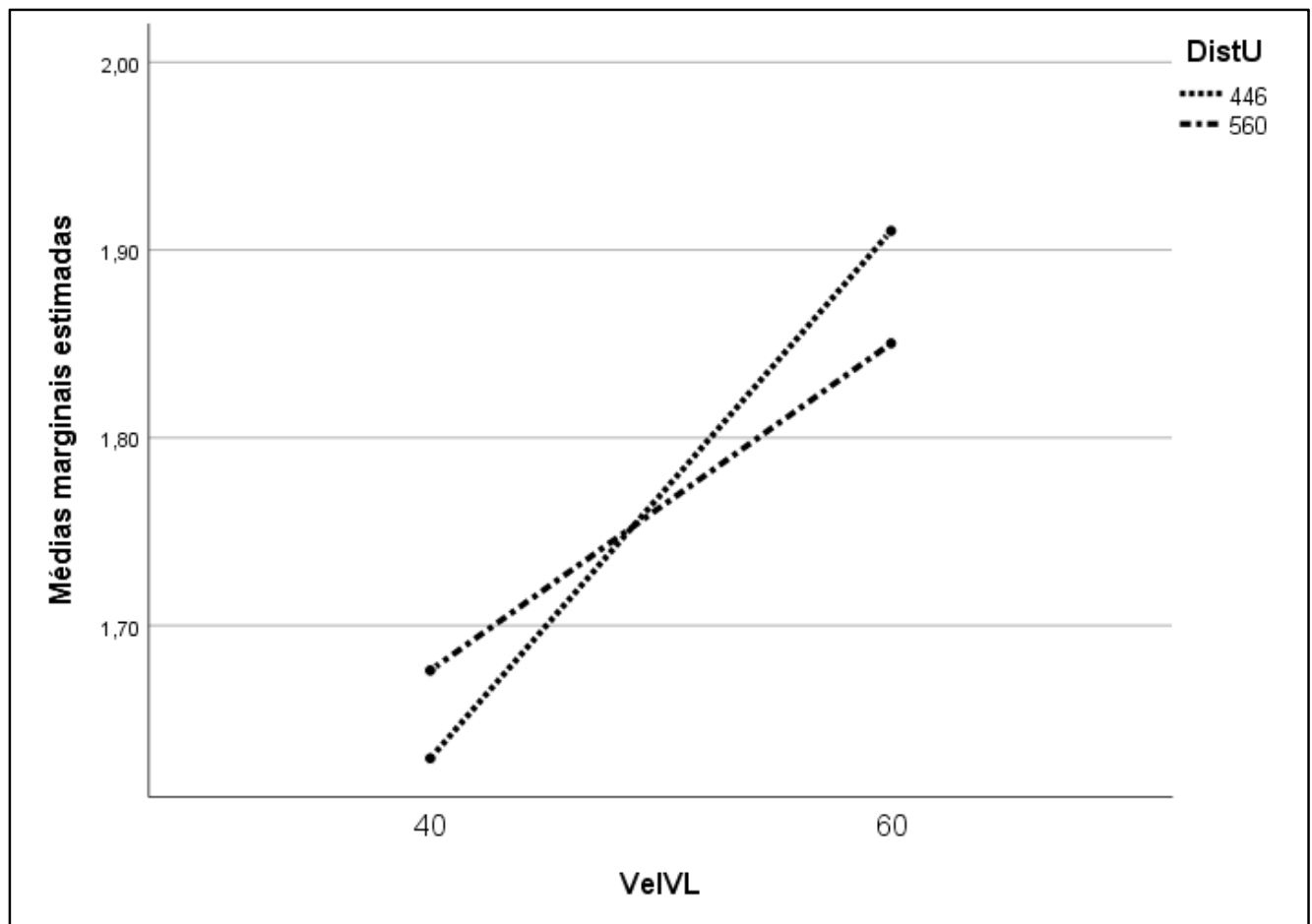

Figura 37 - Gráfico de interação com médias originais entre VelVL e DistU.

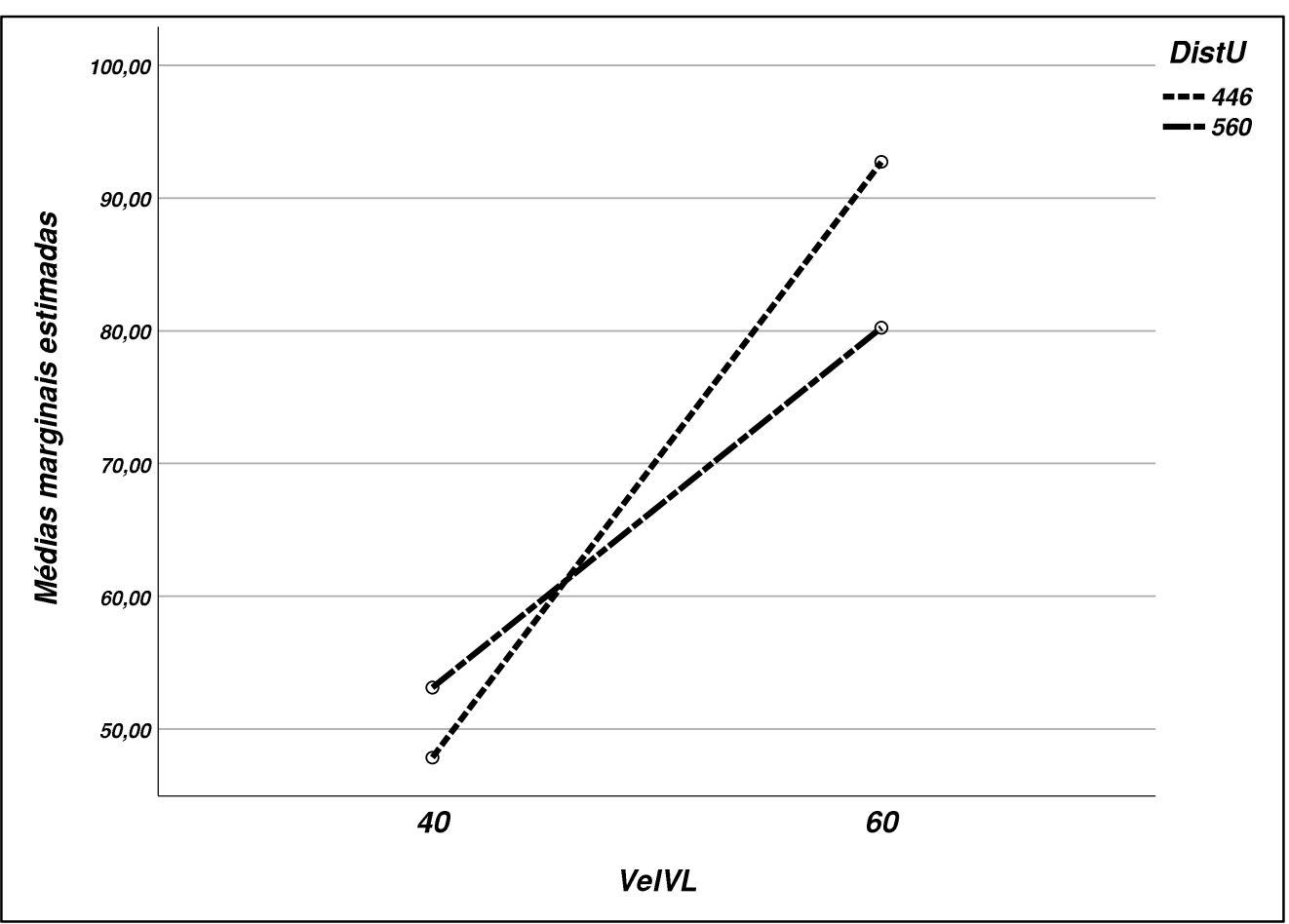

Para complementar a interpretação e localização das diferenças a Tabela 25 apresenta o teste post-hoc de Bonferroni para as comparações entre os três fatores (VeIVL, TipoVL e DistU) 
onde é possível observar que para a velocidade do veículo lento de $60 \mathrm{~km} / \mathrm{h}$ o tipo de veículo (CP ou CA) não apresenta significância na interação $(p<0,05)$.

Tabela 25 - Comparação par a par da VelVL, TipoVL e DistU.

\begin{tabular}{|c|c|c|c|c|c|c|c|c|}
\hline \multirow{2}{*}{ VelVL } & \multirow{2}{*}{ TipoVL } & \multirow{2}{*}{$\begin{array}{c}\text { (I) } \\
\text { DistU }\end{array}$} & \multirow{2}{*}{$\begin{array}{c}\text { (J) } \\
\text { DistU }\end{array}$} & \multirow{2}{*}{$\begin{array}{l}\text { Diferença } \\
\text { média (I-J) }\end{array}$} & \multirow{2}{*}{ Erro } & \multirow{2}{*}{$\mathbf{p}^{b}$} & \multicolumn{2}{|c|}{$\begin{array}{c}\text { 95\% IC para } \\
\text { Diferença }^{\mathrm{b}}\end{array}$} \\
\hline & & & & & & & $\begin{array}{l}\text { Limite } \\
\text { inferior }\end{array}$ & $\begin{array}{l}\text { Limite } \\
\text { superior }\end{array}$ \\
\hline \multirow[t]{4}{*}{40} & \multirow[t]{2}{*}{$\mathrm{CP}$} & 446 & 560 & $-0,059$ & 0,036 & 0,100 & $-0,131$ & 0,012 \\
\hline & & 560 & 446 & 0,059 & 0,036 & 0,100 & $-0,012$ & 0,131 \\
\hline & \multirow[t]{2}{*}{ CA } & 446 & 560 & $-0,034$ & 0,024 & 0,156 & $-0,082$ & 0,013 \\
\hline & & 560 & 446 & 0,034 & 0,024 & 0,156 & $-0,013$ & 0,082 \\
\hline \multirow[t]{4}{*}{60} & \multirow[t]{2}{*}{$\mathrm{CP}$} & 446 & 560 & $0,062^{*}$ & 0,027 & 0,024 & 0,009 & 0,116 \\
\hline & & 560 & 446 & $-0,062^{*}$ & 0,027 & 0,024 & $-0,116$ & $-0,009$ \\
\hline & \multirow[t]{2}{*}{ CA } & 446 & 560 & $0,057^{*}$ & 0,021 & 0,007 & 0,016 & 0,099 \\
\hline & & 560 & 446 & $-0,057^{*}$ & 0,021 & 0,007 & $-0,099$ & $-0,016$ \\
\hline
\end{tabular}

Baseado em médias marginais estimadas

*. A diferença média é significativa no nível 0,05.

b. Ajustamento para diversas comparações: Bonferroni.

Em seguida procedeu-se a ANOVA de medidas repetidas utilizando como fator entre sujeitos (between-subjects) o gênero $(F(1,78)=0,985 ; p>0,05)$, a faixa etária $(F(1,78)=2,042 ; p>$ $0,05)$ categorizada em dois grupos $(<=25$ anos e $>25$ anos) e o tempo de habilitação $(F(1,78)=$ $0,54 ; p>0,05)$ também categorizado em dois grupos (<= 5 anos e $>5$ anos). As análises foram realizadas individualmente para cada fator entre sujeitos, contudo, nenhum destes fatores apresentou significância relevante $(p<0,05)$ sobre a variável dependente $(\mathrm{dVL})$.

E para finalização da ANOVA dos fatores utilizados no experimento, visto que 2 tratamentos da variável resposta ( $(\mathrm{VL})$ não apresentaram normalidade após a transformação, procedeuse também o teste de Friedman, que equivale à anova de medidas repetidas para dados não paramétricos utilizando a variável resposta sem transformação.

O resultado mostrou que a distância entre o veículo do participante e o veículo lento (dVL) na manobra de ultrapassagem diferem entre os tratamentos $\left(X^{2}(7)=190,46 ; p<0,001\right)$. E o teste de comparações múltiplas mostrou que as distâncias entre o veículo do participante e o veículo lento diferem quando a velocidade do veículo lento é igual a $60 \mathrm{~km} / \mathrm{h}$, mas não entre si, confirmando os resultados relatados na ANOVA de medidas repetidas com a variável dependente transformada (Tabela 25). 


\subsection{TIPOS DE ULTRAPASSAGEM}

A classificação das ultrapassagens no experimento resultou em três categorias, conforme apresentados na análise exploratória, que são: não ultrapassagem (U0), ultrapassagem simples(U1) e ultrapassagem completa (U2). Com esses resultados procedeu-se uma investigação através de regressão logística multinomial para avaliar se o tipo de ultrapassagem resultante foi influenciado pelos fatores dos tratamentos do experimento.

O tipo de ultrapassagem foi escolhido como a variável dependente politômica e assume os valores 0,1 e 2 para os respectivos tipos de ultrapassagens classificados como U0, U1 e U2. A aplicação da regressão logística multinomial exige ainda que uma das variáveis resposta seja designada como categoria de referência e as demais comparadas com esta categoria. Neste modelo assumiu-se como categoria de referência a "não-ultrapassagem - Uo".

A estimação permitiu verificar as chances de um condutor realizar uma ultrapassagem simples (U1) ou uma ultrapassagem completa (U2) em relação à não realizar a ultrapassagem (U0), em função das variações dos fatores do experimento, transformados em variáveis do tipo dummy, onde a velocidade do veículo lento (VelVL) de $40 \mathrm{~km} / \mathrm{h}=0$ e $60 \mathrm{~km} / \mathrm{h}=1$; o tipo do veículo (TipoVL) carro de passeio $(\mathrm{CP})=0$ e caminhão $(\mathrm{CA})=1$ e a distância de ultrapassagem permitida (DistU) com $446 \mathrm{~m}=0$ e $560 \mathrm{~m}=1$. E como co-variável do tipo contínua a distância entre o veículo do participante e o veículo lento (dVL).

Foram realizadas duas análises: para o primeiro modelo foram adicionadas somente os fatores do experimento (VeIVL, TipoVL e DistU) e no segundo modelo foi acrescido aos fatores a covariável dVL. A Tabela 26 apresenta as informações dos ajustes dos modelos para efeito de comparação.

Para o Modelo A, dentre as variáveis preditoras, o tipo de veículo não apresentou significância para o modelo $(p=0,187)$, porém no Modelo $B$ após a inserção da variável preditora $d V L$, o tipo de veículo passou a ter significância $(p=0,02)$ e todas as variáveis apresentaram relevância para o modelo ( $p<0,001)$. Em relação a acurácia na classificação dos modelos, $o$ Modelo $\mathrm{A}$ teve um acerto de $57 \%$, não apresentando nenhum acerto global em relação à ultrapassagem do tipo completa. O Modelo B obteve um percentual de $84 \%$ de acerto, contemplando todas as categorias de ultrapassagem. Como critério de escolha do modelo, optou-se pelo modelo com o maior percentual de acerto (Modelo B), indicando que os coeficientes dos parâmetros das variáveis previsoras estimados tornaram os valores observados com maior probabilidade de terem ocorrido. 
Tabela 26 - Ajustes dos modelos e a contribuição dos preditores $(\mathrm{N}=640)$.

\begin{tabular}{|c|c|c|c|c|c|c|c|c|c|}
\hline \multicolumn{5}{|c|}{ Modelo A } & \multicolumn{5}{|c|}{ Modelo B } \\
\hline \multicolumn{2}{|c|}{$\begin{array}{r}\text { Somente Intercepto }= \\
\text { Modelo Final }= \\
\text { LR Chi }{ }^{2}(6)= \\
\text { seudo } \mathrm{R}^{2} \text { Nagelkerke }= \\
\text { Classificação }=\end{array}$} & \multicolumn{2}{|c|}{$\begin{array}{r}227,460 \\
64,190 \\
163,270 \\
0,275 \\
67 \%\end{array}$} & $p<0,001$ & \multicolumn{2}{|c|}{$\begin{array}{r}\text { Somente Intercepto }= \\
\text { Modelo Final }= \\
\text { Qui-quadrado }(8)= \\
\text { Pseudo } \mathrm{R}^{2} \text { Nagelkerke }= \\
\text { Classificação }=\end{array}$} & \multicolumn{3}{|c|}{$\begin{array}{r}1095,192 \\
569,675 \\
525,517 \\
0,684 \\
84 \%\end{array}$} \\
\hline Efeito & $\begin{array}{c}\text { Verossimilha } \\
\text { nça de log -2 } \\
\text { do modelo } \\
\text { reduzido }\end{array}$ & $\begin{array}{c}\text { Qui- } \\
\text { quadrado }\end{array}$ & df & $p$ & Efeito & $\begin{array}{c}\text { Verossimilha } \\
\text { nça de log -2 } \\
\text { do modelo } \\
\text { reduzido }\end{array}$ & $\begin{array}{c}\text { Qui- } \\
\text { quadrado }\end{array}$ & df & $p$ \\
\hline Intercepto & $64,190^{a}$ & 000 & 0 & & Intercepto & $569,675^{a}$ & & 0 & \\
\hline VelVL & 199,240 & 135,050 & 2 & 0,000 & $d V L$ & & 362, & 2 & 0,000 \\
\hline TipoVL & 67,542 & 3,352 & 2 & 0,187 & VelVL & 612,609 & 42,934 & 2 & 0,000 \\
\hline DistU & 92,015 & 27,825 & 2 & 0,000 & TipoVL & 577,549 & 7,874 & 2 & 0,020 \\
\hline & & & & & DistU & 589,676 & 20,001 & 2 & 0,000 \\
\hline
\end{tabular}

LR Chi2 = teste de qui-quadrado da razão de verossimilhança

A estatística qui-quadrado é a diferença no log de verossimilhanças -2 entre o modelo final e um modelo reduzido. 0 modelo reduzido é formado pela omissão de um efeito do modelo final. A hipótese nula significa que todos os parâmetros desse feito são 0 .

a. Esse modelo reduzido é equivalente ao modelo final porque a omissão do efeito não aumenta os graus de liberdade.

O Modelo B com a inclusão das variáveis preditoras apresentou melhor ajuste entre os dados $\left(X^{2}(8, N=640)=525,52, R^{2}\right.$ Nagelkerke $\left.=0,68 ; p<0,001\right)$ e todas as variáveis preditoras foram relevantes para o modelo. $O$ pseudo $R^{2}$ de Nalgerkerke forneceu evidência de que 0 modelo captou uma parte da influência sofrida pela variável dependente em relação aos fatores da análise.

Um modelo logit foi estimado para cada tipo de ultrapassagem, utilizando a não ultrapassagem (U0) como categoria de referência. A Tabela 27 apresenta os coeficientes dos parâmetros (coluna B) estimados do modelo logit multinomial da ultrapassagem simples (U1) e o modelo logit referente ultrapassagem completa (U2). Como as estimativas dos parâmetros são relativas ao grupo de referência (U0), a interpretação padrão do logit multinomial é que, para uma alteração unitária na variável preditora ou mudança de categoria, o logit do resultado em relação ao grupo de referência altere por sua respectiva estimativa de parâmetro (que está em unidades log-odds),

Analisando o erro padrão dos coeficientes (B), nenhum apresentou valor acima de 2 , que pode ser associado a um indicativo de existência de multicolinearidade. A estatística de Wald é utilizada para avaliar a contribuição dos previsores no modelo, informando se o coeficiente "B" de cada previsor é significativamente diferente de zero. Para o logit U1 a variável preditora VelVL não foi significante para o modelo $(p=0,057)$, mas todas as outras preditoras apresentaram $p>0,001$.

A razão de chance (odds ratio) apresentada na coluna OR da Tabela 27 é um indicador da alteração nas chances resultantes da mudança de uma unidade no previsor. Essa proporção 
de mudança na chance (odds) é interpretada da seguinte forma para preditoras categóricas: a razão de chances compara as chances do resultado da comparação em dois níveis diferentes da preditora. O nível de comparação é apresentado na tabela de regressão logística (Tabela 27) e tem uma razão de chance estimada. As razões de chances maiores que 1 indicam que o resultado da comparação se torna mais provável, em relação ao resultado de referência quando a preditora categórica muda do nível de referência para o nível de comparação. As razões de chances menores que 1, indicam que o resultado da comparação se torna menos provável para o resultado de referência quando a preditora categórica muda do nível de referência para o nível de comparação, dado que as variáveis no modelo são mantidas constantes.

\section{- Ultrapassagem U1 em relação a U0}

No modelo logit U1 (Tabela 27), estimado para realizar uma ultrapassagem simples em relação a não realizar a ultrapassagem para a mudança de uma unidade na distância ao veículo lento (dVL), a chance diminui 0,915 em relação a não ultrapassar, mantendo-se todas as outras variáveis constantes. Para a velocidade do veículo lento a chance de efetuar a ultrapassagem simples aumenta 2,228 quando a velocidade muda de $60 \mathrm{~km} / \mathrm{h}$ para $40 \mathrm{~km} / \mathrm{h}$ em relação a não ultrapassar. Para o tipo de veículo lento a chance do condutor realizar a ultrapassagem simples diminui 0,487 quando muda de caminhão para carro de passeio em relação a não ultrapassar, mantidas as demais condições constantes. E para a distância de ultrapassagem permitida a chance do condutor realizar a ultrapassagem simples também diminui 0,440 quando muda de $560 \mathrm{~m}$ para $446 \mathrm{~m}$ em relação a não realizar a ultrapassagem, mantidas as demais condições constantes.

\section{- Ultrapassagem U2 em relação a U0}

No modelo logit U2 (Tabela 27), estimado para realizar a ultrapassagem completa em relação a não ultrapassar, para a mudança de uma unidade na distância ao veículo lento (dVL), a chance diminui 0,971 em relação a não ultrapassar, mantendo-se todas as outras variáveis constantes. Para a velocidade do veículo lento a chance de efetuar a ultrapassagem completa em relação a não realizar a ultrapassagem aumentou 11,022 quando a velocidade muda de $60 \mathrm{~km} / \mathrm{h}$ para $40 \mathrm{~km} / \mathrm{h}$, mantendo-se as outras variáveis constantes. Para o tipo de veículo lento a chance do condutor realizar a ultrapassagem completa diminui 0,987 na presença de um carro de passeio em relação a um caminhão em relação a não ultrapassar, mantidas as demais condições constantes, porém esta variável preditora não foi significante para o modelo $(p=0,973)$. E para a distância de ultrapassagem, a chance do condutor realizar a 
ultrapassagem completa diminui 0,245 em não realizar a ultrapassagem, quando muda de $560 \mathrm{~m}$ para $446 \mathrm{~m}$, mantidas as demais condições constantes.

Tabela 27 - Parâmetros do modelo multinomial para tipo de ultrapassagem.

\begin{tabular}{|c|c|c|c|c|c|c|c|c|c|}
\hline \multirow{2}{*}{ Tipo U } & \multirow{2}{*}{$\begin{array}{l}\text { Variável } \\
\text { Preditora }\end{array}$} & \multirow{2}{*}{ B } & \multirow{2}{*}{ Erro } & \multirow{2}{*}{ Wald } & \multirow{2}{*}{ df } & \multirow{2}{*}{$\mathbf{p}$} & \multirow{2}{*}{ OR } & \multicolumn{2}{|c|}{$\begin{array}{c}95 \% \text { IC para } \\
\operatorname{Exp}(B)\end{array}$} \\
\hline & & & & & & & & $\begin{array}{l}\text { Limite } \\
\text { inferior }\end{array}$ & $\begin{array}{l}\text { Limite } \\
\text { superior }\end{array}$ \\
\hline \multirow[t]{8}{*}{ U1 } & Intercepto & 8,555 & 0,768 & 124,111 & 1 & $0,000^{* *}$ & & & \\
\hline & $d V L$ & $-0,089$ & 0,008 & 135,837 & 1 & $0,000^{* *}$ & 0,915 & 0,902 & 0,929 \\
\hline & [VelVL=40] & 0,801 & 0,421 & 3,617 & 1 & 0,057 & 2,228 & 0,976 & 5,088 \\
\hline & [VelVL=60] & $0^{b}$ & & & 0 & & & & \\
\hline & [TipoVL=CP] & $-0,719$ & 0,351 & 4,184 & 1 & $0,041^{*}$ & 0,487 & 0,245 & 0,970 \\
\hline & {$[\mathrm{TipoVL}=\mathrm{CA}]$} & $0^{b}$ & & & 0 & & & & \\
\hline & {$[$ DistU $=446]$} & $-0,270$ & 0,350 & 0,597 & 1 & 0,440 & 0,763 & 0,385 & 1,514 \\
\hline & [DistU=560] & $0^{b}$ & & & 0 & & & & \\
\hline \multirow[t]{8}{*}{ U2 } & Intercepto & 2,249 & 0,765 & 8,647 & 1 & $0,003^{*}$ & & & \\
\hline & $\mathrm{dVL}$ & $-0,030$ & 0,006 & 21,523 & 1 & $0,000^{\star *}$ & 0,971 & 0,959 & 0,983 \\
\hline & [VelVL=40] & 2,400 & 0,433 & 30,653 & 1 & $0,000^{* *}$ & 11,022 & 4,713 & 25,776 \\
\hline & [VelVL=60] & $0^{b}$ & & & 0 & & & & \\
\hline & [TipoVL=CP] & $-0,013$ & 0,371 & 0,001 & 1 & 0,973 & 0,987 & 0,477 & 2,044 \\
\hline & [TipoVL=CA] & $0^{b}$ & & & 0 & & & & \\
\hline & [DistU $=446]$ & $-1,408$ & 0,383 & 13,509 & 1 & $0,000^{* *}$ & 0,245 & 0,115 & 0,518 \\
\hline & {$[$ DistU $=560]$} & $0^{\mathrm{b}}$ & & & 0 & & & & \\
\hline
\end{tabular}

a. A categoria de referência é: U0 (não ultrapassagem).

b. Este parâmetro é definido para zero porque é redundante.

Nota: ${ }^{*} p<0,05 ;{ }^{* *} p<0,001$

Fonte: a autora

De maneira geral, a distância ao veículo lento na manobra influencia a decisão de efetuar ou não a ultrapassagem, visto que quanto maior for a distância entre o veículo do participante e o veículo lento, menor será a probabilidade de efetuar a ultrapassagem. Em relação a velocidade do veículo lento a redução de $60 \mathrm{~km} / \mathrm{h}$ para $40 \mathrm{~km} / \mathrm{h}$ aumenta a probabilidade do condutor efetuar a ultrapassagem em ambas as situações de ultrapassagem. Os resultados para o tipo de veículo corroboram a análise exploratória onde para as ultrapassagens simples há uma redução das ocorrências de ultrapassagens quando na presença de caminhão em relação a carro de passeio, mantidas as variáveis preditoras fixas. E por fim, a distância de ultrapassagem permitida apresenta uma redução de probabilidade de ocorrência de ultrapassagens, principalmente do tipo completa, quando a distância permitida diminui, condizente com uma situação real. 
O uso do modelo logit para fazer tais previsões resulta em uma previsão correta global de $84,1 \%$ (Tabela 28). Previsões corretas foram mais frequentes nas ultrapassagens simples $(95,6 \%)$ e nas não ultrapassagens $(83,6 \%)$ do que para as ultrapassagens completas $(22,8 \%)$.

Tabela 28 - Classificação do modelo logit multinomial

\begin{tabular}{c|c|c|c|c}
\hline \multirow{2}{*}{ Observado } & \multicolumn{4}{|c}{ Previsto } \\
\cline { 2 - 5 } & U0 & U1 & U2 & $\begin{array}{c}\text { Porcentagem } \\
\text { Correta }\end{array}$ \\
\hline U0 & 112 & 19 & 3 & $83,6 \%$ \\
U1 & 14 & 408 & 5 & $95,6 \%$ \\
U2 & 10 & 51 & 18 & $22,8 \%$ \\
\hline $\begin{array}{c}\text { Porcentagem } \\
\text { global }\end{array}$ & $21,3 \%$ & $74,7 \%$ & $4,1 \%$ & $\mathbf{8 4 , 1 \%}$ \\
\hline
\end{tabular}




\subsection{CaracterizaÇão do PeRFIL do CONdUtor}

A percepção de segurança do motorista no ambiente de direção é uma influência importante no comportamento e desempenho da condução. Surge a questão de como medir a percepção de segurança, visto que depende, em primeiro lugar, da natureza da informação que chega e de forma secundária, mas muito mais importante, do estado emocional e das características pessoais do indivíduo (WANG; HENSHER; TON, 2002).

Partindo desse pressuposto, definiu-se um procedimento para mensurar o comportamento do condutor (CompCondt) a partir das ultrapassagens realizadas/ não realizadas no percurso simulado, associadas com as características individuais cadastradas.

Primeiramente atribuiu-se uma pontuação para cada tratamento, um peso para cada tipo de ultrapassagem e um peso para cada tipo de tentativa abortada que foram realizadas no trecho de simulação. O somatório resultante foi utilizado para gerar a classificação do comportamento do participante em três níveis de risco: Baixo Risco, Médio Risco e Alto Risco. Os critérios adotados são descritos a seguir:

1) Cada tratamento recebeu uma pontuação em função do nível do fator, atribuindo-se 0,25 para baixo risco e 0,75 para alto risco. O somatório das pontuações dos três fatores corresponde à pontuação total do tratamento (ScTrat). Por exemplo, ultrapassar um carro de passeio $(0,25)$ que conduz à uma velocidade de $60 \mathrm{~km} / \mathrm{h}(0,75)$ em um segmento com distância de ultrapassagem permitida de $446 \mathrm{~m}(0,75)$ totaliza a pontuação de 1,75 para o tratamento. Assim, o tratamento com maior risco foi o 60CA446 com 2,25 pontos e o tratamento com menor risco foi o $40 \mathrm{CP} 560$ com 0,75 pontos (Tabela 29).

Tabela 29 - Pontuação dos tratamentos.

\begin{tabular}{cc|cc|cc|c}
\hline VelVL & $\begin{array}{c}\text { Pontuação } \\
\text { VelVL }\end{array}$ & Tipo_VL & $\begin{array}{c}\text { Pontuação } \\
\text { TipoVL }\end{array}$ & DistUltra & $\begin{array}{c}\text { Pontuação } \\
\text { DistUltra }\end{array}$ & $\begin{array}{c}\text { Pontuação } \\
\text { Total } \\
\text { (ScTrat) }\end{array}$ \\
\hline $40 \mathrm{~km} / \mathrm{h}$ & 0,25 & Carro Passeio & 0,25 & 446 & 0,75 & 1,25 \\
$60 \mathrm{~km} / \mathrm{h}$ & 0,75 & Carro Passeio & 0,25 & 446 & 0,75 & 1,75 \\
$40 \mathrm{~km} / \mathrm{h}$ & 0,25 & Caminhão & 0,75 & 446 & 0,75 & 1,75 \\
$60 \mathrm{~km} / \mathrm{h}$ & 0,75 & Caminhão & 0,75 & 446 & 0,75 & 2,25 \\
$40 \mathrm{~km} / \mathrm{h}$ & 0,25 & Carro Passeio & 0,25 & 560 & 0,25 & 0,75 \\
$60 \mathrm{~km} / \mathrm{h}$ & 0,75 & Carro Passeio & 0,25 & 560 & 0,25 & 1,25 \\
$40 \mathrm{~km} / \mathrm{h}$ & 0,25 & Caminhão & 0,75 & 560 & 0,25 & 1,25 \\
$60 \mathrm{~km} / \mathrm{h}$ & 0,75 & Caminhão & 0,75 & 560 & 0,25 & 1,75 \\
\hline
\end{tabular}


2) Aos tipos de ultrapassagem e tipos de tentativas foram atribuídos pesos de ponderação.

a. A não ultrapassagem (U0) e a não tentativa de ultrapassagem (A0) receberam o peso 0;

b. A ultrapassagem simples sem a presença do veículo oposto na manobra (U1) e a tentativa de ultrapassagem sem risco (A1) receberam o peso 1;

c. A ultrapassagem completa com a presença do veículo oposto (U2) e a tentativa de ultrapassagem com risco $(\mathrm{A} 2)$ receberam o peso 2;

3) A pontuação no segmento foi calculada pelo produto da pontuação do tratamento (ScTrat) e peso do tipo de ultrapassagem (TipoU), adicionado ao produto da pontuação do tratamento (ScTrat) e peso do tipo de tentativa (TipoA). A soma total da pontuação de todos os segmentos para o participante resulta na pontuação do comportamento do condutor (CompCondt) no experimento.

$$
\text { CompCondt }=\sum_{i=1}^{n}[(\operatorname{ScTrat} * \operatorname{TipoU})+(\operatorname{ScTrat} * \operatorname{TipoA})]
$$

Com a pontuação do comportamento do condutor (CompCondt), procedeu-se a classificação do nível de risco do condutor. Para segmentação da variável CompCondt utilizou-se a análise de cluster de duas etapas (two step cluster) com medida de distância Log da verossimilhança que resultou em 3 agrupamentos.

Os agrupamentos identificam o nível de risco do condutor (NRiscoCondt) nomeados como Baixo, Médio e Alto, a ser utilizado como variável dependente para caracterização do perfil do condutor.

Em seguida aplicou-se a técnica de árvore de decisão com algoritmo CART para as variáveis descritas na Tabela 30 extraídas do cadastro de participação do participante e agrupadas de acordo com o nível de risco do condutor.

As informações do cadastro de participantes do tipo variável contínua (Faixa etária, Tempo de habilitação e Quilometragem percorrida mensal) foram categorizadas para posterior inserção na análise de caracterização do perfil. Os atributos das variáveis independentes são apresentados na Tabela 30. 
Tabela 30 - Descrição das variáveis do cadastro de participantes.

\begin{tabular}{|c|c|c|c|c|c|c|}
\hline \multirow{2}{*}{$\mathrm{Nr}$} & \multirow{2}{*}{\multicolumn{2}{|c|}{ Descrição das Variáveis }} & \multicolumn{3}{|c|}{$\begin{array}{c}\text { Nível de Risco do } \\
\text { Condutor }\end{array}$} & \multirow{2}{*}{$\begin{array}{c}\text { Total } \\
(\%)\end{array}$} \\
\hline & & & $\begin{array}{l}\text { Baixo } \\
(\%)\end{array}$ & $\begin{array}{l}\text { Médio } \\
(\%)\end{array}$ & $\begin{array}{l}\text { Alto } \\
(\%)\end{array}$ & \\
\hline \multirow[t]{5}{*}{1} & \multirow{5}{*}{$\begin{array}{l}\text { Rodovia Pista } \\
\text { Simples } \\
\text { (RodPistaSimples) }\end{array}$} & Não dirijo & 83,3 & 16,7 & 0,0 & 7,5 \\
\hline & & Algumas vezes por ANO & 34,5 & 34,5 & 31,0 & 36,3 \\
\hline & & Algumas vezes por MÊS & 61,3 & 32,3 & 6,5 & 38,8 \\
\hline & & Algumas vezes por SEMANA & 45,5 & 36,4 & 18,2 & 13,8 \\
\hline & & Todos os DIAS & 33,3 & 33,3 & 33,3 & 3,8 \\
\hline \multirow[t]{3}{*}{2} & \multirow{3}{*}{$\begin{array}{l}\text { Prioridade } 1 \\
\text { (Prior1) }\end{array}$} & Distância de ultrapassagem (Dist) & 50,0 & 36,8 & 13,2 & 47,5 \\
\hline & & Tipo do veículo lento (TipoVL) & 33,3 & 55,6 & 11,1 & 11,3 \\
\hline & & $\begin{array}{l}\text { Velocidade do veículo lento } \\
\text { (VelVL) }\end{array}$ & 54,5 & 21,2 & 24,2 & 41,3 \\
\hline \multirow[t]{2}{*}{3} & \multirow{2}{*}{$\begin{array}{l}\text { Faixa Etária } \\
\text { (GFaixaEtaria) }\end{array}$} & $<=25$ & 50,0 & 35,7 & 14,3 & 52,5 \\
\hline & & $>25$ & 50,0 & 28,9 & 21,1 & 47,5 \\
\hline \multirow[t]{2}{*}{4} & \multirow{2}{*}{$\begin{array}{l}\text { Tempo de } \\
\text { Habilitação } \\
\text { (GTempoHab) }\end{array}$} & $<=5$ & 48,9 & 35,6 & 15,6 & 56,3 \\
\hline & & $>5$ & 51,4 & 28,6 & 20,0 & 43,8 \\
\hline \multirow[t]{2}{*}{5} & \multirow{2}{*}{$\begin{array}{l}\text { Genero do } \\
\text { participante } \\
\text { (Genero) }\end{array}$} & Feminino & 56,0 & 32,0 & 12,0 & 31,3 \\
\hline & & Masculino & 47,3 & 32,7 & 20,0 & 68,8 \\
\hline \multirow[t]{4}{*}{6} & \multirow{4}{*}{$\begin{array}{l}\text { Quilomentragem } \\
\text { percorrida mensal } \\
\text { (CatKmMes) }\end{array}$} & $<100 \mathrm{~km} / \mathrm{mes}$ & 50,0 & 37,5 & 12,5 & 30,0 \\
\hline & & 100 a $500 \mathrm{~km} / \mathrm{mes}$ & 56,0 & 28,0 & 16,0 & 31,3 \\
\hline & & 500 a $1000 \mathrm{~km} / \mathrm{mes}$ & 50,0 & 21,4 & 28,6 & 17,5 \\
\hline & & $>1000 \mathrm{~km} / \mathrm{mes}$ & 41,2 & 41,2 & 17,6 & 21,3 \\
\hline \multirow[t]{2}{*}{7} & \multirow{2}{*}{$\begin{array}{l}\text { Sofreu algum tipo } \\
\text { de acidente } \\
\text { (SofreuAcid) }\end{array}$} & Não sofreu acidente & 53,7 & 25,9 & 20,4 & 67,5 \\
\hline & & Sofreu acidente & 42,3 & 46,2 & 11,5 & 32,5 \\
\hline
\end{tabular}

A Tabela 31 exibe as importâncias normalizadas das variáveis independentes que apresentaram maior impacto para detecção de padrões no perfil do condutor e que foram utilizadas no modelo da árvore de decisão. A variável que reporta a frequência de direção em pista simples (RodPistaSimples) é a mais importante. As outras variáveis que se destacaram em nível de importância foram gênero (Genero) e tempo de habilitação (GTempoHab) com valores próximos de $60 \%$. As demais variáveis apresentaram importância relativamente alta entre $41 \%$ e $54 \%$.

Tabela 31 - Importância das variáveis normalizadas

\begin{tabular}{l|l|r|r}
\hline \multicolumn{2}{c|}{ Variável independente } & Importância & $\begin{array}{r}\text { Importância } \\
\text { normalizada }\end{array}$ \\
\hline RodPistaSimples & Frequência de direção em pista simples & 0,050 & 100,0 \\
Gênero & Gênero do participante & 0,030 & 59,3 \\
GTempoHab & Tempo de habilitação & 0,028 & 55,8 \\
GFaixaEtaria & Faixa etária & 0,027 & 53,8 \\
SofreuAcid & Sofreu acidente como motorista & 0,020 & 40,8 \\
\hline
\end{tabular}


O percentual de acertos obtido pela árvore de decisão com o algoritmo CART foi de 59\%. A árvore de decisão resultante apresentou 13 nós (7 destes são nós terminais). A Figura 38 apresenta a árvore de decisão resultante, demonstrando o número identificador do nó, o percentual da classificação, baseada na variável dependente, e o nível de risco do condutor (Baixo, Médio e Alto) é indicado em cada nó.

Dentre as variáveis independentes, a mais importante para a segmentação dos dados da amostra foi a RodPistaSimples (frequência de condução em pista simples) que dividiu os participantes em dois ramos (nó 1 e nó 2). O nó 1 (não dirige em pista simples e dirige algumas vezes por mês) apresentou menor probabilidade de condutores de alto risco com 5,4\%, enquanto o nó 2 (dirige todos os dias, algumas vezes por semana e algumas vezes por ano) concentrou a maior probabilidade de condutores de alto risco com $27,9 \%$

Em seguida o nó 1 dividiu-se pela variável Genero (gênero do condutor) e ao avaliar as maiores probabilidades dessa divisão, percebe-se que se o gênero for feminino a probabilidade de baixo risco foi de $88,9 \%$ (nó 3) e 0,0\% para alto risco. E, caso masculino, a probabilidade de alto risco foi de $7,1 \%$ (nó 4), enquanto a probabilidade de baixo risco foi de $57,1 \%$, um pouco menor que entre as mulheres. A probabilidade de risco médio para os homens $(35,7 \%)$ foi maior que para as mulheres $(11,1 \%)$. Esse indicativo mostra uma tendência da influência do gênero na classificação de risco do condutor. O resultado encontrado corrobora estudos que avaliam o efeito do gênero em relação à agressividade de condução, que indicam que homens e os condutores mais jovens são mais agressivos em relação às mulheres e os condutores mais velhos (SHINAR; COMPTON, 2004).

O nó 4 dividiu-se em nó 7 e nó 8 através da variável GFaixaEtaria (grupo de faixa etária). Se a idade for maior que 25 anos, então a probabilidade de condutores de baixo risco foi de $77,8 \%$ e $0,0 \%$ para alto risco. E se a idade for menor ou igual a 25 anos a probabilidade de condutores de alto risco aumentou para $10,5 \%$ e o médio risco aumentou para $42,1 \%$. Essa condição pode estar relacionada à menor experiência em avaliar os riscos e, portanto, maior propensão a cometer erros.

O nó 2 dividiu-se em nó 5 e nó 6 através da variável SofreuAcid (o condutor sofreu acidente como condutor). Se o condutor já havia sofrido algum tipo de acidente a probabilidade para médio risco foi de $57,1 \%$ e de alto risco foi de $21,4 \%$. Caso o condutor nunca tenha sofrido algum tipo de acidente, a probabilidade de médio risco diminuiu para $24,1 \%$ e de alto risco aumentou para 31,0\%. Esse resultado associa que a ocorrência de algum tipo de acidente na vida do condutor o induz na redução da probabilidade de alto risco, visto que o condutor tende a aumentar a segurança na direção e assim se arrisca menos. 
Em seguida, o nó 5 dividiu-se pela variável GTempoHab (tempo de habilitação do condutor) onde se o tempo de habilitação foi maior que 5 anos, a probabilidade de baixo risco se destacou com 42,9\%, e quando o tempo de habilitação foi menor ou igual a 5 anos, a probabilidade de baixo risco foi de $0,0 \%$ e o médio risco aumentou consideravelmente para $85,7 \%$. Os resultados indicaram que quanto menor o tempo de habilitação maior o nível de risco do condutor.

Por fim, o nó 6 se dividiu pela variável GFaixaEtaria (grupo de faixa etária): quando a idade do condutor foi maior que 25 anos a probabilidade de alto risco foi de $43,8 \%$ (nó 11), enquanto que, quando a idade do condutor foi menor que 25 anos a probabilidade de alto risco reduziu para $15,4 \%$ (nó 12 ).

Figura 38 - Árvore de decisão para classificação dos condutores.

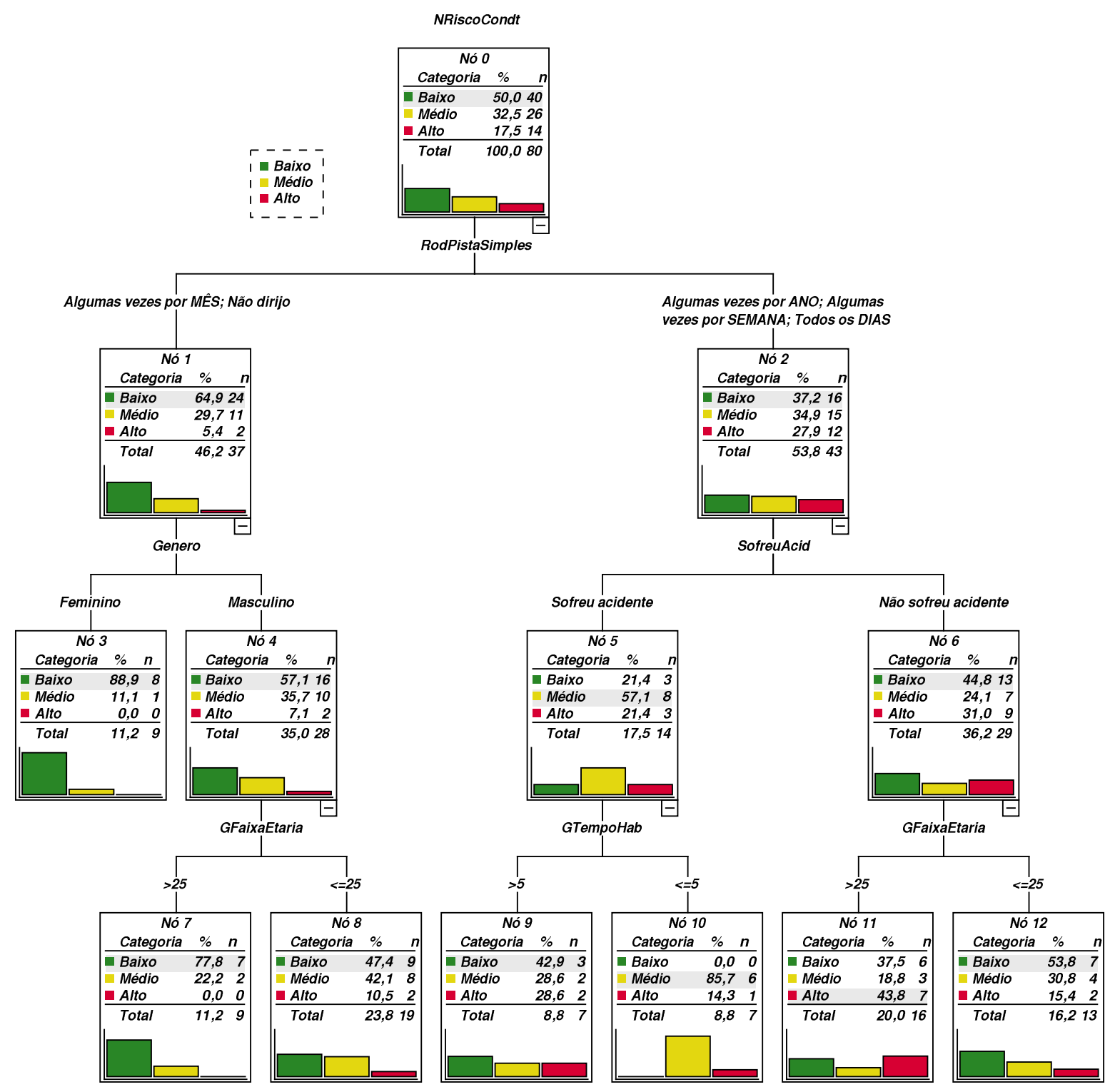


Apesar da amostra ser relativamente pequena (80 participantes) para este tipo de técnica, os resultados encontrados foram condizentes com as análises de registros de acidentes agrupados por pessoas do DATATRAN, no período de 2008 a 2018 (Figura 39). Nos quais, dentre os acidentes do tipo colisão frontal os condutores do gênero masculino correspondem à média anual de $94 \%$ dos envolvidos, esse percentual corresponde a aproximadamente 15 mil condutores mortos em 10 anos. Em relação à faixa etária, os condutores entre 20 e 50 anos são os que mais se envolvem nesse tipo de acidente.

Sendo assim, a técnica de árvore de decisão com algoritmo CART apresenta-se com potencial aplicação para classificação do nível de risco do condutor e requer investigações futuras utilizando-se amostras robustas e outros níveis de classificação.

Figura 39 - Condutores envolvidos em acidentes do tipo colisão frontal por gênero e faixa etária entre 2008 e 2018 (DATATRAN).

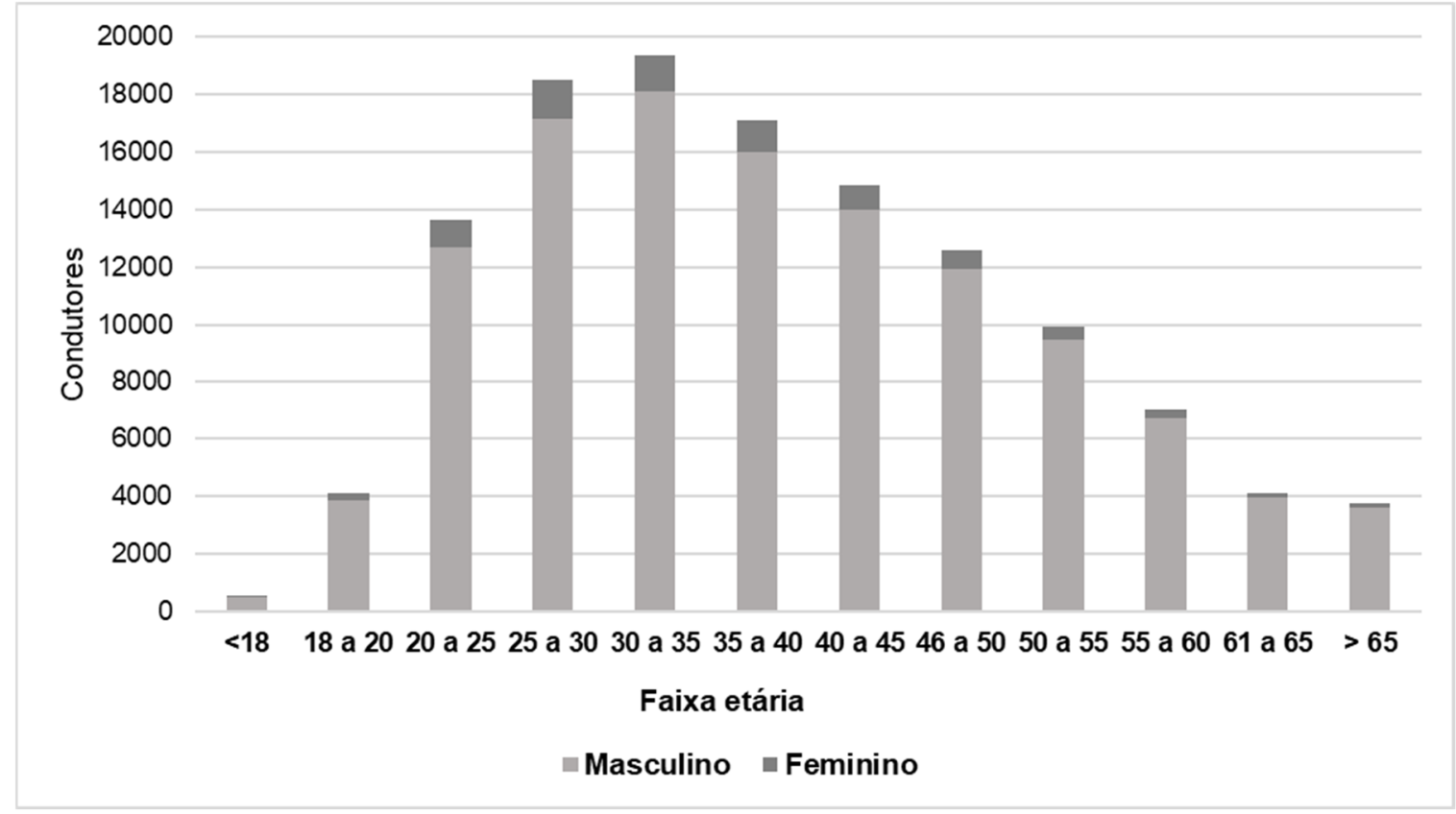

Fonte: DATATRAN, 2018*

*somente dados válidos 


\subsection{Comparativo ENTRE OS MODELOS DE DVU}

Conforme citado na revisão de literatura, o modelo recomendado para a distância de visibilidade de ultrapassagem utilizado atualmente no Brasil apoia-se no modelo da AASHTO de 1994. Baseando-se nesse modelo foram analisados os parâmetros das ultrapassagens realizadas no simulador e as distâncias de ultrapassagens obtidas no simulador comparadas ao modelo do DNIT (1999).

O experimento possibilitou a realização de 640 ultrapassagens. Desse total, foram realizadas 79 ultrapassagens completas (U2) de acordo com o modelo do DNIT (1999), onde a ultrapassagem do veículo lento ocorre com a presença do veículo oposto na faixa contrária da via.

A Tabela 32 apresenta as ocorrências das ultrapassagens completas (U2) por tratamento, onde observa-se que este tipo de ultrapassagem ocorreu com maior frequência quando a velocidade do veículo lento foi de $40 \mathrm{~km} / \mathrm{h}$ associada à distância de ultrapassagem permitida de $560 \mathrm{~m}$.

\begin{tabular}{|c|c|}
\hline Tratamento & Ultrapassagem U2 \\
\hline $40 \mathrm{CP} 446$ & 7 \\
\hline $40 \mathrm{CP} 560$ & 26 \\
\hline 40CA446 & 7 \\
\hline $40 \mathrm{CA} 560$ & 15 \\
\hline $60 \mathrm{CP} 446$ & 4 \\
\hline $60 \mathrm{CP} 560$ & 9 \\
\hline $60 \mathrm{CA} 446$ & 3 \\
\hline 60CA560 & 8 \\
\hline Total & 79 \\
\hline
\end{tabular}

\subsubsection{Parâmetros das ultrapassagens - simulação}

Os parâmetros das ultrapassagens no simulador correspondentes aos parâmetros do modelo do DNIT ( $t_{1}, d_{1}, v, t_{2}, d_{2}, d_{3}$ e $d_{4}$ ) foram extraídos e analisados individualmente e os resultados são descritos a seguir.

\section{a) Tempo de reação e percepção $\left(t_{1}\right)$}

O tempo de reação-percepção não é crítico quando a visibilidade à frente é clara (uma vez que a percepção de um veículo em o condutor que ultrapassa pode ocorrer continuamente, 
enquanto a manobra de passagem está em andamento), mas torna-se crítico quando a distância da visão é limitada.

Os tempos de reação-percepção utilizados nos modelos geralmente variam de 0,9 a 2,5 segundos, dependendo do tipo de situação a ser detectada pelo motorista. Alguns estudos tipificam 0,9 segundos para uma condição de alerta e 1,3 segundos para uma condição de surpresa. O valor mais conservador do tempo de reação e percepção usado em projeto é de 2,5 segundos, usado nos critérios de projeto da AASHTO para a distância de visibilidade de parada (HARWOOD et al., 2008).

O tempo de percepção e reação foi em média de 2 segundos, desde o momento em que o condutor inicia a aproximação do eixo até o ponto em que o pneu frontal esquerdo toca o eixo da via e inicia a invasão da faixa esquerda.

\section{b) Velocidade do veículo que ultrapassa (v)}

O modelo do DNIT (1999) assim como a AASHTO (2004), assume que a velocidade média do veículo que ultrapassa é menor que a velocidade de projeto da rodovia. A velocidade média registrada para as ultrapassagens completas no simulador foi de $97 \mathrm{~km} / \mathrm{h}$, com a velocidade de projeto da via de $80 \mathrm{~km} / \mathrm{h}$. A diferença de $17 \mathrm{~km} / \mathrm{h}$ é condizente com a diferença obtidas em estudos de campo (HARWOOD et al., 2008) que obtiveram uma diferença próxima de 10 $\mathrm{km} / \mathrm{h}$. Considerando que em ambiente simulado as pessoas tendem a aumentar a velocidade durante a condução os valores são compatíveis entre si.

c) Diferença de velocidade entre o veículo que ultrapassa e o veículo ultrapassado (m)

A diferença de velocidade entre os veículos envolvidos na manobra foi avaliada em função da velocidade do veículo a ser ultrapassado. Quando a velocidade do veículo lento era de 40 $\mathrm{km} / \mathrm{h}$ a diferença média foi de $52 \mathrm{~km} / \mathrm{h}$ e quando na presença de um veículo a $60 \mathrm{~km} / \mathrm{h}$ a diferença média foi de $48 \mathrm{~km} / \mathrm{h}$. A diferença média de velocidades apresentada por Glennon (1988) foi de 13 a $19 \mathrm{~km} / \mathrm{h}$. Contudo os modelos sugeridos por Glennon (1988) e Hassan et al., (1996) avaliam que os valores de DVU não são sensíveis à velocidade diferencial entre os veículos, que foram confirmadas pelos resultados obtidos na simulação onde os condutores estiveram mais atentos aos limites de velocidade individuais desenvolvidos. 
d) Headway entre o veículo que ultrapassa e o veículo ultrapassado $\left(\mathrm{h}_{1}\right)$

O headway médio entre o veículo que ultrapassa e o veículo ultrapassado foi de 0,8 segundos, consistente com o valor de 1 segundo recomendado por Glennon (1988) e Hassan et al. (1996).

\section{e) Tempo de ocupação da faixa da esquerda pelo veículo que ultrapassa $\left(t_{2}\right)$}

O modelo do DNIT (1999) e AASHTO (2004) assumem que o tempo gasto ocupando a faixa da esquerda pelo veículo que ultrapassa varia entre 9,3 segundos (velocidade média de 56,2 $\mathrm{km} / \mathrm{h}$ ) e 11,3 segundos (velocidade média de $99,8 \mathrm{~km} / \mathrm{h}$ ). $\mathrm{E}$ os resultados dos estudos de campo para adequação dos parâmetros da AASHTO (2011) o tempo tz registrado foi de 9,9 segundo $(106 \mathrm{~km} / \mathrm{h})$ e 11,3 segundos $(114 \mathrm{~km} / \mathrm{h})$, diferente do esperado que seria uma redução do tempo de ocupação mediante o aumento de potência dos veículos modernos.

O valor obtido no simulador foi em média de 6 segundos e, portanto, existe a necessidade da verificação de dados coletados nas rodovias brasileiras, visto haver discrepância com os próprios valores do modelo e dados obtidos em campo nos Estados Unidos (HARWOOD et al., 2008). Porém, compatível com os tempos totais de ultrapassagem encontrados em experimentos similares com o uso de simulador de direção (HEGEMAN; BROOKHUIS; HOOGENDOORN, 2005; VLAHOGIANNI, 2013).

\section{f) Distância percorrida pelo veículo que ultrapassa na faixa da esquerda $\left(d_{2}\right)$}

A distância percorrida pelo veículo que ultrapassa na faixa esquerda computada no simulador de direção foi de 174 metros, sendo 163 metros para distância de ultrapassagem permitida de 446 m e 178 metros para distâncias de 560 m. Conforme citado anteriormente, a distância corresponde ao tempo médio de ocupação com velocidade média obtida no simulador, sendo que necessitam de verificação com dados obtidos em campo a fim de validação.

\section{g) Intervalo de folga entre o veículo que ultrapassa e o veículo ultrapassado após a conclusão da ultrapassagem $\left(h_{2}\right)$}

O headway entre o veículo que ultrapassa e o veículo ultrapassado ao retornar para a faixa da direita e concluir a ultrapassagem foi de 0,4 segundos que é um valor consistente com a recomendação de 1 segundo feita por Glennon (1988) e Hassan (HASSAN; EASA; ABD EL HALIM, 1996). 
h) Distância de folga entre o veículo que ultrapassa e o veículo oposto $\left(d_{3}\right)$

O modelo DNIT recomenda que a distância mínima entre o veículo que ultrapassa e o veículo oposto após a conclusão da ultrapassagem deve ser em torno de 30 a 90 metros. O modelo de Glennon (1988) e Hassan (HASSAN; EASA; ABD EL HALIM, 1996) sugerem que esse intervalo seja de 1 segundo. O valor obtido no simulador foi de 2,2 segundos, sendo que para a distância permitida de $446 \mathrm{~m}$ foi de 1,7 segundos e para a distância permitida de $560 \mathrm{~m}$ foi de 2,3 segundos.

Os valores resultantes são maiores que os encontrados nos modelos, contudo deve-se ressaltar que a maioria das ultrapassagens completas (84\%) iniciaram antes da zona permitida de ultrapassagem, garantido assim que a distância de folga entre o veículo oposto e o veículo que ultrapassa fosse mais extensa. E que provavelmente o condutor não avaliou a presença de um veículo oposto na faixa contrária.

\section{i) Distância percorrida pelo veículo oposto durante a ultrapassagem ( $\left.d_{4}\right)$}

O resultando anterior refletiu na distância percorrida pelo veículo oposto durante a ultrapassagem, pois devido a antecipação do início da ultrapassagem pelo veículo do participante, a distância média percorrida pelo veículo oposto foi de 57 metros.

\subsubsection{Distância de ultrapassagem: simulador $\mathrm{x}$ modelo DNIT}

Após a análise dos parâmetros individuais calculou-se as distâncias totais de ultrapassagens no simulador e foram comparadas com as distâncias de referência 446 e 560 metros utilizadas no experimento através de um teste t-student para uma amostra em relação ao valor de referência.

Foram realizadas 21 ultrapassagens na distância de ultrapassagem permitida de 446 metros e 58 ultrapassagens na distância de 560 metros. Os valores de ultrapassagem apresentaram distribuição normal tanto na distância de 446 metros $(D(21)=0,116 ; p=0,200)$ quanto na distância de 560 metros $(D(58)=0,114 ; p=0,06)$.

Além disso, com os parâmetros de ultrapassagem ( $\left.t_{1}, a, v, m, t_{2}, v\right)$ obtidos na simulação, calculou-se a distância de ultrapassagem $\left(d_{1}+d_{2}+d_{3}+d_{4}\right)$ do modelo DNIT através das equações (1), (2), (3) e (4). As distâncias calculadas pelo modelo DNIT foram comparadas com as distâncias obtidas na simulação através de um teste t-pareado.

Os resultados são apresentados a seguir agrupados em relação à distância de ultrapassagem delimitada no trecho simulado. 


\section{- DVU 446 metros}

O teste $t$-student para a distância de ultrapassagem realizada na zona permitida de 446 metros mostrou que a média da distância de ultrapassagem obtida no simulador $(M=470,79 ; S D=$ $107,54), t(20)=1,06 ; p=0,30 ; d=0,23$ não difere do valor de referência de 446 metros.

Quando comparamos, através do teste t-pareado, os valores de distância de ultrapassagem obtida no simulador com a distância calculada pelo modelo de DVU do DNIT, a distância de ultrapassagem obtida no simulador, em média $(M=470,79$; $S E=23,47)$, foi maior que a distância de ultrapassagem calculada pelo modelo do DNIT $(M=380,43 ; S E=18,21), t(20)=$ $3,00 ; p=0,007)$.

\section{- DVU 560 metros}

E o teste $t$-student para a distância de ultrapassagem realizada na zona permitida de 560 metros mostrou que a média da distância de ultrapassagem obtida no simulador $(M=551,56$; $S D=116,91), t(57)=-0,55, p=0,58 ; d=0,07$ não difere do valor de referência de 560 metros.

Ao comparar os valores de distância de ultrapassagem obtida no simulador com a distância calculada pelo modelo do DNIT por meio do teste t-pareado, em média, a distância de ultrapassagem obtida no simulador $(M=551,56$; $S E=15,35)$ foi maior que a distância de ultrapassagem calculada pelo modelo do DNIT $(M=396,52 ; S E=11,44), t(57)=7,91 ; p<$ 0,001).

As distâncias de ultrapassagem $\left(d_{1}+d_{2}+d_{3}+d_{4}\right)$ obtidas no simulador foram compatíveis com as zonas de ultrapassagem demarcadas no experimento. Destaca-se que essas distâncias são maiores que as distâncias definidas na AASHTO (2011), onde para a velocidade de projeto de $80 \mathrm{~km} / \mathrm{h}$, a distância mínima recomendada é de 245 metros. Mas, ao computar a distância de ultrapassagem $\left(d_{1}+d_{2}\right)$ sem contabilizar as distâncias $d_{3}$ e $d_{4}$ a distância média de ultrapassagem foi de 225 metros.

Os parâmetros e as distâncias totais de ultrapassagem resultantes devem ser utilizados com parcimônia devido à ausência de informações de campo de ultrapassagens das rodovias brasileiras de pista simples, para efeito comparativo. Porém, as informações detalhadas sobre o movimento dos veículos, a interação entre o motorista que ultrapassa e as condições de ultrapassagem podem ser explorada em maior detalhe através dos dados coletados na simulação e são uma primeira abordagem no estudo deste tipo de manobra. 


\subsection{VALIDAÇÃO DO EXPERIMENTO EM SIMULADOR DE DIREÇÃO}

Os simuladores de direção possuem vários graus de sofisticação, realismo e custos associados, mas apesar do progresso significativo é essencial saber até que ponto os dados coletados refletem os resultados que seriam obtidos no mundo real. Este problema multidimensional é chamado de validação de simulação e tem sido uma preocupação nas pesquisas que envolvem fatores humanos (DENIAUD et al., 2015).

Fisher et al. (2011) ressaltam que cada simulador deve ser validado para um uso específico, pois cada experimento tem seus próprios requisitos relacionados a diferentes aspectos da tarefa de dirigir. Além disso, as características dos participantes também podem influenciar a validade, como a experiência de condução, sua motivação e o desconforto no simulador (BLANA, 1996).

Geralmente, a validade relativa de ambiente virtual envolve uma comparação com resultados de estudos realizados em situações reais. Essa verificação é dispendiosa, pois envolve a necessidade de instrumentação do veículo, extremamente complexa, pois os eventos devem ter um controle rigoroso em um estudo de campo (DENIAUD et al., 2015). Para isso, utilizamse métricas de desempenho e comportamentais como: velocidade, posição lateral (TÖRNROS, 1998; GODLEY; TRIGGS; FILDES, 2002; SHECHTMAN et al., 2009), controle longitudinal e atenção visual (WANG et al., 2010).

Blaauw (1982) propôs a validade comportamental que se refere ao nível de correspondência entre os comportamentos em ambiente simulado e nas estradas reais e é segmentada em grande parte da literatura sobre simuladores de direção em absoluta e relativa (REIMER; D'AMBROSIO; COUGHLIN, 2007). Törnros (1998) argumenta que a validade comportamental relativa é suficiente para estabelecer a eficiência dos simuladores de direção como ferramentas úteis para pesquisa.

Outro conceito de validação que vem se destacando na área de pesquisa em simuladores é a validade ecológica, advindo das pesquisas em psicologia. A validade ecológica caracterizase pela análise do comportamento dentro de contextos ambientais específicos, ou ainda, pode ser definida como uma medida de aproximação da pesquisa ao mundo real. Apresenta-se ainda como alternativa para medir diretamente e comparar estatisticamente o comportamento do simulador e da rodovia.

Essa modalidade de validação consiste em examinar a validade do simulador medindo apenas o desempenho no simulador. Por exemplo, a velocidade que homens e mulheres dirigem em simulador, comparado com o comportamento em estrada real, geralmente mostra 
uma tendência em que os homens dirigem mais rápido do que as mulheres. É uma forma de validade ecológica, pois reflete os padrões reais de comportamento na estrada. Dessa forma, os simuladores podem ser validados para padrões gerais de comportamento, sem medir diretamente o desempenho na estrada como parte do estudo (MULLEN et al., 2011).

É um método menos direto e robusto de estabelecer validade do que o físico. No entanto, pode ser útil na avaliação da validade de um simulador, permitindo conclusões sobre o padrão geral de comportamento no simulador comparado com o comportamento no mundo real (MULLEN et al., 2011).

A validade do simulador tem relevância no contexto desta pesquisa específica pela importância do nível de similaridade dos comportamentos de condução em ambiente simulado com a condição real. Sendo assim, para obter a validade ecológica utilizou-se três informações coletadas durante o experimento, que foram: a avaliação individual dos participantes sobre a simulação, a posição lateral nas curvas durante o experimento e o comportamento visual do condutor nas ultrapassagens.

\subsubsection{Avaliação pelo participante}

Com o surgimento das primeiras pesquisas sobre a realidade virtual, difundiu-se um novo conceito que avalia a questão da validade ecológica do comportamento observado em ambientes virtuais, conhecido como 'presença' e interessou uma ampla gama de áreas acadêmicas (DENIAUD et al., 2015). E pode ser definida como a experiência subjetiva de estar em um lugar ou ambiente, mesmo que fisicamente situado em outro (WITMER; SINGER, 1998).

Esta abordagem de validação por meio de respostas auto relatadas pelos participantes utilizou as respostas do questionário de avaliação da simulação preenchido pelo participante ao final do experimento.

A escala Likert requer que os participantes indiquem seu grau de concordância ou discordância com declarações relativas à opinião que está sendo mensurada. O questionário de avaliação utilizou uma escala do tipo Likert gradativa de 6 pontos, fazendo com que o participante se posicione de forma positiva ou negativamente em cada questão.

A pontuação total da opinião de cada participante é dada pela somatória das pontuações obtidas para cada questão. A taxa de concordância e discordância é apresentada na Figura 40 e mostra que todas as questões possuem mais de $66 \%$ de concordância positiva que indica 
uma boa avaliação da simulação e equipamento. Apenas a questão Q17 "Os mecanismos de direção do cockpit interferiram a realização de alguma tarefa?" apresentou uma taxa de discordância de $34 \%$ que pode estar relacionado com a sensibilidade do volante relatada por alguns participantes.

O feedback dos participantes é importante para auxiliar na validação dos resultados obtidos, visto que o equipamento, a qualidade da projeção e a taxa de renderização podem afetar a resposta do condutor no experimento. A taxa de concordância positiva é um indicativo de que os participantes não foram prejudicados e avaliaram positivamente o equipamento.

Figura 40 - Resultados do questionário de avaliação da simulação.

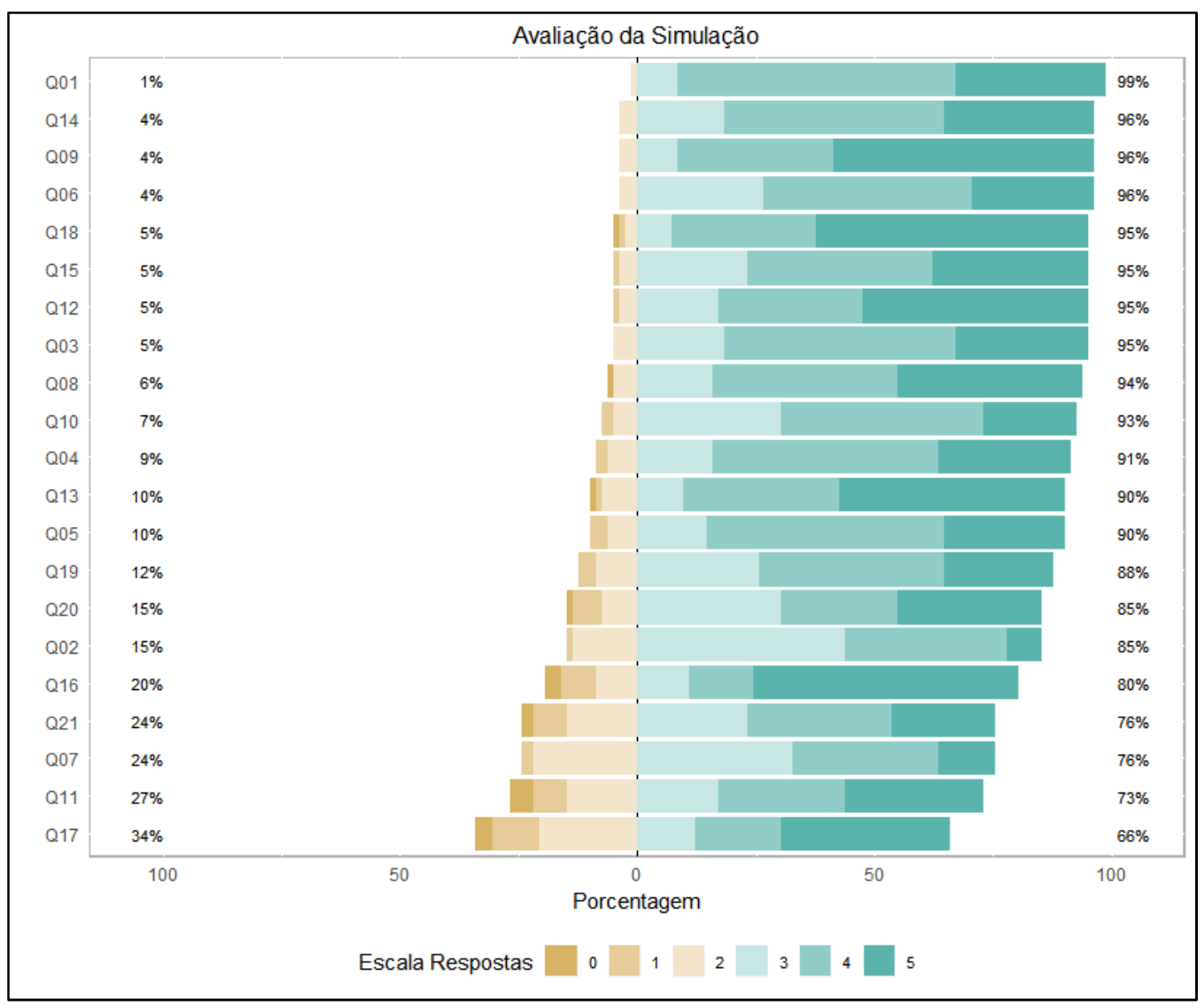

Fonte: a autora

A questão 22 incluída ao final do questionário de avaliação da simulação solicitou ao participante que indicasse os fatores que o influenciam a realizar uma manobra de ultrapassagem. Como alternativas foram apresentados os fatores utilizados no delineamento do experimento.

Em relação a ordem de prioridades, a distância de ultrapassagem com $48 \%$ foi indicada como prioridade 1, seguida da velocidade do veículo lento com $41 \%$. Como prioridade 2, a velocidade do veículo lento com $36 \%$ das respostas e como prioridade 3 o tipo do veículo com 
56\% dos participantes. Sendo assim, a ordem de prioridade relatada pela maioria dos participantes foram: (1) distância de ultrapassagem permitida; (2) velocidade do veículo lento e (3) o tipo de veículo lento. Os resultados são apresentados na Figura 41.

Figura 41 - Ordem de prioridades dos fatores que influenciam na ultrapassagem.

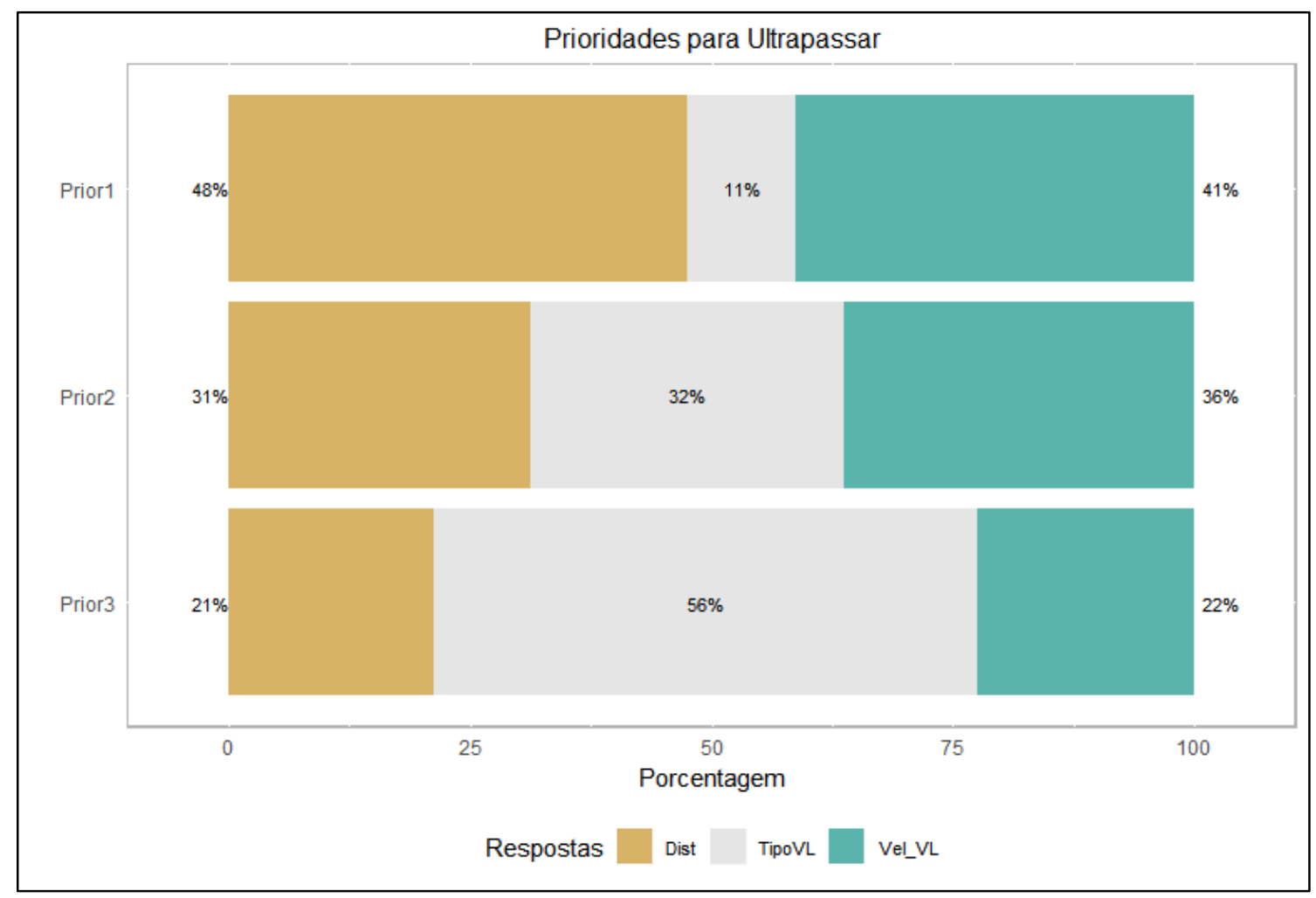

Fonte: a autora

As prioridades relatadas pelos participantes ratificam os resultados obtidos pela ANOVA de medidas repetidas que indicaram que a velocidade do veículo lento e a interação com a distância de ultrapassagem foram os fatores que tiveram maior efeito sobre a variável resposta, bem como que, o tipo de veículo lento não teve influência significativa sobre o tipo de ultrapassagem.

A correlação entre as respostas do participante e o resultado das análises estatística da simulação pelos resultados da ANOVA de medidas repetidas é um indicativo de validade do simulador apontando, que os participantes se comportaram em ambiente simulado da mesma forma que reportaram quando questionados sobre os fatores que o influenciam a realizar a manobra de ultrapassagem. Este resultado conduz à primeira associação à validade ecológica do experimento fortalecendo os resultados obtidos. 


\subsubsection{Posição lateral nas curvas}

A posição lateral representa a trajetória do veículo ao longo da curva que é variável e afetado pelo comportamento do condutor. A percepção da curva pelo motorista e suas respostas subsequentes são altamente variáveis e dependem da personalidade, experiência e atitude do motorista, bem como do ambiente da pista e das características do veículo (SHINAR, 2017).

A posição lateral é uma das métricas de comportamento de condução utilizadas para avaliar o controle do veículo simulado e características do perfil do condutor. A Posição lateral se refere à posição de um veículo na estrada em relação ao centro da faixa em que o veículo está trafegando. As métricas de posição lateral mais utilizadas são a posição lateral média, o desvio padrão da posição na pista e a proporção de tempo fora da faixa (MAURIELLO et al., 2018).

Spacek (2005) investigou a trajetória de percurso em curvas rodovias e as classificou em seis tipos (Figura 42): (1) corte (cutting), (2) balanço (swinging), (3) deriva (drifting), (4) correção (correcting), (5) comportamento normal (normal behavior) e (6) comportamento ideal (ideal behavior). O autor constatou que a maioria dos motoristas seguia a trajetória de correção em curvas de raios menores e a trajetória de corte em raios maiores.

Figura 42 - Tipos de trajetórias dos veículos em curvas.

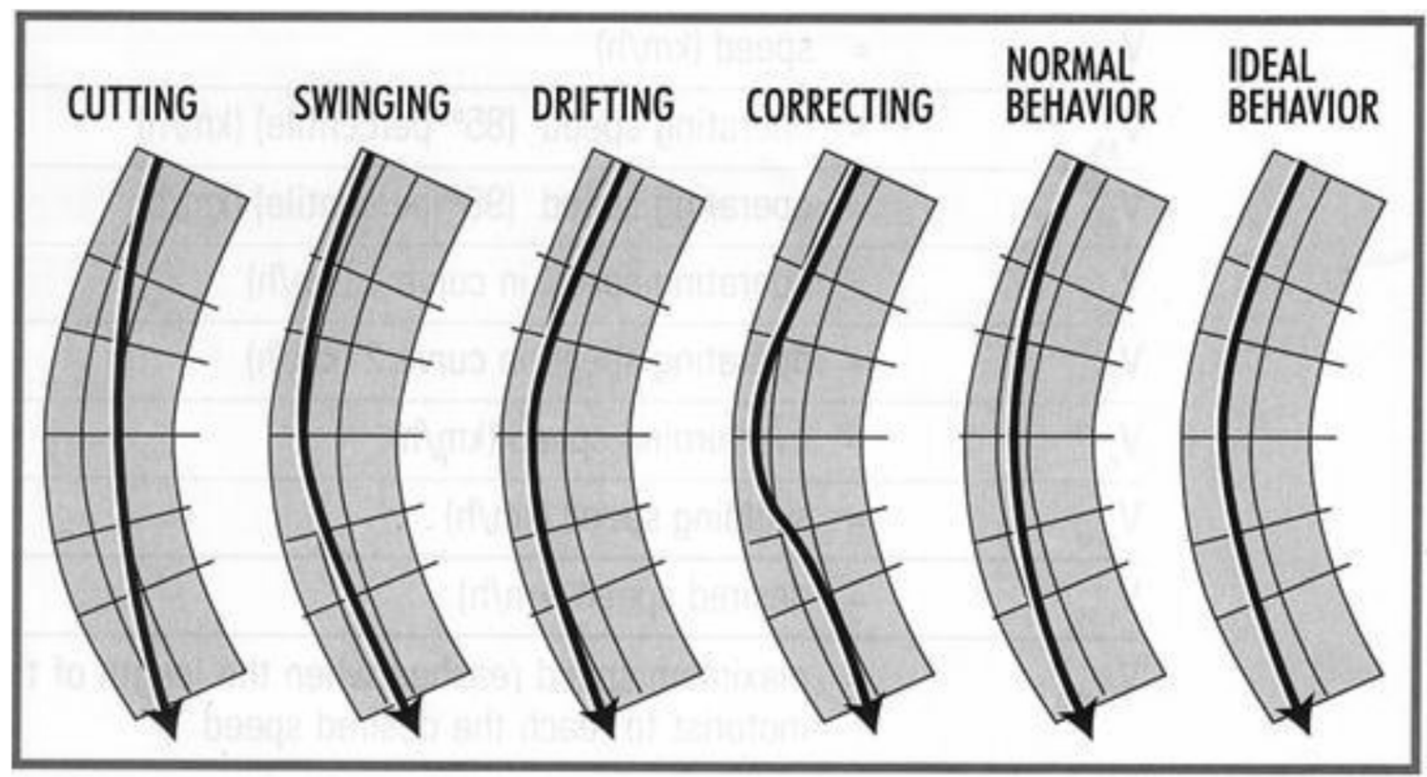

Fonte: Spacek (2005)

Mauriello et al. (2018) em pesquisa com simulador de direção reforçou a classificação do comportamento em curvas horizontais categorizando-as em seis tipos: (1) comportamento 
ideal, (2) comportamento normal, (3) condução próxima ao eixo da via, (4), condução para fora na entrada da curva (5) corte e (6) correção.

No experimento foi calculado o afastamento lateral médio (DistE) para identificar os inícios de ultrapassagem e a partir deste foram avaliadas as posições laterais nas curvas.

O afastamento lateral médio (DistE) é a distância média do centro de gravidade do veículo do participante ao eixo da via. O afastamento lateral médio nas curvas apresentou distribuição normal (Figura 43) segundo o teste de Komogorov-Smirnof $(D(640)=0,054 ; p>0,05)$. Ao analisarmos em relação ao sentido direita e esquerda (Figura 44), o afastamento lateral médio nas curvas à direita apresentou distribuição normal com correção de Liliefors $(D(320)=0,200$; $p>0,05)$, porém o afastamento lateral médio das curvas à esquerda não apresentou distribuição normal $(D(320)=0,009 ; p<0,05)$.

Figura 43 - Histograma do afastamento lateral médio nas curvas.

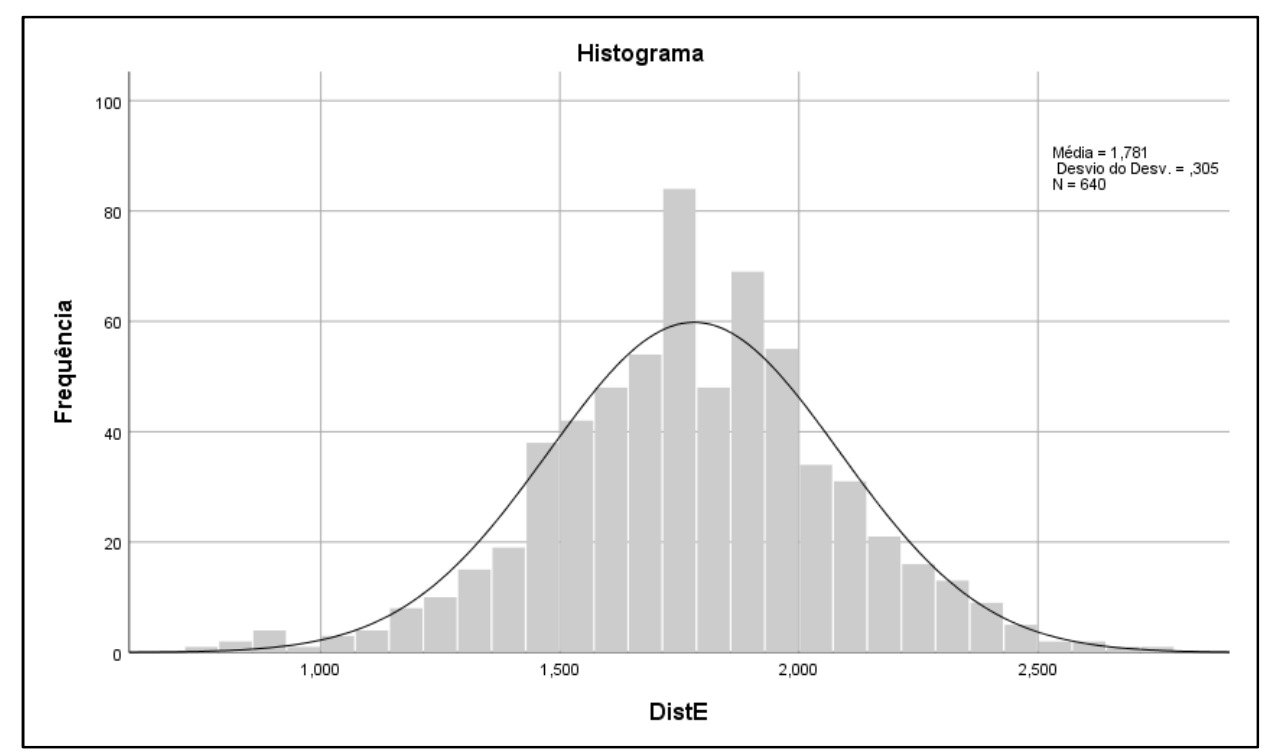

Figura 44 - Histograma o afastamento lateral médio das curvas a esquerda e a direita.
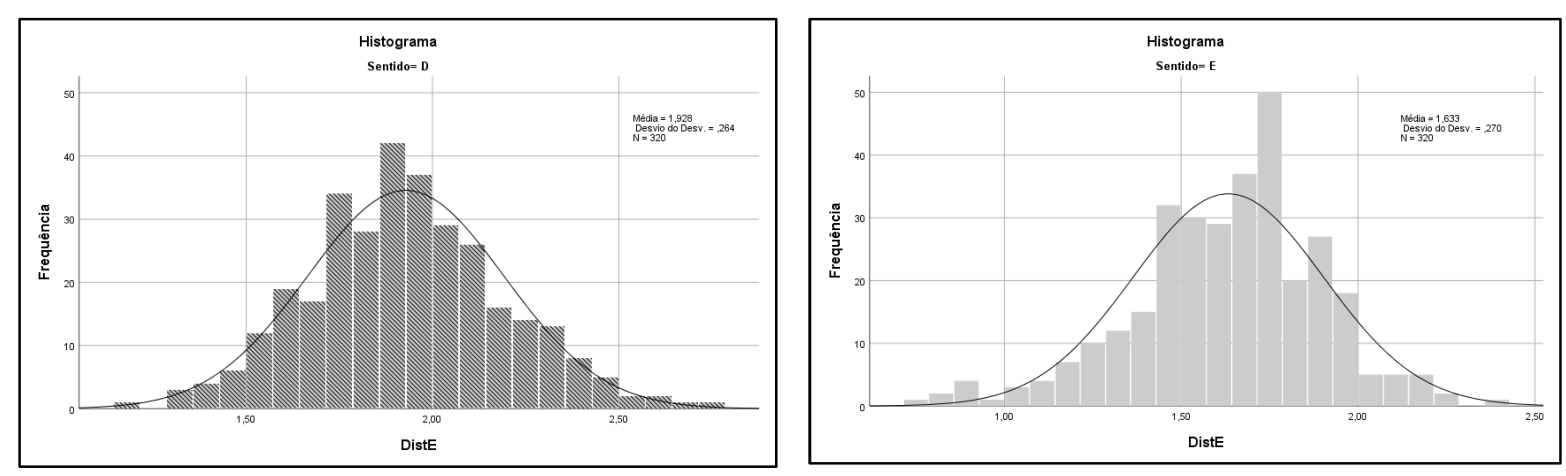
Considerando curvas de raio igual a 1000 metros, com largura da faixa de 3,60 metros e o eixo da faixa está a 1,8 metros do eixo da via, o afastamento lateral médio nas curvas (Figura 45) indicou que os condutores quando trafegaram nas curvas à esquerda, se posicionaram próximos ao eixo da via $(M=1,63 ; S D=0,27)$, e nas curvas à direita, o posicionamento lateral dos condutores indicou a proximidade ao bordo da via $(M=1,93 ; S D=0,26)$. Considerando que o simulador de direção de base fixa não transmite ao condutor a sensação da superelevação nas curvas, o padrão de afastamento lateral encontrado em relação ao sentido das curvas refletiu o comportamento do condutor em uma situação real. Essa constatação contribui para a segunda associação à validade ecológica do simulador de direção para o experimento desta pesquisa.

Em relação à posição lateral na faixa durante o percurso nas curvas, os resultados oscilaram em média entre comportamento ideal e comportamento normal em relação ao eixo da faixa segundo a classificação de Spacek (2005) e Mauriello et al. (2018). O comportamento ideal caracteriza-se por uma trajetória suave na curva, onde o desvio padrão da posição lateral não excede $0,15 \mathrm{~m}$, enquanto que um comportamento normal é caracterizado por um valor absoluto máximo da diferença entre os valores máximo e mínimo da posição lateral, não sendo superior a 1,00 m (MAURIELLO et al., 2018).

Dentre os condutores destacam-se dois comportamentos padrões, os condutores \#16, \#66 e \#78 como uma condução próxima ao eixo segundo a classificação de Mauriello et al. (2018) e o condutor \#36 dirigindo próximo ao bordo da via (Figura 45).

Figura 45 - Afastamento lateral médio nas curvas.

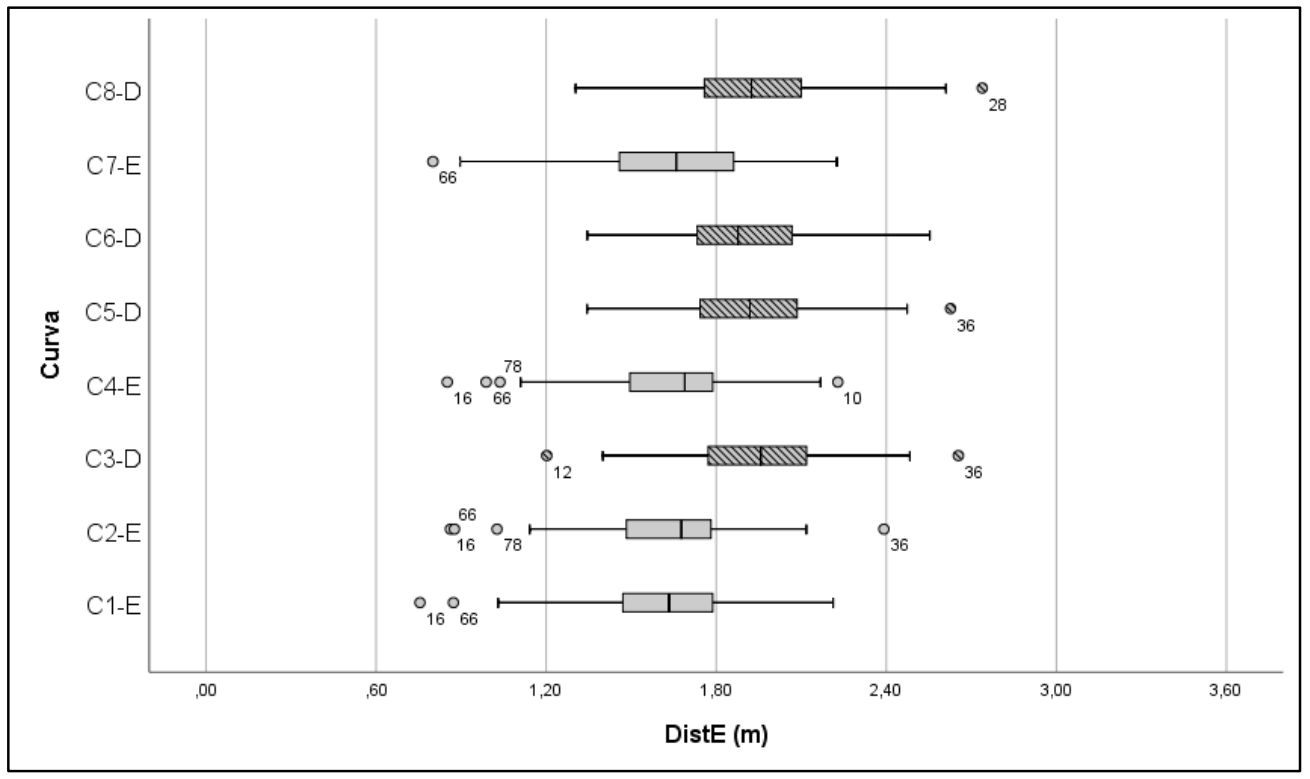




\subsubsection{Comportamento visual nas ultrapassagens}

O comportamento visual do condutor ao efetuar uma manobra de ultrapassagem difere da estratégia visual de outros momentos durante a condução. Ao confrontar-se com um veículo lento no fluxo à sua frente, antes de decidir ultrapassar, o condutor avalia o entorno para verificar se a manobra pode ser efetuada com segurança. Essa avaliação é feita mediante as condições de visibilidade, mas também está altamente relacionada ao comportamento, habilidades e experiência do condutor.

Dentre as habilidades, as estratégias de busca visual durante as ultrapassagens diferem entre condutores experientes e inexperiente. Condutores experientes tendem a alocar seu campo de visão mais amplamente no plano horizontal e na direção longitudinal, no entanto, os condutores inexperientes tendem a prestar mais atenção a um campo de visão mais estreito à frente deles.

O sistema de rastreio do olhar permite acompanhar o movimento do olhar dos condutores durante todo o percurso da simulação. Com o software Mapps foi possível delimitar as regiões de interesse (ROI) e dessa forma quantificar as fixações do olhar do condutor nessas áreas. Por se tratar de um experimento de manobra de ultrapassagem, as ROls de interesse (Figura 46) demarcadas foram os retrovisores direito (DIR), esquerdo (ESQ), traseiro (TRAS) e o velocímetro (VEL) indicados na projeção.

Figura 46 - Regiões de interesse para verificação de fixações.

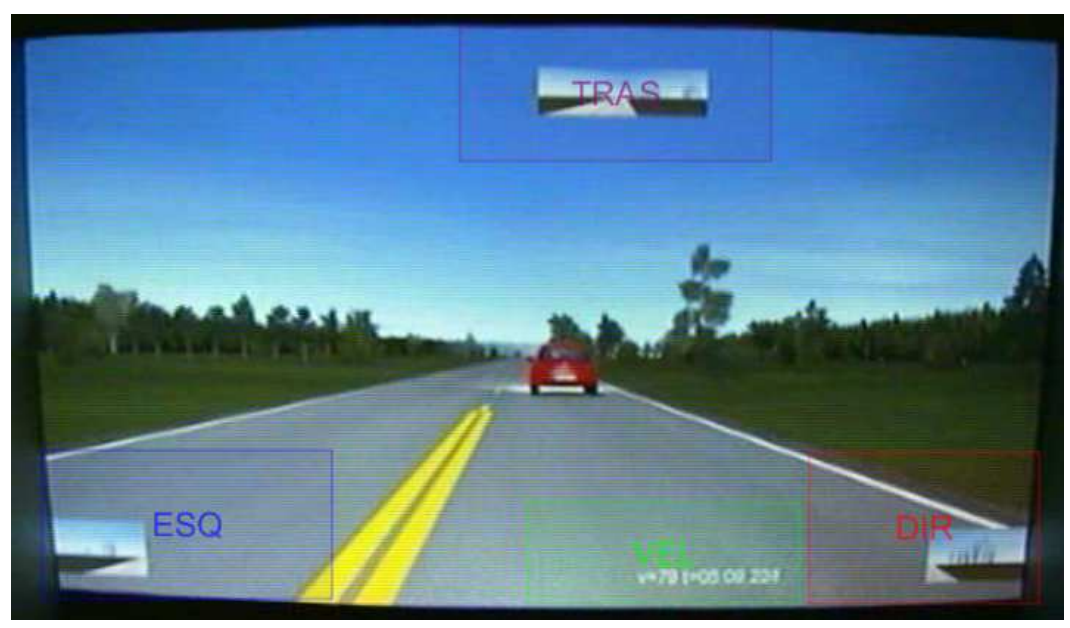

Fonte: A autora

$\mathrm{Na}$ análise dos dados coletados pelo sistema de rastreio buscou-se a identificação de padrões de comportamento que indicassem semelhança com uma situação real de ultrapassagem.

Dessa forma, analisou-se as fixações do olhar do condutor \#20 em um segmento do trecho simulado durante uma ultrapassagem, mais precisamente entre o tempo 00:50 e 1:34. No final 
da curva e início da tangente o condutor fez uma avaliação do entorno e da estrada à frente (Figura 47a). Ao perceber a presença de um veículo no fluxo, o condutor avaliou a situação através da observação do retrovisor esquerdo para verificar a presença de veículos no mesmo sentido do fluxo (Figura 47b). Em seguida, as fixações do olhar se concentraram na parte central da projeção, com a presença do veículo no fluxo contrário e mantendo-se a uma distância segura do veículo à frente (Figura 47c).

Após o veículo oposto desocupar a faixa da esquerda, o condutor realizou a ultrapassagem e procedeu o retorno à faixa direita do fluxo. Neste momento, realizou uma nova verificação, dessa vez nos retrovisores direito e traseiro para avaliar a distância de segurança em relação ao veículo ultrapassado (Figura 47d).

A verificação visual constante ao velocímetro pode estar relacionada à atenção em não ultrapassar o limite da velocidade de projeto, visto que em ambiente simulado o condutor não possui elementos físicos de referência para determinar sua velocidade e a sinalização indicativa ou alertava a velocidade regulamentada.

Figura 47 - Comportamento visual do condutor 20 entre o tempo 00:50 e 1:34.

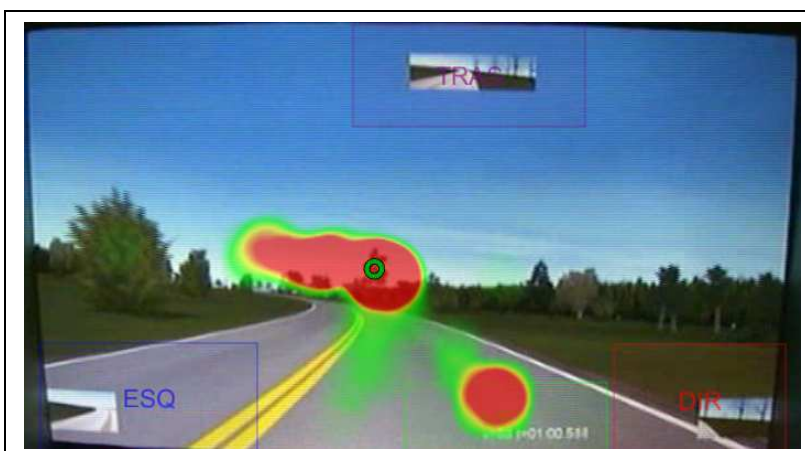

a. Final da curva e início da tangente entre 00:50 e 1:00

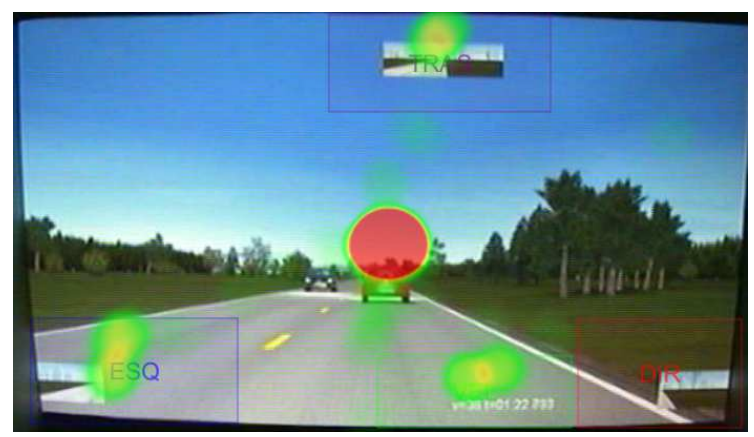

c. Aguardando liberação da faixa oposta entre 1:11 e 1:22

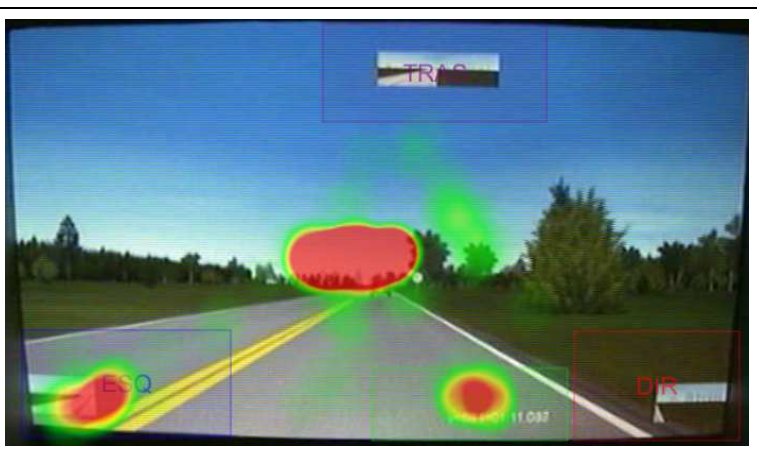

b. Presença de veículo à frente e identificação do veículo oposto entre $1: 00$ e $1: 11$

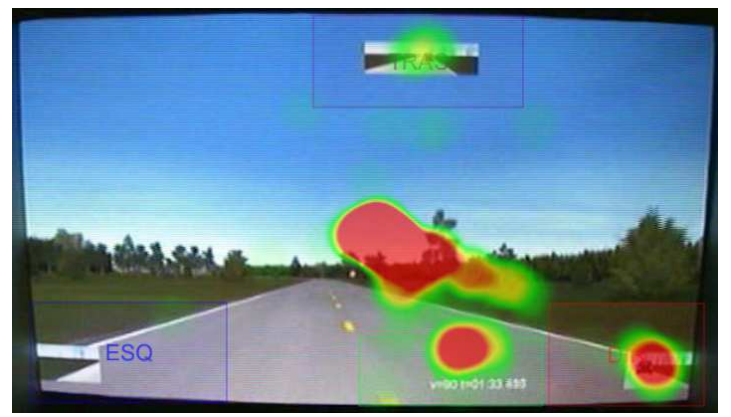

d. Ultrapassagem do veículo lento entre $1: 22$ e $1: 34$

Fonte: A autora 
Figura 48 - Total de fixações do condutor \#20 entre o tempo 00:50 e 1:34.

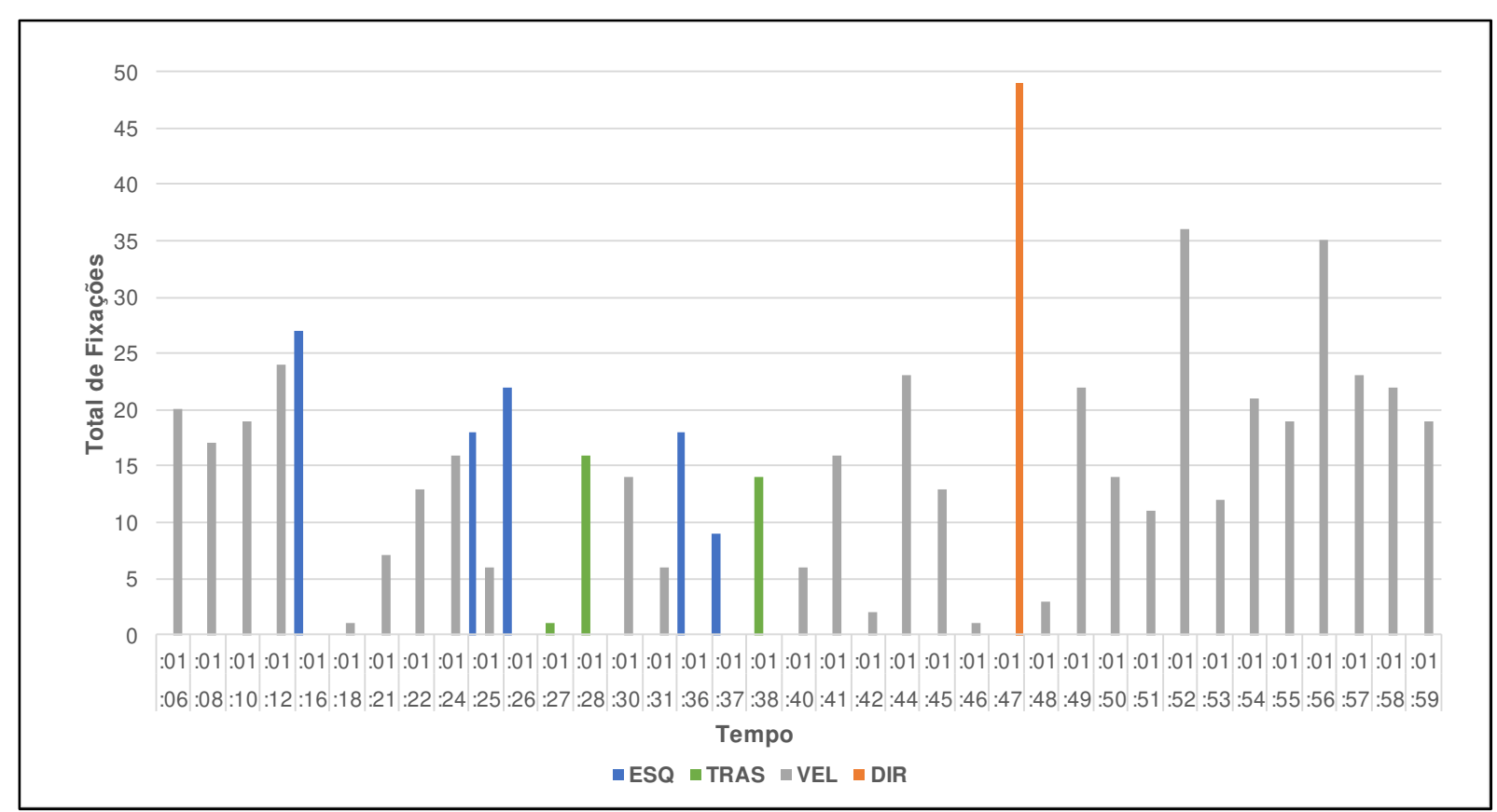

Fonte: A autora

O comportamento visual identificado durante a condução no trecho simulado indica forte correspondência à uma situação real de ultrapassagem. A Figura 49 apresenta o mapa de calor com as fixações acumuladas do segmento para o condutor \#20.

Figura 49 - Mapa de calor das fixações acumuladas no segmento 1 (Condutor \#20).

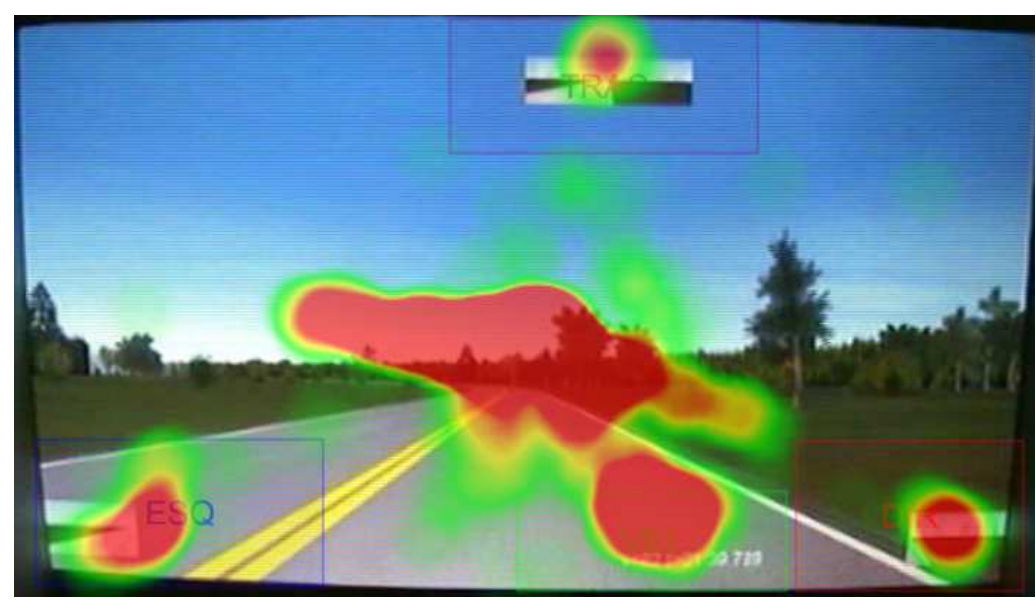

Fonte: A autora

Foram gerados os mapas de calor das fixações acumuladas de alguns condutores (Figura 50) ao longo do percurso total do trecho simulado. A confrontação com as fixações analisadas do condutor \#20, identificou-se forte similaridade entre os padrões, com fixações nos retrovisores e velocímetro. Essa terceira constatação enfatiza a validação ecológica entre o 
comportamento do condutor em ambiente simulado e em ambiente real - apesar da estratégia visual variar em função das habilidades e experiência do condutor.

Figura 50 - Mapa de calor das fixações acumuladas no trecho simulado.

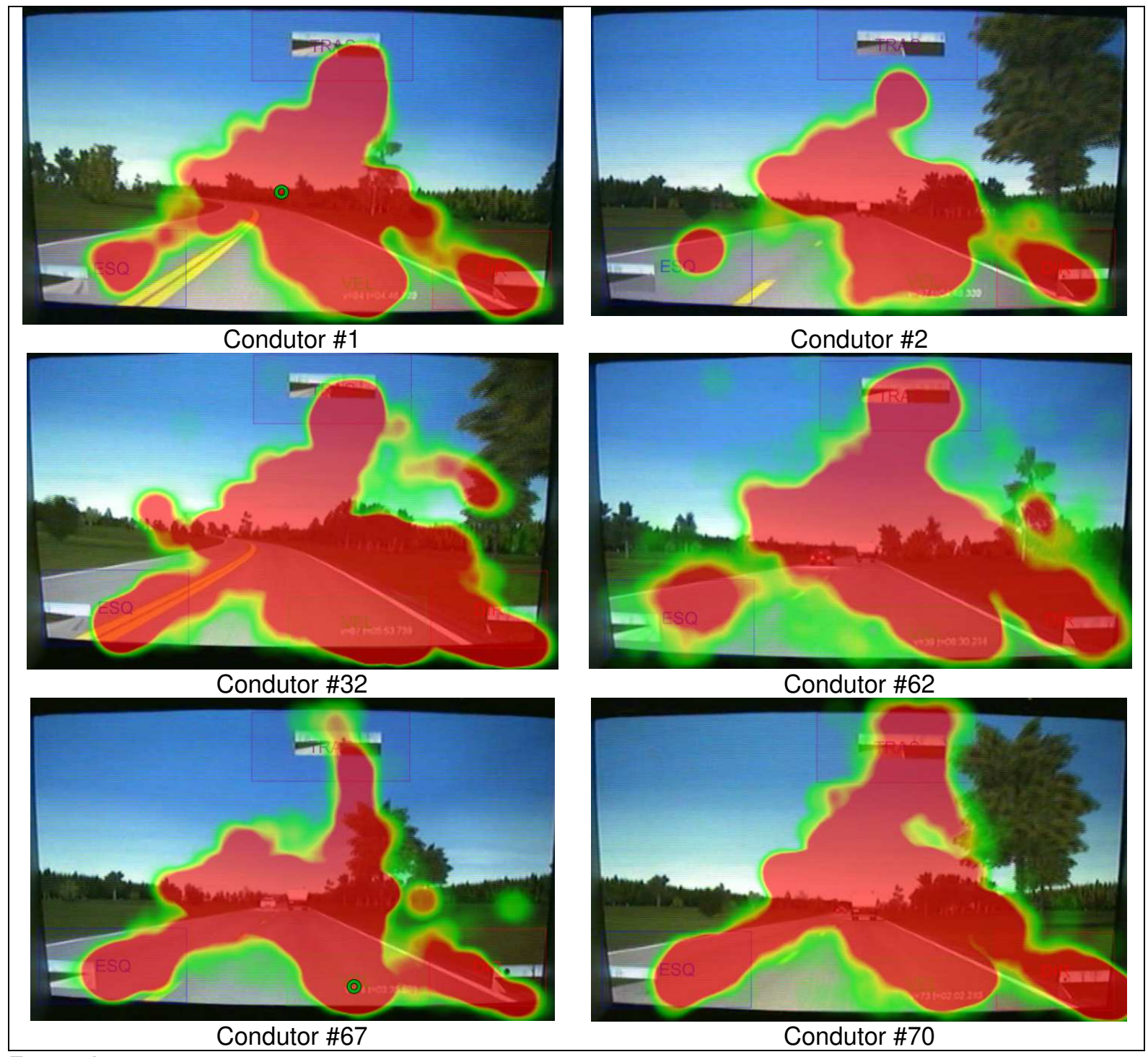

Fonte: A autora 



\section{CONCLUSÕES}

Esta pesquisa teve como foco principal a análise da manobra mais complexa do sistema rodoviário: as ultrapassagens em rodovias de pista simples bidirecional. Para a coleta de dados em campo seriam necessárias gravações em vídeo através de câmeras posicionadas em trechos extensos em rodovia por longos períodos, o que dificultaria e inviabilizaria o projeto desta pesquisa. Sendo assim, com o intuito de agir de forma ética e não colocar em risco a vida do condutor utilizou-se um simulador de direção de base fixa. Os simuladores de direção permitem que experimentos sejam conduzidos em condições controladas para coletar dados confiáveis e entender melhor as interações entre os motoristas e o entorno da via.

Para a análise das manobras de ultrapassagem foi elaborado um experimento onde foi possível avaliar a influência da velocidade e do tipo de veículo a ultrapassar associado à distância de ultrapassagem permitida. A pesquisa contou com a participação de oitenta voluntários e pode ser considerada como uma primeira abordagem no estudo do comportamento do condutor em manobras de ultrapassagem em pista simples.

Em relação aos fatores avaliados no experimento, o resultado da ANOVA de medidas repetidas apresentou significância da influência da velocidade do veículo a ultrapassar sobre a distância entre o veículo que ultrapassa e o veículo ultrapassado, indicando que quanto maior a velocidade do veículo a ultrapassar, maior a distância entre os veículos envolvidos na ultrapassagem. Além disso, também apresentou efeito significante da interação entre a velocidade do veículo a ultrapassar com a distância de ultrapassagem permitida em relação a distância entre o veículo que ultrapassa e o veículo a ultrapassar. Esta interação mostrou que para o veículo lento com velocidade de $40 \mathrm{~km} / \mathrm{h}$ os condutores tendem a manter menores distâncias entre si, sendo que esta distância aumenta quando a distância de ultrapassagem permitida aumenta para $560 \mathrm{~m}$. E quando a velocidade do veículo lento é de $60 \mathrm{~km} / \mathrm{h}$ associada à distância de ultrapassagem de 560 m, a distância média ao veículo lento é menor que quando comparado à distância de ultrapassagem de $446 \mathrm{~m}$, que aumenta em média de 12,5 metros.

Uma das vantagens relacionada à condução em simuladores é que os motoristas podem ser confrontados repetidamente com eventos, que no cotidiano, raramente podem ocorrer. $\mathrm{O}$ delineamento do experimento propiciou 8 ultrapassagens sequenciais por condutor, totalizando a possibilidade de 640 ultrapassagens no experimento. As ultrapassagens realizadas foram classificadas em três tipos distintos, sendo: não ultrapassagem, quando o condutor não ultrapassa o veículo lento no segmento; ultrapassagem simples, quando o 
condutor aguarda que o veículo oposto desocupe a faixa oposta e ultrapassa o veículo lento em segurança e ultrapassagem completa, quando o condutor ultrapassa o veículo lento com a presença do veículo oposto na faixa oposta.

A ultrapassagem completa é a que apresenta maior risco na execução durante a manobra, devido a presença do veículo oposto na faixa contrária. Mesmo assim, apesar das alegações a respeito da sensação de segurança transmitida por experimentos em simulador de direção, a ultrapassagem, incluindo o veículo oposto, 79 ocorrências foram registradas, enquanto a ultrapassagem sem a presença do veículo oposto - mais segura - ocorreu 427 vezes e mais 134 ocorrências em que não foi efetuada a ultrapassagem.

Os tipos de ultrapassagens obtidos foram analisados através de regressão logística multinomial que forneceu a razão de chance da ocorrência entre as ultrapassagens simples e completas tendo como referência as não ultrapassagens. O resultado que se destaca é a confirmação da influência da velocidade do veículo a ultrapassar que indica que a mudança de $60 \mathrm{~km} / \mathrm{h}$ para $40 \mathrm{~km} / \mathrm{h}$ as chances aumentam em 11 vezes na realização da ultrapassagem completa em relação a não ultrapassar. A modelagem produziu dois modelos logits, um para cada tipo de ultrapassagem e obteve um acerto de $84 \%$.

A indicação da velocidade do veículo lento confirmada a partir de dois resultados estatísticos corrobora a hipótese $(A)$ que desta pesquisa, em que afirma que os fatores analisados influenciam a manobra de ultrapassagem.

O experimento em simulador permitiu ainda o acesso a informações individuais dos voluntários por meio de um cadastro preliminar de participação. Estas informações associadas ao comportamento do condutor avaliadas a partir das ultrapassagens realizadas no experimento propiciaram a caracterização do perfil dos condutores da amostra com o uso da técnica de árvores de decisão. Os resultados indicaram que os homens possuem maior probabilidade de se arriscarem mais do que as mulheres e corrobora com a análise da base de dados do DATATRAN - entre os condutores envolvidos em acidentes do tipo colisão frontal, $94 \%$ são homens.

Apesar da obtenção de um acerto de 59\%, a inserção de outras métricas coletadas durante as manobras, bem como variáveis relacionadas às características do condutor, devem ser avaliadas. Para o melhoramento da classificação do perfil do condutor, sugere-se que seja incorporado ao cadastro de participantes as seguintes informações: estado civil, quantidade de filhos, renda individual e familiar. Estas informações adicionais podem auxiliar no aumento de acerto do modelo de classificação, assim como a inserção de outras métricas obtidas da simulação, como: - o afastamento lateral em relação à faixa de condução; - ultrapassagens 
realizadas fora da zona de ultrapassagem permitida; - diferença de velocidade acima da velocidade regulamentada, entre outras.

A delimitação do perfil do condutor que se envolve nos acidentes do tipo colisão frontal pode auxiliar na elaboração e direcionamento de campanhas educativas com foco nesse público alvo, bem como restringir a amostra de pesquisas futuras que tenham como enfoque principal o estudo de colisões frontais.

Outra análise realizada diz respeito aos parâmetros de ultrapassagem extraídos dos dados coletados no experimento. Estes parâmetros $\left(t_{1}, d_{1}, v, t_{2}, d_{2}, d_{3}\right.$ e $\left.d_{4}\right)$ foram aplicados nas equações do modelo do DNIT, a fim de comparar as distâncias obtidas pela simulação e as distâncias calculadas pelo modelo normatizado. Dentre os parâmetros, a distância $\mathrm{d}_{2}$ (distância de ocupação da faixa da esquerda) extraídas da simulação, apresentou valor inferior (174 $\mathrm{m}$ ) ao da distância $\mathrm{d}_{2}$ calculado pelo modelo. Este resultado se deve ao tempo de ocupação da faixa esquerda ( $\left.\mathrm{t}_{2}\right)$, que foi, em média, de 6 segundos, e o modelo pressupõe uma variabilidade entre 9,3 e 11,3 segundos. Os outros parâmetros citados apresentam similaridade com os estudos de campo realizados em outros países.

Em seguida, as distâncias de ultrapassagem registradas no simulador foram comparadas com as distâncias de referência demarcadas no experimento (446 m e 560 m). Após as análises concluiu-se que a média das distâncias de ultrapassagens no simulador não diferem das distâncias de ultrapassagem permitidas - demarcadas nos segmentos, tanto para a extensão de $446 \mathrm{~m}$, quanto para $560 \mathrm{~m}$.

Estas constatações fornecem uma visão inicial a respeito das manobras de ultrapassagem e embasa a hipótese (B) que afirma a compatibilidade com as distâncias de ultrapassagem obtidas em simulador com o modelo do DNIT. Esta comprovação não isenta a necessidade de coleta de ultrapassagens em campo, a fim de verificar o modelo de DVU atual, bem como uma possível adequação do modelo para que englobe as particularidades do perfil do condutor brasileiro.

A realização de experimento em simulador de direção traz a preocupação de que os dados obtidos pudessem ser divergentes das condições reais de direção e, por conseguinte, apresentar resultados enviesados e embora esta pesquisa não fosse um comparativo com dados de campo, era imperativo a identificação de comportamentos a partir dos dados explorados que apresentassem similaridade com situações em ambiente real indicando uma validade ecológica do simulador de direção. 
Para isso, procedeu-se a validação do simulador através de três abordagens: avaliação da simulação por meio de respostas auto relatadas dos participantes, a posição lateral dos condutores nas curvas e o comportamento visual durante a manobra de ultrapassagem

A avaliação da simulação resultou numa taxa de concordância positiva alta obtida pelo questionário de avaliação reportado pelos participantes. Além disso, ao relatar via questionário sobre os fatores de influência na decisão de efetuar uma ultrapassagem as respostas corroboraram os resultados obtidos pelas análises estatísticas, indicando a velocidade do veículo a ultrapassar e a distância permitida de ultrapassagem como fatores de maior prioridade a serem avaliados antes da execução da manobra de ultrapassagem.

A segunda abordagem de validade ecológica foi obtida a partir do afastamento lateral dos condutores nas curvas horizontais. A avaliação indicou similaridade de comportamento em estrada real considerando um posicionamento em relação às curvas à direita próximo ao bordo da via, e em curvas à esquerda próximos ao eixo da via.

E por fim, a validade ecológica pode ser ratificada mediante a análise de estratégia visual durante a ultrapassagem. As sequências de fixações foram analisadas e apresentaram comportamento similar à uma ultrapassagem em estrada, visto que o condutor avalia a estrada à frente e o entorno, em seguida concentra-se no retrovisor esquerdo e traseiro para avaliar os veículos do entorno e durante a ultrapassagem do veículo lento, concentra-se no retrovisor direito para avaliar a distância entre o veículo ultrapassado.

A validação ecológica obtida não isenta a necessidade de uma validação com dados de campo, mas é um assertivo indicador do potencial do uso de simuladores de direção como ferramenta de pesquisa em estudos de comportamento do condutor em manobras nas ultrapassagens.

No caso das manobras de ultrapassagem, os condutores tendem a executar a manobra motivados em chegar a um determinado lugar e estão sendo impedidos no fluxo de tráfego por um veículo lento. Essa motivação não pode ser "transportada" para um simulador de direção, sem interferir no comportamento do condutor (como orientá-lo a realizar a ultrapassagem). Essa conduta não foi adotada nesta pesquisa, deixando o participante livre para conduzir de forma natural. Apesar disso, esperava-se que os participantes efetuassem mais ultrapassagens com a presença do veículo oposto na faixa contrária, por não haver risco real de colisão. No entanto, este tipo de ultrapassagem foi a que ocorreu com menor frequência e a ultrapassagem sem a presença do veículo oposto foi a que ocorreu com maior frequência, demonstrando que os participantes não se arriscaram apesar das condições propícias. 
O exposto corrobora a hipótese (C) que afirma a viabilidade do uso de simulador de direção aplicado à estudos de fatores humanos em manobras de ultrapassagem, ante à similaridade comportamental em ambiente virtual ser compatível com o comportamento real.

Sendo assim, apesar de algumas limitações, os simuladores de direção possuem potencial para avaliação dos efeitos relativos a diversos fatores ou análise das complexidades do comportamento do motorista. A pesquisa proposta pode ser complementada, no futuro, pelo estudo do comportamento do condutor em manobra de ultrapassagem sob condições climáticas críticas (chuva, neblina, etc), influência dos níveis de serviços da rodovia, influência de veículos de tamanhos diferentes e o efeito da idade e da experiência de direção do condutor através de uma amostra mais robusta.

\subsection{Sugestões para Trabalhos Futuros}

A diversidade de aplicações de simulador fornece uma prévia dos futuros desafios e oportunidades na condução da pesquisa e uma indicação do potencial de como os simuladores podem ajudar a resolvê-los e como sugestões para trabalhos futuros e complementares são apresentados alguns pontos para discussão.

\section{- Determinação do início da ultrapassagem}

O monitoramento do surgimento de um veículo na mesma faixa de tráfego durante uma manobra de ultrapassagem em andamento pode ser a condição de maior alerta encontrada por um motorista na rodovia.

Na elaboração do algoritmo para extração dos parâmetros do modelo de ultrapassagem, um dos maiores desafios foi determinar o ponto em que o condutor inicia a ultrapassagem, que é reportado na literatura como a distância que engloba o tempo de percepção e reação. $A$ identificação do momento exato em que o condutor inicia a ultrapassagem é extremamente difícil devido à variedade de comportamento dos condutores, o que torna a implementação da rotina uma tarefa laboriosa.

A análise dos dados obtidos através do simulador de direção sinalizou a influência de outros fatores na determinação do tempo de percepção e reação e que merecem mais atenção em pesquisas posteriores, a exemplo do comportamento de condução na faixa da via.

\section{- Analisar as tentativas seguida de abortagem}

Em simulador de direção as tentativas de ultrapassagem seguidas de abortagens podem ser analisadas sem risco ao condutor. Durante o experimento foram registradas 22 abortagens 
que resultaram em não ultrapassagem e 45 abortagens que resultaram em ultrapassagens simples. Análises posteriores podem auxiliar na identificação dos fatores que influenciaram o condutor a desistir da ultrapassagem inicial. A identificação desses parâmetros pode auxiliar na definição de medidas que influenciem o comportamento do condutor a não efetuar manobras de risco.

\section{- Analisar a ultrapassagem de veículos maiores a ultrapassar}

No experimento conduzido nesta pesquisa foram analisados a ultrapassagem de um veículo do tipo caminhão e um carro de passeio, de maneira alternada. Apesar de não obter influência significativa do tipo de veículo a ultrapassar, propõe-se a avaliação de ultrapassagem de diferentes tipos de caminhões a exemplos dos encontrados nas rodovias brasileiras. Durante a manobra de ultrapassagem o condutor pode subestimar o tamanho do veículo a ser ultrapassado, independentemente do tipo de veículo (LEVULIS; DELUCIA; JUPE, 2015). O modelo de Wang e Cartmell (1998) também indicou que o aumento do comprimento do veículo tem um impacto importante na distância de visibilidade de ultrapassagem (DVU) permitida, ou seja, a DVU é consideravelmente maior ao ultrapassar um caminhão longo do que ultrapassar um carro de passeio comum.

A hipótese é que o tamanho do caminhão influencia na decisão do condutor em ultrapassar. Além disso, através da coleta de dados em simulador de direção seria possível verificar e identificar comportamentos específicos para este tipo de ultrapassagem associado ao modelo de Wang e Cartmell (1998) que é um dos mais complexos modelos propostos, pois incorpora a trajetória do veículo que ultrapassa durante a ultrapassagem.

\section{- Classificação das manobras de ultrapassagem}

A classificação das manobras de ultrapassagens a partir de uma abordagem comportamental seria uma melhoria na abordagem das manobras com base em uma avaliação qualitativa das condições de ultrapassagem.

A partir de observações de campo as manobras de ultrapassagem podem ser analisadas para determinar o tipo de comportamento de ultrapassagem e os resultados podem auxiliar na avaliação de trechos de ultrapassagem das rodovias.

A identificação de comportamentos específicos poderia ser utilizada para complementar ou atualizar os critérios de projetos do modelo de ultrapassagem e dessa forma garantir uma melhor orientação aos condutores, e assim, uma melhoria na segurança dos trechos de ultrapassagem. 


\section{- Avaliação do comportamento visual dos condutores nas ultrapassagens}

A avaliação visual durante a condução é feita mediante as condições de visibilidade, mas também está altamente relacionada ao comportamento, habilidades e experiência do condutor. Dentre as habilidades, as estratégias de busca visual durante as ultrapassagens diferem entre condutores experientes e inexperiente. Condutores experientes tendem a alocar seu campo de visão mais amplamente no plano horizontal e na direção longitudinal, no entanto, os condutores inexperientes tendem a prestar mais atenção a um campo de visão mais estreito à frente deles.

Um estudo sobre as estratégias e padrões visuais deve ser aprofundado, com o intuito de quantificar tempos de fixações durante a manobra de ultrapassagem. Sabendo que as estratégias de busca visual em manobras de ultrapassagem estão associadas à acidentes, é importante melhorar as capacidades de detecção de perigos potenciais. Visto que durante as aulas de habilitação o motorista não tem oportunidade de realizar esse tipo de manobra.

\section{- Coleta de dados de observações de ultrapassagens em campo}

A exemplo dos estudos realizados por Harwood et al. (2008), a coleta de observações de campo seria um avanço para validação dos resultados do simulador. A complexidade e custos para essa tarefa fogem da alçada de uma pesquisa individual, mas claramente pode ser realizada mediante esforços conjuntos de equipes de pesquisas nas áreas de segurança viária e órgãos governamentais.

As coletas de dados de campo podem ser obtidas através de vídeo, sensores óticos e outras tecnologias para posterior validação com os resultados de simuladores de direção. E como sugestão, a seleção das rodovias e seções de estrada para coleta de dados pode ser baseada no resultado das análises dos dados de acidentes georreferenciados disponibilizados pelo DATATRAN, desde 2018.

Por fim, fica claro, que é premente esforços para incentivar e promover pesquisas não só relacionadas ao tema em tela, mas à acidentalidade rodoviária de forma geral, em simuladores de direção e em campo. Outrossim, retomando às discussões sobre as manobras de ultrapassagem, as informações que são extraídas, por exemplo, com o simulador de direção, contribuem enormemente para compreender o comportamento dos condutores ao realizá-las.

Adicionalmente, visto que, durante o processo de habilitação, o aprendiz não tem muitas oportunidades de realizar uma manobra de ultrapassagem, os experimentos controlados ou em campo permitem treinamento. A habilidade do condutor em avaliar as lacunas de risco, 
para ultrapassar em segurança são aperfeiçoadas com a prática e o tempo de habilitação. Ainda desta forma, o excesso de confiança do condutor pode influenciar e interferir no processo de avaliação da lacuna de ultrapassagem e, consequentemente, culminar com uma colisão frontal.

O domínio dessas informações comportamentais tem implicações práticas significativas na determinação da distância de ultrapassagem de projeto e na segurança do tráfego, conforme discutido no capítulo 2. As análises e resultados podem auxiliar o desenvolvimento de alternativas para melhorar a segurança em rodovias de pista simples e contribuir para o melhoramento dos modelos de ultrapassagem desenvolvidos em programas de microsimulação e sistemas inteligentes de assistência à direção. 
AMERICAN ASSOCIATION OF STATE HIGHWAY AND TRANSPORTATION OFFICIALS (AASHTO). A policy on geometric design of highways and streets. [s.I.] American Association of State Highway and Transportation Officials, 2004.

AMERICAN ASSOCIATION OF STATE HIGHWAY AND TRANSPORTATION OFFICIALS (AASHTO). A policy on geometric design of highways and streets. [s.l.] American Association of State Highway and Transportation Officials, 2011.

ASAITHAMBI, G.; SHRAVANI, G. Overtaking behaviour of vehicles on undivided roads in nonlane based mixed traffic conditions. Journal of Traffic and Transportation Engineering (English Edition), v. 4, n. 3, p. 252-261, 2017.

AUBERLET, J.-M.; ROSEY, F.; ANCEAUX, F.; AUBIN, S.; BRIAND, P.; PACAUX, M.-P.; PLAINCHAULT, P. The impact of perceptual treatments on driver's behavior: From driving simulator studies to field tests-First results. Accident Analysis \& Prevention, v. 45, p. 9198, mar. 2012.

BAR-GERA, H.; SHINAR, D. The tendency of drivers to pass other vehicles. Transportation Research Part F: Traffic Psychology and Behaviour, v. 8, n. 6, p. 429-439, nov. 2005.

BELLA, F. How traffic conditions affect driver behavior in passing maneuver. Advances in Transportation Studies, n. SPEC, p. 113-126, 2011.

BELLA, F.; D'AGOSTINI, G. Combined Effect of Traffic and Geometrics on Rear-End Collision Risk. Transportation Research Record: Journal of the Transportation Research Board, v. 2165, n. 1, p. 96-103, jan. 2010.

BLAAUW, G. J. Driving Experience and Task Demands in Simulator and Instrumented Car : A Validation Study. Human Factors, v. 24, n. 4, p. 473-486, 1982.

BLANA, E. Driving simulator validation studies: A literature review. [s.I.] Institute of Transport Studies, University of Leeds, 1996. .

BROWN, R. L.; HUMMER, J. E. Determining the Best Method for Measuring No-Passing Zones. Transportation Research Record: Journal of the Transportation Research Board, v. $1701, \quad$ n. $1, \quad$ p. 61-67, jan. 2000. Disponível em: <http://journals.sagepub.com/doi/10.3141/1701-08>.

BRUZELIUS, F.; KARLSSON, M. A.; AUGUSTO, B. Realism of overtaking situations in motion based driving simulators. In: International Conference Road Safety and Simulation RSS2013, October, Rome, Italy. Rome, Italy: 2013.

CAMPBELL, J. L.; LICHTY, M. G.; BROWN, J. L.; RICHARD, C. M.; GRAVING, J. S.; GRAHAM, J.; O'LAUGHLIN, M.; TORBIC, D.; HARWOOD, D. NCHRP Report 600 - Human Factors Guidelines for Road Systems. Washington, D.C.: Transportation Research Board (TRB), 2012. .

CAPALDO, F. S.; RISOLI, L. Passing Maneuver: Models, Surveys and Simulation. Procedia - Social and Behavioral Sciences, v. 43, p. 790-798, 2012. 
CASTILLO, M. A. Análise da percepção da sinalização vertical por parte do condutor, utilizando ambientes simulados de direção: um estudo de caso na rodovia br-116. 2015. Dissertação (Mestrado Infraestrutura de Transportes) - Escola de Engenharia de São Carlos, Universidade de São Paulo, 2015.

CASTRO, M.; GARCIA-ESPONA, A.; IGLESIAS, L. Terrain Model Resolution Effect on Sight Distance on Roads. In: Periodica Polytechnica Civil Engineering, 2, 2015.

CHARISSIS, V.; NAEF, M.; ARAFAT, S.; VLACHOS, G. On the Impact of User's Computer Knowledge on Driving Simulation Test Results - HUD Simulation Case Study Vassilis. In: 27th European Annual Conference on Human Decision-Making and Manual Control, Delft, The Netherlands. Delft, The Netherlands: 2008.

CHRISTOPOULOS, D. T. RootsExtremalnflections: Finds Roots, Extrema and Inflection Points of a Curve, 2017. .

CONSELHO NACIONAL DE TRÂNSITO (CONTRAN). Sinalização horizontal - volume iv. Brasília: Conselho Nacional de Trânsito Brasil, 2007a. v. IV

CONSELHO NACIONAL DE TRÂNSITO (CONTRAN). Sinalização vertical de regulamentação - volume i. [s.I.] Conselho Nacional de Trânsito Brasil, 2007b. v. I

COUFAL, T.; SEMELA, M. Determination of Selected Crash Parameters in Head-on Vehicle Collision with Rollover. PROMET - Traffic\&Transportation, v. 28, n. 1, p. 71-79, 26 fev. 2016.

DENIAUD, C.; HONNET, V.; JEANNE, B.; MESTRE, D. The concept of "presence" as a measure of ecological validity in driving simulators. Journal of Interaction Science, v. 3, n. 1, p. 1, 2015.

DEPARTAMENTO NACIONAL DE INFRAESTRUTURA DE TRANSPORTES (DNIT). Manual de projeto geométrico de rodovias rurais. [s.I.] Departamento Nacional de Infraestrutura de Transportes (DNIT), 1999.

DEPARTAMENTO NACIONAL DE INFRAESTRUTURA DE TRANSPORTES (DNIT). Manual de sinalização rodoviária. [s.I.] Departamento Nacional de Infraestrutura de Transportes (DNIT), 2010.

DEPARTAMENTO NACIONAL DE TRÂNSITO (DENATRAN). Direção defensiva - trânsito seguro é um direito de todos. [s.I.] Departamento Nacional de Trânsito, 2005.

DEWAR, R. E.; OLSON, P. L. Perception and Information Processing. In: Human Factors in Traffic Safety, Second Edition. [s.I.] Lawyers \& Judges Pub., 2002. p. 549p.

DUPUIS, M.; WUNIBALD, K. Virtual Test Drive - User Manual, 2012. .

ESKANDARIAN, A.; DELAIGUE, P.; SAYED, R.; MORTAZAVI, A. Development and verification of a truck driving simulator for driver drowsiness studies, 2008. .

FARAH, $\mathrm{H}$. Modeling drivers' passing duration and distance in a virtual environment. IATSS Research, v. 37, n. 1, p. 61-67, jul. 2013.

FARAH, H.; AZEVEDO, C. L. Safety analysis of passing maneuvers using extreme value theory. IATSS Research, v. 41, n. 1, p. 12-21, abr. 2017.

FARAH, H.; BEKHOR, S.; POLUS, A. Risk evaluation by modeling of passing behavior on twolane rural highways. Accident Analysis \& Prevention, v. 41, n. 4, p. 887-894, jul. 2009. 
FARAH, H.; TOLEDO, T. Passing behavior on two-lane highways. Transportation Research Part F: Traffic Psychology and Behaviour, v. 13, n. 6, p. 355-364, nov. 2010.

FEDERAL HIGHWAY ADMINISTRATION (FHWA). Pavement and Curb Marking. In: Manual on Uniform Traffic Control Devices. 2009. ed. [s.I.] Federal Highway Administration (FHWA), 2012. p. 862.

FIELD, A. Descobrindo a estatística usando o spss. 2 ed. ed. Porto Alegre: Artmed, 2009.

FIGUEIRA, A. C.; LAROCCA, A. P. C. Avaliação de Simulador de Direção a partir Questionário de Presença. In: Anais $32^{\circ}$ Congresso de Pesquisa e Ensino em Transportes, Associação Nacional de Pesquisa e Ensino em Transportes, 2018.

FISHER, D. L.; RIZZO, M.; CAIRD, J.; LEE, J. D. Handbook of driving simulation for engineering, medicine, and psychology. [s.I.] CRC Press, 2011.

FORBES, G. J. Origin of minimum passing sight distances for no-passing zones. ITE Journal (Institute of Transportation Engineers), v. 60, n. 12, p. 20-24, 1990.

GARCÍA, D. S. P.; DI RADO, G. R.; OLIVEIRA, M. C.; SCHMIDT, R. G.; LANES, T. K. Análise de projeto de sinalização horizontal sob a ótica da distância de visibilidade de ultrapassagem: confronto entre norma, realidade e modelagem tridimensional. In: XXX Congresso Nacional De Pesquisa Em Transporte Da Anpet, 2016.

GARCÍA, D. S. P.; NODARI, C. T.; WANDSCHEER, M. A.; SANTOS, F. F. de F. dos; D'AZEVEDO, Z. S.; RADO, G. R. Di. Diretrizes para o desenvolvimento de um sistema avançado para estudos e projetos viários: análise da visibilidade de ultrapassagem horizontal em curvas à direita. In: XXVIII Congresso Nacional De Pesquisa Em Transporte Da Anpet, 2014.

GLENNON, J. C. New and improved model of passing sight distance on two-lane highways. Transportation Research Record: Journal of the Transportation Research Board, $n$. 1195, p. 132-137, 1988.

GODLEY, S. T.; TRIGGS, T. J.; FILDES, B. N. Driving simulator validation for speed research. Accident Analysis \& Prevention, v. 34, n. 5, p. 589-600, 1 set. 2002.

GRAY, R.; REGAN, D. M. Perceptual Processes Used by Drivers During Overtaking in a Driving Simulator. Human Factors: The Journal of the Human Factors and Ergonomics Society, v. 47, n. 2, p. 394-417, 2005.

HARWOOD, D. W.; GILMORE, D. K.; RICHARD, K. R.; DUNN, J. M.; SUN, C. NCHRP Report 605 - Passing Sight Distance Criteria. [s.I.] NCHRP (National Cooperative Highway Research Program), 2008. .

HASSAN, S. A.; CHE PUAN, O.; MASHROS, N.; ABDUL SUKOR, N. S. Factors Affecting Overtaking Behaviour On Single Carriageway Road: Case Study at Jalan Kluang-Kulai. Jurnal Teknologi, v. 71, n. 3, p. 87-91, 7 dez. 2014.

HASSAN, Y.; EASA, S. M.; ABD EL HALIM, A. O. Passing sight distance on two-lane highways: Review and revision. Transportation Research Part A: Policy and Practice, v. 30, n. 6 PART A, p. 453-467, 1996. 
HEGEMAN, G.; BROOKHUIS, K.; HOOGENDOORN, S. Opportunities of advanced driver assistance systems towards overtaking. European Journal of Transport and Infrastructure Research, EJTIR, v. 5, n. 4, p. 281-296, 2005.

HEGEMAN, G.; HOOGENDOORN, S.; BROOKHUIS, K. Observations overtaking manoeuvres on bi-directional roads. Advanced OR and Al Methods in Transportation, v. 1, p. 505-510, 2005.

JENKINS, J. M.; RILETT, L. R. Application of Distributed Traffic Simulation for Passing Behavior Study. Transportation Research Record: Journal of the Transportation Research Board, v. 1899, n. 1, p. 11-18, 29 jan. 2004.

JENKINS, J. M.; RILETT, L. R. Classifying Passing Maneuvers - A behavioral approach. Transportation Research Record: Journal of the Transportation Research Board, n. 1937, p. 14-21, 2005.

KABBACH JR, F. I. Notas de Aula - Distâncias de visibilidade: Considerações gerais. São Paulo: Universidade de São Paulo (USP), 2017. .

KAPTEIN, N.; THEEUWES, J.; VAN DER HORST, R. Driving Simulator Validity: Some Considerations. Transportation Research Record: Journal of the Transportation Research Board, v. 1550, p. 30-36, 1996.

KASHANI, A. T.; AYAZI, E.; RAVASANI, M. S. Identifying Significant Variables Influencing Overtaking Maneuvers on Two-lane, Two-way Rural Roads in Iran. Periodica Polytechnica Transportation Engineering, v. 44, n. 3, p. 155-163, 2016.

KEITH, K.; TRENTACOSTE, M.; DEPUE, L.; GRANDA, T.; HUCKABY, E.; IBARGUEN, B.; KANTOWITZ, B.; LUM, W.; WILSON, T. Roadway Human Factors and Behavioral Safety in Europe. Washington, DC: Federal Highway Administration (FHWA), 2005. .

KELLY, M.; LASSACHER, S.; SHIPSTEAD, Z. A high fidelity driving simulator as a tool for design and evaluation of highway infrastructure upgrades. [s.l.] Montana Department of Transportation, 2007.

KENNEDY, R. S.; LANE, N. E.; BERBAUM, K. S.; LILIENTHAL, M. G. Simulator Sickness Questionnaire: An Enhanced Method for Quantifying Simulator Sickness. The International Journal of Aviation Psychology, v. 3, n. 3, p. 203-220, 1993.

KHOURY, J. El; HOBEIKA, A. G. Assessing the Risk in the Design of Passing Sight Distances. Journal of Transportation Engineering, v. 133, n. 6, p. 370-377, jun. 2007.

KLÜVER, M.; HERRIGEL, C.; HEINRICH, C.; SCHÖNER, H.-P.; HECHT, H. The behavioral validity of dual-task driving performance in fixed and moving base driving simulators. Transportation Research Part F: Traffic Psychology and Behaviour, v. 37, p. 78-96, fev. 2016.

KRONFOL, R.; GRIMM, A. Driving Simulators: a classified bibliography. Traffic Safety, v. UMTRI-90-9, n. March, 1990.

LEE, J. D.; MCGEHEE, D. V.; BROWN, J. L.; RICHARD, C. M.; AHMAD, O.; WARD, N. J.; HALLMARK, S.; LEE, J. Matching Simulator Characteristics to Highway Design Problems. Transportation Research Record: Journal of the Transportation Research Board, v. 2248, n. 1, p. 53-60, jan. 2011. 
LEVULIS, S. J.; DELUCIA, P. R.; JUPE, J. Effects of oncoming vehicle size on overtaking judgments. Accident Analysis \& Prevention, v. 82, p. 163-170, set. 2015.

LLORCA, C.; FARAH, H. Passing Behavior on Two-Lane Roads in Real and Simulated Environments. Transportation Research Record: Journal of the Transportation Research Board, v. 2556, p. 29-38, 2016.

LLORCA, C.; GARCÍA, A. Evaluation of Passing Process on Two-Lane Rural Highways in Spain with New Methodology Based on Video Data. Transportation Research Record: Journal of the Transportation Research Board, v. 2262, n. 1, p. 42-51, 22 jan. 2011.

LO, W. T.; SO, R. H. Y. Cybersickness in the presence of scene rotational movements along different axes. Applied Ergonomics, v. 32, n. 1, p. 1-14, 2001.

MAURIELLO, F.; MONTELLA, A.; PERNETTI, M.; GALANTE, F. An Exploratory Analysis of Curve Trajectories on Two-Lane Rural Highways. Sustainability, v. 10, n. 11, p. 4248, 17 nov. 2018.

MERAT, N.; JAMSON, A. H. The effect of three low-cost engineering treatments on driver fatigue: A driving simulator study. Accident Analysis \& Prevention, v. 50, p. 8-15, jan. 2013.

MEULMAN, J. J.; KOOIJ, A. J. Van der; HEISER, W. J. Principal Component Analysis with Nonlinear Optimal Scaling Transformations for Ordinal and Nominal Data. In: Handbook of Quantitative Methods in the Social Sciences. 2455 Teller Road, Thousand Oaks California 91320 United States of America: SAGE Publications, Inc., 2004. p. 49-70.

MILETICS, D. Human decisions at irregular overtakings. In: 6th IEEE Conference on Cognitive Infocommunications, CogInfoCom 2015 - Proceedings, 2016.

MOCSÁRI, T. Analysis of the Overtaking Behaviour of Motor Vehicle Drivers. Acta Technica Jaurinensis, v. 2, n. 1, p. 97-106, 2009.

MOHAMMED, $\mathrm{H}$. The influence of road geometric design elements on highway safety. International Journal of Civil Engineering and Technology, v. 4, n. 4, p. 976-6308, 2013.

MOLINO, J. a.; KATZ, B. J.; HERMOSILLO, M. B. Simulator Evaluation of Low Cost Safety Improvements on Rural, Two-Lane, Undivided Roads: Nighttime Delineation for Curves; and Traffic Calming for Small Towns. TRB 89th Annual Meeting, v. 064, n. february, p. 14, 2010.

MONTELLA, A.; ARIA, M.; AMBROSIO, A. D.; MAURIELLO, F. Analysis of powered twowheeler crashes in Italy by classification trees and rules discovery. Accident Analysis and Prevention, v. 49, p. 58-72, 2012.

MULLEN, N.; CHARLTON, J.; DEVLIN, A.; BÉDARD, M. Simulator Validity: Behaviors Observed on the Simulator and on the Road. In: Handbook of Driving Simulation for Engineering, Medicine, and Psychology. [s.I.] CRC Press, 2011.

MWESIGE, G.; FARAH, H.; BAGAMPADDE, U.; KOUTSOPOULOS, H. N. A model and its applications for predicting passing rate at passing zones on two-lane rural highways. Journal of Transportation Engineering: American Society of Civil Engineers, v. 142, n. 3, p. 111, 2016.

NODARI, C. T.; BOTTESINI, G. Influência de medidas de segurança de trânsito no comportamento dos motoristas. TRANSPORTES, v. 19, n. 1, p. 77, 4 nov. 2011. 
PELLEGRINI, P. T. Contribuição para o estudo das distâncias de visibilidade de ultrapassagem para rodovias bidirecionais com duas faixas de tráfego. 2006. (Dissertação de Mestrado) Universidade de São Paulo, São Paulo, 2006.

PIMENTA, C. R. T.; SILVA, I. da; OLIVEIRA, M. P.; SEGANTINE, P. C. L. Projeto geométrico de rodovias. $1^{\text {a }}$ ed. Rio de Janeiro: Elsevier, 2017.

POLUS, A.; LIVNEH, M.; FRISCHER, B. Evaluation of the Passing Process on Two-Lane Rural Highways. Transportation Research Record: Journal of the Transportation Research Board, v. 1701, n. 1, p. 53-60, 14 jan. 2000.

\section{PRADHAN, A. Driving Simulator Lab.}

PRF. Datatran - Núcleo de Estatística da Polícia Rodoviária. Distrito Federal: Polícia Rodoviária Federal (PRF), 2018. .

REIMER, B.; D'AMBROSIO, L. A.; COUGHLIN, J. F. Secondary analysis of time of day on simulated driving performance. Journal of Safety Research, v. 38, n. 5, p. 563-570, 2007.

RICHTER, T.; RUHL, S.; ORTLEPP, J.; BAKABA, E. Prevention of Overtaking Accidents on Two-lane Rural Roads. Transportation Research Procedia, v. 14, p. 4140-4149, 2016. Disponível em: <https://linkinghub.elsevier.com/retrieve/pii/S235214651630391X>.

SAHAMI, S.; SAYED, T. How drivers adapt to drive in driving simulator, and what is the impact of practice scenario on the research? Transportation Research Part F: Traffic Psychology and Behaviour, v. 16, p. 41-52, 2013.

SANTOS, M. I. dos; OLIVEIRA, P. T. M. e S. de; RIBEIRO, R. L.; LAROCCA, A. P. C.; KABBACH JUNIOR, F. I. Conceito, configuração e aplicação de um simulador de direção no Brasil - Estudo de caso. TRANSPORTES, v. 25, n. 2, p. 1, 31 ago. 2017.

SHECHTMAN, O.; CLASSEN, S.; AWADZI, K.; MANN, W. Comparison of Driving Errors Between On-the-Road and Simulated Driving Assessment: A Validation Study. Traffic Injury Prevention, v. 10, n. 4, p. 379-385, 14 jul. 2009.

SHINAR, D. Traffic safety and human behavior. Boston, MA: Emerald Publishing Limited, 2017.

SHINAR, D.; COMPTON, R. Aggressive driving: An observational study of driver, vehicle, and situational variables. Accident Analysis and Prevention, v. 36, n. 3, p. 429-437, 2004.

SPACEK, P. Track Behavior in Curve Areas: Attempt at Typology. Journal of Transportation Engineering, v. 131, n. 9, p. 669-676, set. 2005.

STRAUS, S. H. New, Improved, Comprehensive, and Automated Driver's License Test and Vision Screening System. [s.I: s.n.].

THEEUWES, J.; GODTHELP, H. Self-explaining roads. Safety Science, v. 19, n. 2-3, p. 217225, 1995.

TÖRNROS, J. Driving behaviour in a real and a simulated road tunnel-a validation study. Accident Analysis \& Prevention, v. 30, n. 4, p. 497-503, jul. 1998.

TORQUATO, T. L. de L. Jerk como indicador de consistência geométrica para rodovias. 2019. (Tese de Doutorado) Escola de Engenharia de São Carlos da Universidade de São Paulo, 2019. 
UNDERWOOD, G.; CRUNDALL, D.; CHAPMAN, P. Driving simulator validation with hazard perception. Transportation Research Part F: Traffic Psychology and Behaviour, v. 14, n. 6, p. 435-446, 2011.

VAN DER HORST, A.; HOGEMA, J. Driving Simulator Research on Safe Highway Design and Operation. Transportation Research Record: Journal of the Transportation Research Board, v. 2248, p. 87-95, 2011.

VAN ELSLANDE, P.; NAING, C.; ENGEL, R. Analyzing human factors in road accidents. [s.I.] TRaffic Accident Causantion in Europe, 2008.

VASSILIS, P.; DIMITRIS, N.; EVANGELIA, P.; NICOLAS, M. The effects of changes in the traffic scene during overtaking. Accident Analysis and Prevention, v. 79, p. 126-132, 2015.

VERCRUYSSEN, M.; HENDRICK, H. W. Behavioral research an analysis: an introduction to statistics within the context of experimental design. 4th. ed. [s.I.] CRC Press, 1981.

VIEIRA, F. S. Evaluation of drivers'behavior performing a curve under mental workload. 2016. School of Engineering of São Carlos - University of São Paulo, 2016.

VLAHOGIANNI, E. I. Modeling duration of overtaking in two lane highways. Transportation Research Part F: Traffic Psychology and Behaviour, v. 20, p. 135-146, 2013.

VLAHOGIANNI, E. I.; GOLIAS, J. C. Bayesian modeling of the microscopic traffic characteristics of overtaking in two-lane highways. Transportation Research Part F: Traffic Psychology and Behaviour, v. 15, n. 3, p. 348-357, 2012.

WANG, B.; HENSHER, D. A.; TON, T. Safety in the road environment: A driver behavioural response perspective. Transportation, v. 29, n. 3, p. 253-270, 2002.

WANG, Y.; CARTMELL, M. P. New model for passing sight distance on two-lane highways. Journal of Transportation Engineering, v. 124, n. 6, p. 536-544, 1998.

WANG, Y.; MEHLER, B.; REIMER, B.; LAMMERS, V.; D'AMBROSIO, L. A.; COUGHLIN, J. F. The validity of driving simulation for assessing differences between in-vehicle informational interfaces: A comparison with field testing. Ergonomics, v. 53, n. 3, p. 404-420, 2010.

WINTER, J. . C. F.; MORVAN, H.; ROBACHE, F.; NAVETEUR, J.; PACAUX, M. P. Using a high-fidelity driving simulator to predict self-reported driving style and crash involvement: a preliminary study. In: 30th European Annual Conference on Human Decision-Making and Manual Control, Braunschweig. Braunschweig: 2012.

WITMER, B. G.; JEROME, C. J.; SINGER, M. J. The Factor Structure of the Presence Questionnaire. Presence, v. 14, n. 3, p. 298-312, 2005.

WITMER, B. G.; SINGER, M. J. Measuring Presence in Virtual Environments: A Presence Questionnaire. Presence, v. 7, n. 3, p. 225-240, 1998.

WOCHINGER, K.; EMERY, C.; ALICANDRI, E. FHWA's Driver Performance Laboratory. [s.I.] Public Roads, 1999. .

YANG, L.; LI, X.; GUAN, W.; ZHANG, H. M.; FAN, L. Effect of traffic density on drivers' lane change and overtaking maneuvers in freeway situation-A driving simulator-based study. Traffic Injury Prevention, v. 19, n. 6, p. 594-600, 18 ago. 2018. 
ZEFREH, M. M.; TÖRÖK, Á. Improving Traffic Flow Characteristics by Suppressing Shared Taxis Maneuvers. Periodica Polytechnica Transportation Engineering, v. 44, n. 2, p. 6974, 2016.

ZHANG, Y.; HOOGENDOORN, R.; MAZO, M.; HELLENDOORN, H. Steering Controller Identification and Design for Human-like Overtaking. Procedia Manufacturing, v. 3, n. Ahfe, p. 2526-2533, 2015. 
Nesta seção são apresentados os gráficos de afastamento lateral de todos os participantes ao longo do trecho simulado. Nos gráficos são indicados o número identificador do condutor (\#01 a \#82) e o cenário (C1 a C8). O afastamento lateral corresponde à distância em que o participante dirigiu em relação ao eixo da via.

Os gráficos serão apresentados similar ao trecho de pista simples, considerando que a plataforma de pista simples possui largura de 7,20 metros (3,6 m por faixa). $O$ gráfico foi dividido em faixa da direita (fluxo da via) com eixo da faixa a $1,80 \mathrm{~m}$ do eixo da via e faixa da esquerda (fluxo contrário), com o eixo da faixa a $-1,8 \mathrm{~m}$ do eixo da via. Na parte inferior do gráfico foram indicados os segmentos em tangentes (T0 a T8) com os respectivos tratamentos e as curvas circulares (C1 a C8) a direita (D) e esquerda (E).

Os trechos destacados em vermelho representam a ocupação da faixa da direita, durante uma ultrapassagem ou tentativa de ultrapassagem seguida de abortagem. A nomenclatura dos tipos de ultrapassagens segue a classificação adotada nesta pesquisa, sendo U0 - não ultrapassagem; U1 - ultrapassagem simples e U2 - ultrapassagem completa. E as tentativas de ultrapassagem seguida de abortagem são classificadas como: $\mathrm{A} 0$ - não houve tentativa; A1 - tentativa sem risco e A2 - tentativa com risco. 

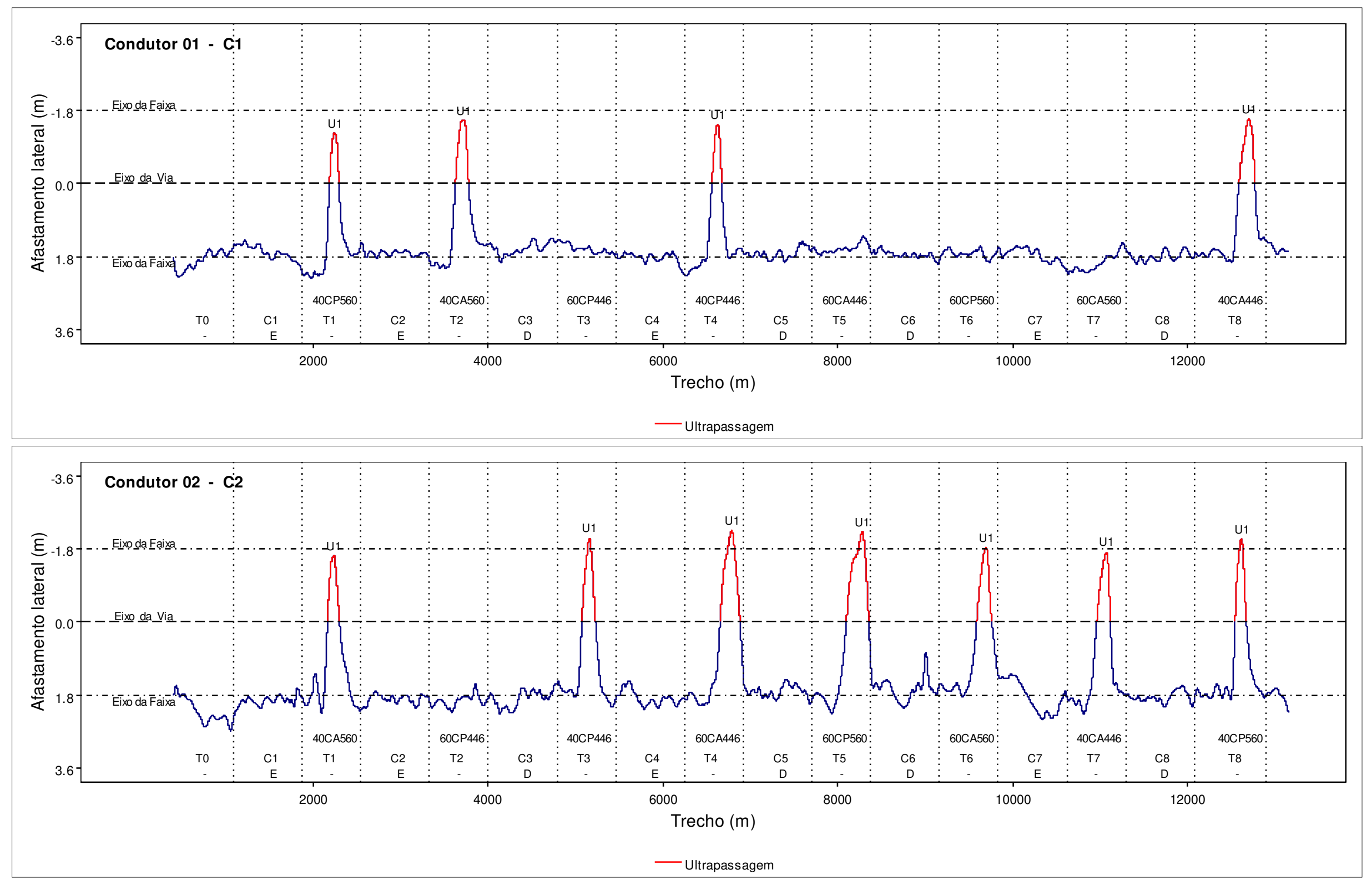

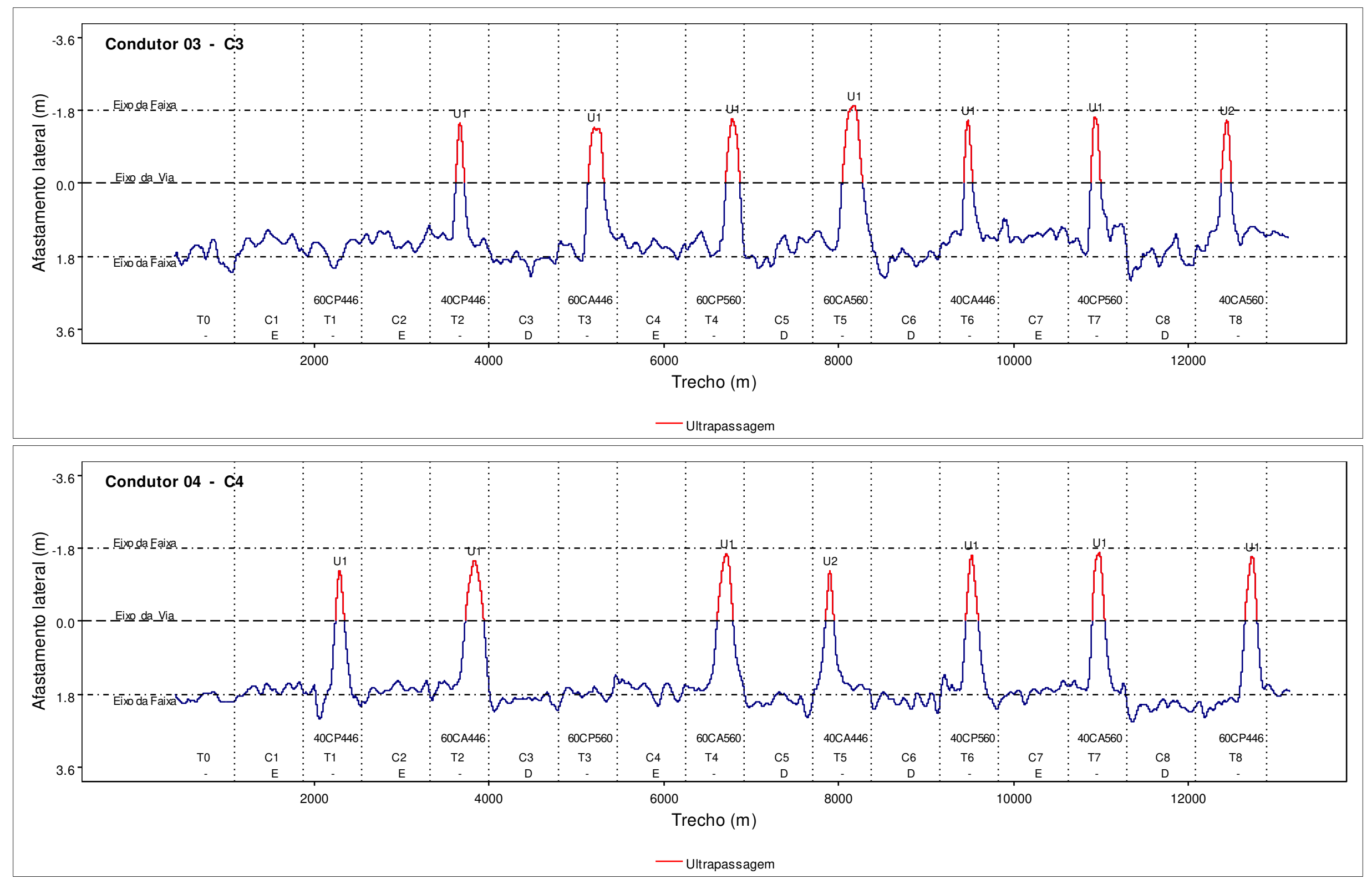

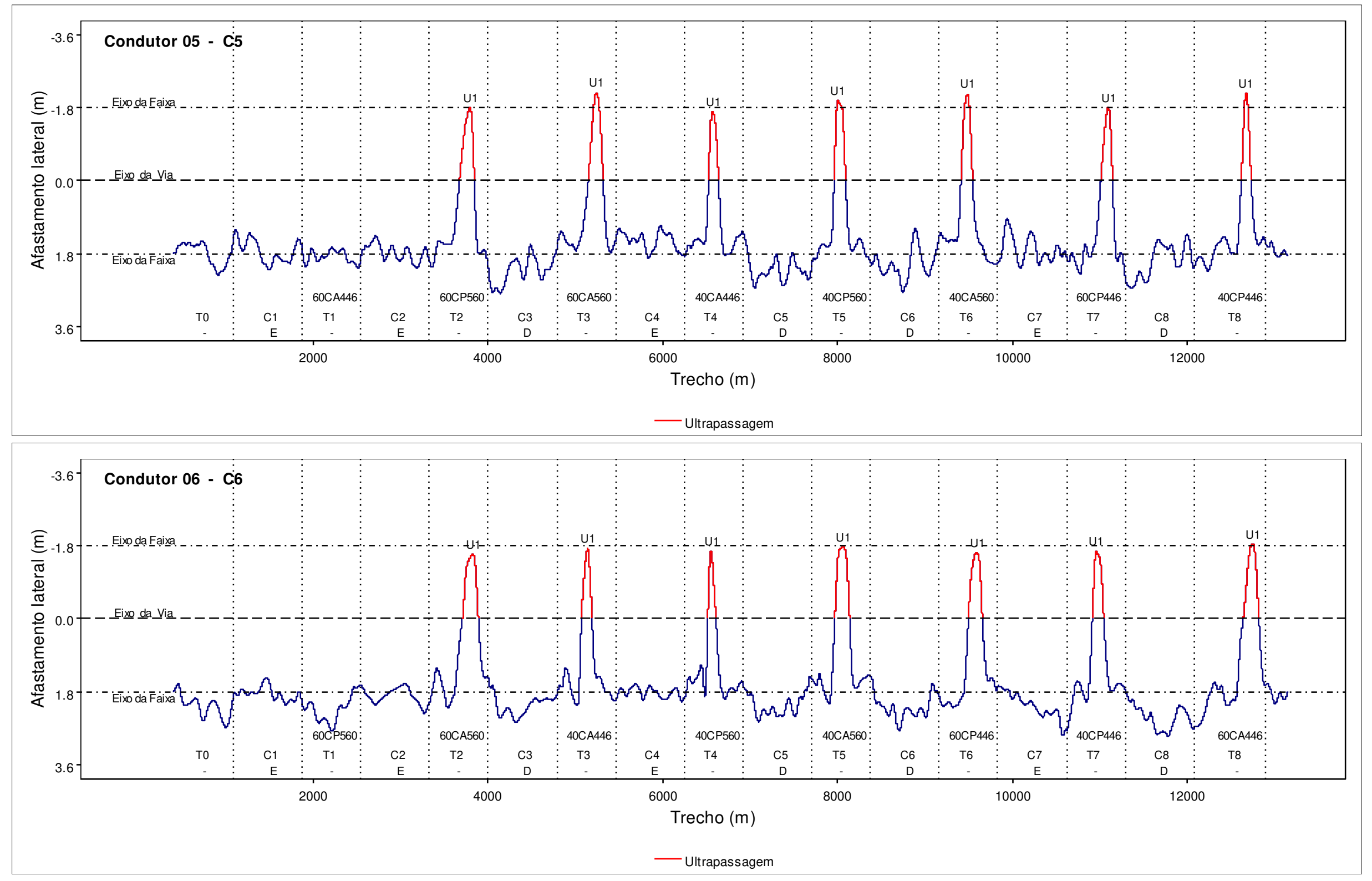

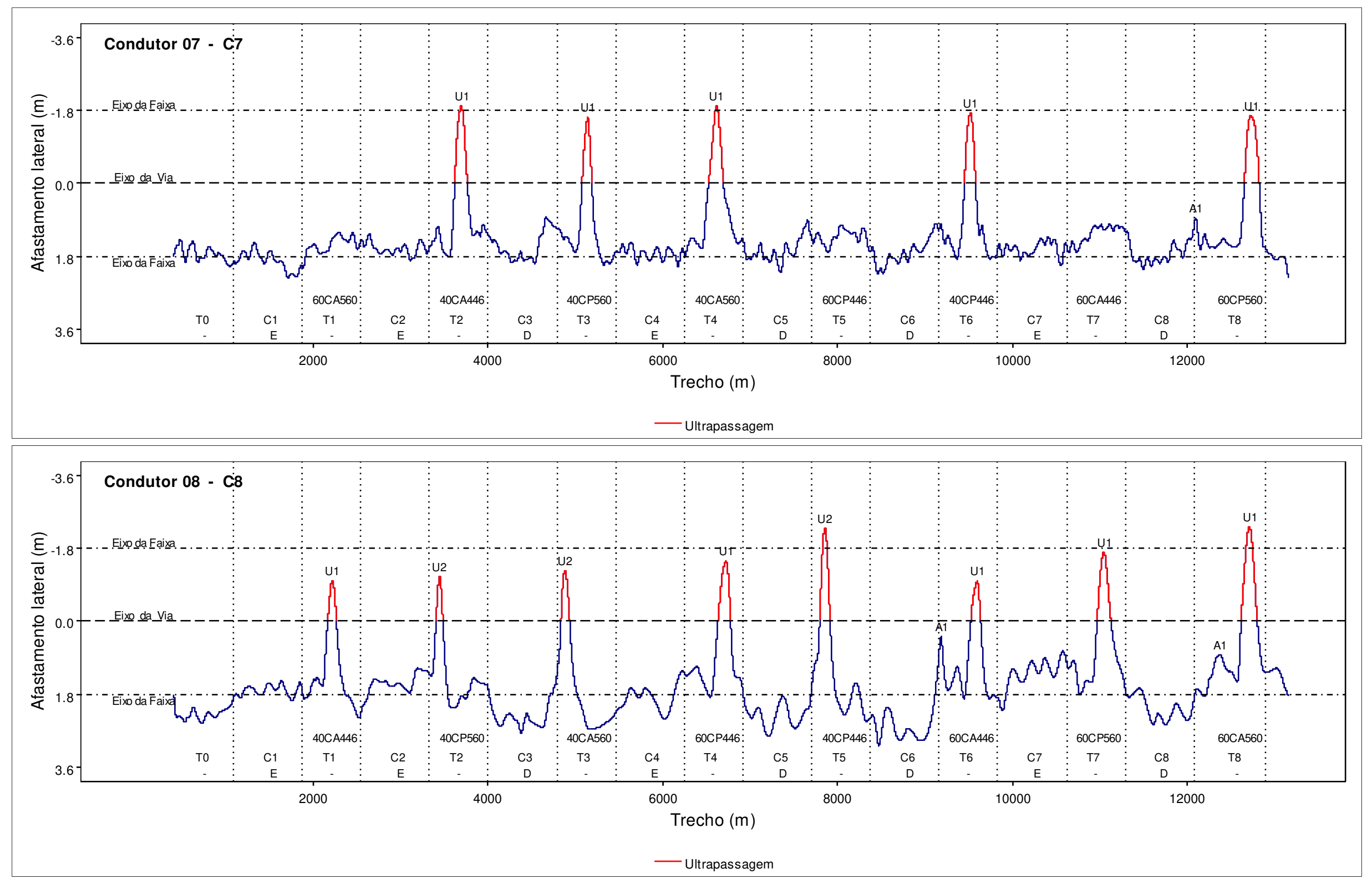

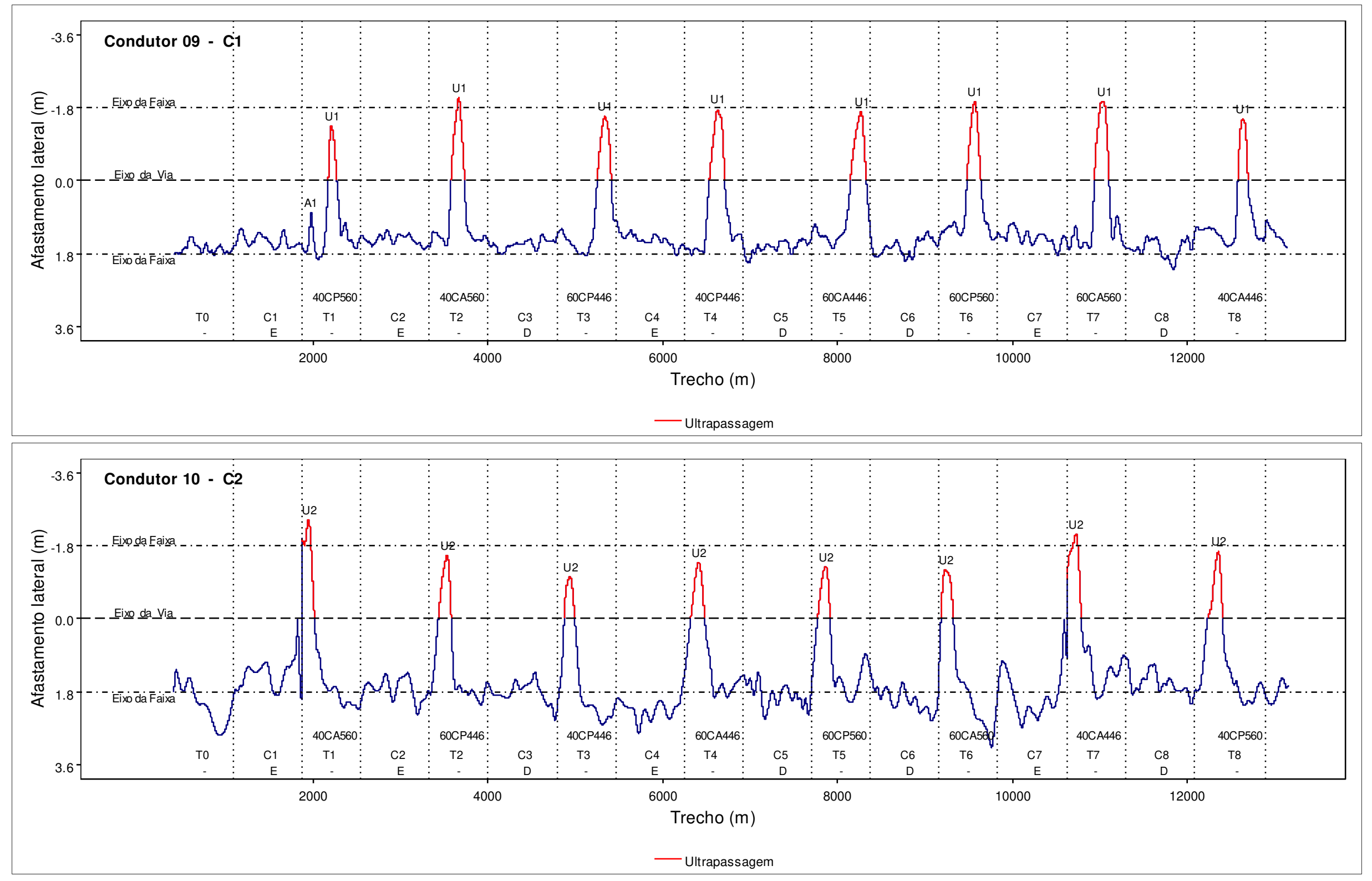
171
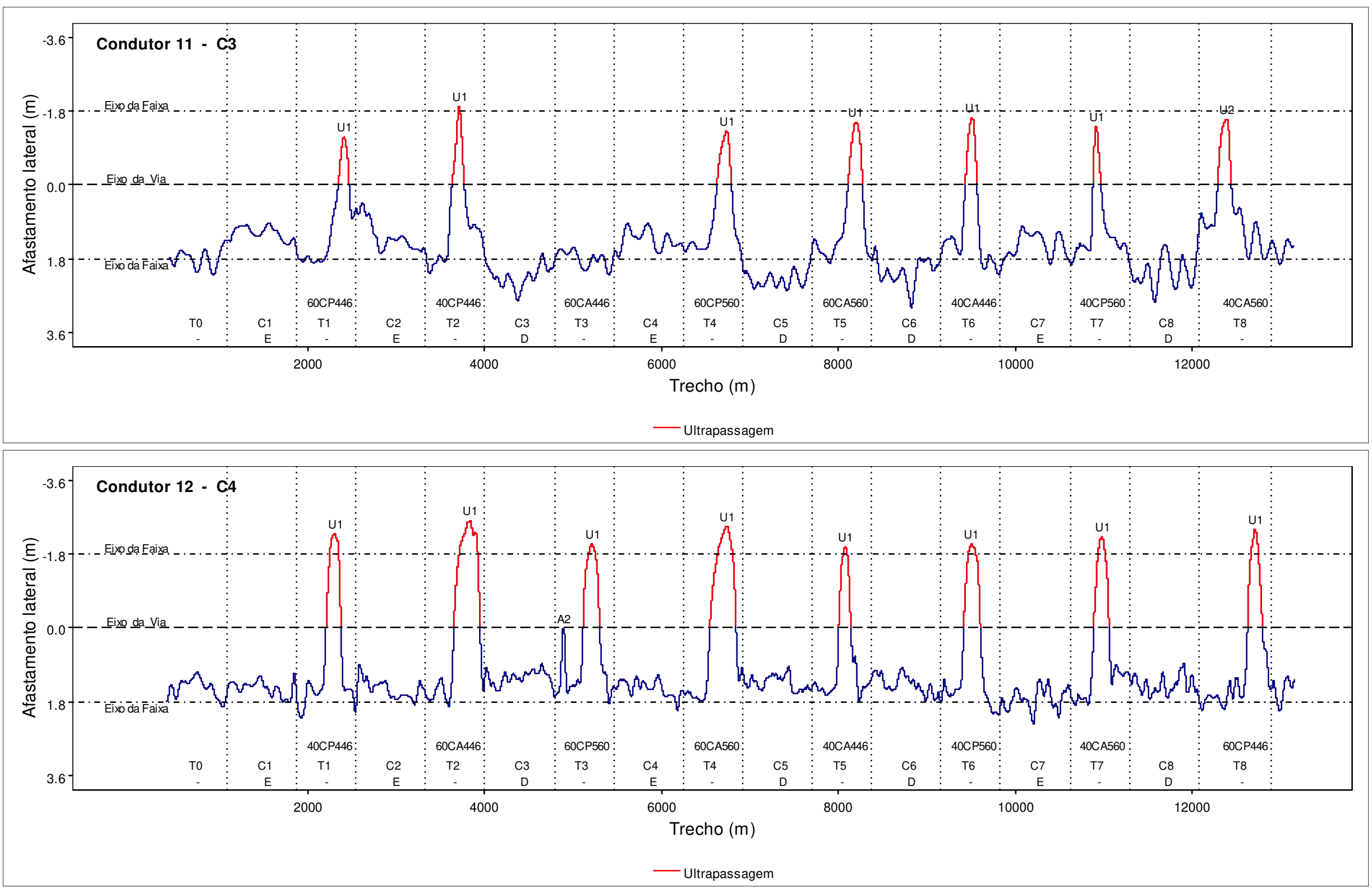

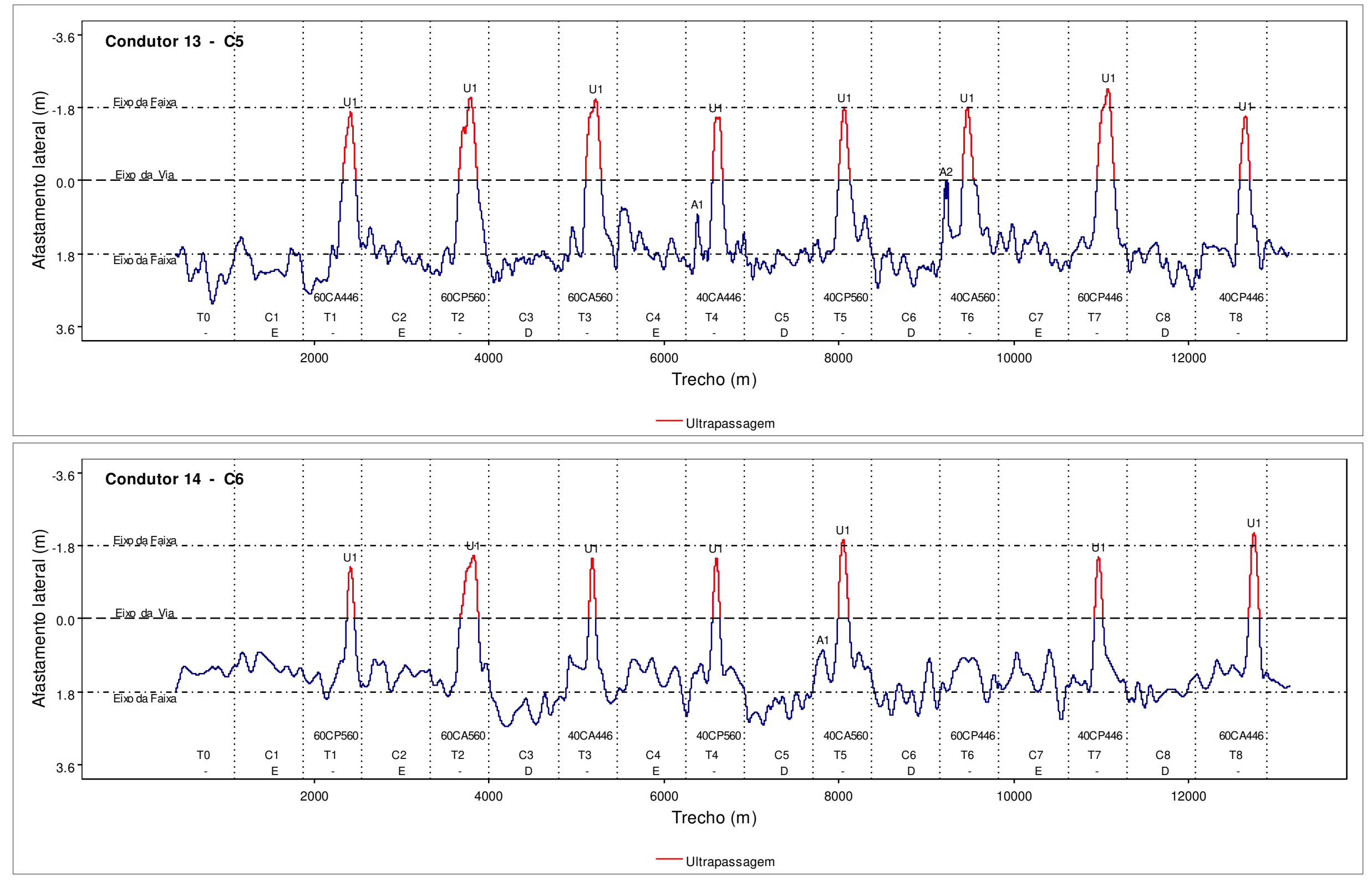

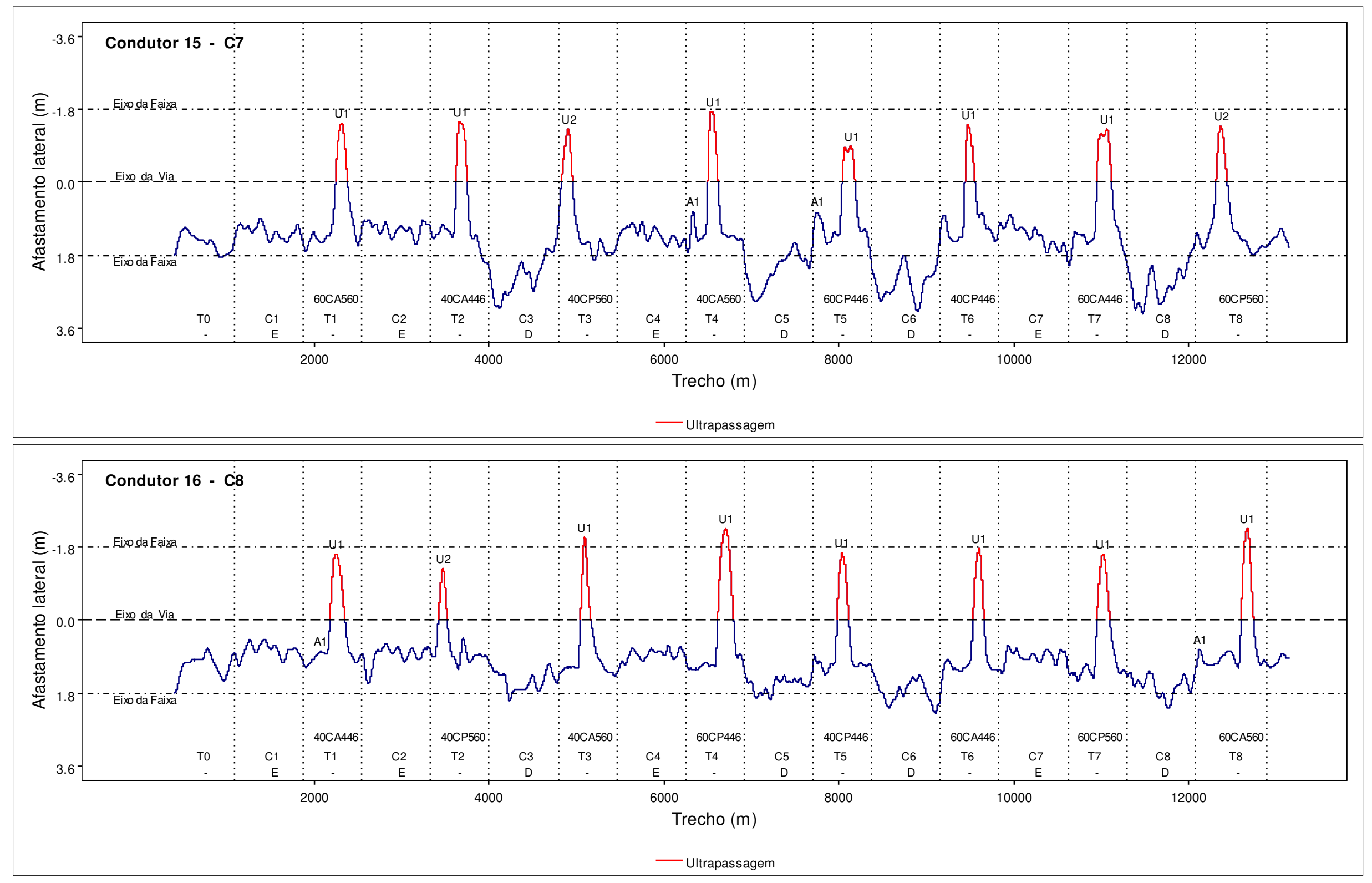

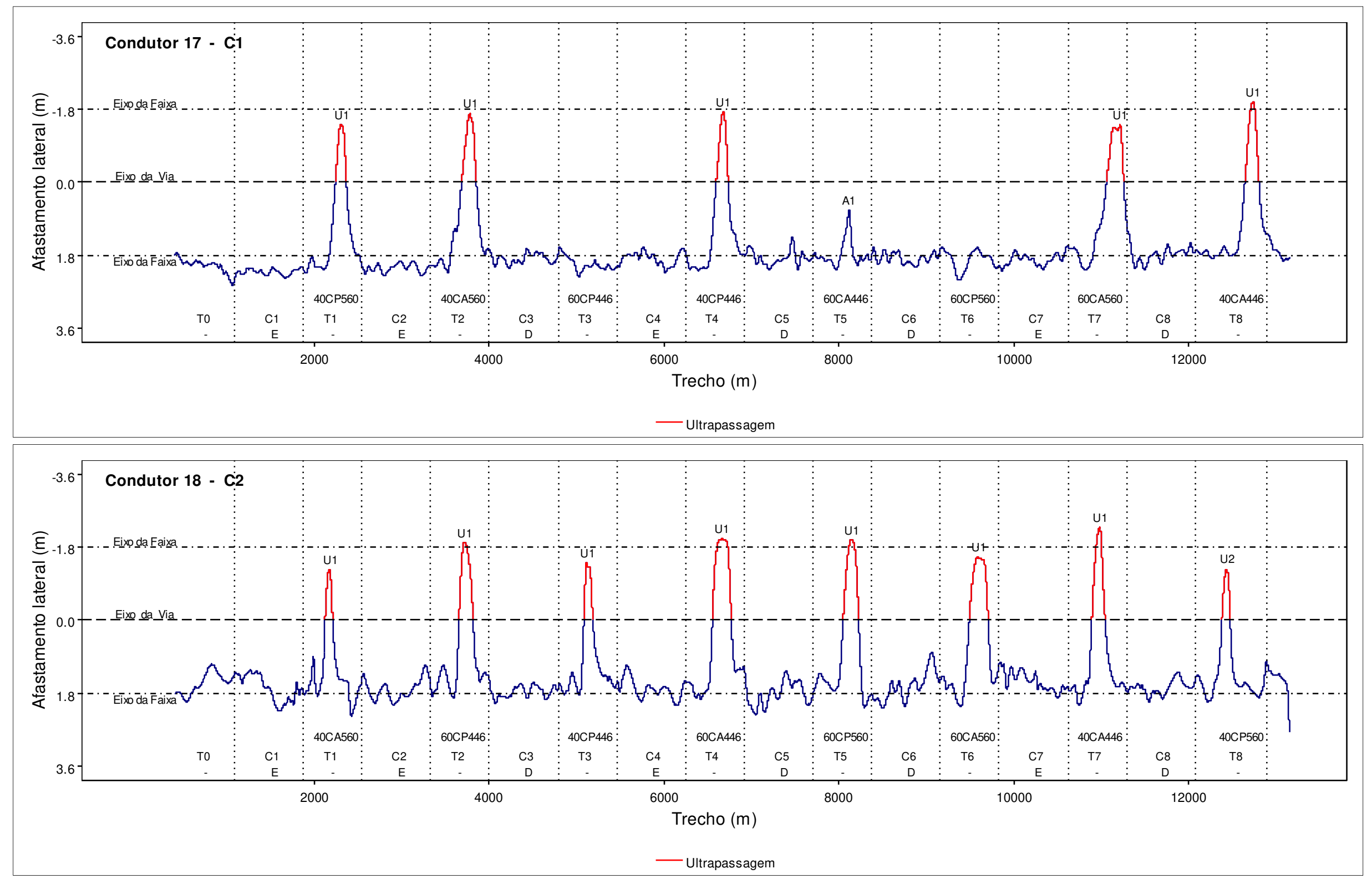

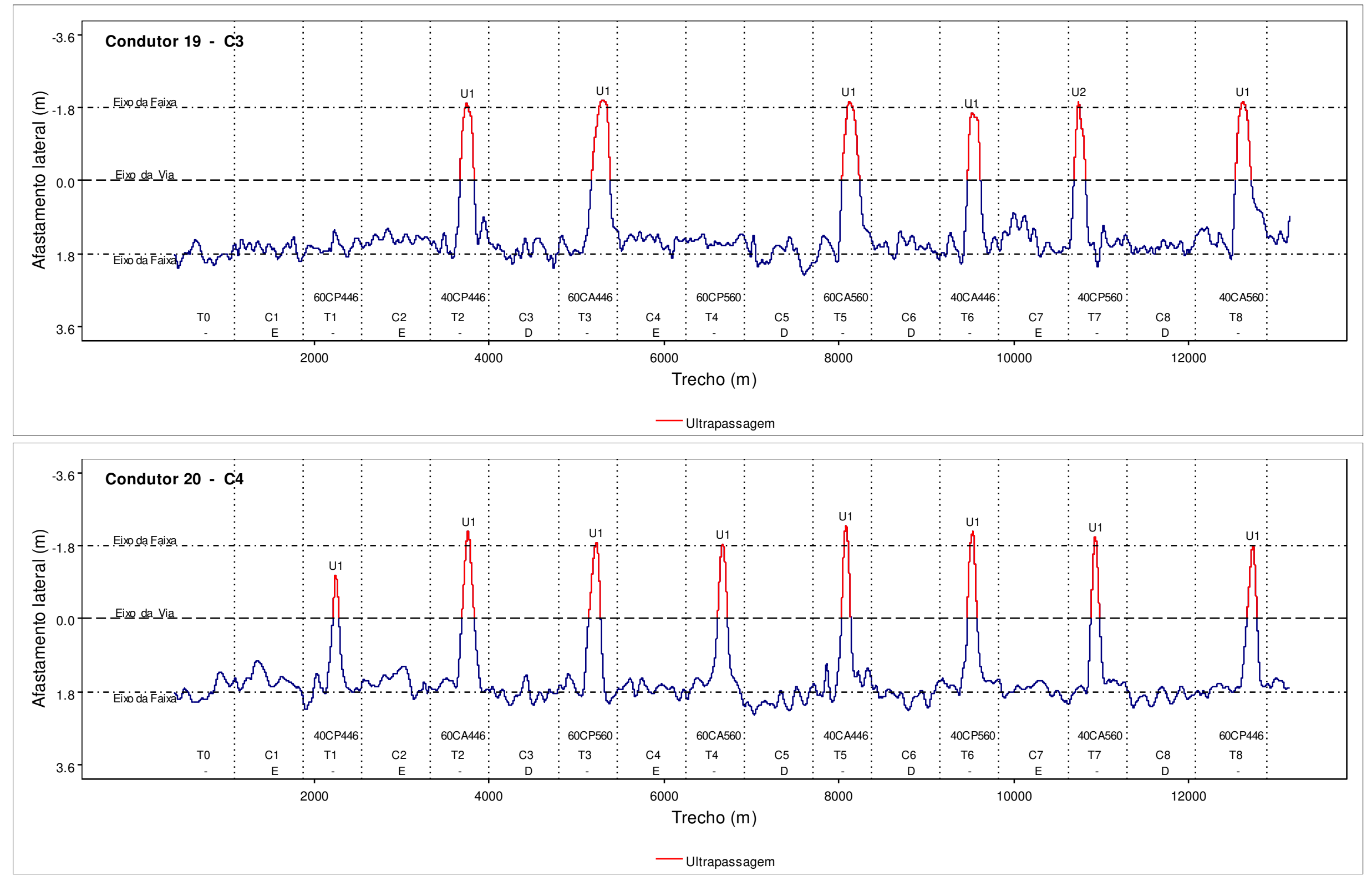

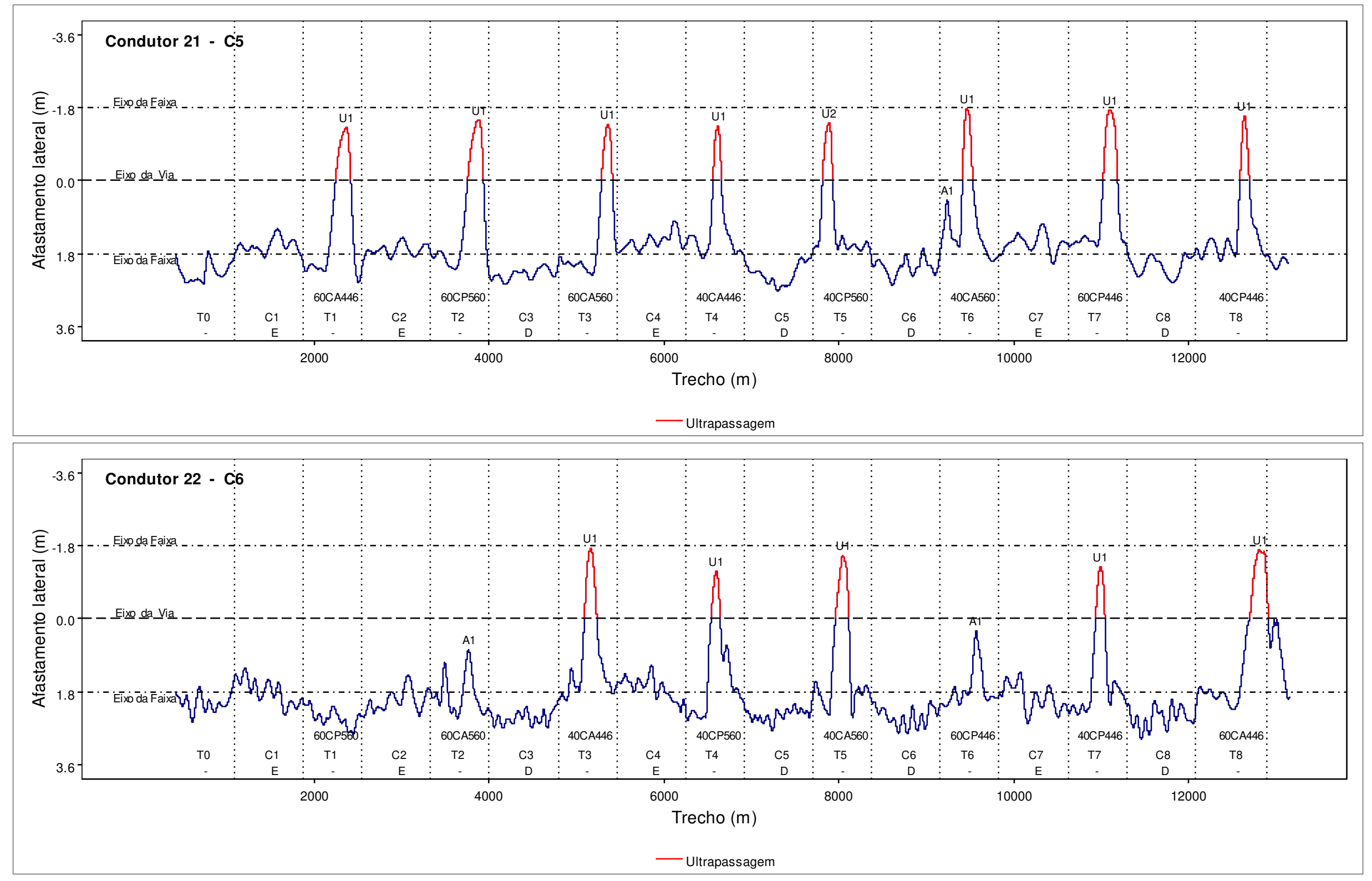

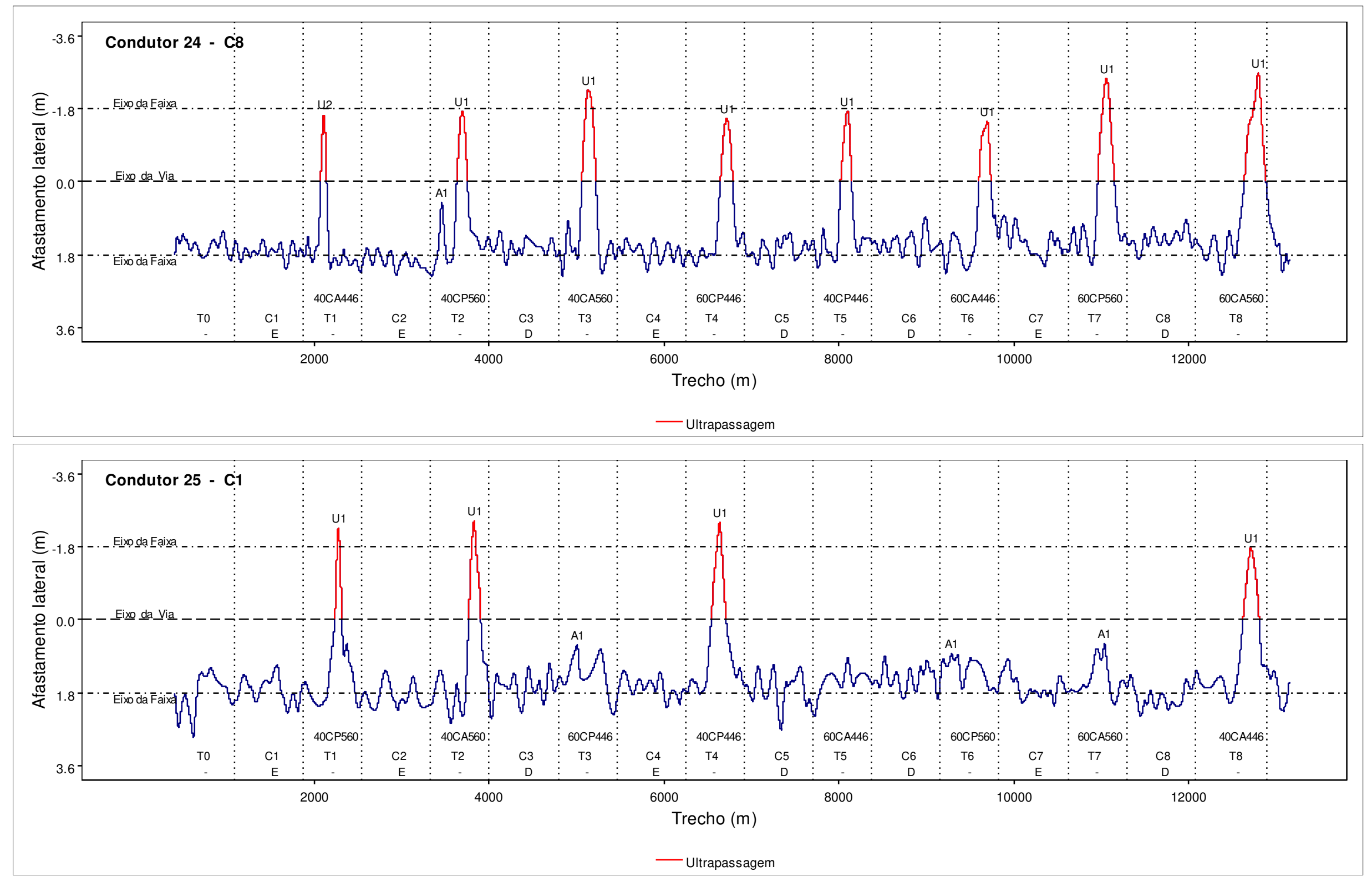

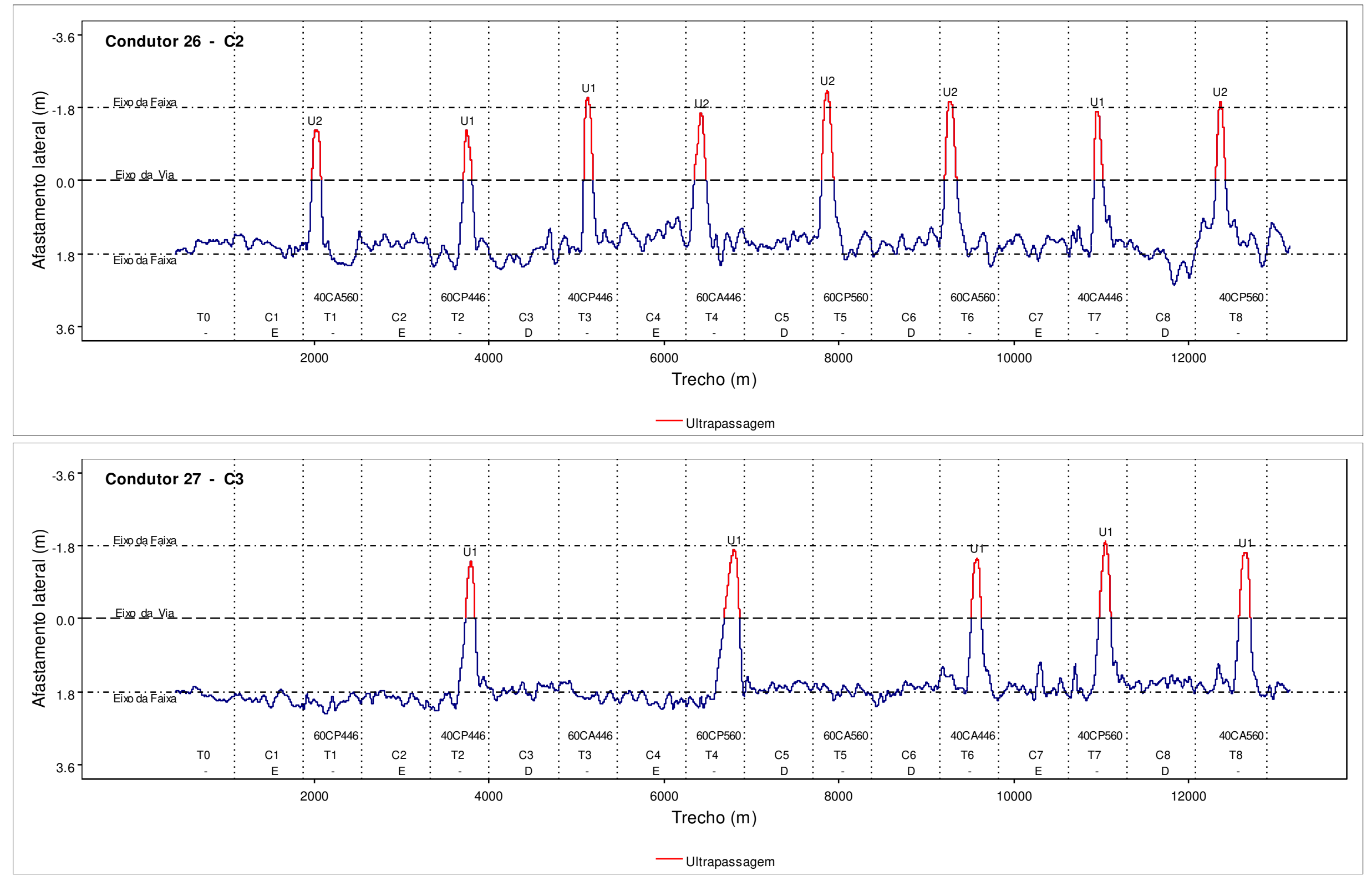

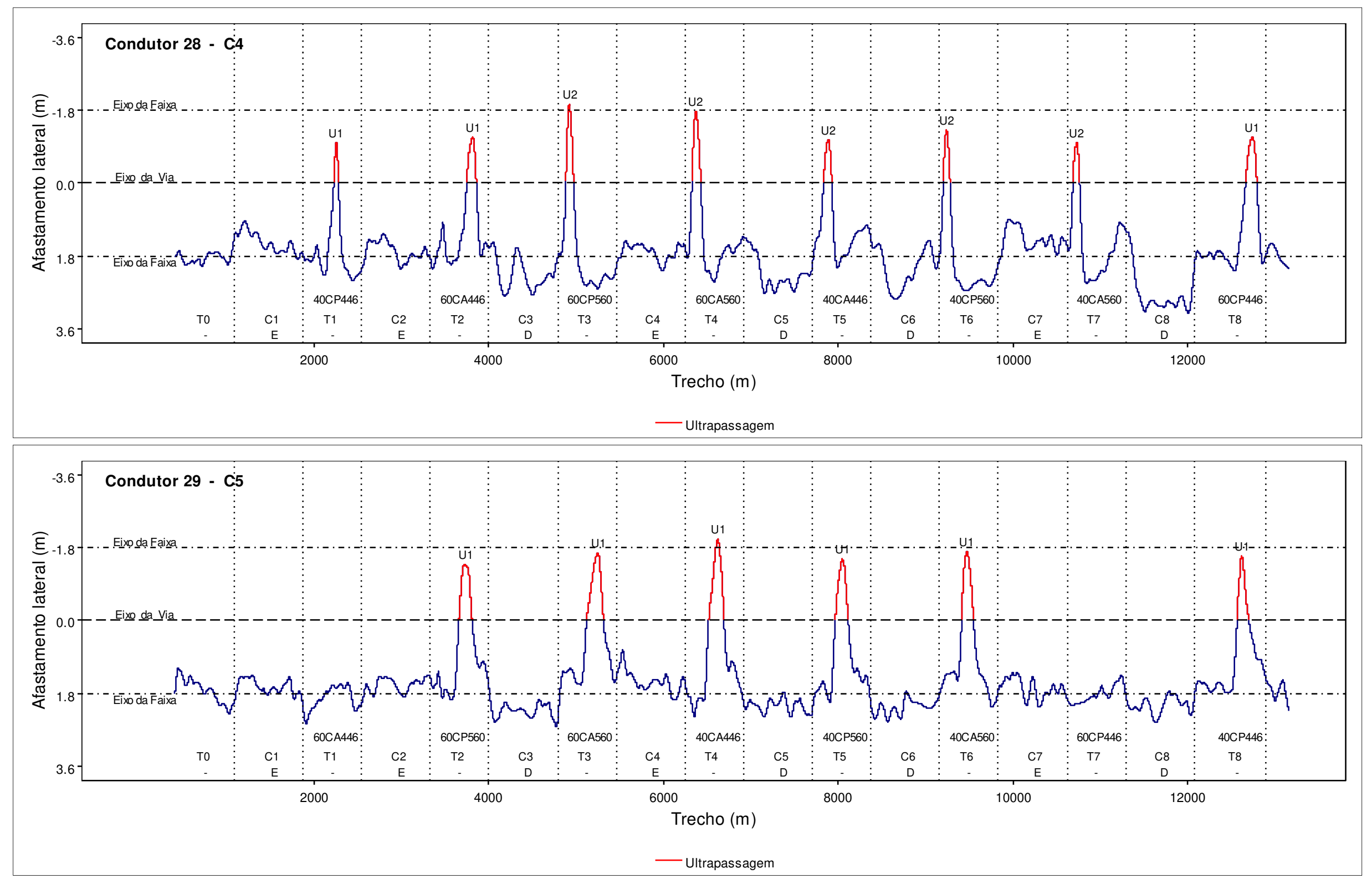

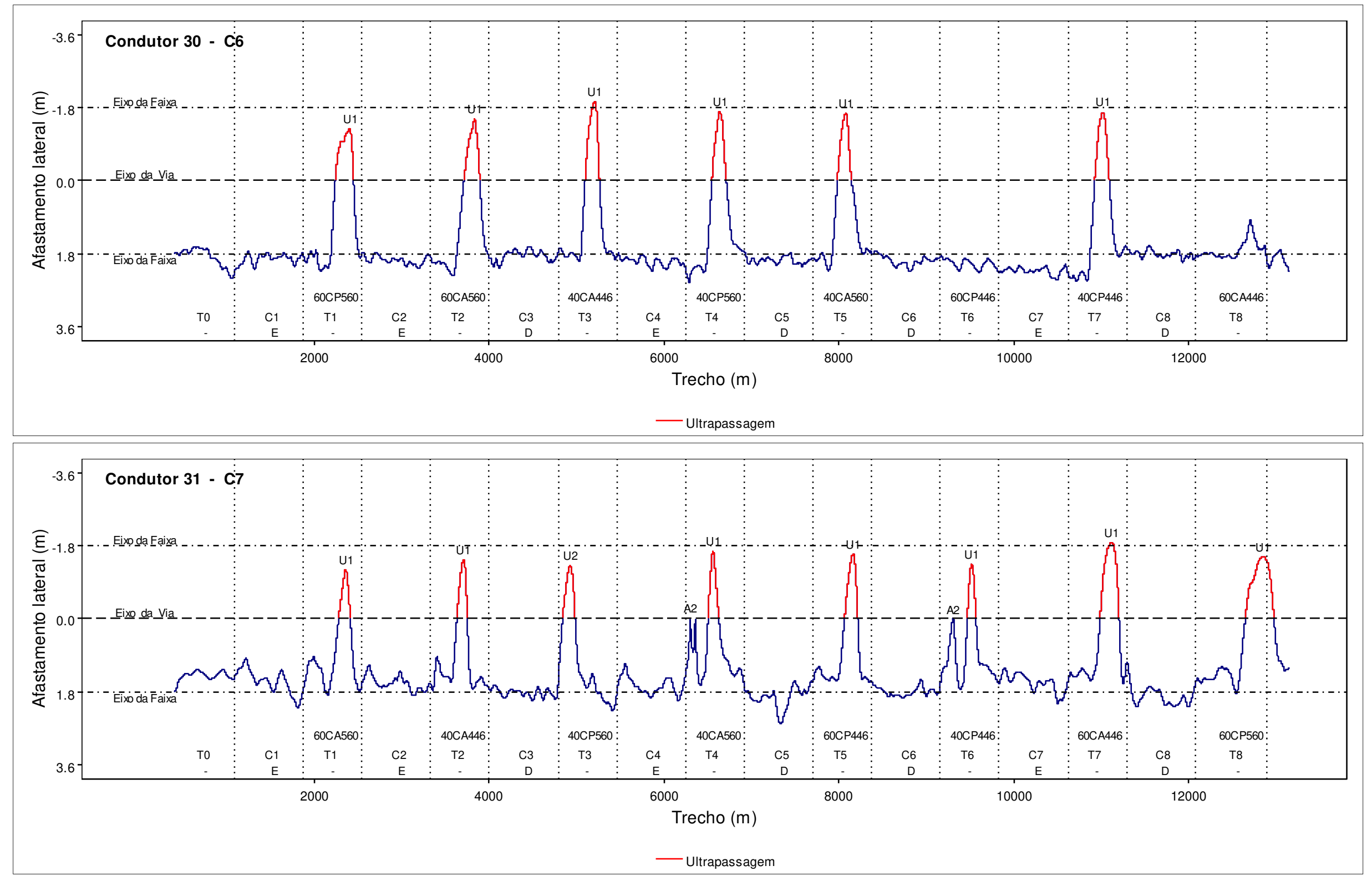

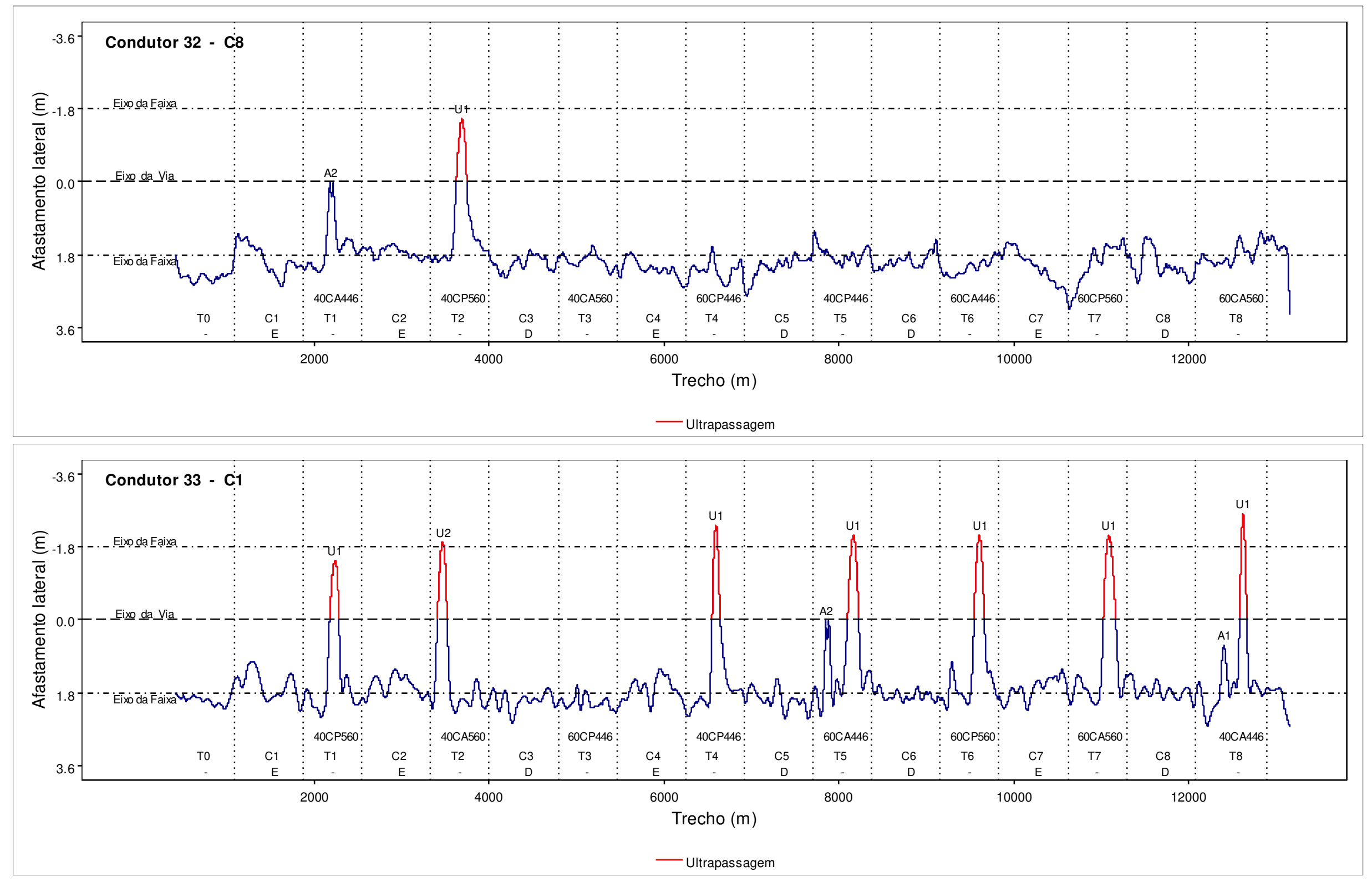

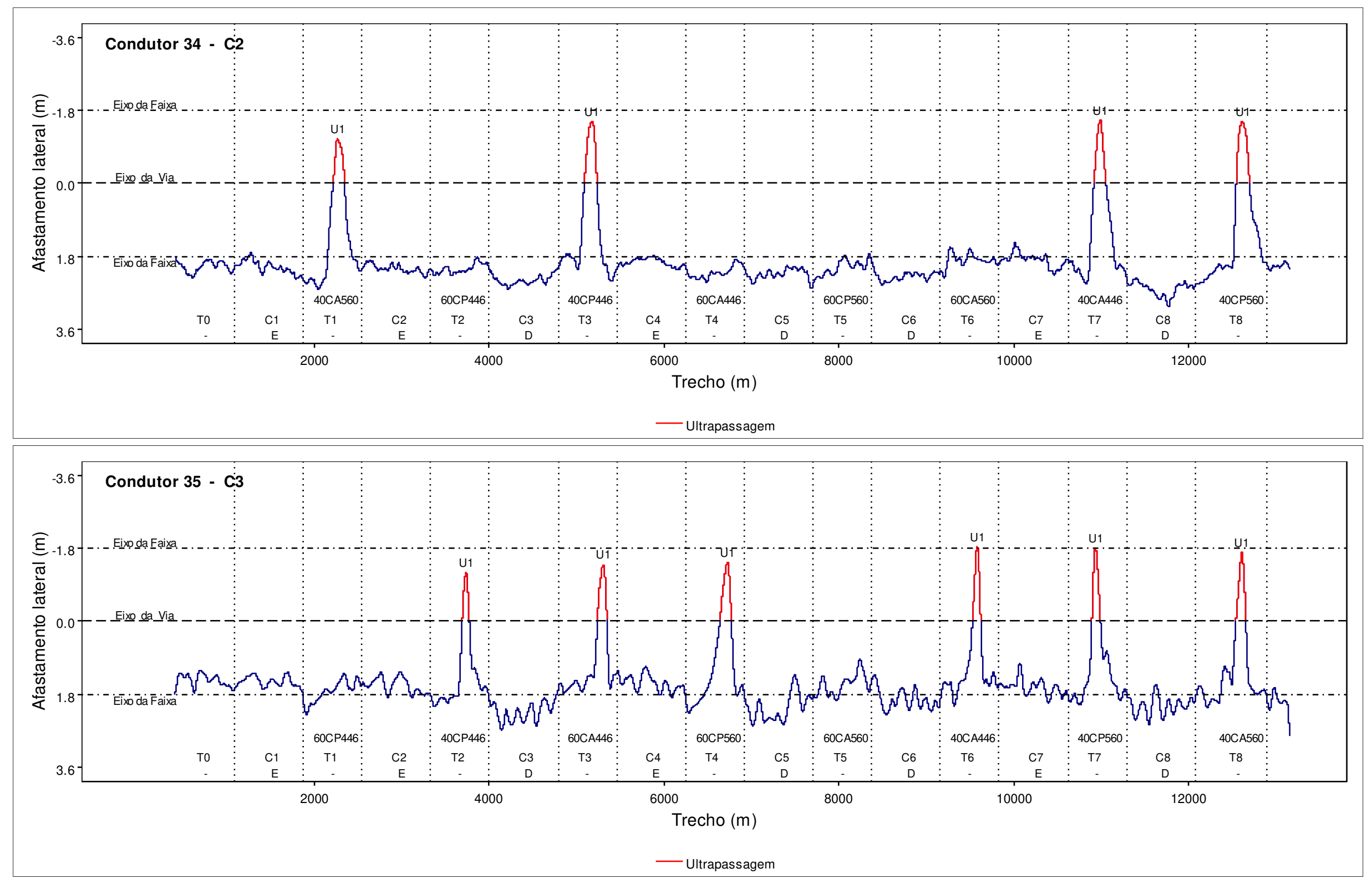

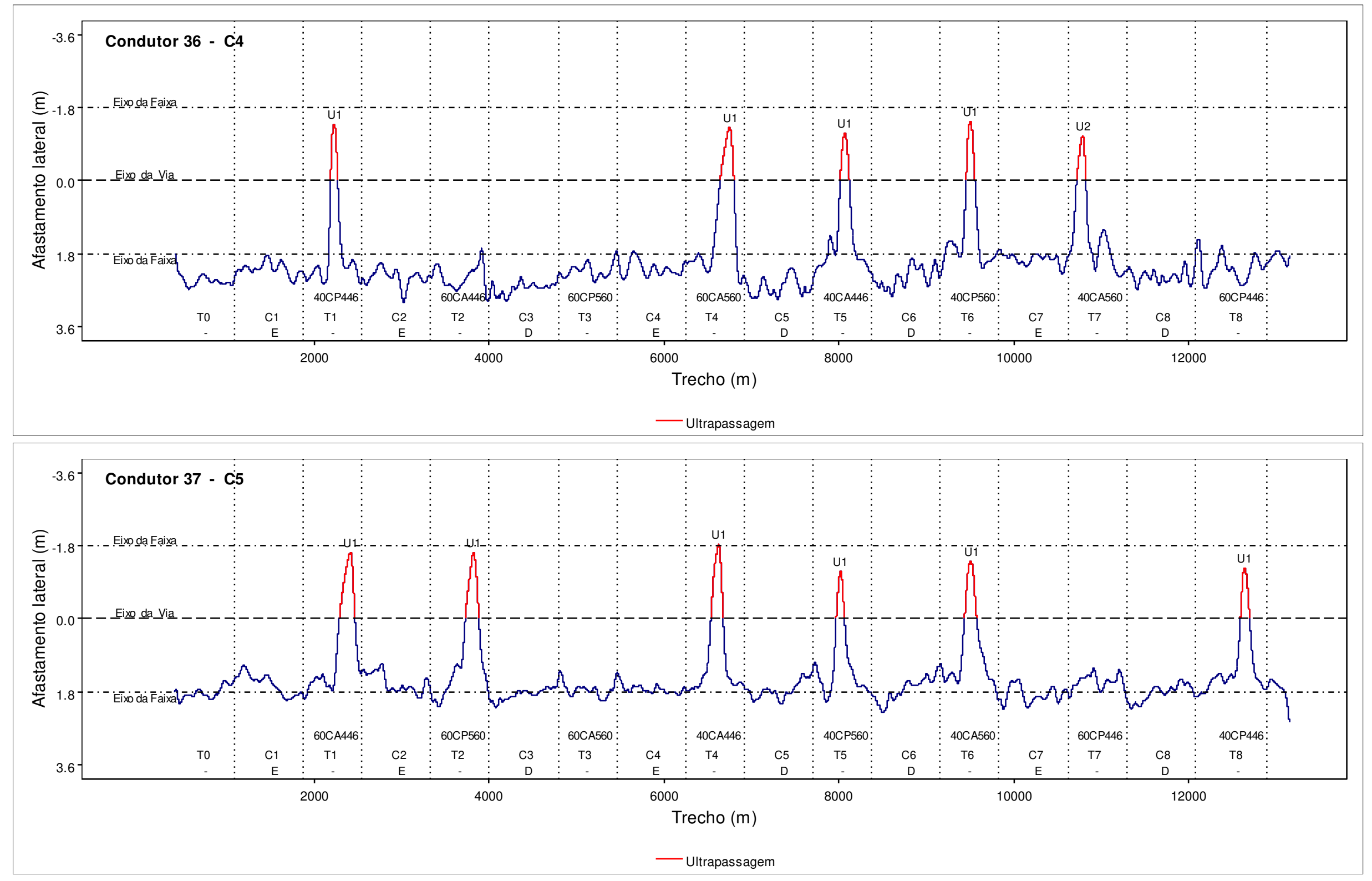

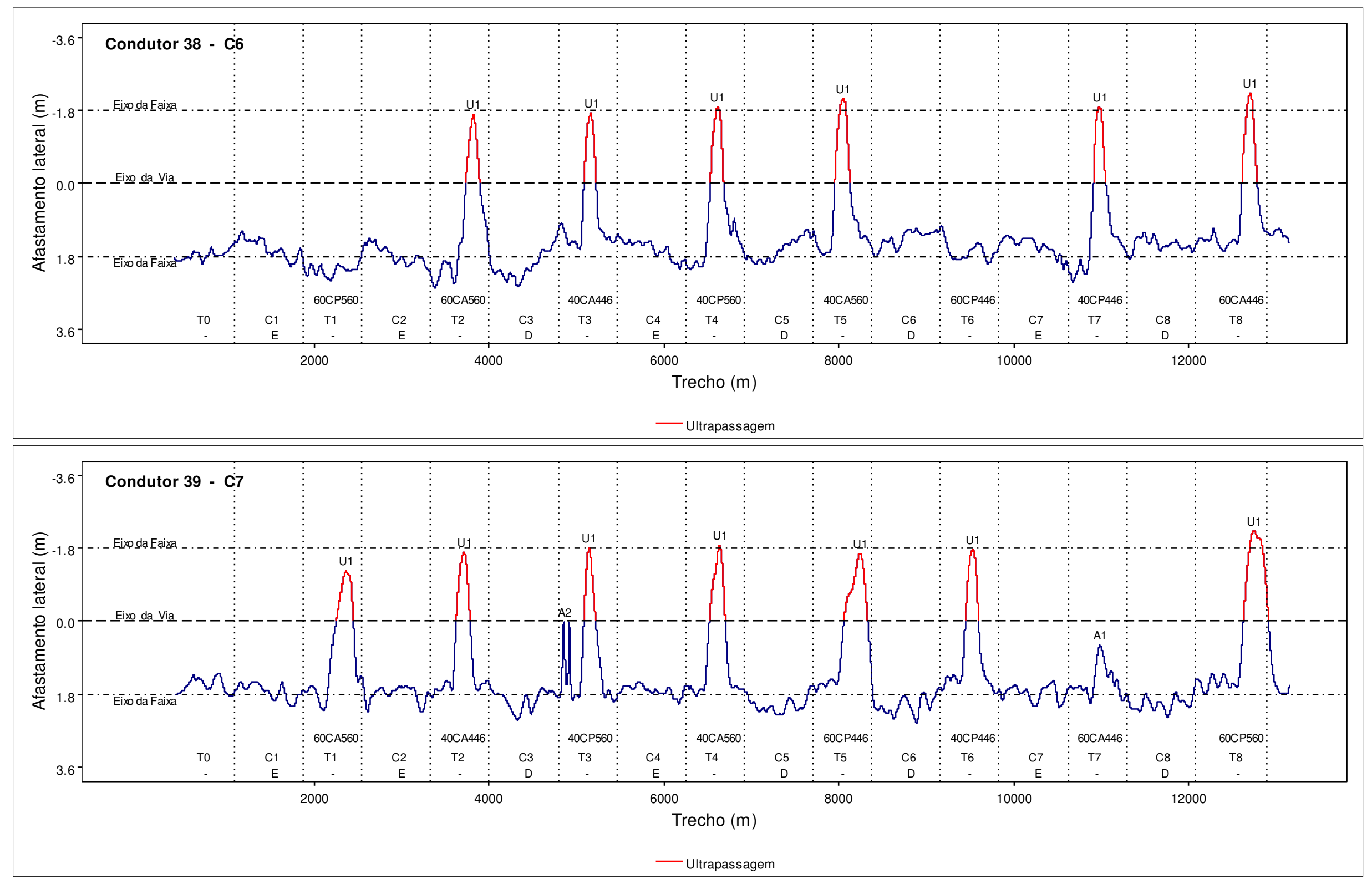

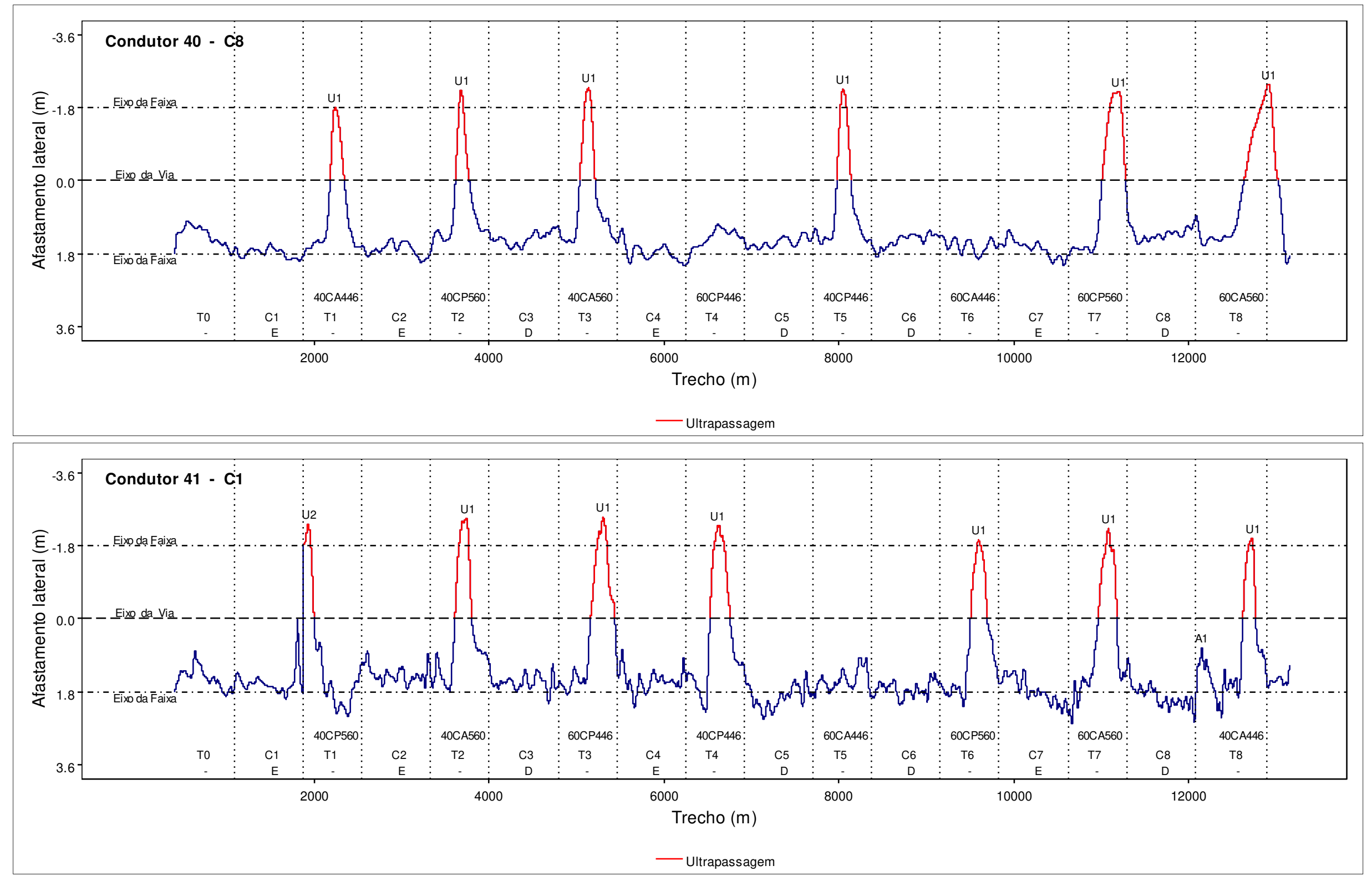

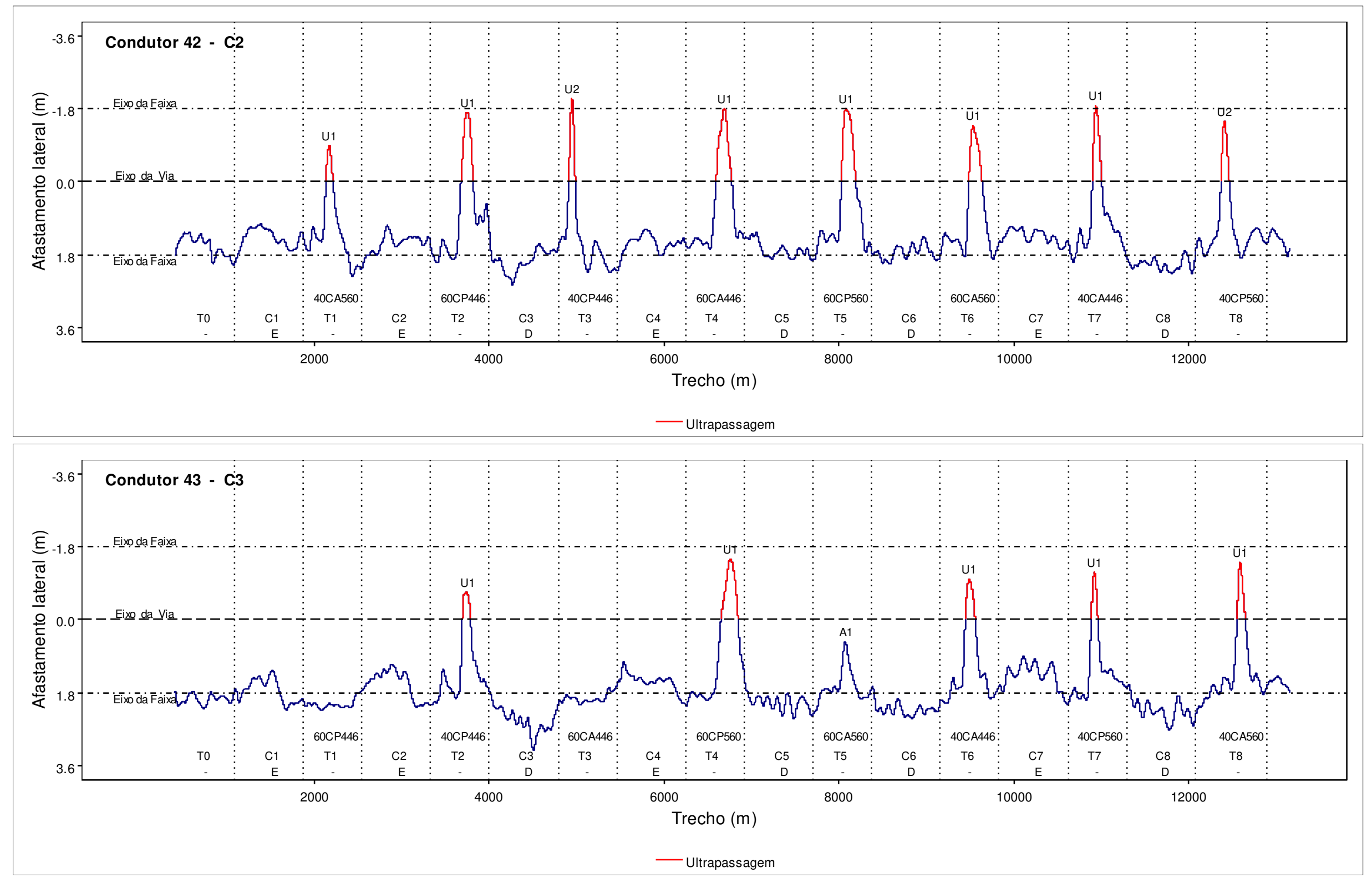

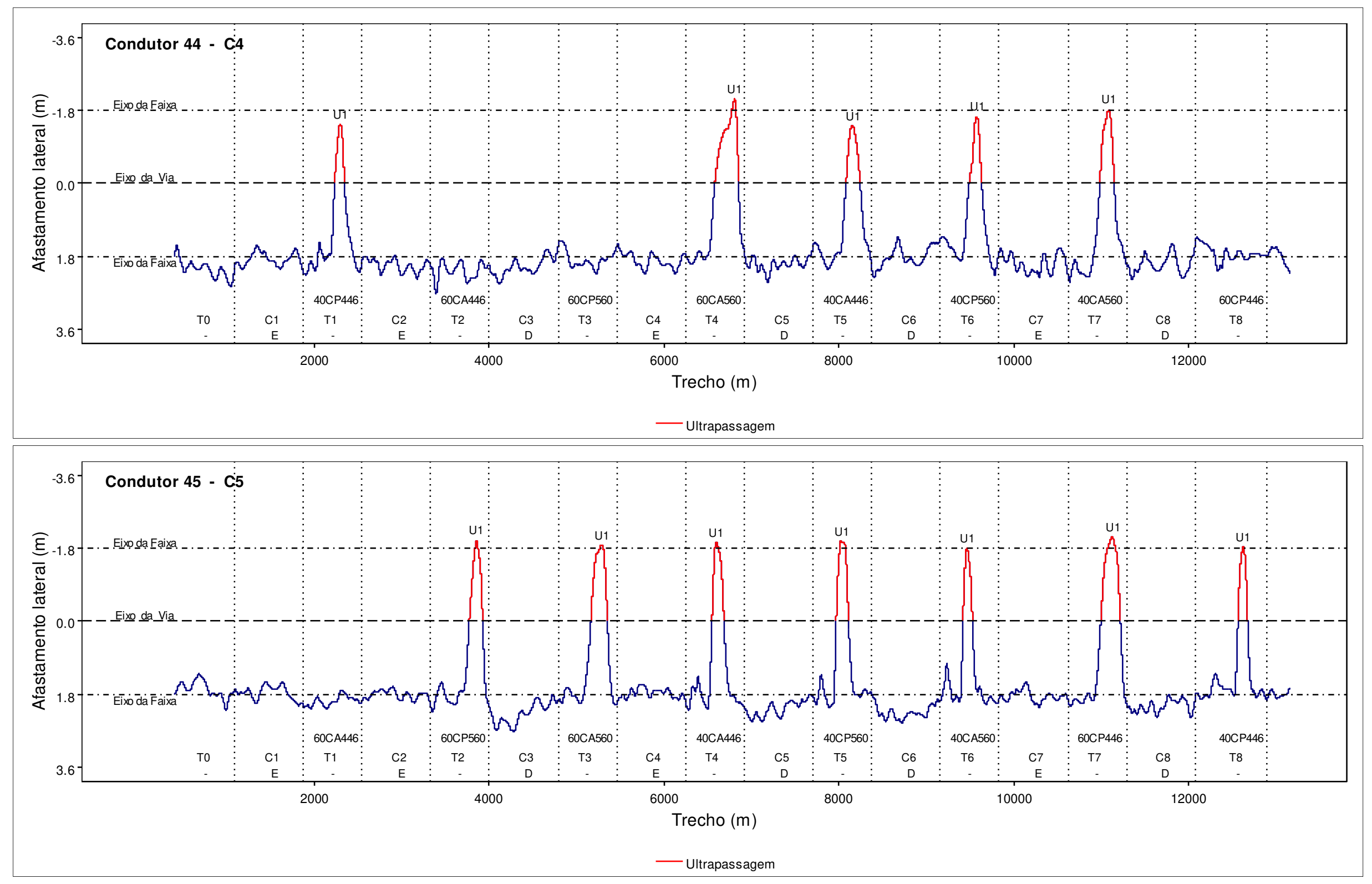

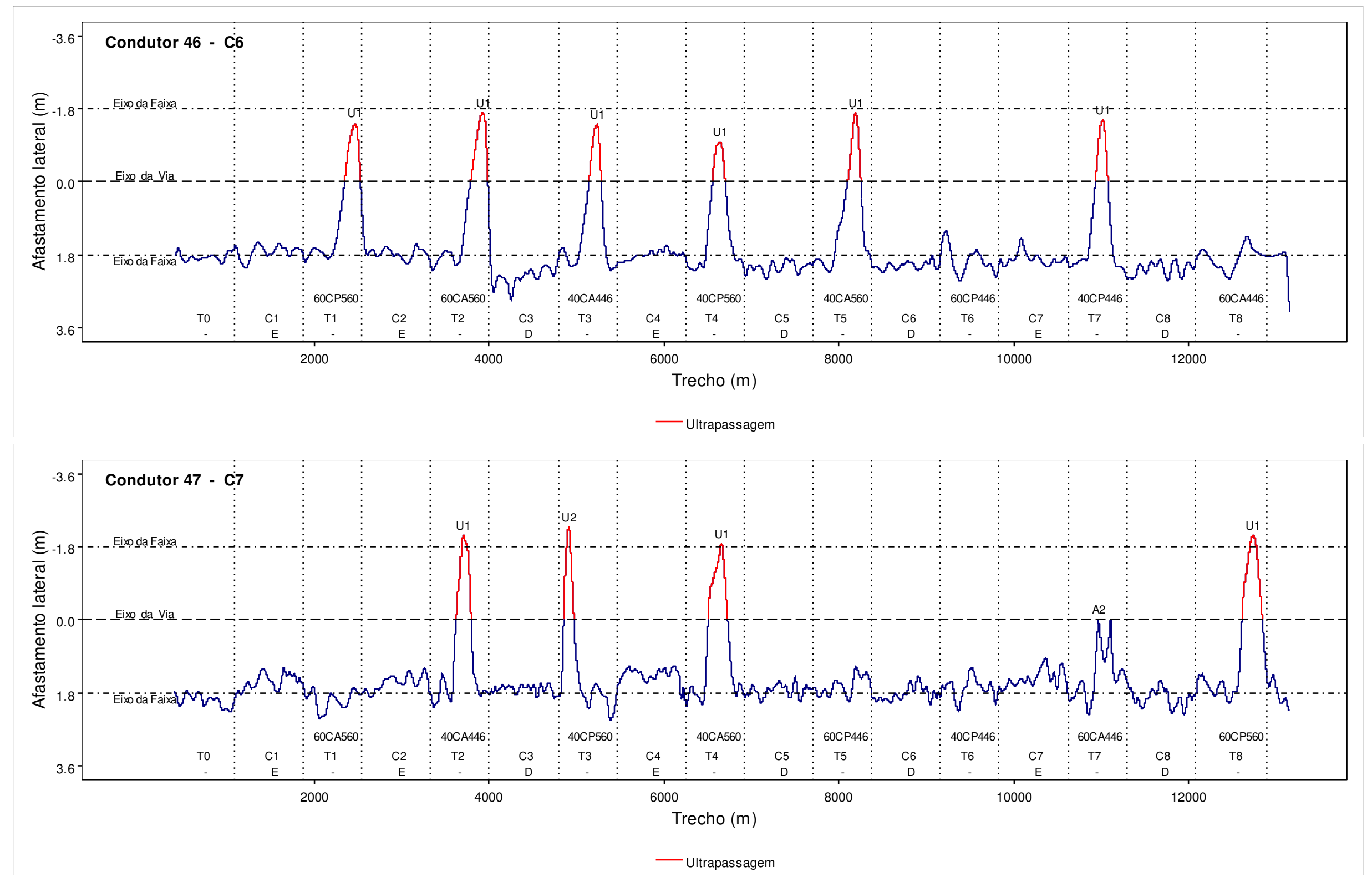

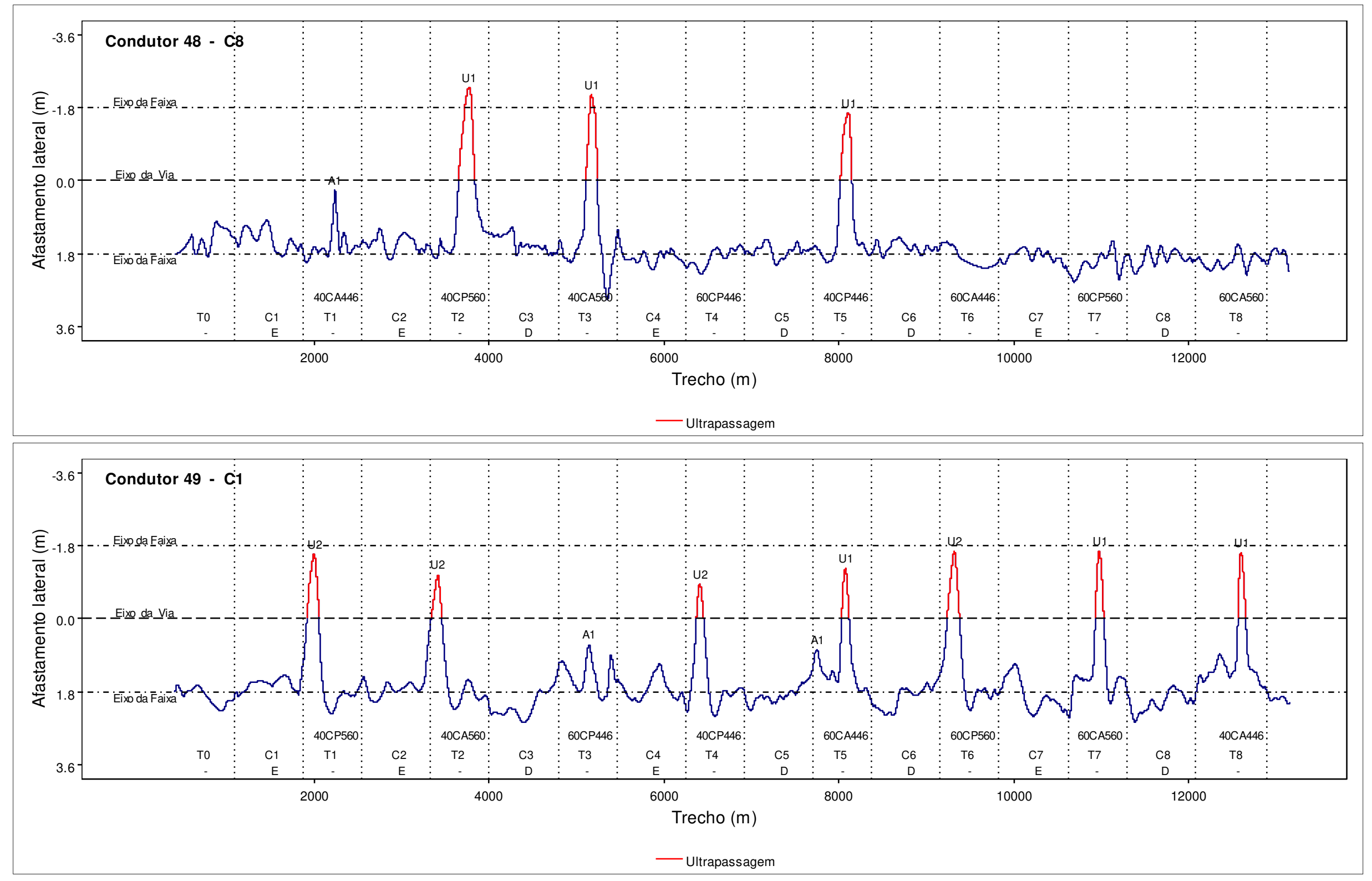

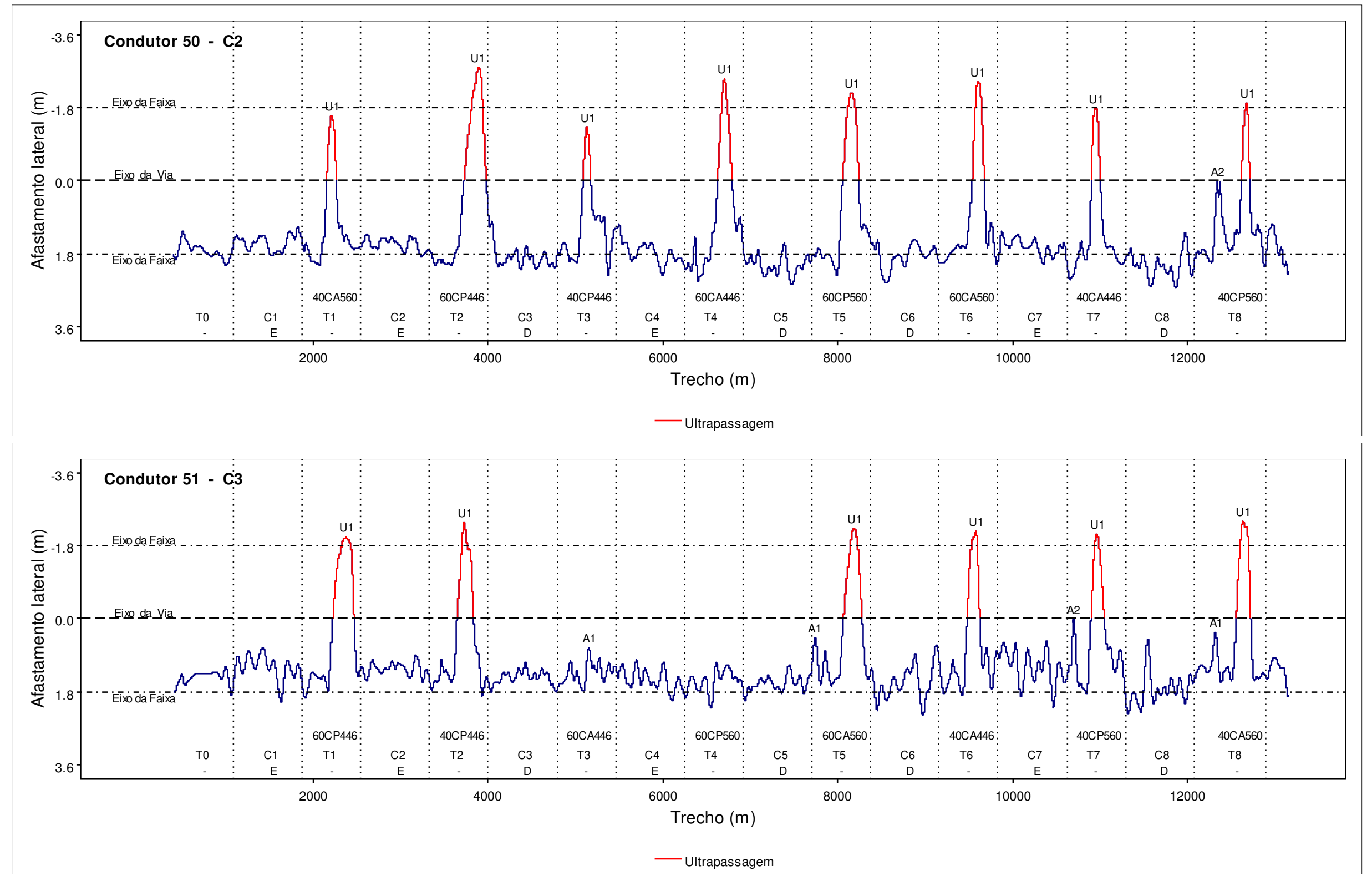

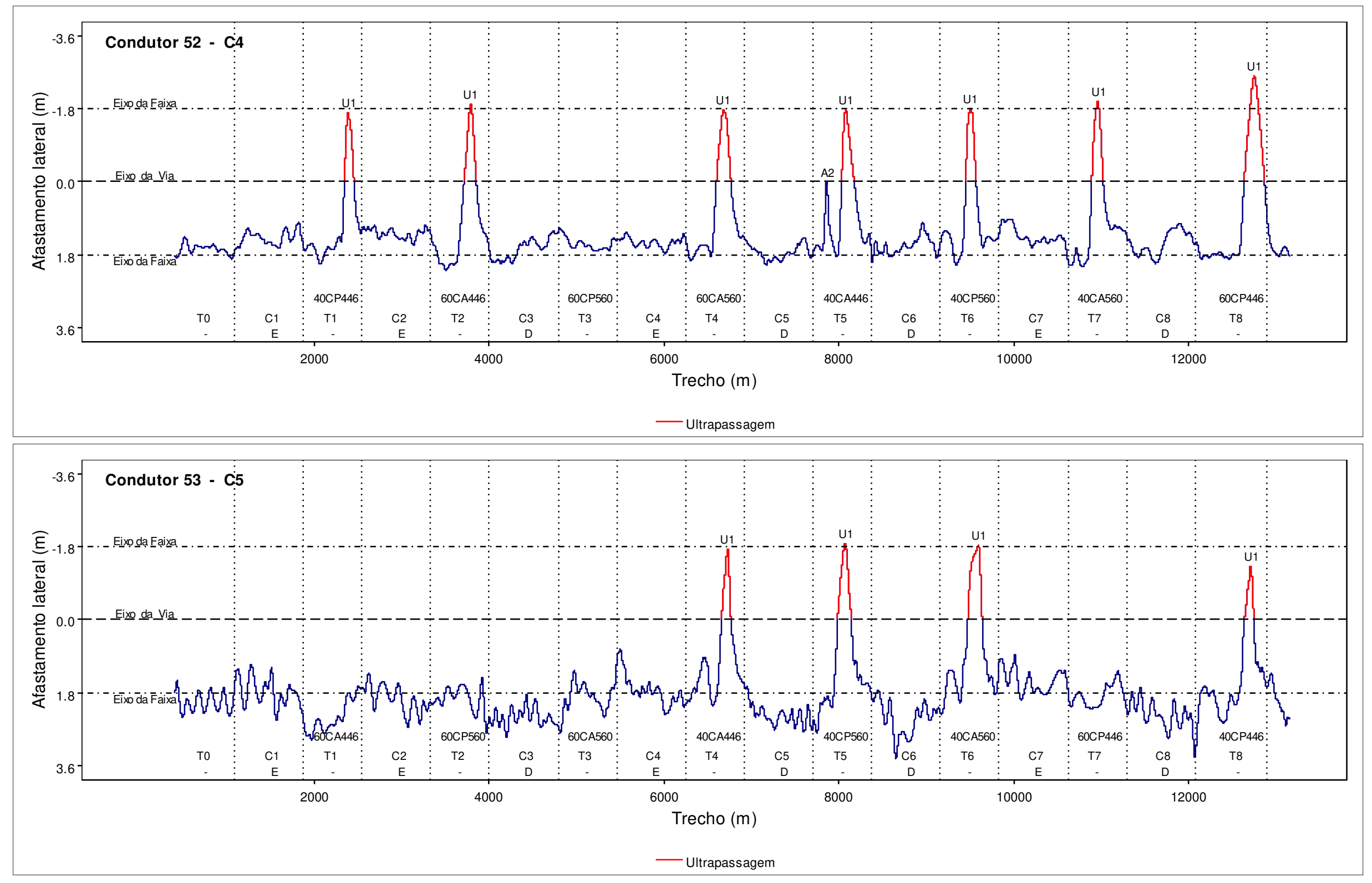

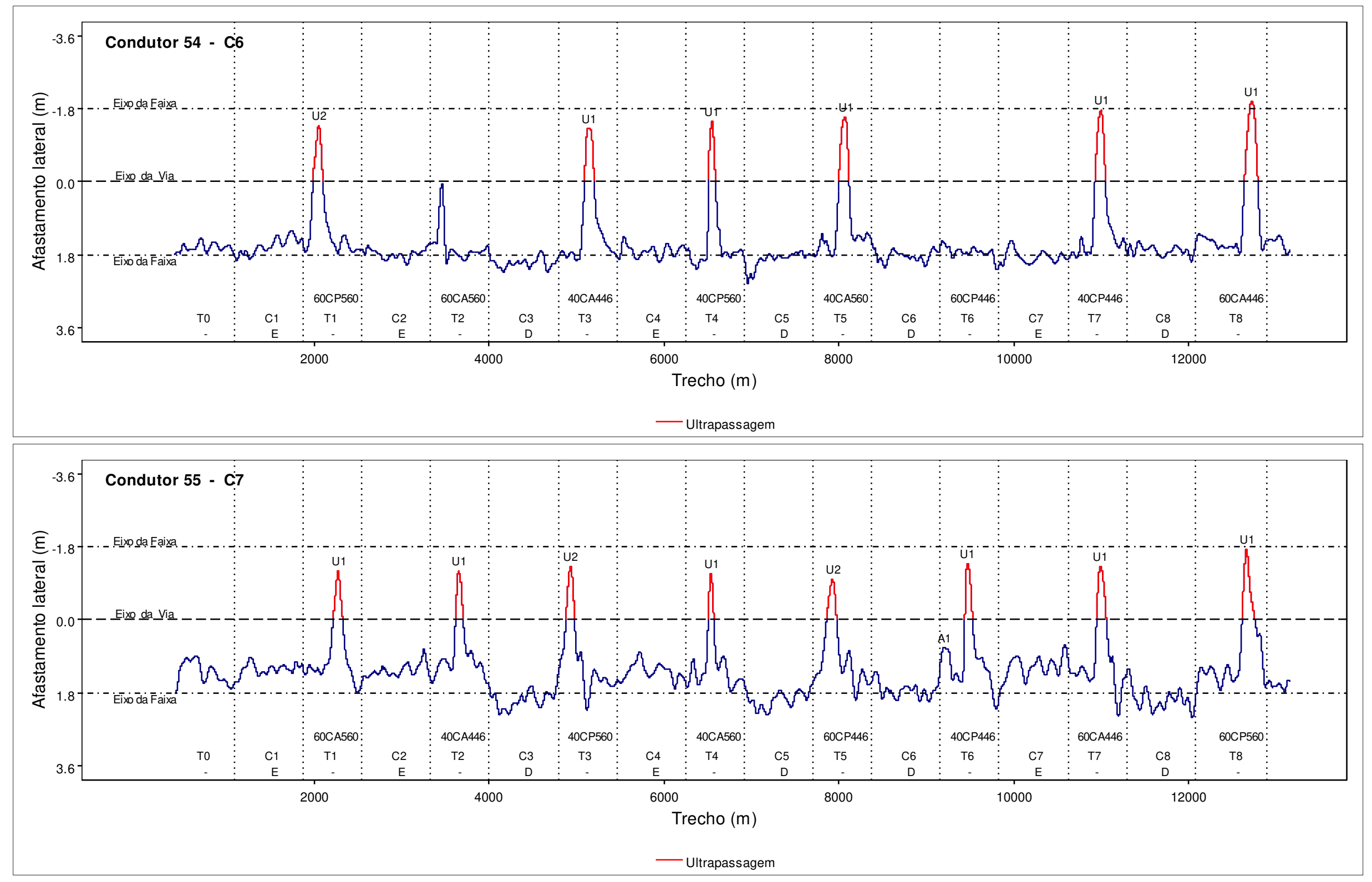

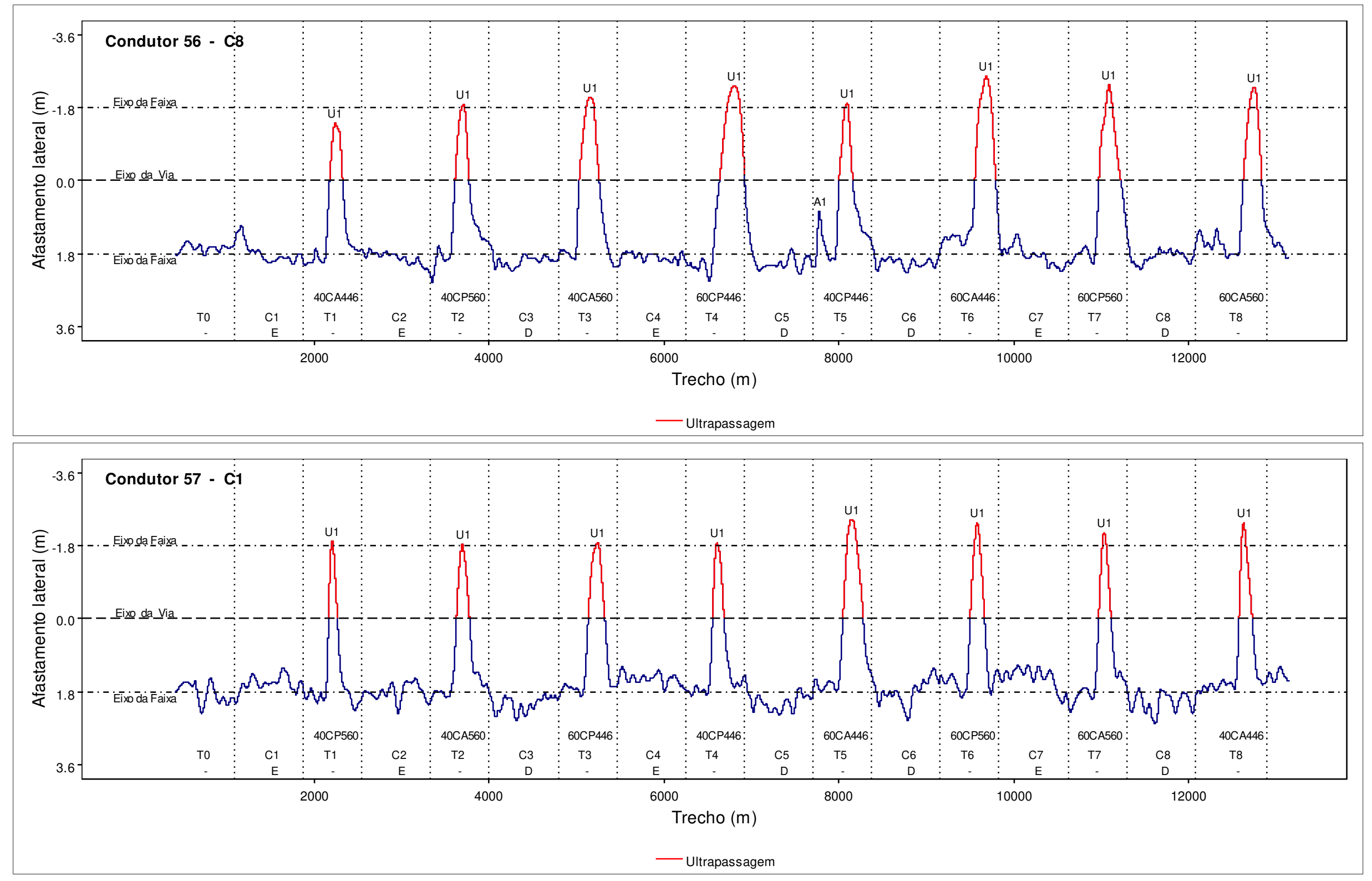

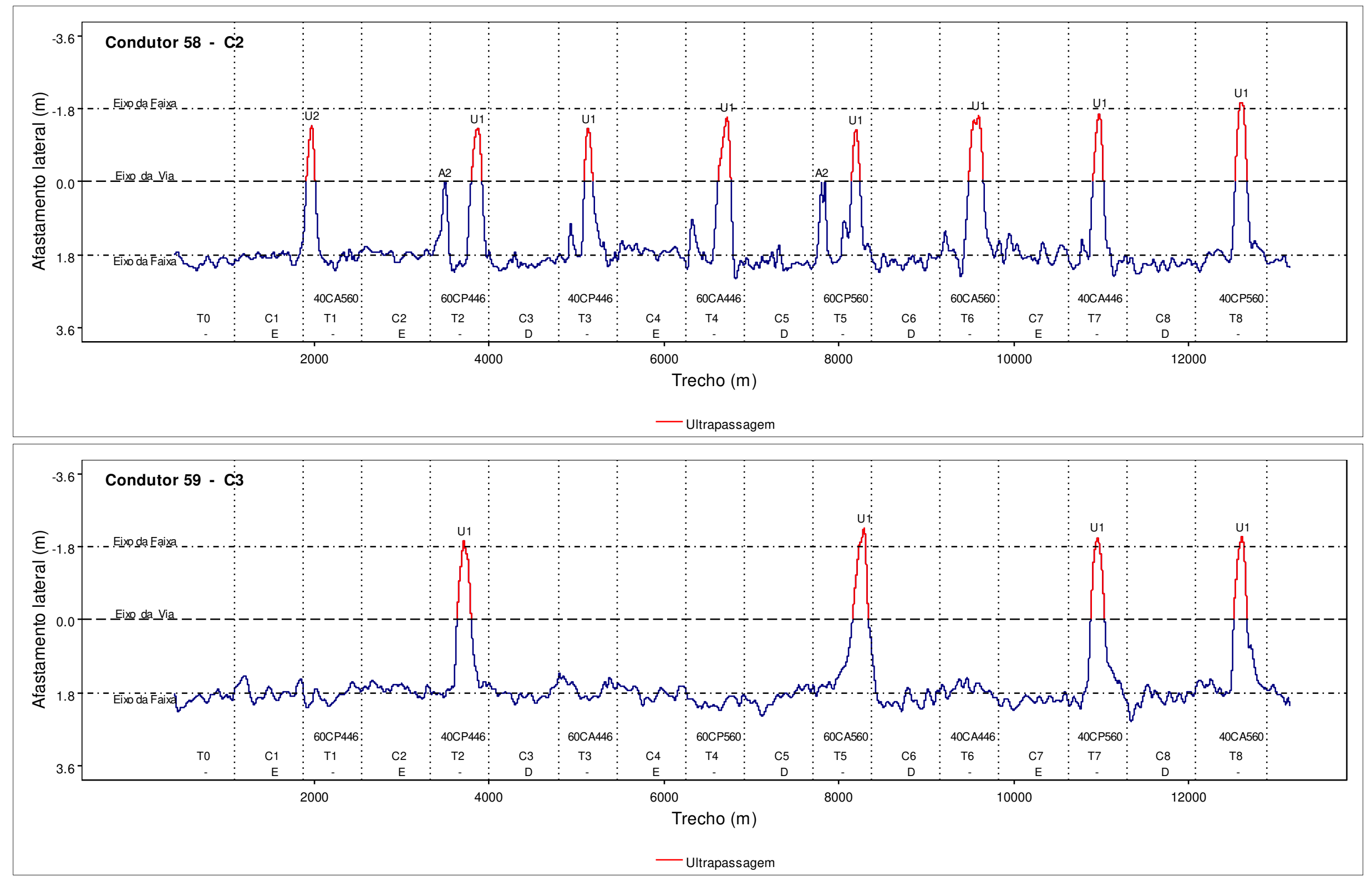

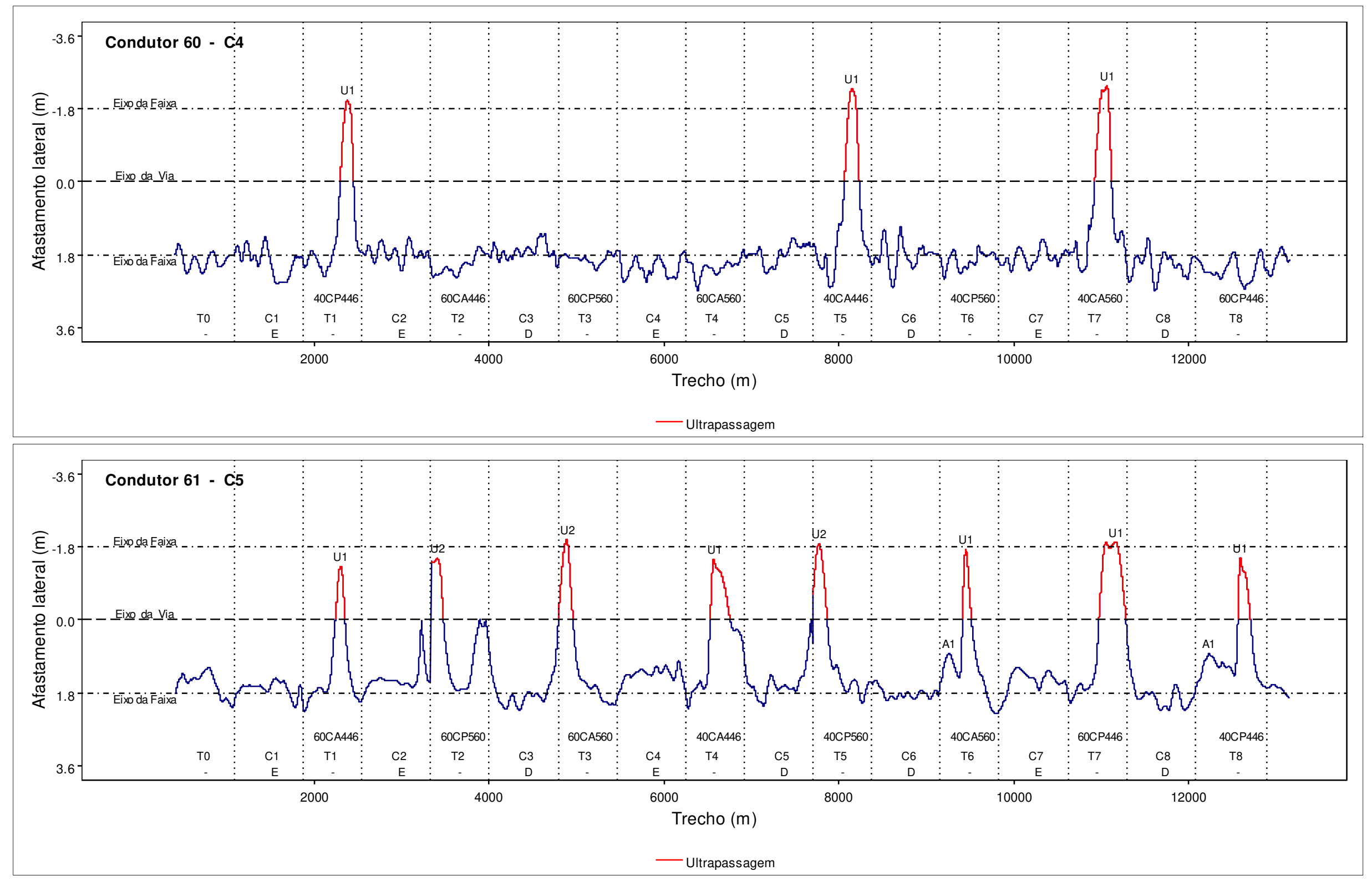

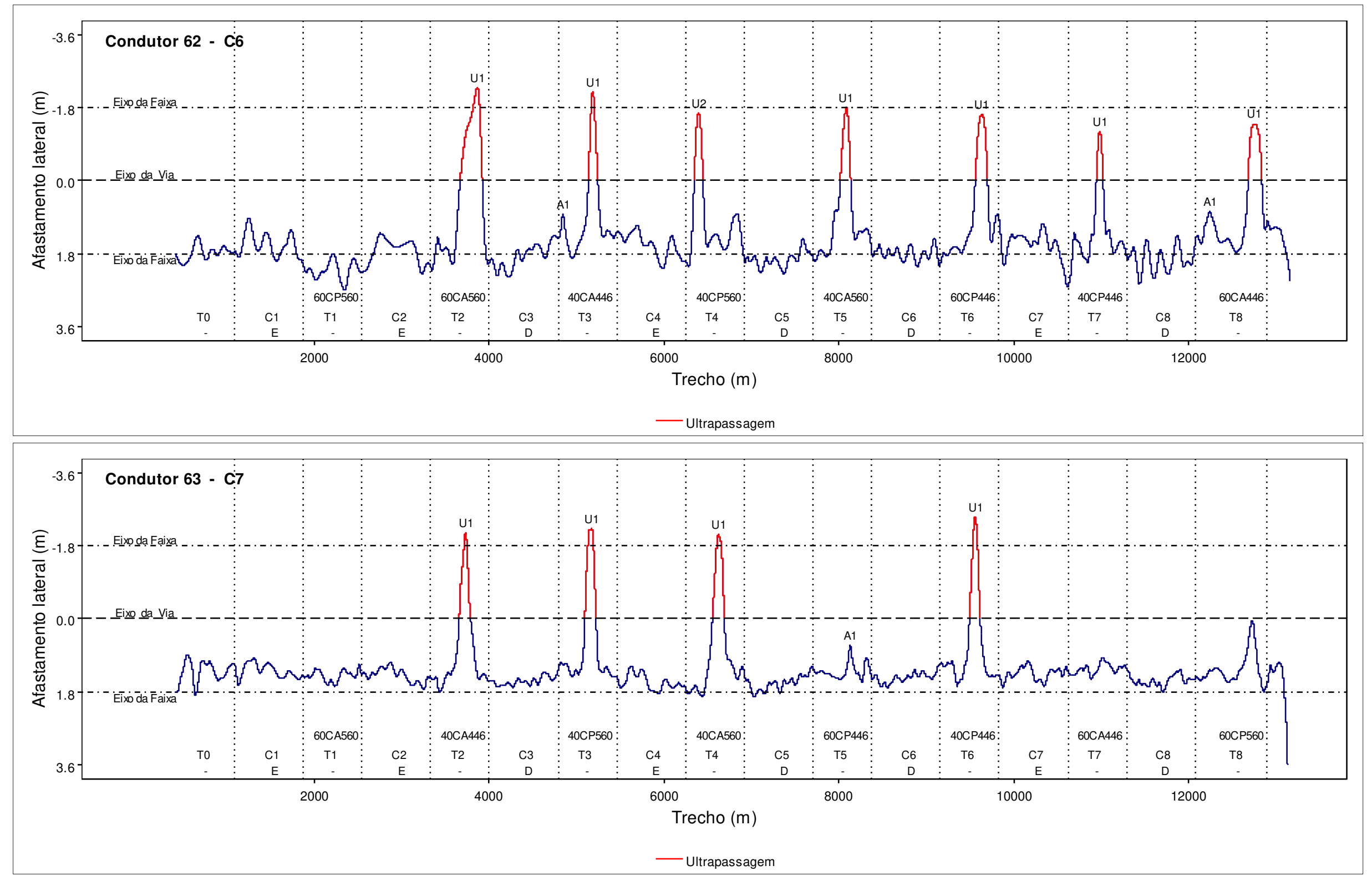

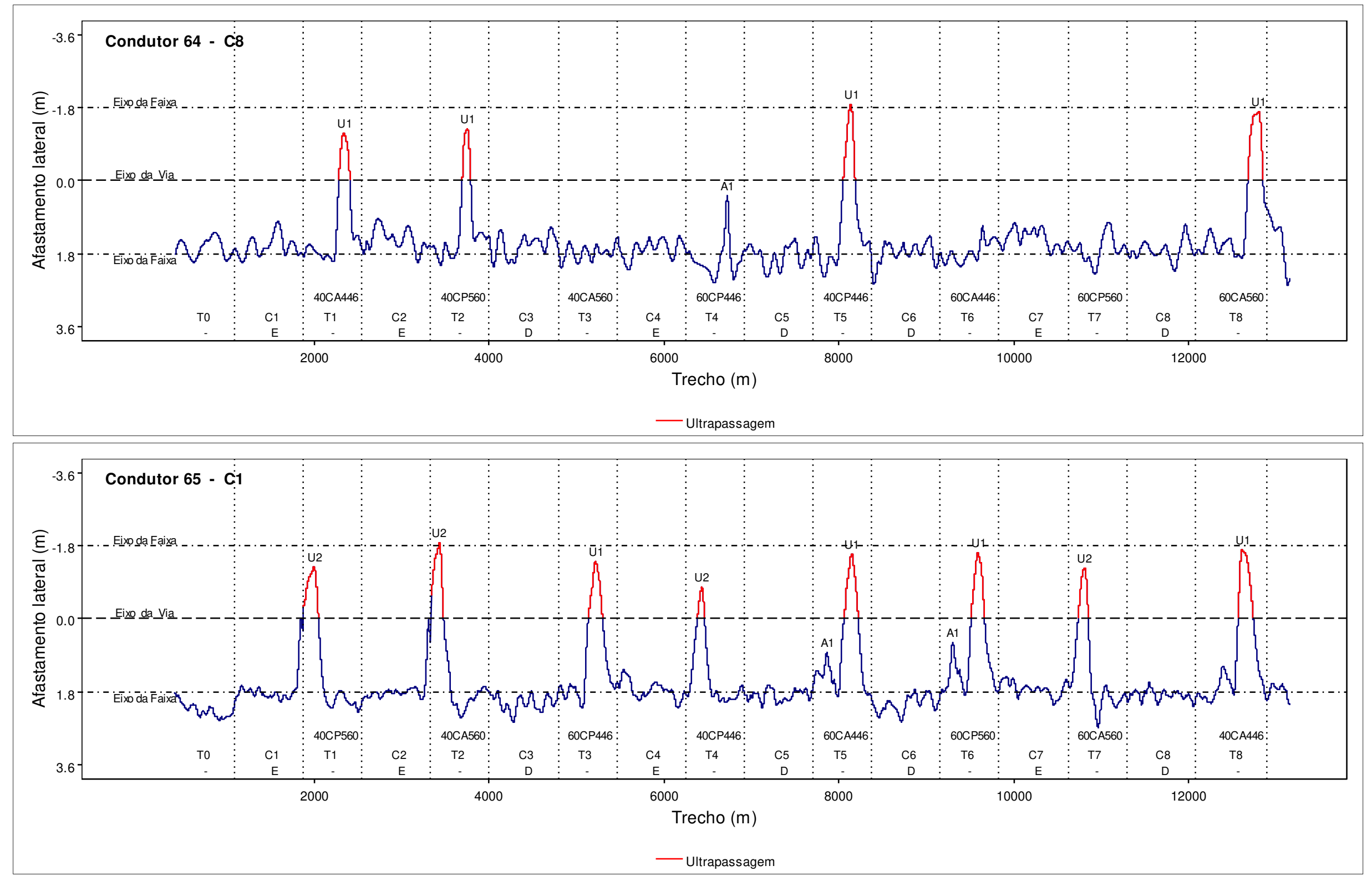

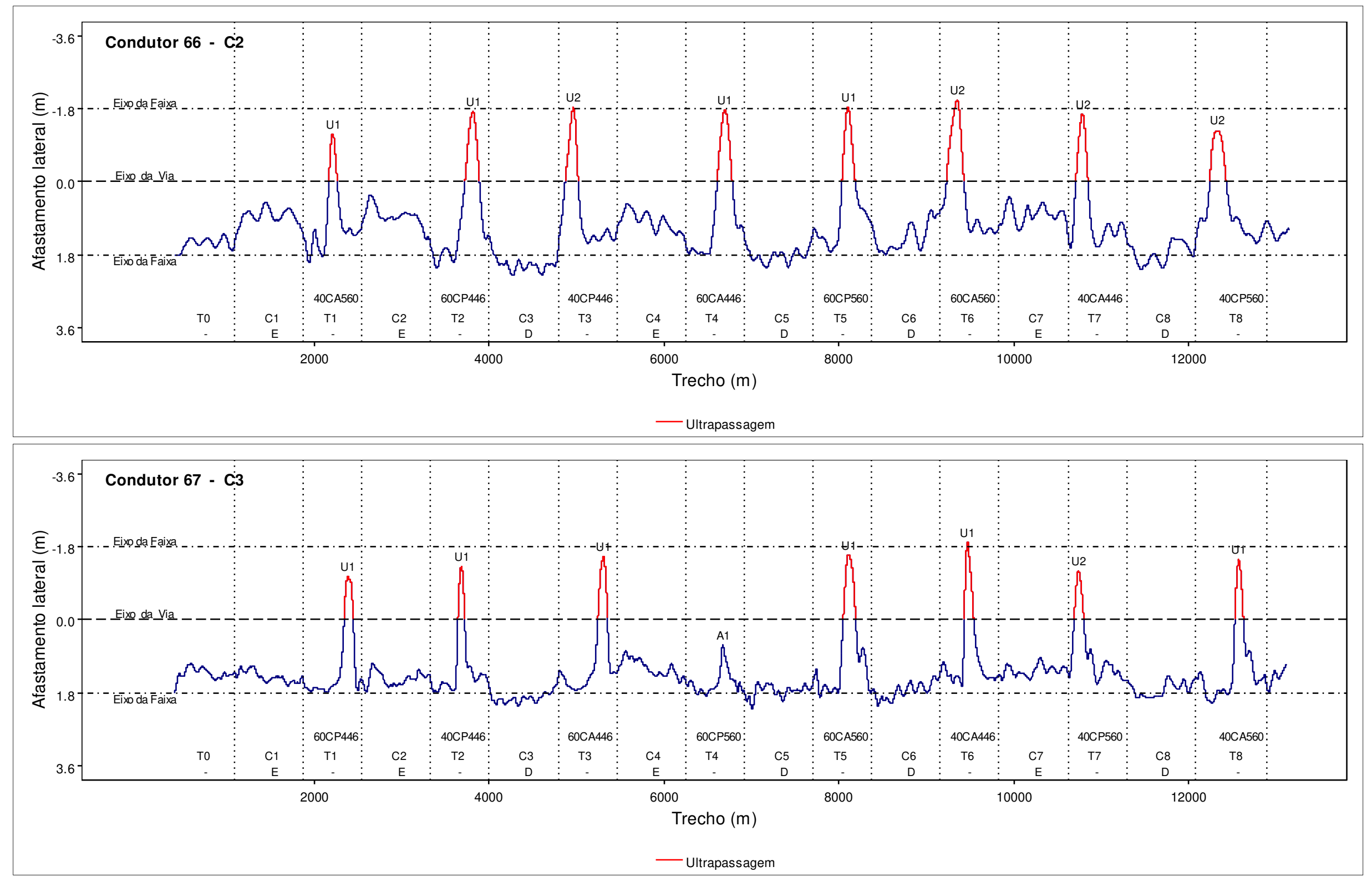

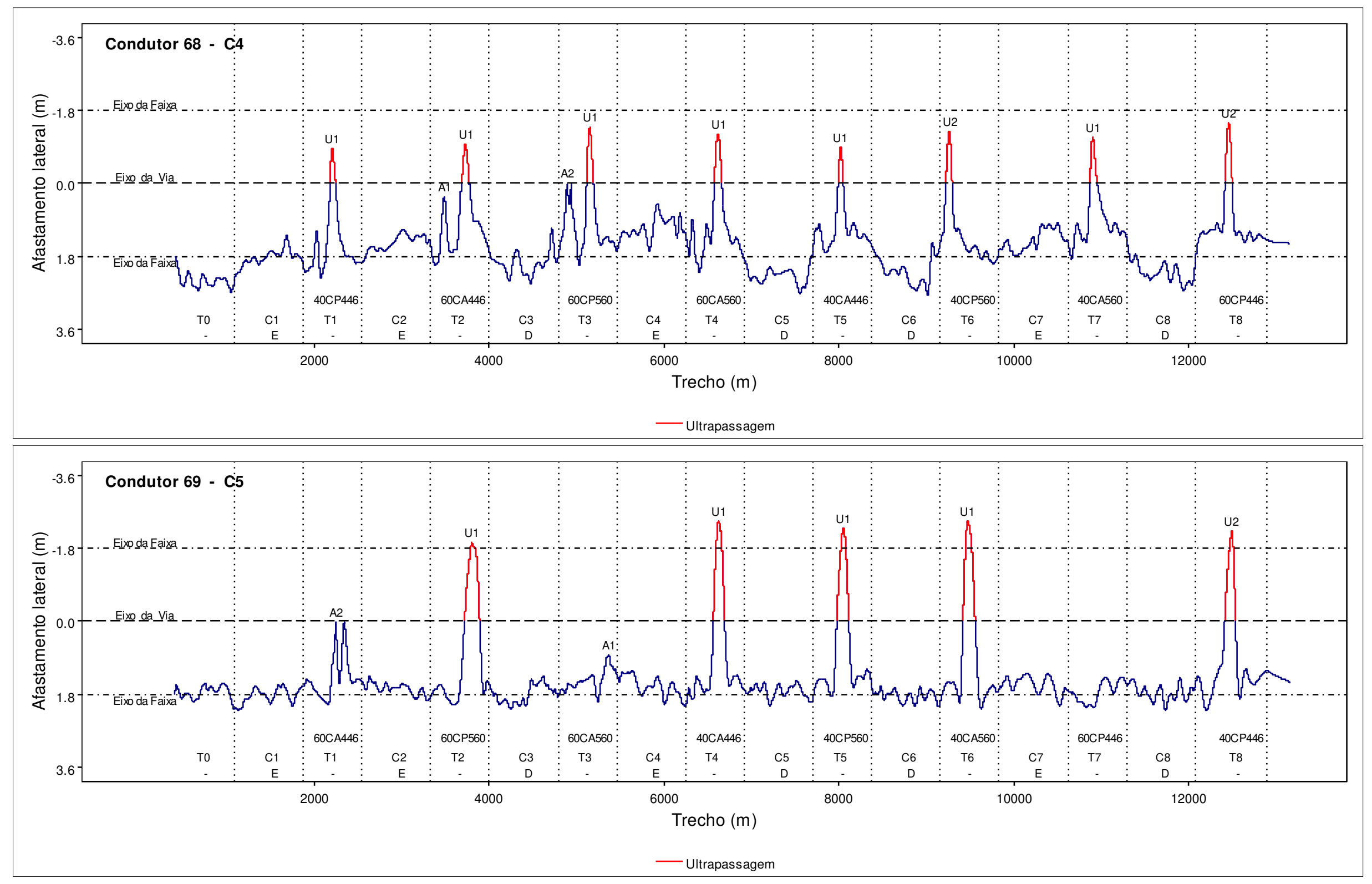

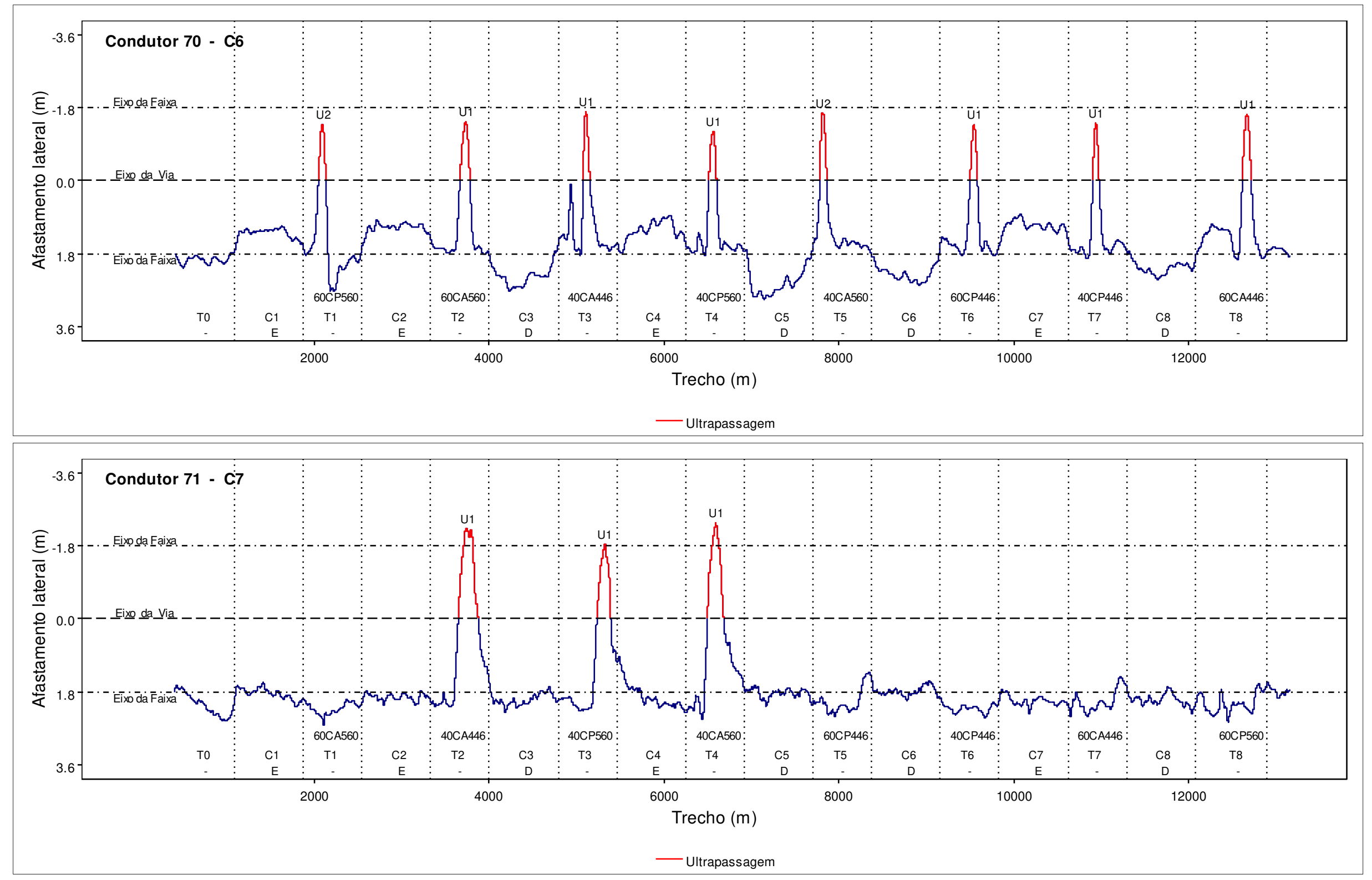

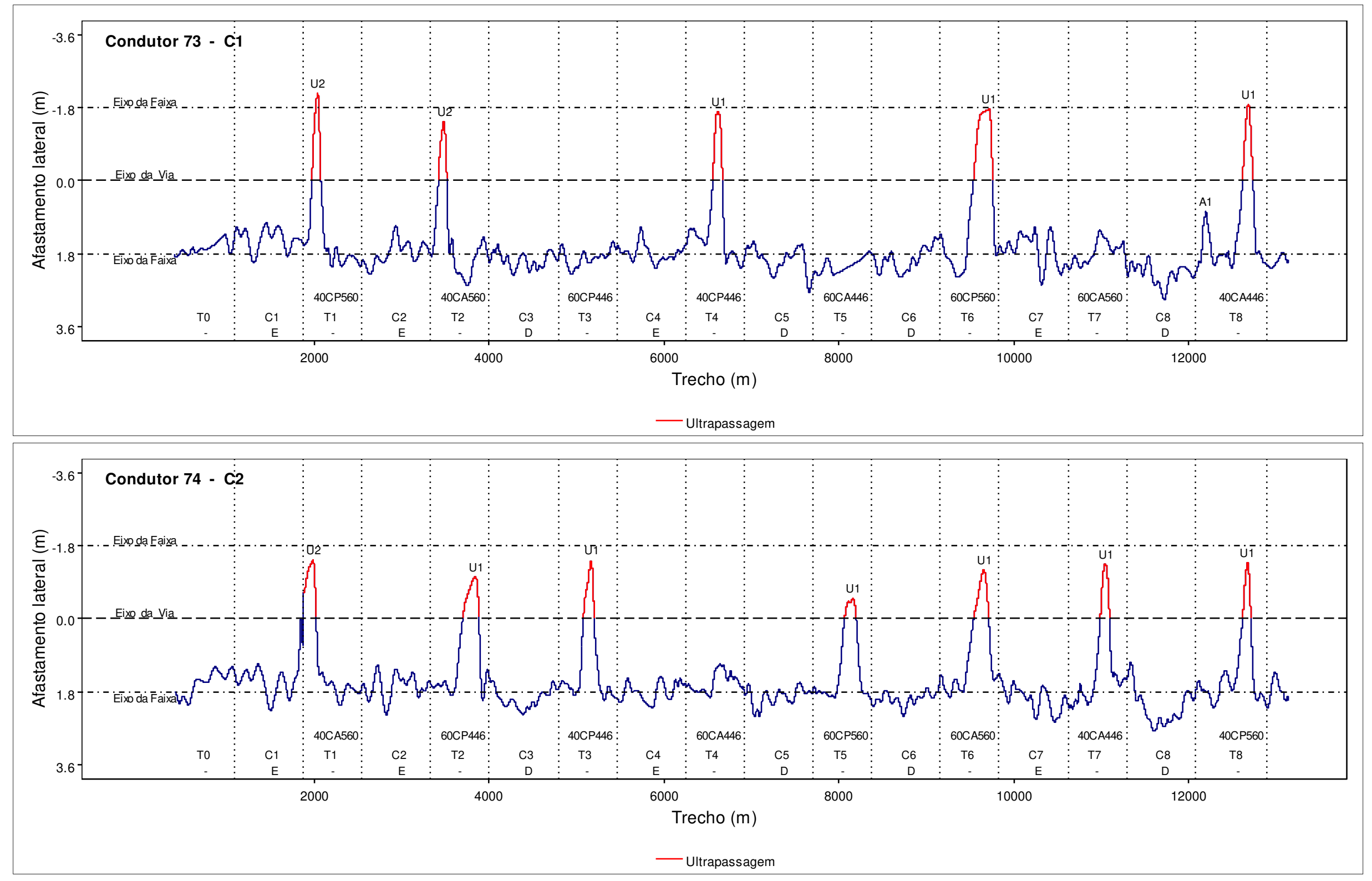

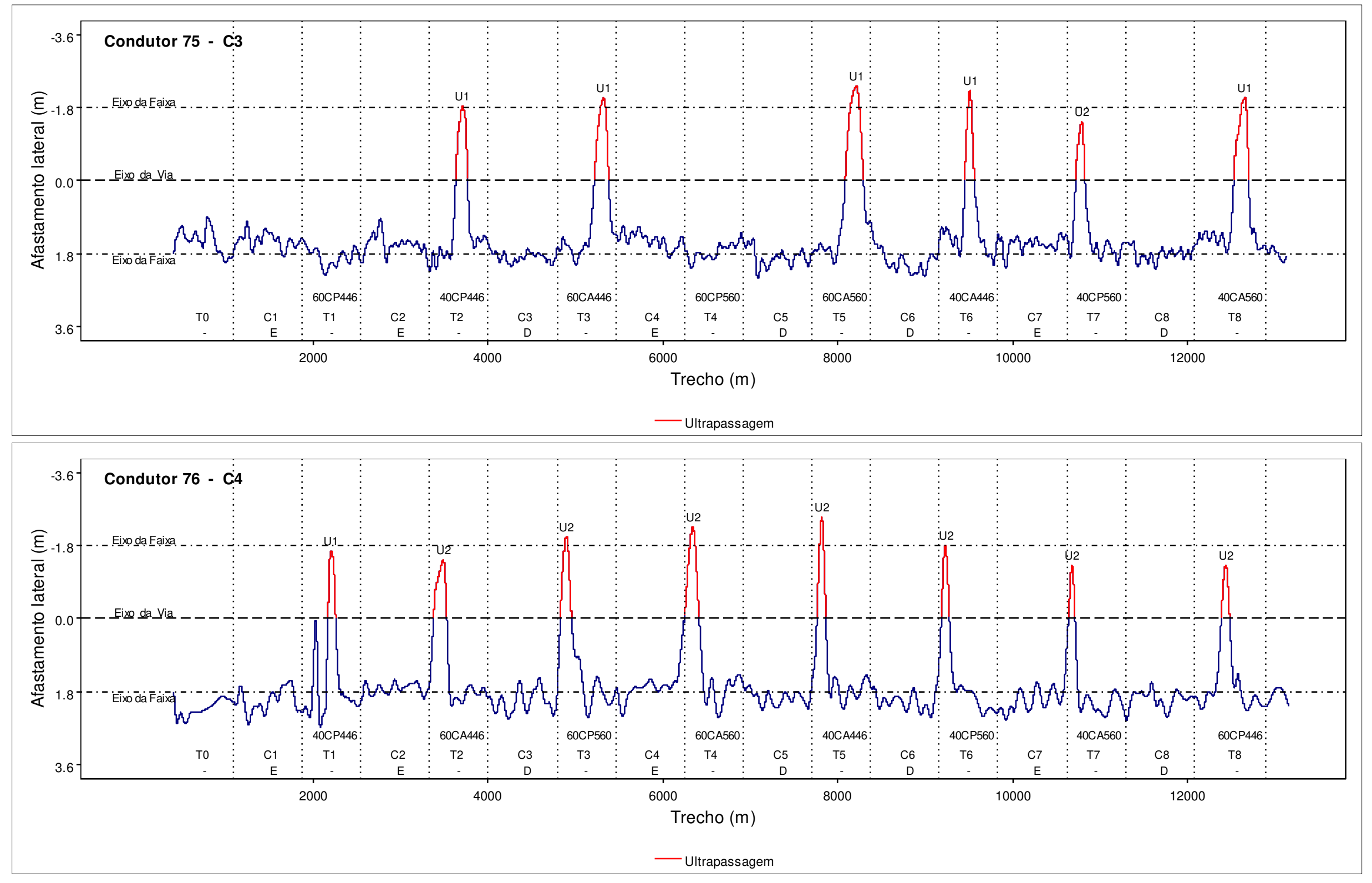

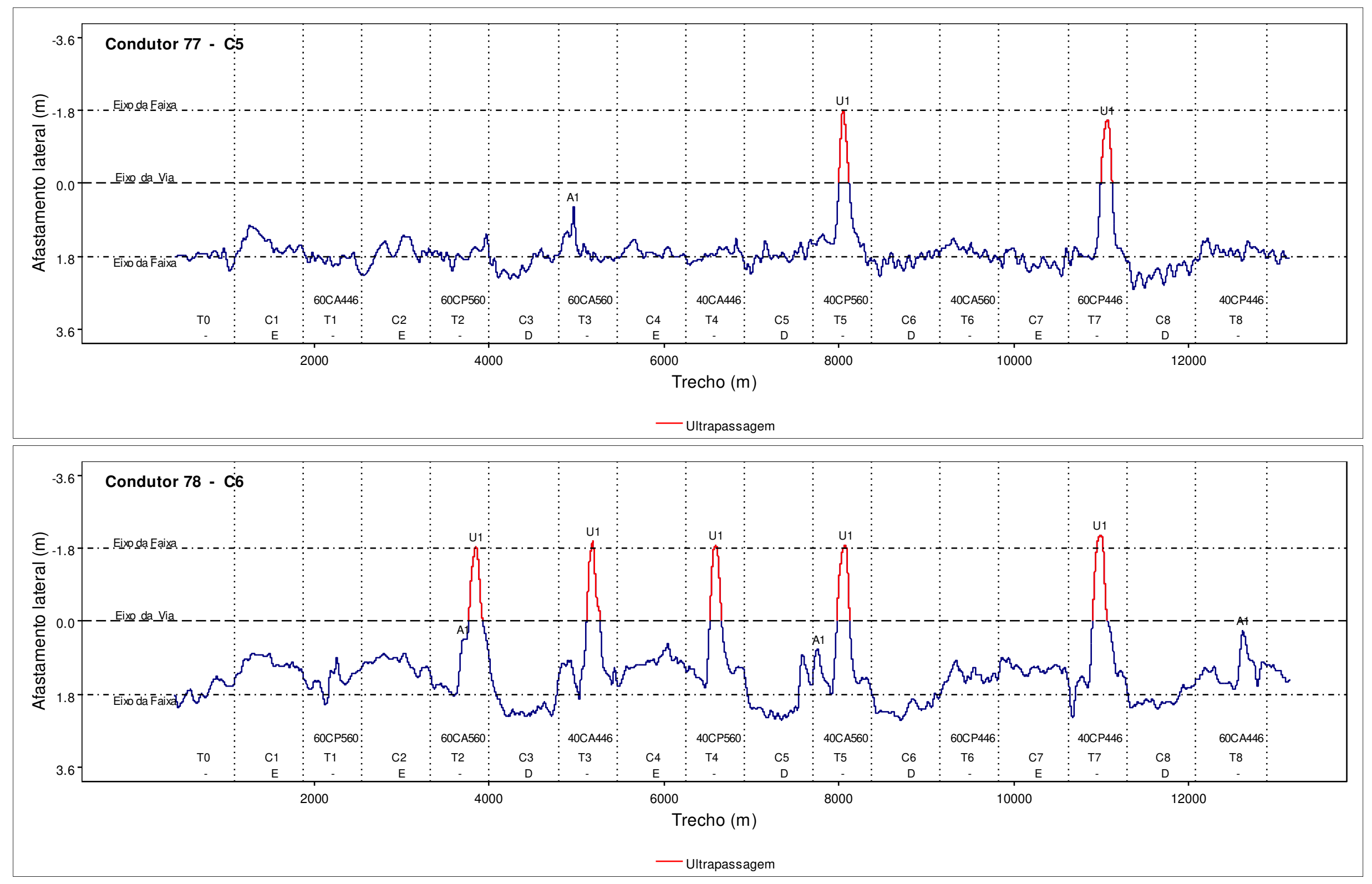

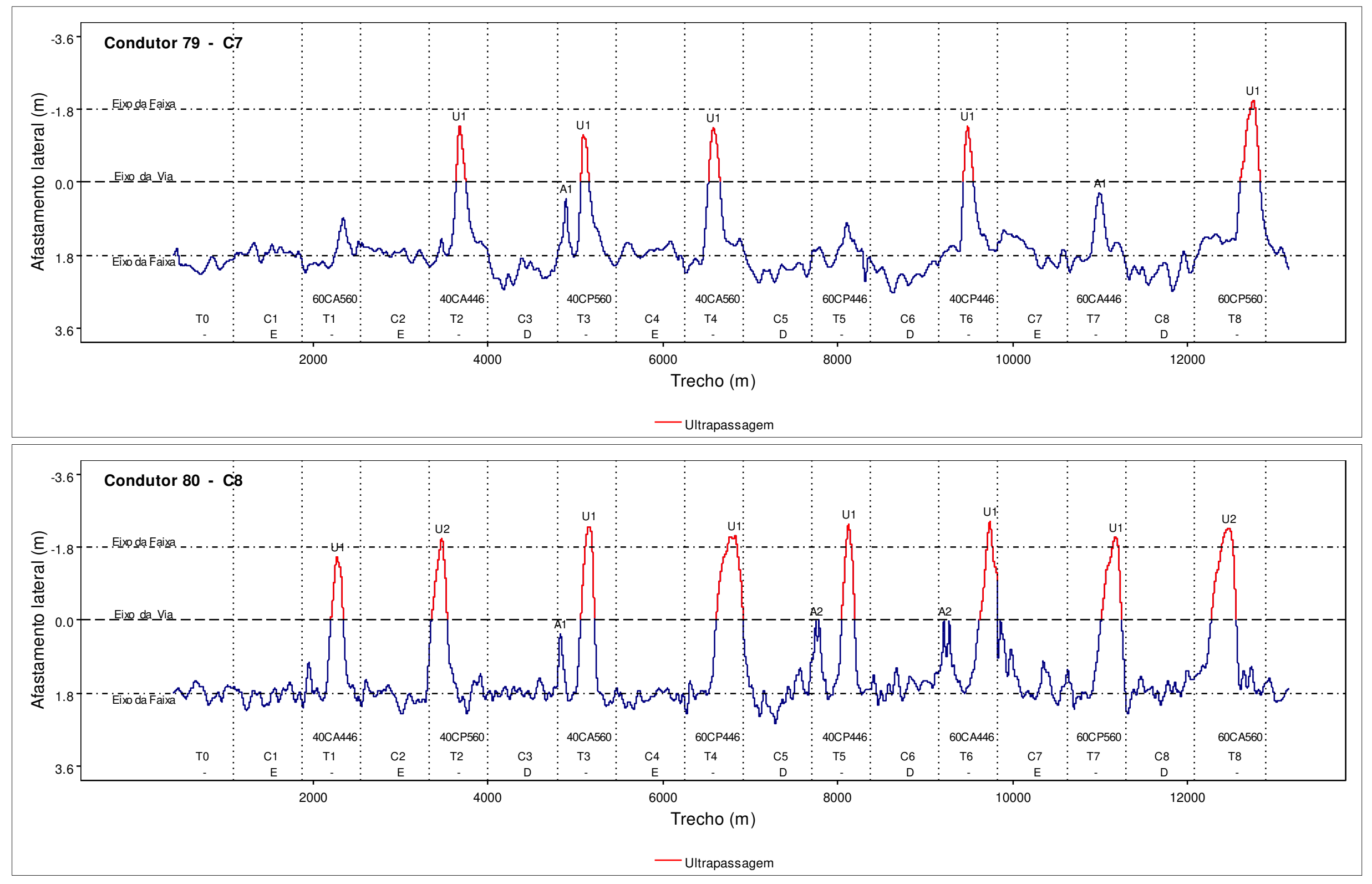

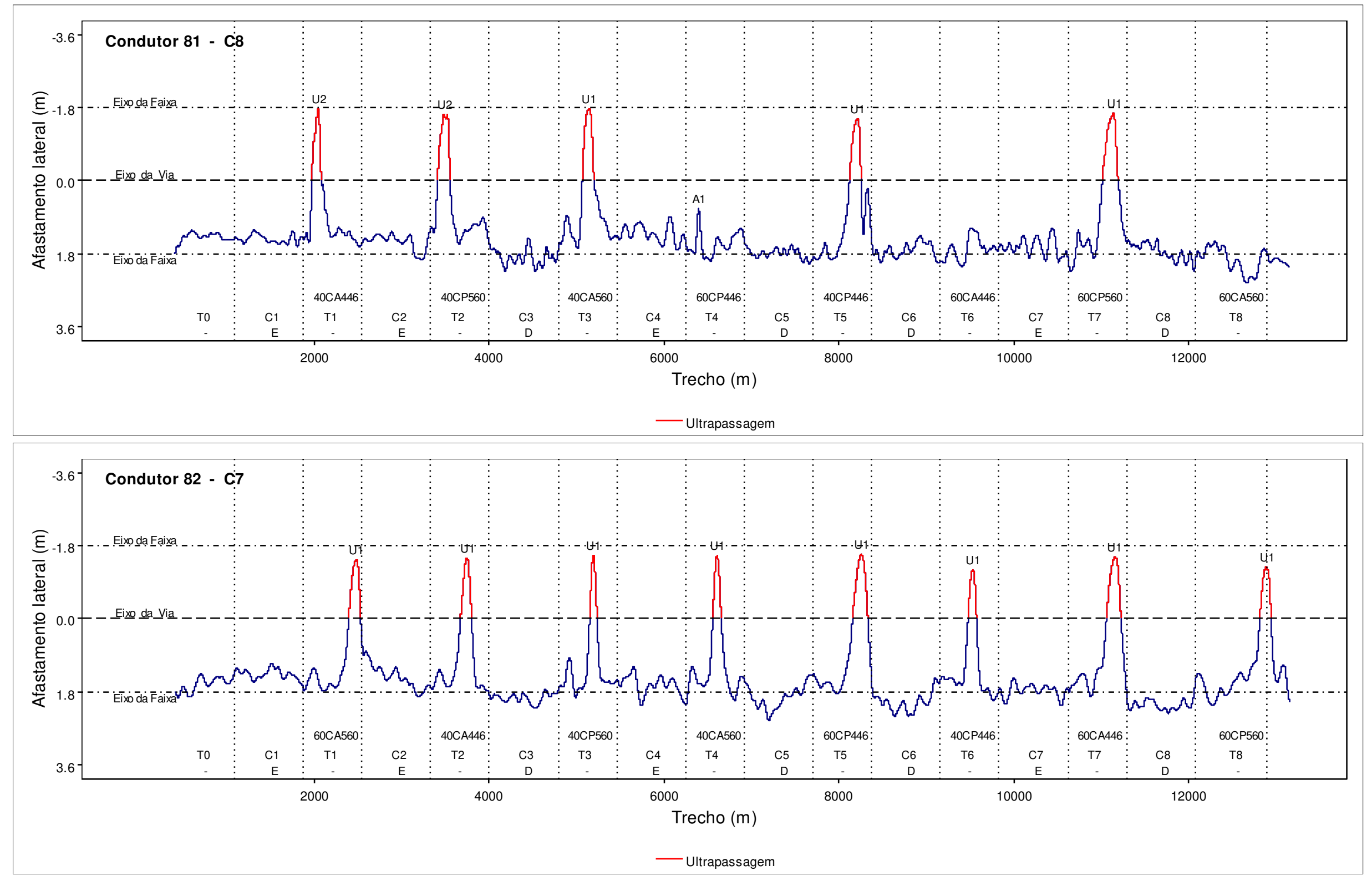



\section{CADASTRO PARA TESTE COM SIMULADOR DE DIREÇÃO}

\section{Informações Pessoais}

1. Nome:

2. Gênero: ( )Masculino ( ) Feminino

3. Data de Nascimento:

4. Profissão:

5. Escolaridade:

( ) Ensino básico( ) Ensino secundário ( )Graduaçāo( ) Pósgraduaçāo ( )Pósdoutorado

6. Faz uso das seguintes tecnologias?

( ) Jogos (Playstation, Wii, XBox, ( ) Smartphones, etc) ( )Filmes 3D (cinema, TV 3D, etc)

( ) Realidade Virtual

\section{Informações relativas ao Motorista}

Sobre suas experiências com a atividade de direção

7. Ano da Garteira de Habilitação:

8. Qual a categoria da sua Carteira de Habilitação?

( ) Permissâo pra Dirigir (recém habilitado, menos de 1 ano)

( ) Categoria B ou $A B$ (carro e/ou moto)

( ) Categoria $\mathrm{C}, \mathrm{D}, \mathrm{E}$ (inclusive caminhão, ônibus e carretas)

9. Usa óculos durante a condução? ( ) Sim（ Não

10. Qual tipo de veículo dirige regularmente?

( ) Não dirige

( ) Veículo pessoal (carro de passeio, utilitário)

( ) Veiculo comercial (caminhâo, caminhoneta, van)

( ) Moto

( ) Outro:

11. Qual a estimativa de quilòmetros percorridos ( $\mathrm{km} / \mathrm{mês})$ ? 
12. Em vias URBANAS, você dirige com que frequência? Vias urbanas ruas dentro da cidade que reside.

( ) Todos os DIAS

( ) Algumas vezes por SEMANA

( ) Algumas vezes por MÊS

( ) Algumas vezes por ANO

( ) Não dirijo

13. Em rodovias de PISTA DUPLA, você dirige com que frequência?

( ) Todos os DIAS

( ) Algumas vezes por SEMANA

( ) Algumas vezes por MÊS

( ) Algumas vezes por ANO

( ) Não dirijo

14. Em rodovias de PISTA SIMPLES, você dirige com que frequência?

( ) Todos os DIAS

( ) Algumas vezes por SEMANA

( ) Algumas vezes por MÊS

( ) Algumas vezes por ANO

( ) Não dirijo

14. Já sofreu/envolveu em algum tipo de acidente rodoviário?

( ) Sim, como motorista.

( ) Sim, como passageiro.

( ) Sim, como ciclista.

( ) Sim, como pedestre.

( ) Nunca

15. Email para contato:

16. Telefone para contato: 


\section{APÊNDICE C - Termo de Consentimento Livre E Esclarecido (TCLE)}

\section{Termo de Consentimento Livre e EscLarecido}

Você está sendo convidado a participar, como voluntário, de uma pesquisa cujo objetivo é estudar o comportamento do condutor brasileiro em pistas simples. Assim, contamos com a sua valiosa colaboração e divulgação de nossa pesquisa aos seus contatos, para que um número expressivo de pessoas possa fazer parte deste estudo e, portanto, contribuir para os interesses da segurança viária brasileira.

Os seus dados pessoais não serão divulgados em NENHUM momento. Qualquer informação que possa identificá-lo será omitida nos resultados da pesquisa, e o material será armazenado em local seguro.

Para participar desta pesquisa, você precisa ter mais de 20 anos e carteira de habilitação categoria B.

Não haverá ganhos financeiros para nenhuma das partes ou benefícios diretos e individuais.

As informações obtidas serão tratadas com confidencialidade e utilizadas exclusivamente para a realização desta pesquisa. Se você se sentir constrangido com alguma questão, você tem o direito de se recusar a respondê-la.

0 teste em simulador de direção será realizado nas dependências da Escola de Engenharia de São Carlos (EESC/USP), individualmente. 0 participante irá conduzir em um simulador de direção por aproximadamente 15 min. Ao final irá responderá a dois questionários: para avaliação do realismo do cenário e outro para relatar possíveis desconfortos durante 0 experimento como, enjo0, tontura, dor de cabeça, etc por se tratar de um ambiente virtual.

0 participante poderá cancelar sua concordância com este termo de consentimento a qualquer momento, sem nenhum tipo de prejuízo, bastando apenas não concluir o preenchimento do questionário.

Esta pesquisa é vinculada ao Departamento de Engenharia de Transportes (STT) da Escola de Engenharia de São Carlos (EESC/USP) e foi aprovada pelo Comitê de Ética em Pesquisa da Universidade Federal de São Carlos (CEP/UFSCar), de acordo com os requisitos da Resolução CNS 466/96, sob parecer $n^{0}$ 2.094.027, intitulada "Avaliação do Comportamento do Condutor em Manobra de Ultrapassagem: Simulação em Pista Simples" sob a orientação da Profa. Dra. Ana Paula Camargo Larocca.

A pesquisadora responsável é Aurenice da Cruz Figueira, e poderá ser contatada através do e-mail simuladorusp@gmail.com ou pelo telefone (16)3373-9617.

Se houver alguma dúvida ou consideração sobre a ética da pesquisa, entre em contato com o Comitê de Ética em Pesquisa com Seres Humanos da Universidade Federal de São Carlos (CEP/UFSCar), pelo telefone (16) 3351-9683 ou pelo e-mail cephumanos@ufscar.br. 0 Comitê de Ética é a instância que tem por objetivo defender os interesses dos participantes da pesquisa em sua integridade e dignidade e para contribuir no desenvolvimento da pesquisa dentro de padrões éticos. 
Dessa forma o comitê tem o papel de avaliar e monitorar o andamento do projeto de modo que a pesquisa respeite os princípios éticos de proteção aos direitos humanos, da dignidade, da autonomia, da não maleficência, da confidencialidade e da privacidade.

\section{Aurenice Figueira}

Pesquisadora

Concordo e acredito ter sido suficientemente informado a respeito do presente estudo, pois ficaram claros para mim quais são os seus propósitos, os procedimentos a serem utilizados e as garantias de confidencialidade. Confirmo a informação de que tenho mais de 20 anos e possuo carteira de habilitação categoria B. Concordo em participar deste estudo voluntariamente e estou ciente de que posso interromper a minha participação a qualquer momento, sem penalidades ou prejuízos.

$\square$ Não concordo.

São Carlos, de de

(Assinatura do participante da pesquisa) 


\section{APÊNDICE D - AvaliaÇão da SimULAÇÃo}

\section{AVALIAÇÃO DA SIMULAÇÃo}

Nr Condutor:

Marque na escala o valor que melhor traduz a sua sensação durante a simulação. Responda as questōes na ordem apresentada, sem alterar a resposta depois de assinalada.

COM RELAÇAO A SUA EXPERIÉNCIA NA SIMULAÇA0...

\begin{tabular}{|c|c|c|c|c|c|c|c|}
\hline & & $\begin{array}{ll}0 & 1\end{array}$ & 2 & 3 & 4 & 5 & \\
\hline $\begin{array}{l}\text { 1. Conseguiu controlar (volante, pedal, etc) } 0 \\
\text { veiculo simulado? }\end{array}$ & $\begin{array}{l}\text { Nenhum } \\
\text { Controle }\end{array}$ & $\square \square$ & $\square$ & $\square$ & $\square$ & $\square$ & Controle Total \\
\hline $\begin{array}{l}\text { 2. Em função das respostas do simulador, qual o } \\
\text { nivel de realidade sentida para suas açōes? }\end{array}$ & $\begin{array}{l}\text { Pouco } \\
\text { real }\end{array}$ & $\square \square$ & $\square$ & $\square$ & $\square$ & $\square$ & $\begin{array}{c}\text { Murto } \\
\text { real }\end{array}$ \\
\hline $\begin{array}{l}\text { 3. Qual o nivel de naturalidade com o qual voce } \\
\text { interagiu com o simulador? }\end{array}$ & Artificial & $\square \square$ & $\square$ & $\square$ & $\square$ & $\square$ & Natural \\
\hline $\begin{array}{l}\text { 4. Em que nivel } 0 \text { aspecto visual do simulador } \\
\text { conseguiu te envolver no ambiente? }\end{array}$ & Nenhum & $\square \square$ & $\square$ & $\square$ & $\square$ & $\square$ & Completamente \\
\hline $\begin{array}{l}\text { 5. Como foi o seu controle dos mecanismos de } \\
\text { direção do simulador? }\end{array}$ & Artifictal & $\square \square$ & $\square$ & $\square$ & $\square$ & $\square$ & Natural \\
\hline $\begin{array}{l}\text { 6. Qual o nivel de conviç̣ão que você daria para } \\
\text { os objetos presentes na simulação? }\end{array}$ & Baixo & $\square \square$ & 7 & $\square$ & $\square$ & $\square$ & $\begin{array}{c}\text { Murto } \\
\text { Alto }\end{array}$ \\
\hline $\begin{array}{l}\text { 7. Quão idêntico é o ambiente simulado } \\
\text { comparado com uma experiência de direção } \\
\text { real? }\end{array}$ & $\begin{array}{l}\text { Nada } \\
\text { Identico }\end{array}$ & $\square \square$ & 7 & $\square$ & $\square$ & $\square$ & $\begin{array}{l}\text { Murto } \\
\text { Identico }\end{array}$ \\
\hline $\begin{array}{l}\text { 8. Vocé foi capaz de prever o que aconteceria na } \\
\text { simulaçāo logo após executar alguma ação no } \\
\text { simulador (cockpit)? }\end{array}$ & Nunca & $\square \square$ & $\square$ & $\square$ & $\square$ & $\square$ & Sempre \\
\hline $\begin{array}{l}\text { 9. Quanto você conseguiu explorar visualmente o } \\
\text { ambiente para tomar decisōes baseadas no } \\
\text { entorno? }\end{array}$ & Nunca & $\square \square$ & $\square$ & $\square$ & $\square$ & $\square$ & Sempre \\
\hline $\begin{array}{l}\text { 10. Quantos detalhes vocé foi capaz de identificar } \\
\text { nos objetos ao observá-los? }\end{array}$ & Nenhum & $\square \square$ & $\square$ & $\square$ & $\square$ & $\square$ & Murtos \\
\hline $\begin{array}{l}\text { 11. Considerando um mesmo objeto a diferentes } \\
\text { distancias, vocé percebeu diferença no nivel de } \\
\text { detalhamento? }\end{array}$ & $\begin{array}{l}\text { Nenhuma } \\
\text { Diterença }\end{array}$ & $\square \square$ & $\square$ & $\square$ & $\square$ & $\square$ & $\begin{array}{c}\text { Muita } \\
\text { Diferença }\end{array}$ \\
\hline $\begin{array}{l}\text { 12. Quâo envolvido com } 0 \text { ambiente virtual voce } \\
\text { esteve? }\end{array}$ & $\begin{array}{c}\text { Nada } \\
\text { envolvido }\end{array}$ & $\square \square$ & $\square$ & $\square$ & $\square$ & $\square$ & $\begin{array}{l}\text { Completamente } \\
\text { envolvioo }\end{array}$ \\
\hline $\begin{array}{l}\text { 13. Como classifica o tempo entre uma ação } \\
\text { tomada e a resposta do simulador? }\end{array}$ & Lento & $\square \square$ & $\square$ & $\square$ & $\square$ & $\square$ & Rapido \\
\hline 14. 0 quanto se sentiu adaptado ao simulador? & $\begin{array}{l}\text { Nao me } \\
\text { adaptel }\end{array}$ & $\square \square$ & $\square$ & $\square$ & $\square$ & $\square$ & $\begin{array}{c}\text { Murto } \\
\text { adaptado }\end{array}$ \\
\hline $\begin{array}{l}\text { 15. No fim da simulação, como você classificaria } \\
\text { seu nivel de aptidão para dirigir no simulador? }\end{array}$ & Ruim & $\square \square$ & $\square$ & $\square$ & $\square$ & $\square$ & $\begin{array}{c}\text { Murto } \\
\text { competente }\end{array}$ \\
\hline
\end{tabular}




\begin{tabular}{|c|c|c|c|c|c|c|c|c|}
\hline & & 0 & 1 & 2 & 3 & 4 & 5 & \\
\hline $\begin{array}{l}\text { 16. A qualidade do vídeo interferiu na realização de } \\
\text { alguma tarefa? }\end{array}$ & Näo intenteriv & $\square$ & $\square$ & $\square$ & $\square$ & $\square$ & $\square$ & $\begin{array}{l}\text { Interneriv } \\
\text { multo }\end{array}$ \\
\hline $\begin{array}{l}\text { 17. Os mecanismos de direção do cockpit } \\
\text { interferiram a realização de alguma tarefa? }\end{array}$ & Nao interteriu & $\square$ & $\square$ & $\square$ & $\square$ & $\square$ & $\square$ & $\begin{array}{l}\text { Interneriu } \\
\text { multo }\end{array}$ \\
\hline $\begin{array}{l}\text { 18. Quanto voce conseguiu se concentrar } \\
\text { efetivamente na simulaçấo, ao invés de desviar a } \\
\text { atençâa para os mecanismos de direçáo? }\end{array}$ & $\begin{array}{l}\text { Desviel a } \\
\text { atençao }\end{array}$ & $\square$ & $\square$ & $\square$ & $\square$ & $\square$ & $\square$ & Concentrado \\
\hline $\begin{array}{l}\text { 19. Em que nivel } 0 \text { aspecto auditivo conseguiu te } \\
\text { envolver no ambiente? }\end{array}$ & Nennum & $\square$ & $\square$ & $\square$ & $\square$ & $\square$ & $\square$ & Completamente \\
\hline 20. Quão bem voce conseguiu identificar os sons? & Muto mal & $\square$ & $\square$ & $\square$ & $\square$ & $\square$ & $\square$ & Mutto bem \\
\hline 21. Conseguiu identificar as origens dos sons? & $\begin{array}{c}\text { Nao } \\
\text { Identiliquel }\end{array}$ & $\square$ & $\square$ & $\square$ & $\square$ & $\square$ & $\square$ & $\begin{array}{c}\text { Identufiquel } \\
\text { completamente }\end{array}$ \\
\hline
\end{tabular}

22. Enumere os fatores, em ordem crescente de motivação (de 1 a 3) que 0 (a) influencia a realizar uma manobra de ultrapassagem:

( ) Velocidade do veículo lento à frente

( ) Distância permitida de ultrapassagem

( ) Tipo de veículo à frente (caminhão ou carro de passeio)

Obrigado (a) pela sua colaboração! 


\section{AVALIAÇÃO DE SINTOMAS Nr Condutor:}

Indique o grau de cada um dos sintomas, caso esteja sentindo neste momento, decorrente da simulaçăo/uso do simulador.

Utilize a seguinte escala: não está tendo nenhum sintoma; sintoma leve, sintoma moderado ou sintoma severo.

\begin{tabular}{|l|cccc|}
\hline SINTOMAS & Não & Leve & Moderado & Severo \\
\hline 1. Desconforto Geral & $\square$ & $\square$ & $\square$ & $\square$ \\
\hline 2. Fadiga & $\square$ & $\square$ & $\square$ & $\square$ \\
\hline 3. Dor de cabeça & $\square$ & $\square$ & $\square$ & $\square$ \\
\hline 4. Esforço visual & $\square$ & $\square$ & $\square$ & $\square$ \\
\hline 5. Dificuldade em focar & $\square$ & $\square$ & $\square$ & $\square$ \\
\hline 6. Salivação excessiva & $\square$ & $\square$ & $\square$ & $\square$ \\
\hline 7. Suor excessivo & $\square$ & $\square$ & $\square$ & $\square$ \\
\hline 8. Naúsea & $\square$ & $\square$ & $\square$ & $\square$ \\
\hline 9. Dificuldade de concentração & $\square$ & $\square$ & $\square$ & $\square$ \\
\hline 10. "Cabeça pesada" & $\square$ & $\square$ & $\square$ & $\square$ \\
\hline 11. Visão turva & $\square$ & $\square$ & $\square$ & $\square$ \\
\hline 12. Tontura com os olhos abertos & $\square$ & $\square$ & $\square$ & $\square$ \\
\hline 13. Tontura com os olhos fechados & $\square$ & $\square$ & $\square$ & $\square$ \\
\hline 14. Vertigem & $\square$ & $\square$ & $\square$ & $\square$ \\
\hline 15. Dor de estômago & $\square$ & $\square$ & $\square$ & $\square$ \\
\hline 16. Gases / Arrotos & $\square$ & $\square$ & $\square$ & $\square$ \\
\hline
\end{tabular}



anexo a - Parecer do Conselho de Ética e Pesquisa (CeP)

\section{UFSCAR - UNIVERSIDADE FEDERAL DE SÃO CARLOS

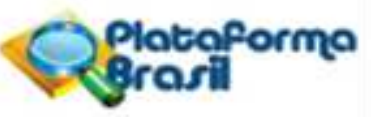

\section{PARECER CONSUBSTANCIADO DO CEP}

\section{DADOS DO PROJETO DE PESQUISA}

Titulo da Pesquisa: AVALIAÇÄO DO COMPORTAMENTO DO CONDUTOR EM MANOBRA DE ULTRAPASSAGEM: SIMULAÇÄO EM PISTA SIMPLES

Pesquisador: AURENICE DA CRUZ FIGUEIRA

Área Temática:

Versão: 2

CAAE: 65267917.7 .0000 .5504

Instituiçäo Proponente: UNIVERSIDADE DE SAO PAULO

Patrocinador Principal: Financiamento Próprio

\section{DADOS DO PARECER}

Número do Parecer: 2.094 .027

Apresentaçäo do Projeto:

O projeto contem todas as informações pertinentes.

Objetivo da Pesquisa:

Esta pesquisa pretende avaliar o comportamento do condutor durante a execuçäo de manobras de ultrapassagem em rodovias do tipo pista simples, a serem observadas em experimentos com o uso de simulador de condução.

Avaliação dos Riscos e Beneficios:

Riscos e beneficios são apresentados e estão de acordo com a pesquisa.

Comentários e Consideraçöes sobre a Pesquisa:

A pesquisa apresenta relevância científica e tecnológica.

Consideraçöes sobre os Termos de apresentaçäo obrigatória:

O TCLE é apresentado e contem todas as informações pertinentes.

Conclusōes ou Pendências e Lista de Inadequaçōes:

Não há pendências.

Considerações Finais a critério do CEP:

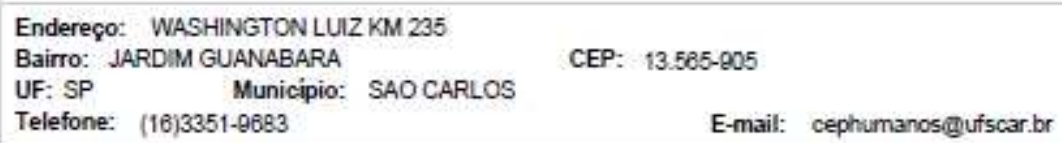




\section{UFSCAR - UNIVERSIDADE Plotoforma FEDERAL DE SÃO CARLOS}

Continuzç5o do Parecer. 2.094 .027

Este parecer foi elaborado baseado nos documentos abaixo relacionados:

\begin{tabular}{|c|c|c|c|c|}
\hline Tipo Documento & Arquivo & Postagem & Autor & Situaçāo \\
\hline $\begin{array}{l}\text { Informações Básicas } \\
\text { do Projeto }\end{array}$ & $\begin{array}{l}\text { PB_INFORMAÇŌES_BASAICAS_DO_P } \\
\text { ROJETO 418379.pdf }\end{array}$ & $\begin{array}{c}18 / 05 / 2017 \\
16: 37: 23\end{array}$ & & Aceito \\
\hline $\begin{array}{l}\text { TCLE / Termos de } \\
\text { Assentimento / } \\
\text { Justificativa de } \\
\text { Ausência }\end{array}$ & TCLE_Aurenice_Figueira_v2.docx & $\begin{array}{c}18 / 05 / 2017 \\
16: 36: 55\end{array}$ & $\begin{array}{l}\text { AURENICE DA } \\
\text { CRUZ FIGUEIRA }\end{array}$ & Aceito \\
\hline Folha de Rosto & Folha_Rosto.PDF & $\begin{array}{c}14 / 02 / 2017 \\
09: 11: 57\end{array}$ & \begin{tabular}{|l|} 
AURENICE DA \\
CRUZ FIGUEIRA \\
\end{tabular} & Aceito \\
\hline Outros & $\begin{array}{l}\text { Quest_Avaliacao_Indisposicao_Apos_T } \\
\text { este_Simulador.pdf }\end{array}$ & $\begin{array}{c}14 / 02 / 2017 \\
09: 11: 27\end{array}$ & \begin{tabular}{|l|} 
AURENICE DA \\
CRUZ FIGUEIRA \\
\end{tabular} & Aceito \\
\hline Outros & $\begin{array}{l}\text { Quest_RECRUTAMENTO_TESTES_SI } \\
\text { MULADOR.pdf }\end{array}$ & $\begin{array}{c}14 / 02 / 2017 \\
09: 10: 18\end{array}$ & \begin{tabular}{|l|} 
AURENICE DA \\
CRUZ FIGUEIRA \\
\end{tabular} & Aceito \\
\hline $\begin{array}{l}\text { Projeto Detalhado / } \\
\text { Brochura } \\
\text { Investigador }\end{array}$ & Projeto_Pesquisa_Aurenice.pdf & $\begin{array}{c}14 / 02 / 2017 \\
09: 08: 31\end{array}$ & $\begin{array}{l}\text { AURENICE DA } \\
\text { CRUZ FIGUEIRA }\end{array}$ & Aceito \\
\hline $\begin{array}{l}\text { TCLE / Termos de } \\
\text { Assentimento / } \\
\text { Justificativa de } \\
\text { Ausência }\end{array}$ & TCLE_Aurenice_Figueira.doc $x$ & $\begin{array}{c}14 / 02 / 2017 \\
09: 08: 07\end{array}$ & $\begin{array}{l}\text { AURENICE DA } \\
\text { CRUZ FIGUEIRA }\end{array}$ & Aceito \\
\hline
\end{tabular}

Situação do Parecer:

Aprovado

Necessita Apreciação da CONEP:

Não

SAO CARLOS, 31 de Maio de 2017

Assinado por:
Priscilla Hortense

(Coordenador)

Endereço: WASHINGTON LUIZ KM 235
Bairro: JARDIM GUANABARA
UF: SP Municipio: SAOCARLOS
CEP: $13.585-805$

Telefone: (16)3351-9683

E-mail: cephumanos(gufscar.br 